\title{
the pedestrian workplace
}

affective relationships on the street

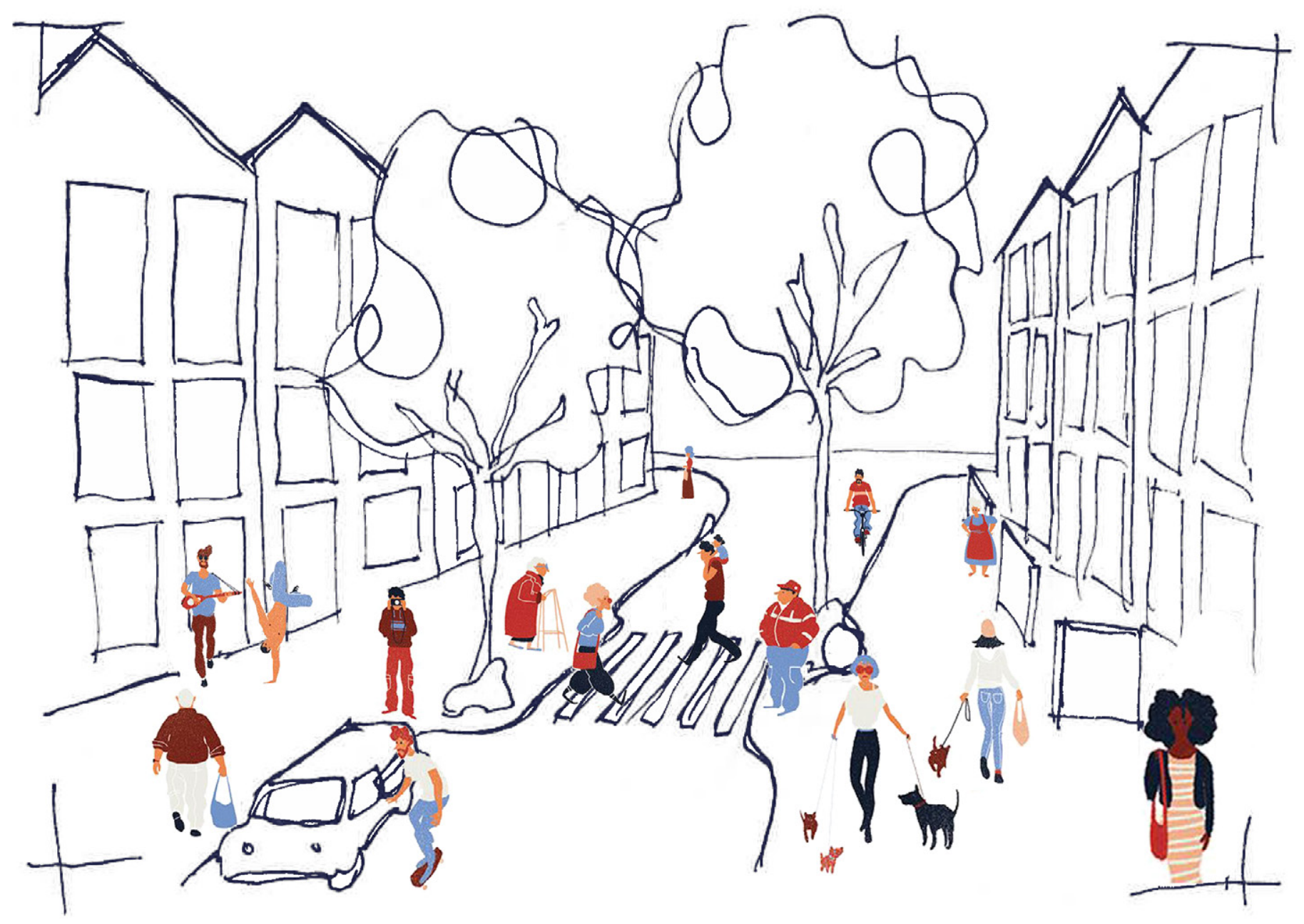




\title{
the pedestrian workplace
}

affective relationships on the street

by

Bronté Davenport

\author{
A 120-point thesis submitted to the Victoria \\ University of Wellington in partial fulfillment \\ of the requirements for the degree of Master of \\ Architecture [Professional]
}

Victoria University of Wellington 


\section{abstract}

How can analysis of affective relationships enable the public street as a pedestrian workplace?

When thinking of places we feel a bond to - an attachment to - home commonly comes to mind. In today's world, where many of us spend just as much time at home as at work, do we feel a similar connection to our workplace? As mobility increase through technology, and we can work anywhere, anytime, do we take this affective bond with us... everywhere?

Every place has an affect; a sense about it, a feeling. The street has particular affect, as encounters between the place and the pedestrian continuously occur. In recent years, there has been an increase of awareness in urban design of public environments as places of work. People are able to perform working behaviours anywhere, at any time, thanks to technology even as they walk down the street. In response to the new mobility of the contemporary workplace, this thesis aims to explore affective relationships that take place in the street - where the worke takes on the role of pedestrian.
Previous research into this area has discovered a dichotomy in opinions - as our mobility increases, do we form stronger bonds to places, or does this mobility rob us of any place attachments? Do third places catering to mobile working conditions necessarily diminish and recreational life? I am interested in firstly exploring what affects are occurring within the street, and later to explore how architectural design intervention can manipulate the affective response of a pedestrian.

The research will employ analogue and digital media, alongside theoretical research, to explore the interactions and affective links that occur between work and street. The ability to design with affective encounters in mind will be the driving force. The implications will be an exploration of affect within the context of the street system, specifically when the street is considered as a place where working behaviours may occur alongside social and recreational behaviours. This will further the understanding of the connections people have with places, and how this manifests in daily life. 
To my supervisor; Joanna Merwood-Salisbury, to my family, and my friends. Many thanks to you all, for

the guidance, support, and encouragement.

vii

\section{-}


Research Question

3

Introduction

Aims and Objectives

Methodology....

Key Definitions...

Literature Review

Workplace.

Affect................

Space and Place..

Case Study Exploration.r.ment

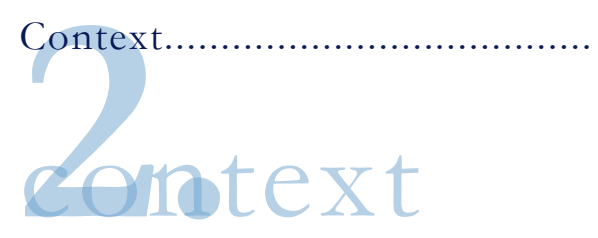

Design Tests

Embodied Perception …. 38

- Atmosphere and Social Encounter......... 46

Imitation of Bodily Gestures................... 62

Summary: Design Tests...

Wellington History

Site Analys

City Life: Streets of Wellington

\section{contents}

site analysis

Site Selection...

- Plimmer Steps.

Woodward Street.

Initial Design...

Design Tests...

114

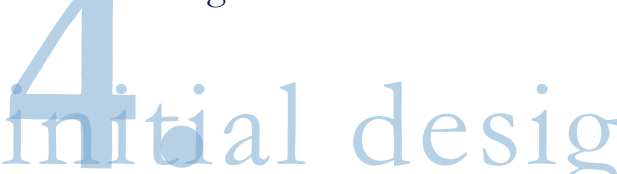

- Embodied Perception

Develōped Design...................... Interventions....................................... 156 Design Development........................... 162

Critical Reflection..................... Conclusion.......................................... 202

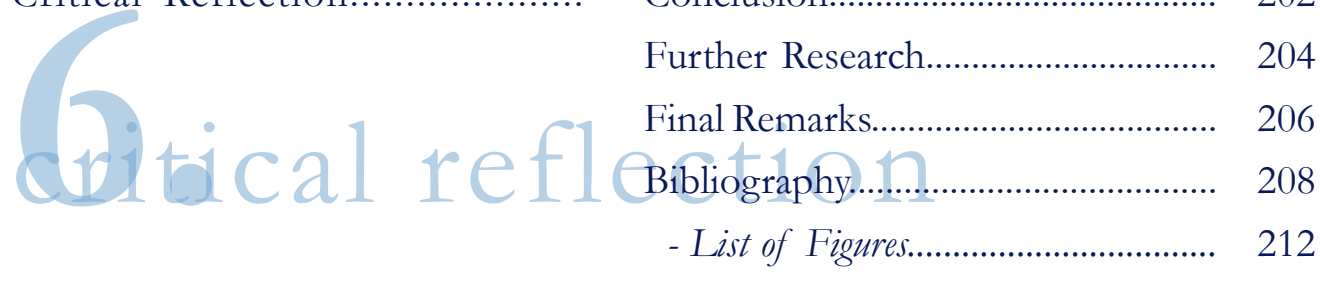

- Community of Designers................... 215 


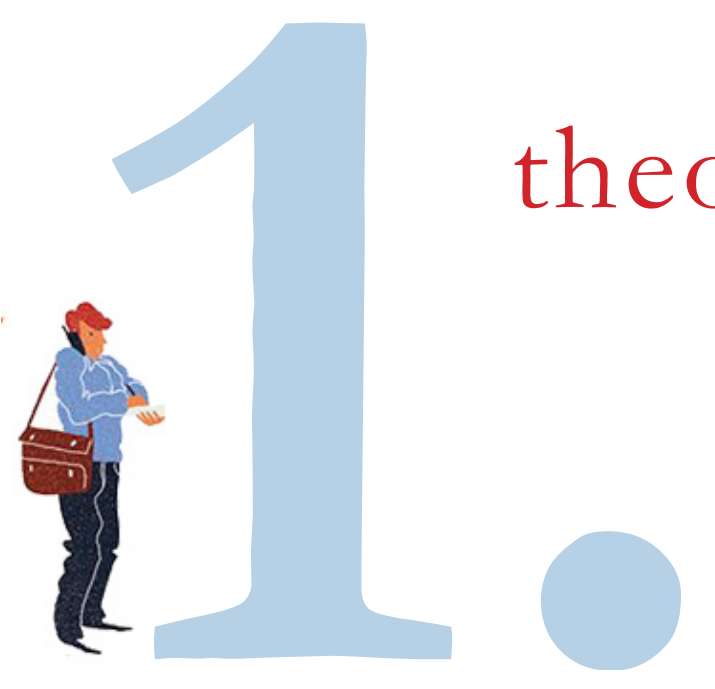

Research Question Introduction Aims and Objectives Methodology Key Definitions Literature Review

\section{-}


How can analysis of affective relationships enable the public street as a pedestrian workplace?

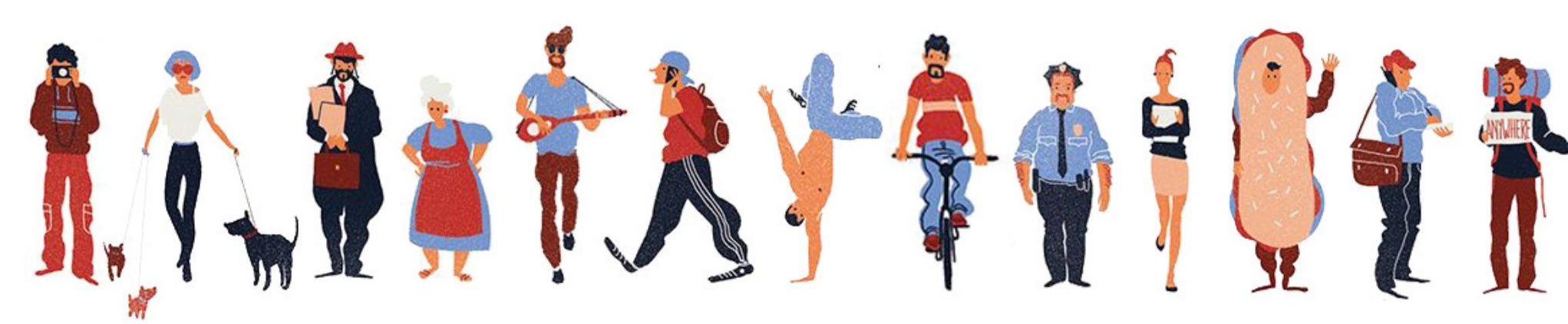


Research Question:

How can analysis of affective relationships enable the public street as a pedestrian workplace?

This thesis explores the relationship that occurs when the working individual interacts with public space; specifically when the worker is a pedestrian. To do so, affective relationships between individual and architecture are explored at a street level.

There is an existing relationship between person and place that is inherently affective; a charged connection that can evoke a bond to the place. The public street provides a site for the exploration of affective bonds to take place. The relationship between person and place will be explored here where the person is the pedestrian, and the place is the public street, through the intervention of working activity. This proposition creates the opportunity to redesign selected street sites in Wellington's Central Business District to be pedestrian workplaces; an alternate workplace typology where mobile and freelance working behaviours can occur alongside social, community creating activity.

A literature review of critical texts on the topics of workplace, affect, and space and place initiate a design-led research process. At multiple scales - from city, to street, to individual - through urban and architectural the design-led research process uses design to reveal the affective relationships present in the selected street sites, and how this can be harnessed to redesign the selected street sites.

The initial design testing phases firstly explore case study sites in Wellington city; as they With imagined interventions, to understand current affective relationships and how these may shift. Next, the same testing is carried out on the selected street sites; Plimmer Steps and Woodward Street. The final design proposals redesign these two sites; transforming them into urban third places; where one can interact with others and occupy the spaces created as 21 st century 'workspaces'. The design aims to provide opportunity along these access routes for pause, by way of seating areas and sheltered moments. Through this, working activities are supported alongside typical pedestrian activity

Through critical reflection on how affective relationships can be invoked, enhanced, and changed, both the design process and the current conception of the public street can be analysed. This thesis proposes that current understandings of what the street is can be broadened through design, engaging pedestrians to relate with the site in different ways, benefiting both the pedestrian worker and the wider city context. 

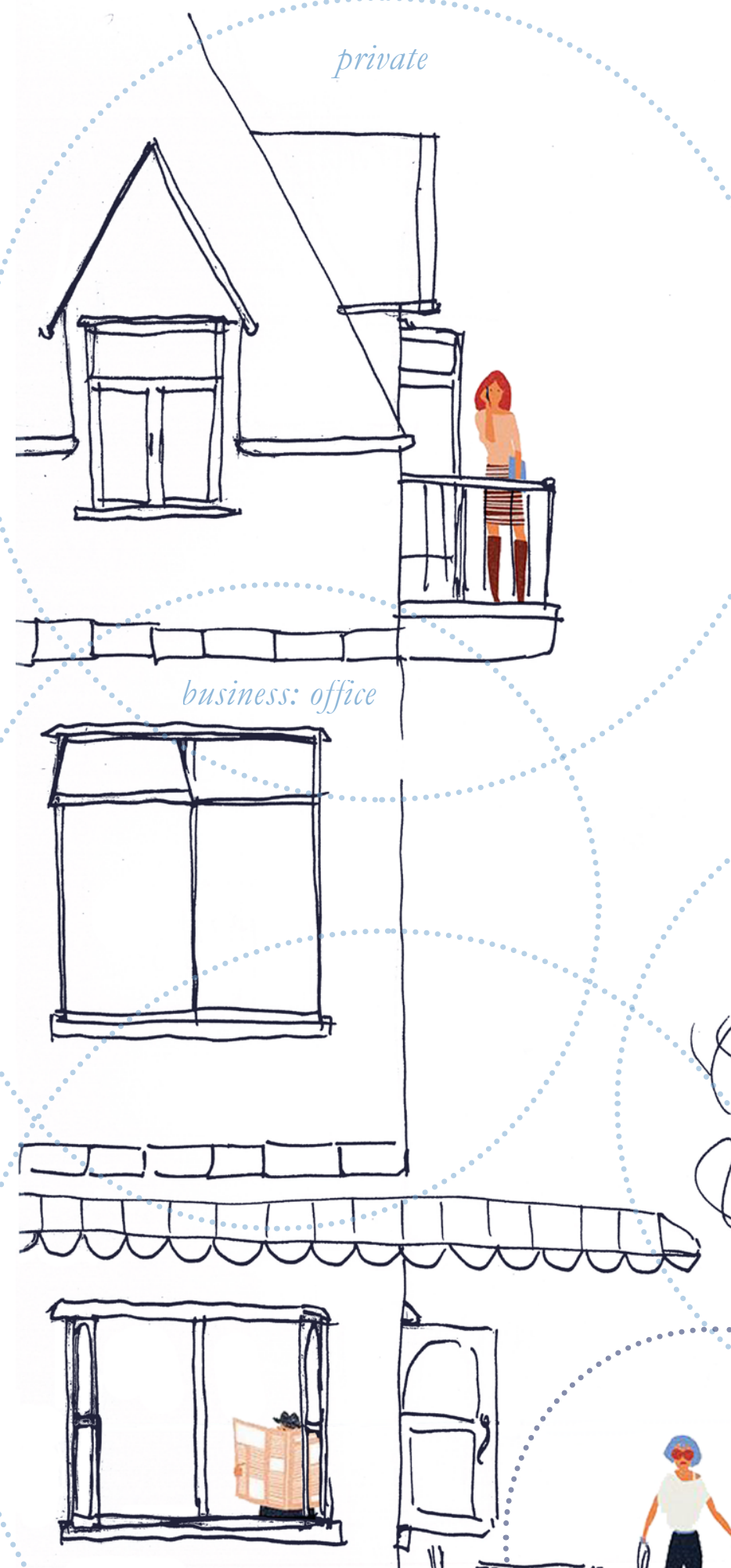

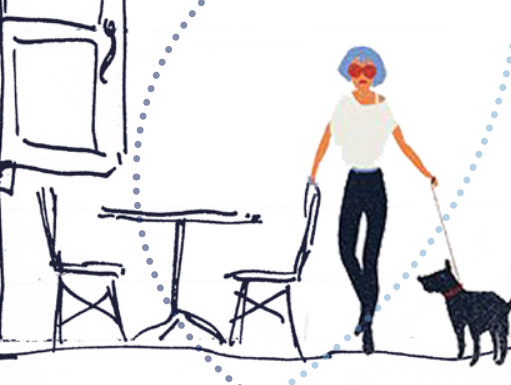

business: retail

transportation:

pedestrian aim \& objectives

The exploration of affective

relationships in an urban

contemporary workplace context.

Exploration of the interacting

'street' system

: business - office, retail

: private - residential

: ecology

:transportation - pedestrian,

vehicular

and the affective encounters that

occur within this. CLIVS

methodology

Phase Two:

A site analysis involving research

The primary research method this thesis employs is design by

that is iterative; testing will be key as designs are generated and repeated.

I anticipate activation through drawing, watercolour, modelling, and digital media, throughout all phases of design and research.

Phase One:

Literature Review into theories of workplace, affect, and space and place.

Case Study exploration through design tests adapted from literature. into the history and context of the selected sites.

To employ design as research, repeat the design tests on the selected sites. Adapt information collected through design tests into initial design responses.

\section{Phase Three:}

Use initial design responses to inform possible interventions on selected sites.

Design development phase, where the redesign of the selected sites creates possibilities for public social interaction and working activities to occur. 


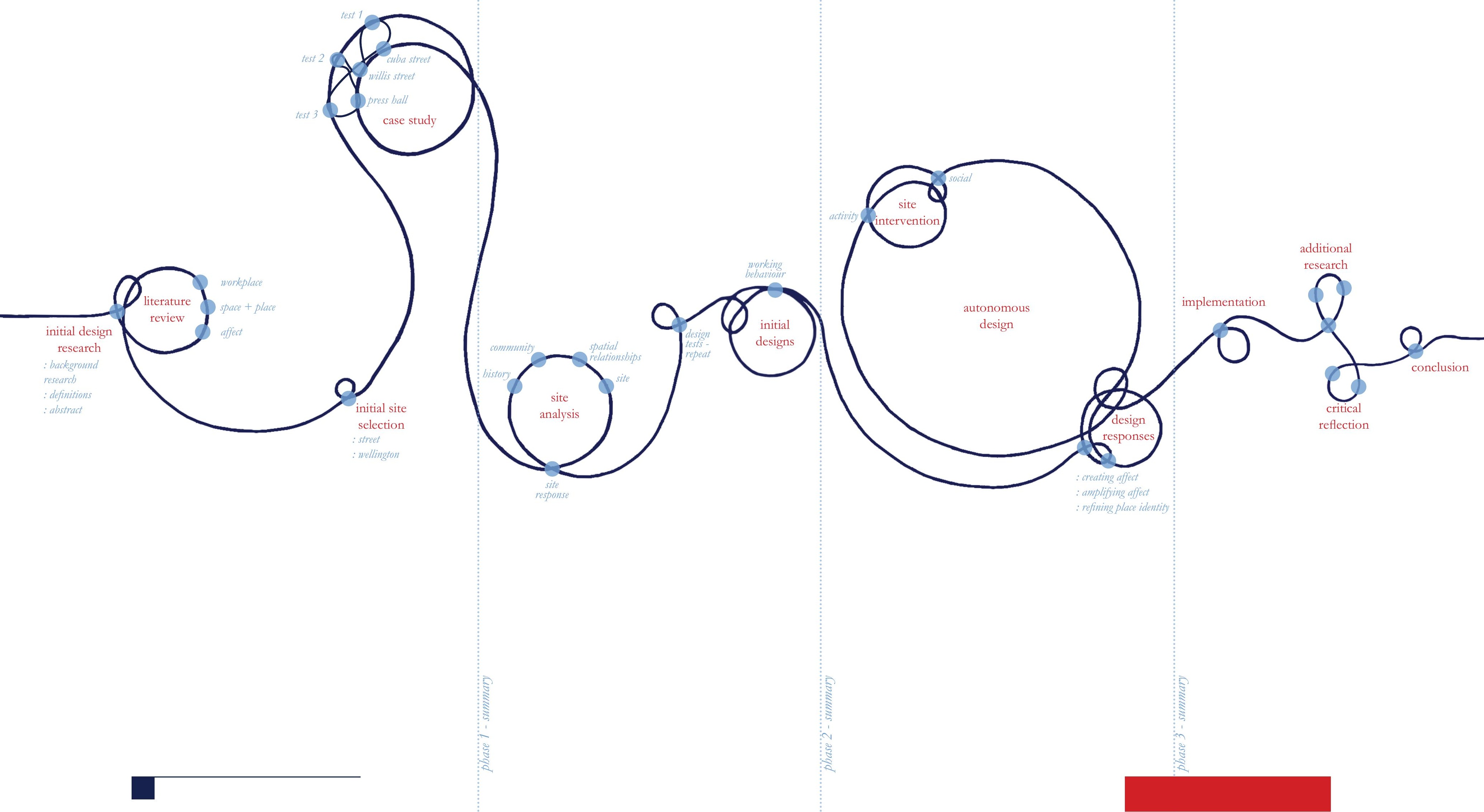




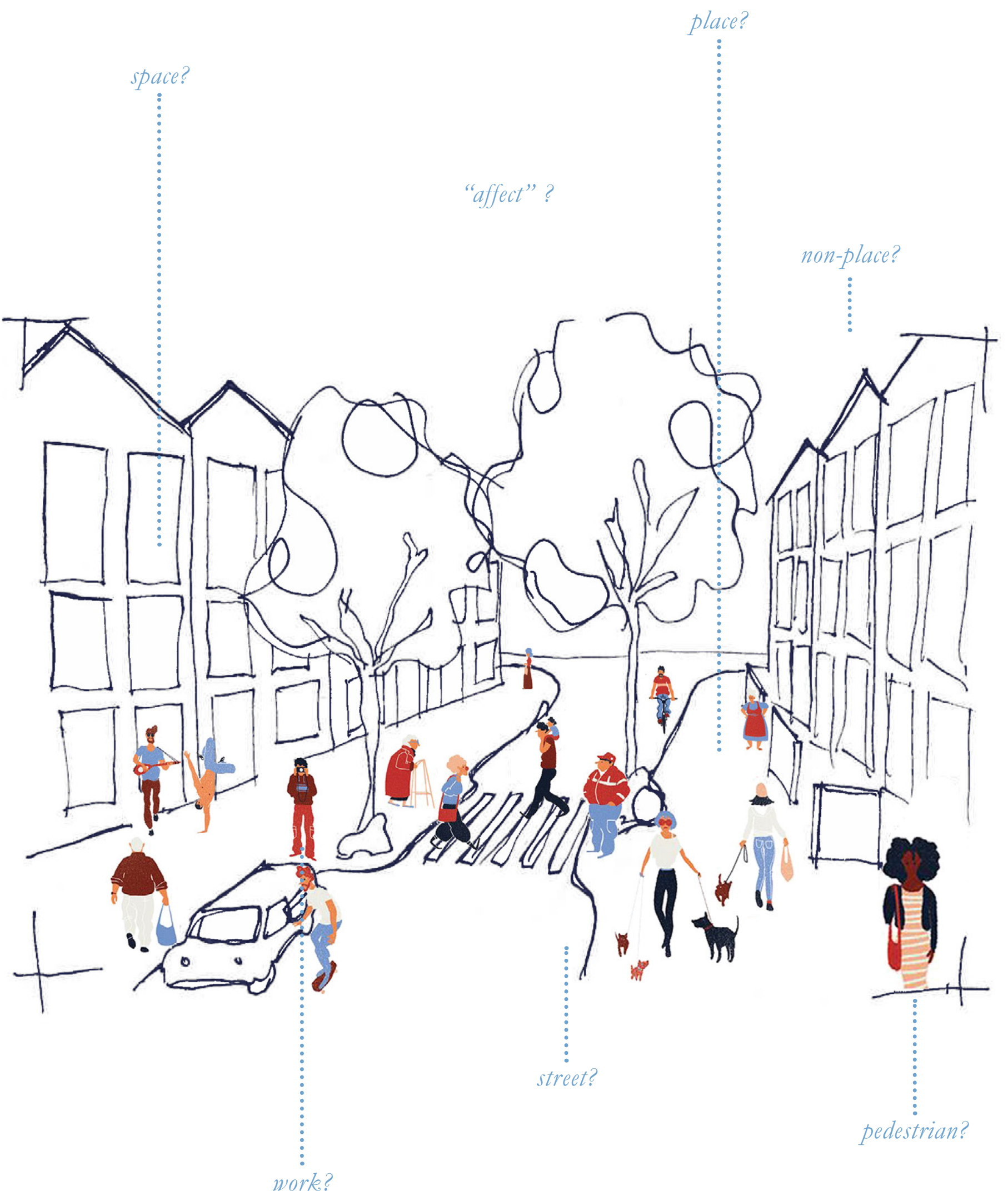

Affect

the charge of space;

the effection of an emotional response

"a sense of push in the world" (Kraftl and Adey, 2008, p. 215).

imitation of bodily gestures

"when you affect something you are at the same time opening yourself up to being affected in turn” (Massumi, 2003)

“the 'adaptive unconscious' working ceaselessly and unconsciously interpolate/interpellate the world" (Thrift, 2008, p. 14)

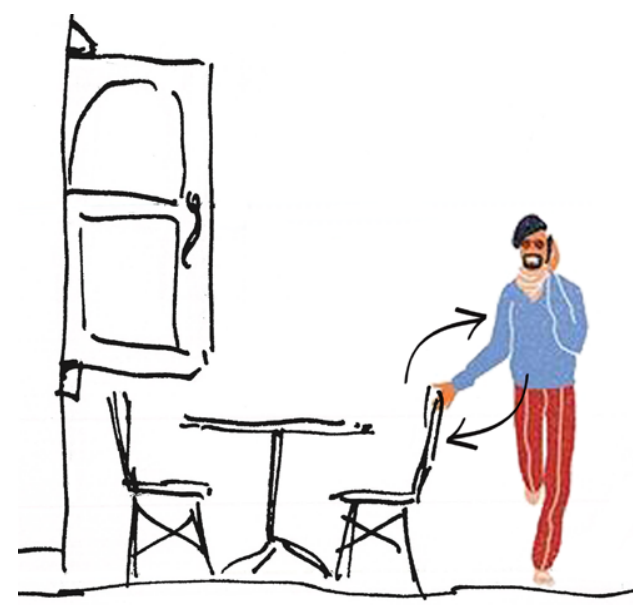

Work - to perform work, or fulfil duties regularly

Street - a public thoroughfare, often paved and containing means for transport and access. Usually includes adjacent walkways and buildings.

Pedestrian - someone interacting with the street

Topophilia - "the affective bond between people and place" (Tuan, 1974, p.4)

Space - "the name for that most encompassing reality that allows for things to be located within it" (Casey, 2001, p. 404).

Place - "the immediate ambience of [the] lived body and its history" (Casey, 2001, p. 404).

Non-place - "a space which cannot be defined as relational, or historical, or concerned with identity" (Augé, 1992, p.79).

Third Place, "great good place" social space separate from the home and workplace; used for community building (Oldenberg, 1991, p. 2).

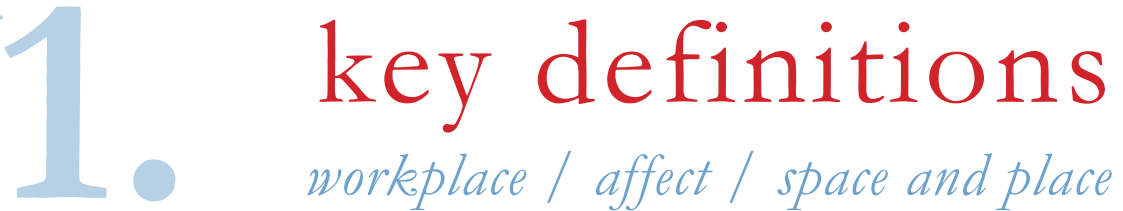


Workplace

Contemporary literature explore how the nature of work, and therefore its assigned environment, is changing, and analysis of key texts helps define the scope for the design research.

"The office is no more. We work anytime, anywhere" (Idenburg, 2013, p. 117). As technology has advanced, our lifestyles have been changing - now the notion of "working" has become interchangeable with other aspects of our lives. We work "through a myriad of mutating platforms and dynamic structures... work is everywhere but in the traditional office" (Idenburg, 2013, p. 117) Not only has where and how we work changed, but the notion of what work is has changed. Work has, for many of us, become a "meroing of leisure and obligation" (Idenburg, 2013, p. 117).

The mobile connected office might be defined by a laptop, headphones, and a caffeinated beverage. There is no dependence on a fixed workplace; with a laptop filled with data and headphones to provide a portable floating atmosphere, one can work anywhere - and at any time, when fuelled by coffee (Mozas, 2017, p 50). The downside of this is the constant pressure to be productive; emails can be answered while out for dinner, conference calls can be

\section{A constant stream of} activity; meetings, workshops, encounters, exhibitions, dinners,

pop-ups, meet-ups...

answered on vacation many time zones away... when do we get the chance to not work? Undefined hours and locations have dissolved the solidity of the modern office; all sorts of other places are now pervaded with work

Self-employed work is becoming more wide-spread. Co-working paces have risen in popularity, supporting a constant stream of activity; meetings, workshops, encounters, exhibitions, dinners, pop-ups, meet-ups... they are spaces of collaboration and interaction, blending working behavio the social and public world (see fig. 1.5 , p. 12)

The office is no longer static, and other places we live our lives in and through are adapting to allow worklike activities to occur within them as well, such as home. Architecture 
has the opportunity to "highlight the physical connections among people and between them and their environment" (Idenburg, 2013, p. 117). It is possible that many working behaviours are being performed in public spaces. How are working activities affecting pedestrian behaviour? Phone calls and emails can be responded to at any time, in public spaces that aren't currently designed to cater effectively to this behaviour. Adapted street design can facilitate, rather than hinder, working activities.
Places we live our lives in and through are adapting to allow work-like activities to occur within them

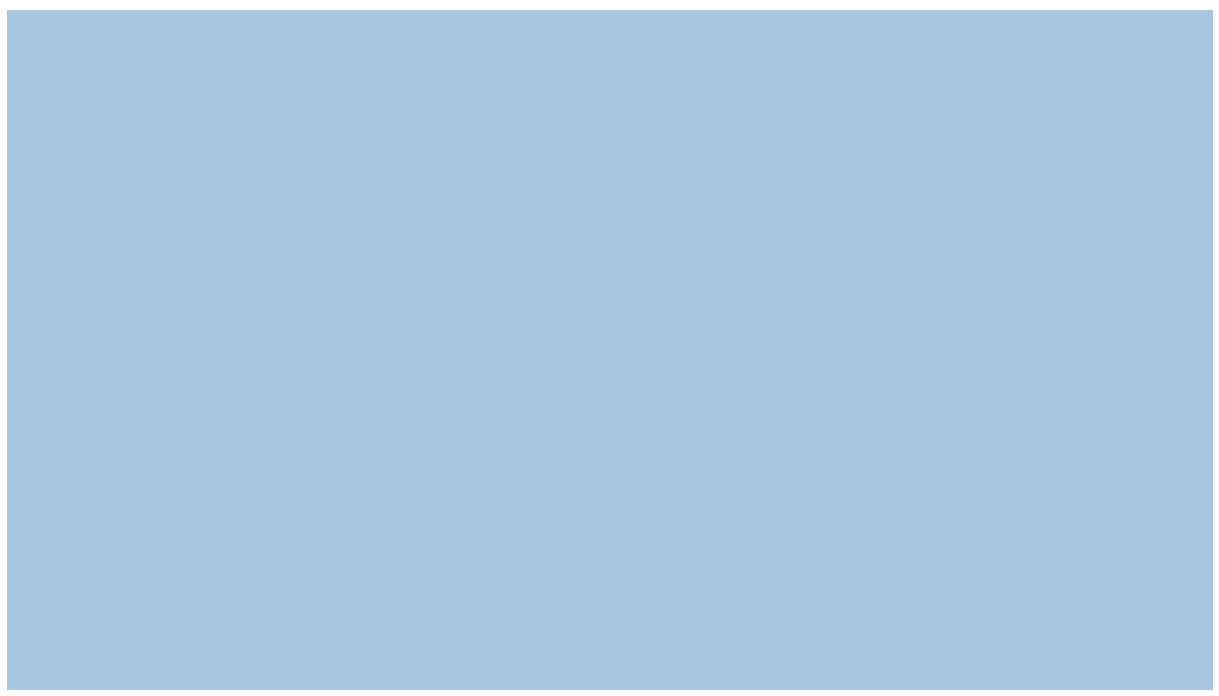

Fig. 1.05: Wallpaper based on the 'global spirit of a modern digital workspace'
In discussing ways in which the street might be designed to accommodate work, the notion of affect is useful to define and explore.

feel, think, or act" $(2008$, p. 215, ref. Thrift, 2004, p. 64). Affect is also discussed as being the relationship between bodies; different bodies and

Often the discussion of affect is vague and related strongly to emotion. In the first chapter of Parables for the Virtual; titled "The Autonomy of Affect", Massumi explores the dynamics of affect, offering explanations that tend towards a definition of the term (2002). Affect begins with The Subject and The Body. It is through interaction that the body influences affective encounters.

Mind and body are two different levels that encounter an event in different, but parallel, ways (Massumi, 2002, p. 32). There is a third level, an origin point of receptivity, that falls between Affect is always almost perceived, yet never really is. The moment where the affective encounter is experienced is that of a turning point; a critical moment, where the physical system embodies potential, and one experience from this is "selected" (Massumi, 2002 pp. 32, 33). Affect occurs as the point of emergence where many levels - perhaps an infinite number - come into play; there is "an unleashing of potential" (Massumi, 2002, p. 33). Kraftl and Adey refer to affect as being "“a sense of push in the world'... [it] presents itself socially as something that is pushing, pulling, or lifting us to
“[Affect] presents itself socially as something that is pushing, pulling, or lifting us to feel, think, or act"

Kraftl \& Adey, 2008, p. 215

their "qualities of relation constitute different affects and therefore different feelings, emotions, Adey, 2008, p. 215).

A definition is further approached by Frichot in application to the exploration of the artist Olafur Eliasson's work; "Affect is the movement between emotional registers rather than the emotion itself once it can be named. Likewise, the percept is less about the named perception than what happens in the encounter that causes a pure percept to emerge. The percept facilitates a landscape of p. 34). For Eliasson, "atmosphere is inextricably linked with socia that they engage to create a mutual transformation of space and person (Frichot, 2008, p.33). Eliasson subtly encourages this by titling his works activities and actions" (Kraftl \& sensation to unfurl"' (Frichot, 2008, 
with second-person pronouns; the was designed to work with the ownership is with the beholder; the development of young children. created affect is incomplete without The spaces created are enclosed perception and interaction.

through soft curves and warm lighting generating a womb-like sanctuary The following works explore santu ways affect can be implemented childhood can be protected (Kraftl in architectural design and art \& Adey, 2008, pp. 221, 222).

installation, by considering the

atmospheric qualities perhaps already present that may be enhanced, or how a new affect can be created through the design.

Kraftl and Adey compare a Welsh Steiner School and the Liverpool John Lennon Airport, to see how the construction of the architectura spaces has created affect within each building. The design of the Nant-yCwm Steiner School in West Wales focused on an imitation of bodily gestures through the architecture to imbue the architecture with "styles of bodily doing, because of the push that the particular relationship

\section{An imitation of bodily}

gestures... the push

that the [relationship

between body and

building] could bring

about: an affect

Adapted from Kraffl \& Adey, 2008, p. 217

between a body and that building could bring about: an affect" (Kraftl \& Adey, 2008, p. 217).

The Kindergarten, in particular,
Airports are often designed to create spaces where people can relax and feel calm, as airports are such rushed, busy places. The redevelopment scheme of the airport included the installation of a prayer room and a garden, with both spaces aiming to create a homely and relaxing affect. It is the affectual intensity of not only pressure and anxiety, but also excitement, which perpetuates the "rushed" environment of termina spaces. The prayer room and garden exude calm and serenity, affecting Adey, 2008, p. 223).

As we move through our daily lives, architecture acts as a backdrop, it tends not to be something we consciously focus our attention on, but this does not mean we are not perceiving it Peri Bader introduces dimensions of attention, based on the model developed by Aron Gurwich and P. Sven Arvidson (2015, p. 246). The three dimensions are marginal consciousness, thematic field, and theme.

Through our everyday interaction with the built environment, we are likely absorbing information through the two outer dimensions; an "oasis amongst chaos" (Kraftl \& marginal consciousness, or thematic field. Through these dimensions, we understand that the object (or architecture) in question is there, however it does not grasp our full focus. Peri Bader establishes that it is when architecture creates a disturbance within our perception that it moves up to the focal dimension; theme (2015, p. 248).

As an example, in the experiment, one participant spoke of how her decision to wear high heels led to her becoming aware of the architecture of an atrium space as she came down the stairs (Peri Bader, 2015 , p. 253). Her choice of footwear, which is part of her at that moment, conflicted with the architecture.

The stairs became treacherous, her movements required focus if she were to safely descend the stairwell (Peri Bader, 2015, p. 253)

In this case, the disturbance the architecture created brought it to her focus, as she became "frightened by the thought of stumbling on [her] way down. [She] held tight to the metal handrail, and that forced [her] to look down at the marble flooring" (Peri Bader, 2015, p. 253). Thus, for architecture to move into the full-focus dimension of theme, it needs to disturb our occupation in some way.

Artist Olafur Eliasson creates internal atmospheres that impact all who experience them. Manipulating weather conditions and landscapes within the interior, Eliasson creates
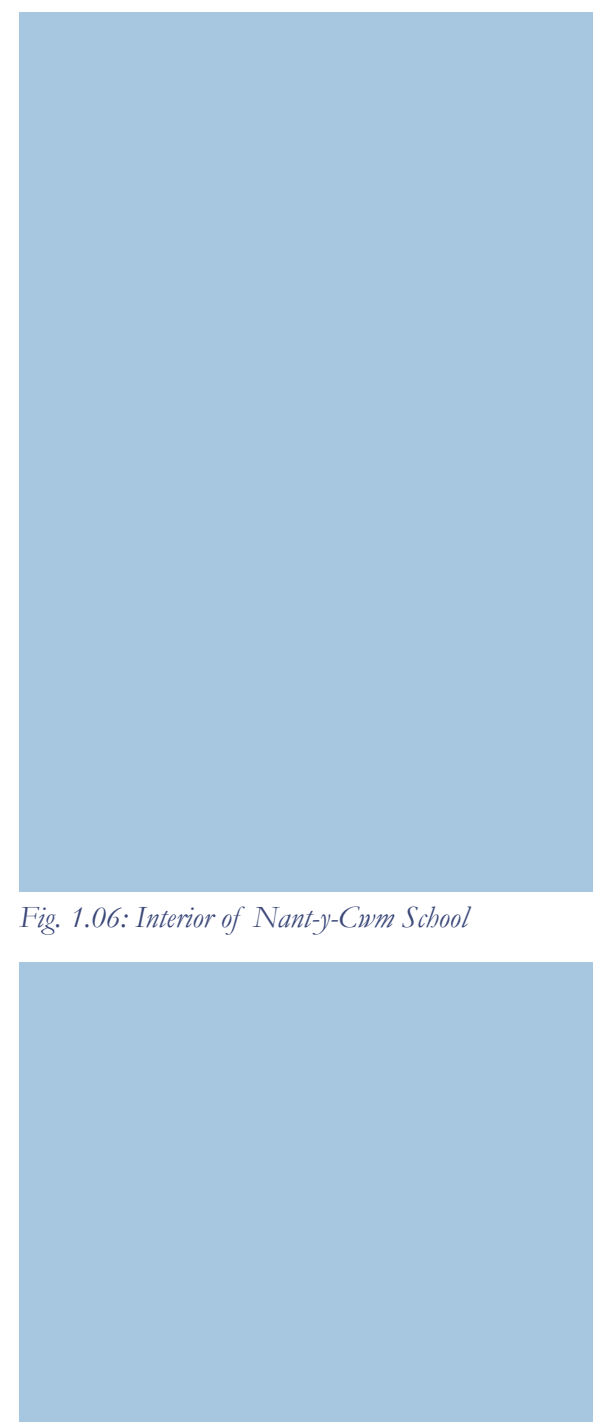

Fig. 1.07: Garden at Liverpool John Lemnon Airport

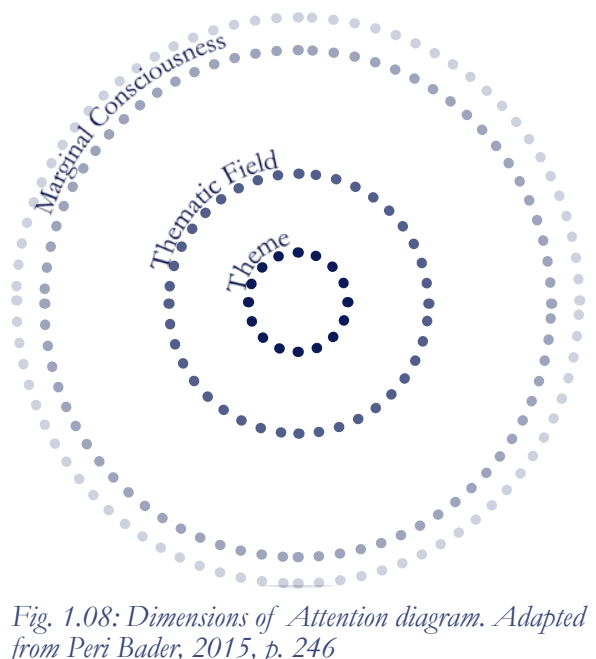


"an intimate relay between the artwork and those who enter into contact with it" (Frichot, 2008, p. 32). In the space, he dissolves material through manipulation of elements; colour, light, transparency, to enhance specific sensory qualities and invoke affect. In this context affects are transformative shifts, we become subjects that recognise ou subjectivity; Eliasson states that "We learn to see ourselves in a different light" (Frichot, 2008, p.34).

It may be argued that our contemporary world is one of empty consumerism, and therefore that there is a waning of affect. If this is the case, it is work like Eliasson's that augments atmosphere and reintroduces "a realm of affect and percept" (Frichot, 2008, p. 34). His art actively effects encounters between many kinds of bodies; from architectural to natural, inducing affective response.

We interact, "[passing] into the

\section{One expects to be a}

spectator... however, the

affective charge invokes

an irresistible theatrical

\section{experience}

landscape as the landscape passes through us", moving in temporality as the encounter shows us our part in the world (Frichot, 2008, p. 35).
Both artist and architect can manipulate the affect of a particula space through intervention. Oskar Schlemmer designed walls for the Rabe House by Adolf Rading (1930) that heighten a theatrical experience within the space. The wall designs "summon a multi-layered human presence", inspired by Schlemmer's studies of the human and the 179). Movement architecture; parts move; sliding, swinging and pivoting. Amongst this, human movements are also tracked and plotted, forming a dependent partnership. Patterns are created, and performances occur. The architect suggests intended movement, however, there are ways we can move and perform that go beyond; a theatrical experience can occur (Feuerstein, 2013, p. 178). Through Schlemmer's figures, the affective presence of the space is enhanced with almost-human charisma.

Walls themselves are architectura elements that define and create space, but Schlemmer saw them also as a backdrop for moving "energies", and also as the provocation of movement itself. This is seen through the etymology of the German word for Wand; wall, that can be found in the verbs wandlen; change, walk, stroll, and wandler, wander, travel, move shift, hike. Through these words, a wall shifts from being fixed in space to being an element imbued with ideas of movement, and rooms shift from simply space to performance space (Feuerstein, 2013, p. 182) The human body is entwined with space, recasting architecture as a performing art (Feuerstein, 2013, p. act as more than murals, there is a distinct architectural quality as they interact with and affect the space. Architectural elements of the space create a frame for the figure to be encased within, but the surfaces cross an ambiguous threshold as they "break (or burst) open the frame and join to the wall becoming part of a larger surface, part of a larger space than themselves..." (Schlemmer, 1990, p. 73)

The theatrical play created by the wall designs casts inhabitants of the Rabe House as both audience and actor, suggestive of the theory of "AffectingPresence"; aconceptfrom folklore and cultural anthropology (Feuerstein, 2013, p. 189). A society has cultural and aesthetic traditions, and performance, that impacts participants of traditions. One expects to be a spectator of the "artworks" on the walls, however, the affective charge invokes an irresistible theatrical experience (Feuerstein, 2013, p. 187). Mundane daily tasks pursued by occupants of the spaces become playful experiences within Schlemmer's world of giants.

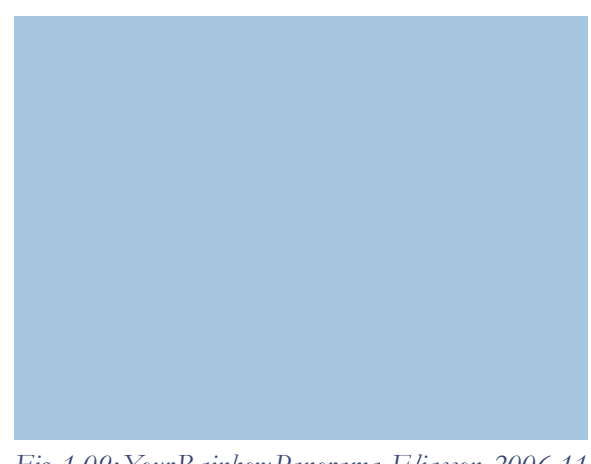

Fig. 1.09: YourRainbow Panorama, Eliasson, 2006-11

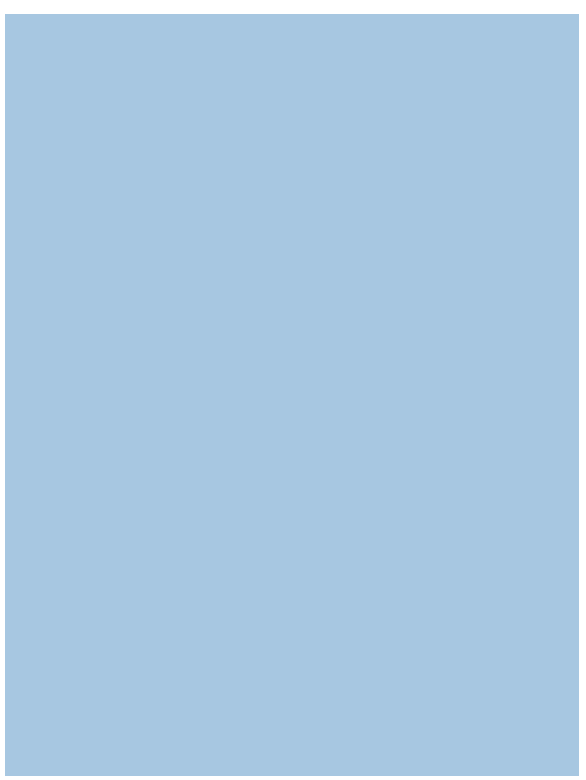

Fig. 1.10: The Weatber Project, Eliasson, 200

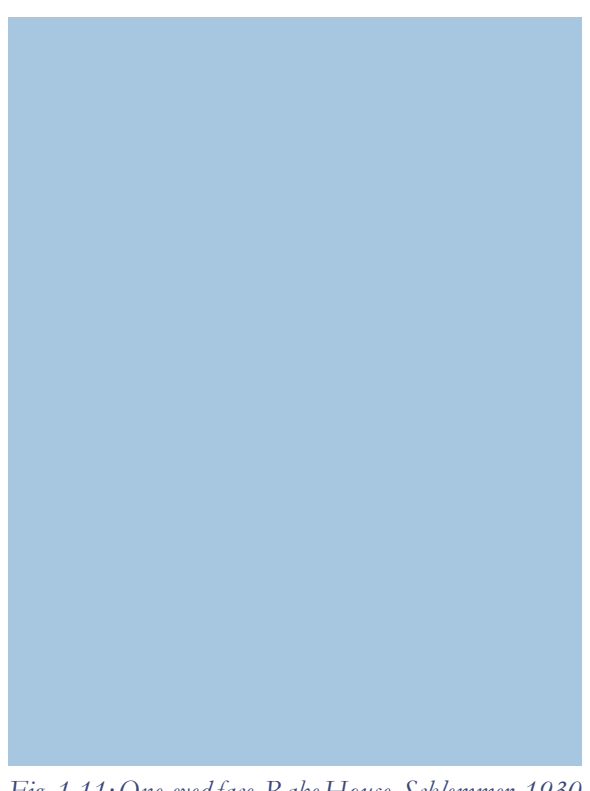

19 
between modernism and postmodernism, the modernist insisting on the priority of space, and the postTaking the theme of affect, and the idea of affect as a tangible thing that can be experienced, the research moves into the application of affect to space and place, and additionally, theories of place and space concerning contemporary urban design theory.

The relationship and difference between the notions of place and space have been considered through philosophical and geographic thought, beginning with postmodernism in the 1970s. The importance of both terms, and the definitions given, have changed with each person's writings. The two concepts can easily become confused; not interchangeable, they denote two different orders of being. There has been a perpetuating assumption that space is "simply a material

\section{Identity is created} both internally within

our minds, but also externally; through our interactions with the world

which exists to be 'made into' places" (Easthope, 2004, p. 129). Casey interprets this unresolved relationship as "the entire debate modernist conversely maintaining the primacy of place and, in particular, lived place." (2001, p 404). Casey settles on the following definitions;

'Space' as the "most encompassing reality that allows for things to be located within it."

"Place' as "the immediate ambience of [the] lived body and its history."

With the definition of place come the role it plays in shaping identity. Understanding the relationship between place and identity became a popular area of study with geographers in the 1970s, with the key text being Tuan's Topophilia . Topophilin is the "affective bond between people and place". This bond not only causes affect within the place, but also "actively produce places for people" (Duncan and Duncan, 2001, p. 41). Identity is created both internally within our minds, but also externally; through our interactions with the world.

Tuan explores perception; "the response of the senses to external stimuli", and the registering of phenomena through purposefu activity (Iuan, 1974, p. 4). Human respond to the world through sensitivity, including more than the 'five senses'; examples include some peoples' innate sense of direction, and others sensitivity to changes in temperature (Tuan, 1974, p.6) Tuan explores the psychological responses humans have to what we perceive in the world around us focusing here on the perception of scale and space (1974,pp. 6,7). For us all, many things influence ou perceptions and response, from sensory intake to cultura experiences; from personal preferences to world views. Al experiences influence the affect we detect, us individuals to specific places.

Casey's titular terms; self, body, and landscape, come into focus as notions that each address a "different dimension of place" (2001, p. 405). Self has typically been tied to consciousness in Western philosophy, that personal identity "always accompanies thinking," it has nothing to do with place (Locke, 1959, p. 449). In modernist view, place has no relation to self, self belongs to consciousness and place to the physical realm (Casey, 2001, p. 405). Late modern thought, moving into postmodern, started to contest this. Following Descartes, now the body and self are integra to one another, meaning place is an essential aspect of self. Thus, the notions body self and landscape are intrinsic to one another; "there is no place without self, and no self without place" (Casey, 2009, p. 406). The body links self to lived place, and landscape can be interpreted to be the "layout of a set of places" (Casey, 2009, p. 405)

Duyvendak explores place attachment and notions of home through thick and thin space. The widely held belief is that an increase of mobility in our 'globalised' world has changed what notions

Notions of body, self,

and landscape are

intrinsic... "there is no self without place, and no place without self" Casey, 2009, p. 405

of place and space mean. There are many positions, but the binary falls thus; universalist positions versus particularist. Universalists' argue that a revitalisation of meaning has occurred in the 'mobile Particularists' believe local places have increased in importance in this new world (Duyvendak, 2011, p.8).

The Universalist position sees a scepticism about the importance of place and space attachment. People are always becoming increasingly mobile, thus everyday practices are not intrinsically linked to physical places (Gustafson, 2001, p. 668). Gustafson argues that social meaning is no longer with places, but with the 'space of flows'; tied into mobility and movement. Perhaps, if people are mobile and nomadic, they may have an incapacity to connect to place, as places have become more generic nd less 'attachable' (Duyvendak, 2011, p. 10). 
Particularists argue that places they be 'mobile' or 'rooted' people, matter, specifically places where place an importance on feeling people live, as places can provide "a at home, on creating meaningful sense of 'home' in an increasingly connections to a place; affective turbulent world" (Duyvendak, 2011， relationships.

10). The world has taken on a mobile, global environment, leading to specific places increasing in local particularism. Feeling attachment to place is no longer guaranteed in the mobile world, thus leading to perhaps more value when belonging truly is felt. There is a clear opposition in these opinions - what has happened to place attachment in this world of increased mobility? Are places now more important, or less? Is place attachment more or less difficult now?

Duyvendak also discusses notions of thick and thin places. 'Thick' places are those tied up in belonging and familiarity, while 'thin' relate to a sense of restlessness and movement (Duyvendak, 2011, pp. 2 \& 18). The strongest example of thick space

'Space' "is a 'frequented place', 'an intersection

of moving bodies': it is the pedestrians who transform a street"

Auge, 1992, p. 79, ref. de Certeau, 1984, .. 97

is the feeling of a place being 'home'. There is a common prior assumptioninalotof research within the area that all people, whether
With discussion of place attachment rises the issue of what a place is if it is unable to be identified with. 'Nonplace' is a term coined by Augé in this key text on the subject. Augé describes it thus, "If a place can be defined as relational, historical, and concerned with identity, describes it thus, "If a place can be defined as relational, historical, and concerned with identity, then a space which cannot be defined as relational, identity will be a non-place" (1992, pp. 77-78) Supermodernity; the era of the excess of the modern, produces non-places. Place and space were viewed as oppositions within postmodern thought, and the further distinction between place and non-place created by Augé derives from this opposition. Place and non-place are opposed; "the first is never completely erased the second never totally completed" (Augé, 1992, p. 79).

Augé references de Certeau; that 'space' 'is a 'frequented place', 'an intersection of moving bodies': it is the pedestrians who transform a street" (1992, p. 79, ref. de Certeau, 1984, p. 97). The term 'place' has been more defined than 'space'; it refers to an event, myth, or history, where space is ambiouous, like 'area', it is a distance, an expanse. or historical, or concerned with
In recent years there has been a shift within the professions of landscape and urban design, where projects have started to fall between the two categories, and the emphasis has moved from the desion of specifically enclosed spaces to the design and manipulation of the landscape as the urban surface (Wall, 1999, p. 233). The landscape is viewed as an active surface, where interactions between various elements are supported, and conditions that promote new relationships are formed. The landscape is viewed as more than "green" or recreational space; it is the entire ground structure that supports activities within the city, both fixed and changing (Wall, 1999, p. 233). When understood this way, the urban surface becomes responsive, dynamic, unfolding.

Today, cities are ever-changing rapidly evolving. Networks of

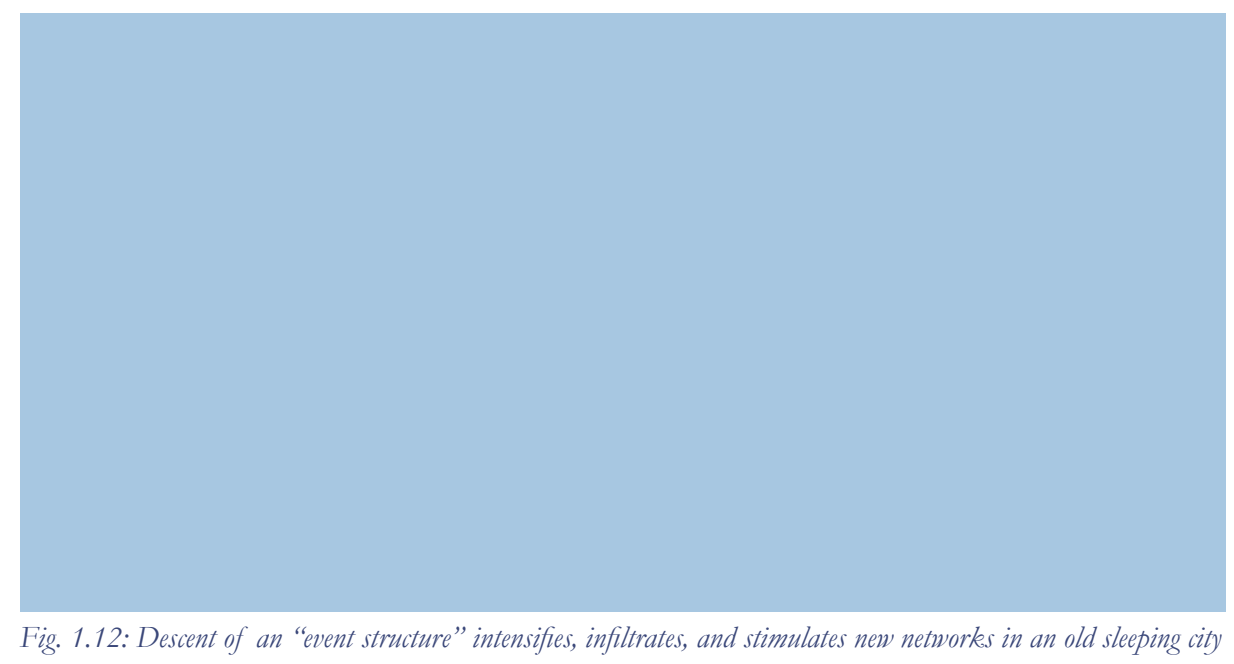

The flow and overlap over static spatial boundaries..
the urban environment is dynamic and responsive

The flow and overlap over static spatial boundaries..
the urban environment is dynamic and responsive

communication, transportation, production, and consumption overlap (Wall, 1999, p. 234). This "web" experience has led to the importance of the flow and overlap over static spatial boundaries. This has shifted the focus from "form" to "process"; that the urban environment is dynamic and responsive, and desion responses need to be adaptive, not a fixed formal solution (Wall, 1999, p. 234)

Three recent changes have significantly affected the planning and design of urban spaces;

1. Spaces that have risen in importance include the "ambiguous areas that are caught between enclaves". These are seemingly peripheral sites, but are the spaces where people actively live, they are access routes and social spaces.

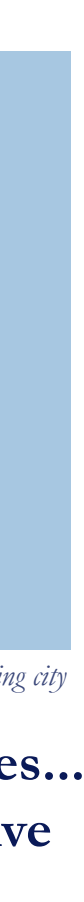


2. There has been an increase in (Gruen, 1955, p. 18). To design access and mobility; not just through transportation alternatives, but also through density of population, and the availability of media and information.

3. Thirdly, a consequence of the above two is the shift in focus from viewing cities formally, to an understanding of them as dynamic and ever-changing (see fig. 1.12, p. 21). Familiar urban typologies, such as district, park, or square, are no longer as significant or useful as an understanding of the flow of networks, and therefore the rising significance of ambiguous spaces (Wall, 1999, p. 234).

Recent history that influenced these changes includes the rapid spread of cities; as buildings rose across landscapes, the distinction between urban and countryside areas blurred, and the differences between types of places became less distinct (Wall,

\section{The urban surface}

must be staged to

be anticipatory and

accommodating... so it

can change

1999, p. 235). Buildings should not be considered individually, but rather as an aspect of their environment; as a function within a broader context for changing programs, the urban surface must be staged to be anticipatory and accommodating created with a framework in mind, so it can change as the needs of the city change (Wall, 1999, p. 237)

OMA and Rem Koolhaas started rethinking new technologies and desion approaches in the 1970 s to address the changing state of urbanism. For the new town of Melun-Senart in France, voids were given design importance over buildings, flipping the "formal and structural roles of figure and ground, building and open space" (see fig. 1.13) (Wall, 1999, p. 238). each derived from analysis of existing conditions; infrastructure corridors, historical fragments, habitats, and proposed new programs. One condition was slid over another, allowing for future adaptive change without loss of the proposed organisational structure (Wall, 1999, p. 238).

Third places, or great good places, are defined by urban sociologist Ray Oldenburg as "[places] of refuge other than the home or workplace where people can regularly visit and commune with friends, neighbours, coworkers, and even strangers" (Oldenburg, 1991). For a third place to be successful, it is comfortable, welcoming, visited by regulars, and facilitates the meeting of people, both old friends and new (Mehta and Bosson, 2010, p. 780). Third Each void was given a programme,

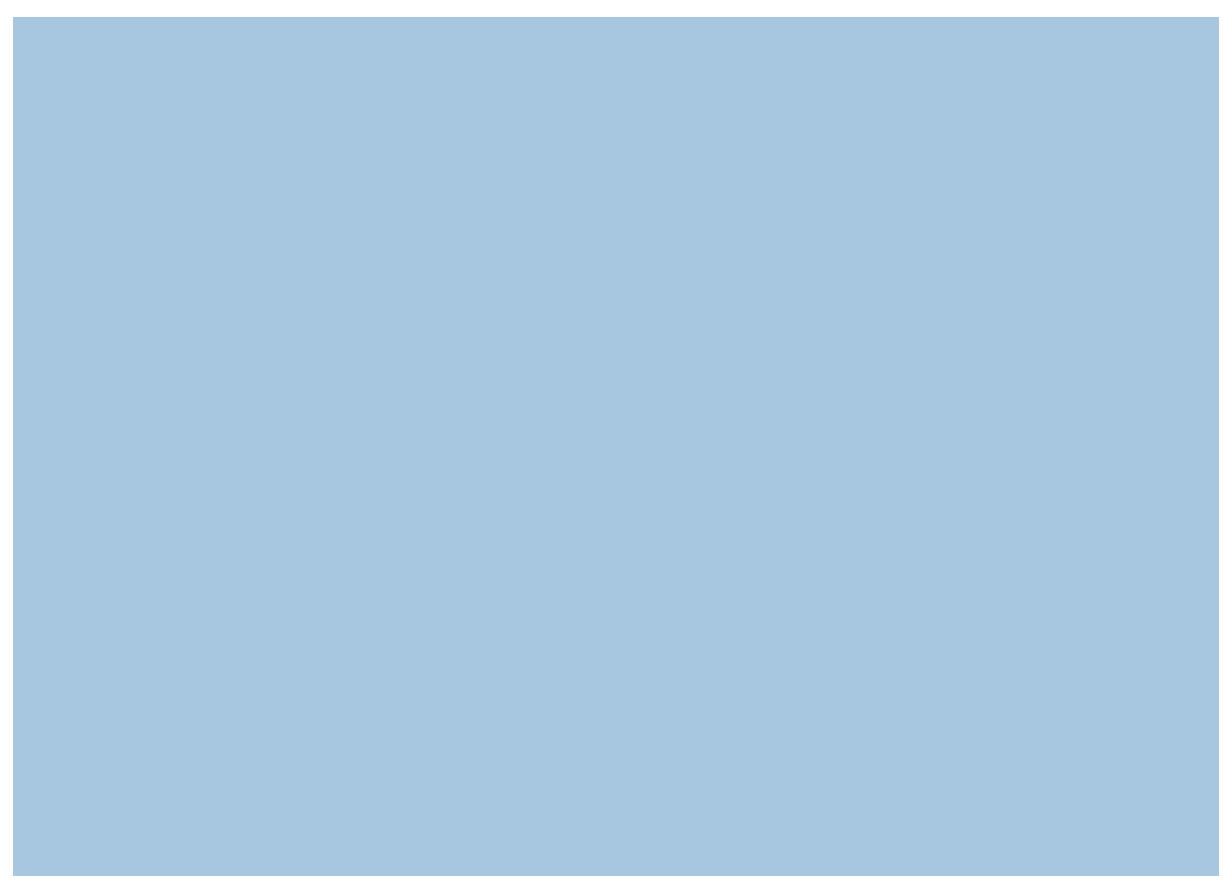

Fig. 1.13: Ville-Nouvelle-Melun-Senart Masterplan, OMA, 1987, site diagram

One condition was slid over another, allowing for future adaptive change

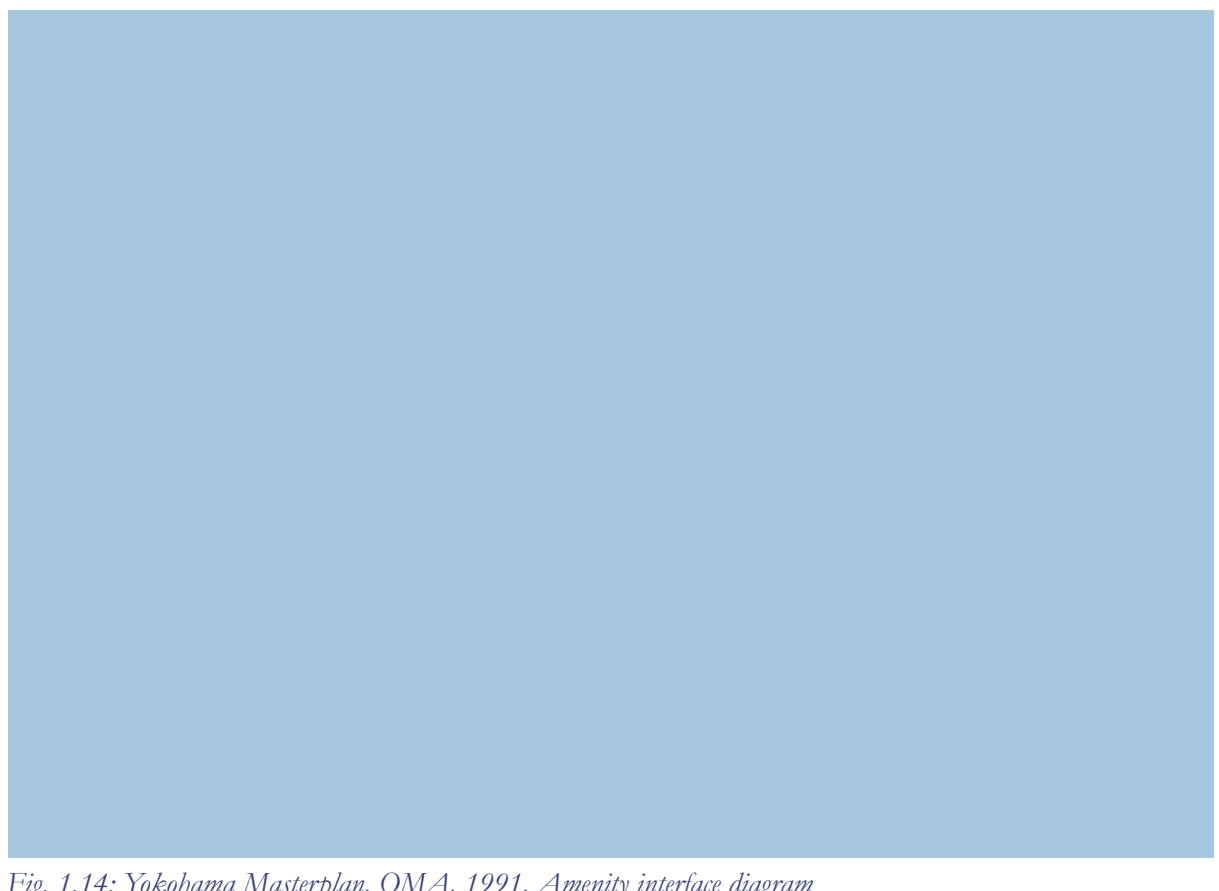

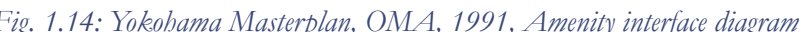


places are inclusively social places separate to the first place; of domestic activity, and the second place; of productivity (Oldenburg, 1991, p. 14).

These "distinctive informal public gathering places" are crucial to the growth and refinement of civilisations such as cities and towns (Oldenburg, 1991, p. 2). Being a large part of individual citizens' daily lives, third places become intrinsic to the urban landscape, and across the world, dominate the perception of the city; London with pubs, Florence with piarzas, Paris with café's spilling onto the footpaths (Oldenburg, 1991, p. 2). Human contact; diverse relationships between all kinds of people, feeds the culture and "feel" of a place, becoming the essence of the place (Oldenburg, 1991, p. 2).

Third places are essential due to their establishment of neutral

"Distinctive informal public gathering places" are crucial to the growth and refinement

\section{of civilisation}

Oldenburr, 1991, p. 2

ground. When socialising in private, we will not welcome every type of person into our lives and spaces,

but when public spaces allow for socialisation, people become much feer in who they are willing to interact with (Oldenburg, 1991, p. 22). The character of the third place is that it is neutral, inclusive, accessible, accommodating, and promotes conversation (Oldenburg, 1991, pp. 22-32). Due to their nature as places where everyone is equal and welcome, with no pressures to play host or complete specific productive tasks, the focal activity becomes conversation, and through this, community is built Oldenburg, 1991, p. 29).

Four characteristics are proposed by Mehta and Bosson (2010) as creating public spaces that support social interaction and frequent use are personalisation, permeability, seating, and shelter.

The article focuses on what businesses can do to enhance the streetscape, but physical characteristics implemented by larger authorities, such as footpath width, street furniture, or green spaces, can also support human interaction (Mehta and Bosson, 2010, pp. 780, 781). These elements can be both place-based and people-based; the result of characteristics of the physical environment, and a consequence of human actions (Mehta and Bosson, 2010 , p. 780$)$

Personalisation is a way for people to change the environment to meet their needs and specific activity patterns". Through this, individuals

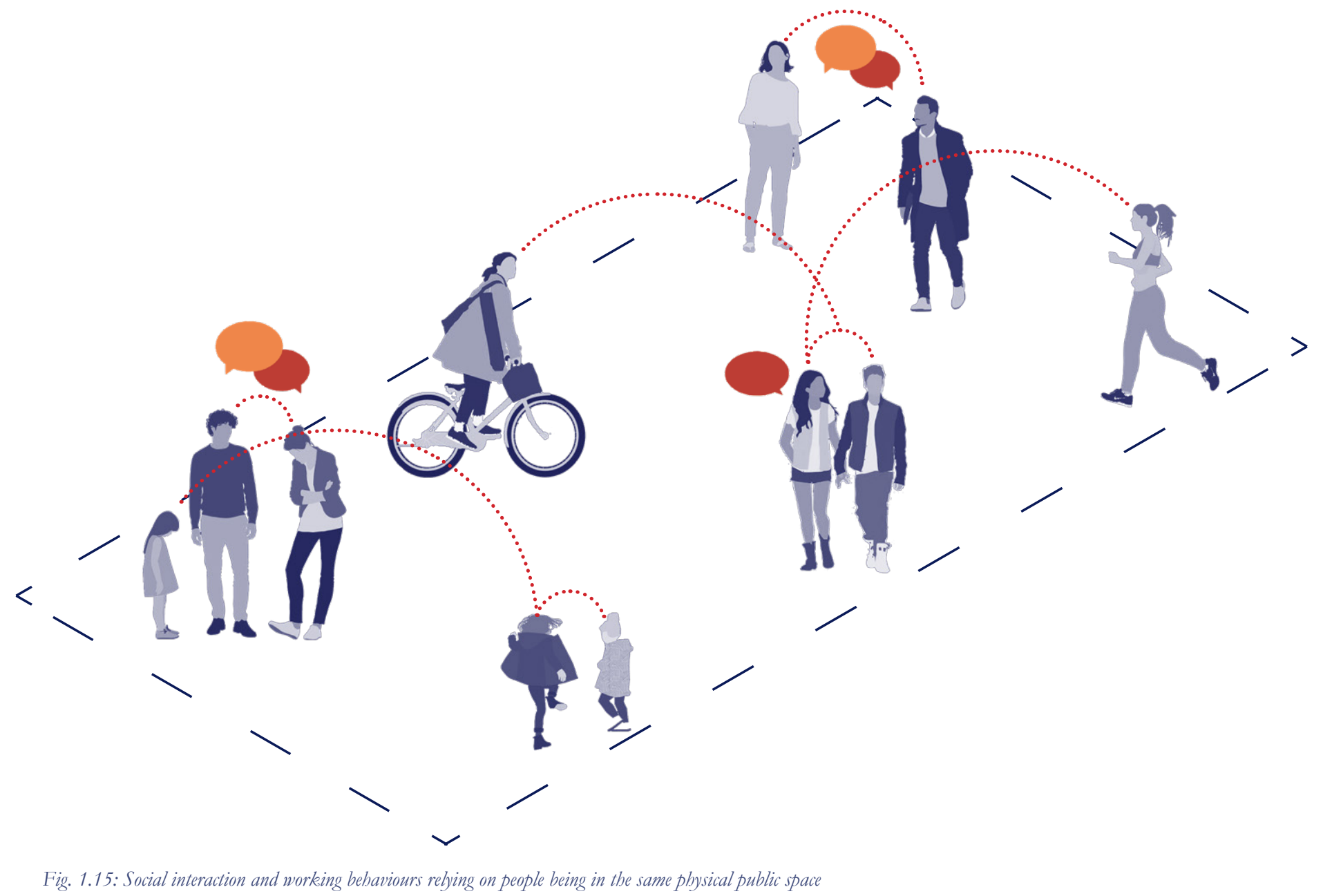

27 
can make a place identifiable, distinctive, feel safe, and can create a symbolic aesthetic. Change is encouraged, generating interest and stimulation within a familiar setting, which facilitates social interaction (Mehta and Bosson, 2010, p. 781).

Permeability in the street front of buildings is a way to actively reveal the interior, bringing a connection between these activities to the outside. Besides acquiring goods, many people go to shopping streets to walk, meet friends, people watch, and look around (Mehta and Bosson, 2010, pp. 781, 782). Permeability generates a sensory experience for pedestrians.

To sustain public spaces, and

support social behaviours, seating is essential. The opportunity to pause extending time pedestrians spend at a specific location. There is also the possibility to consume goods in a public setting; eating and drinking being activities that are associated with relaxation, and particularly socialising (Mehta and Bosson, 2010, p. 782)

Environmental factors are integral to the support of outdoor activities. Pe most successful when oriented to receive sunlight, however, shade and shelter are also necessary to accommodate changing seasons and weather conditions (Mehta and Bosson, 2010, p. 782).

The character of the third place is that it is neutral, inclusive, accessible, accommodating, and promotes conversation

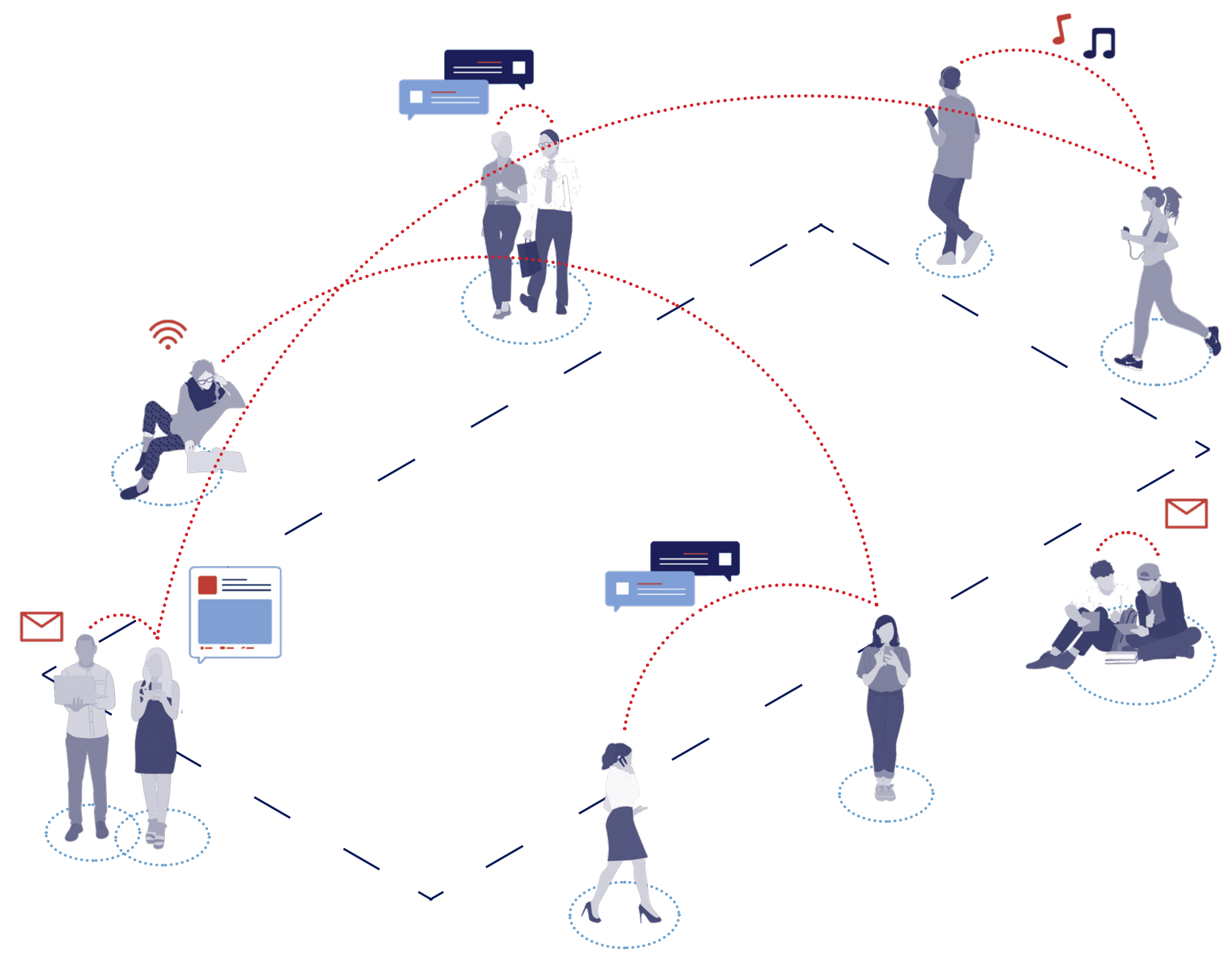

Fig. 1.16: Social interaction and working behaviours can occur without the need for individuals to be in a shared physical space through mobile connectivit 
These theories of place and space in relationship to contemporary urban design theory influence the proposed design process that the exploration of the thesis question will be explored through. Through the implementation of affect and place attachment theory, understanding of social and working activities that may be present on given street site comes to light.

In the past, social interaction and working behaviours required on people being in the same physical space (see figure 1.X, p. 25). Moving forward, with the progression of technology, it is possible to connect across large distances, through various networks provided by mobile connectivity (see figure 1.X, p. 27). This has enabled the changes occurring in the contemporary workplace sphere; working anywhere, at any time, but has also infiltrated our entire lives, altering how we behave in physical space. Design research can propose the possibility of moving toward specifically designed streets that facilitate all forms of working behaviour and social interaction; be those face-to-face, or technological see figure 1.X, opposite).

Through the redesign of selected streetscapes, unique places can be formed that allow for place attachment; places where people feel that they belong, where the affect enhances the experience and encourages bonding.

Throughout the research discussed in this review, each element examined throughout the process of research by design. Firstly, affect is examined through the initial case study design tests. Place and space theory is explored throughout the site analysis process. Through the initial and developed design phases, affect, workplace, and place and space theory are all periodically, and sometimes simultaneously, considered, to facilitate a design process that explores the thesis question;

how can analysis of affective relationships enable the public street as a pedestrian workplace?

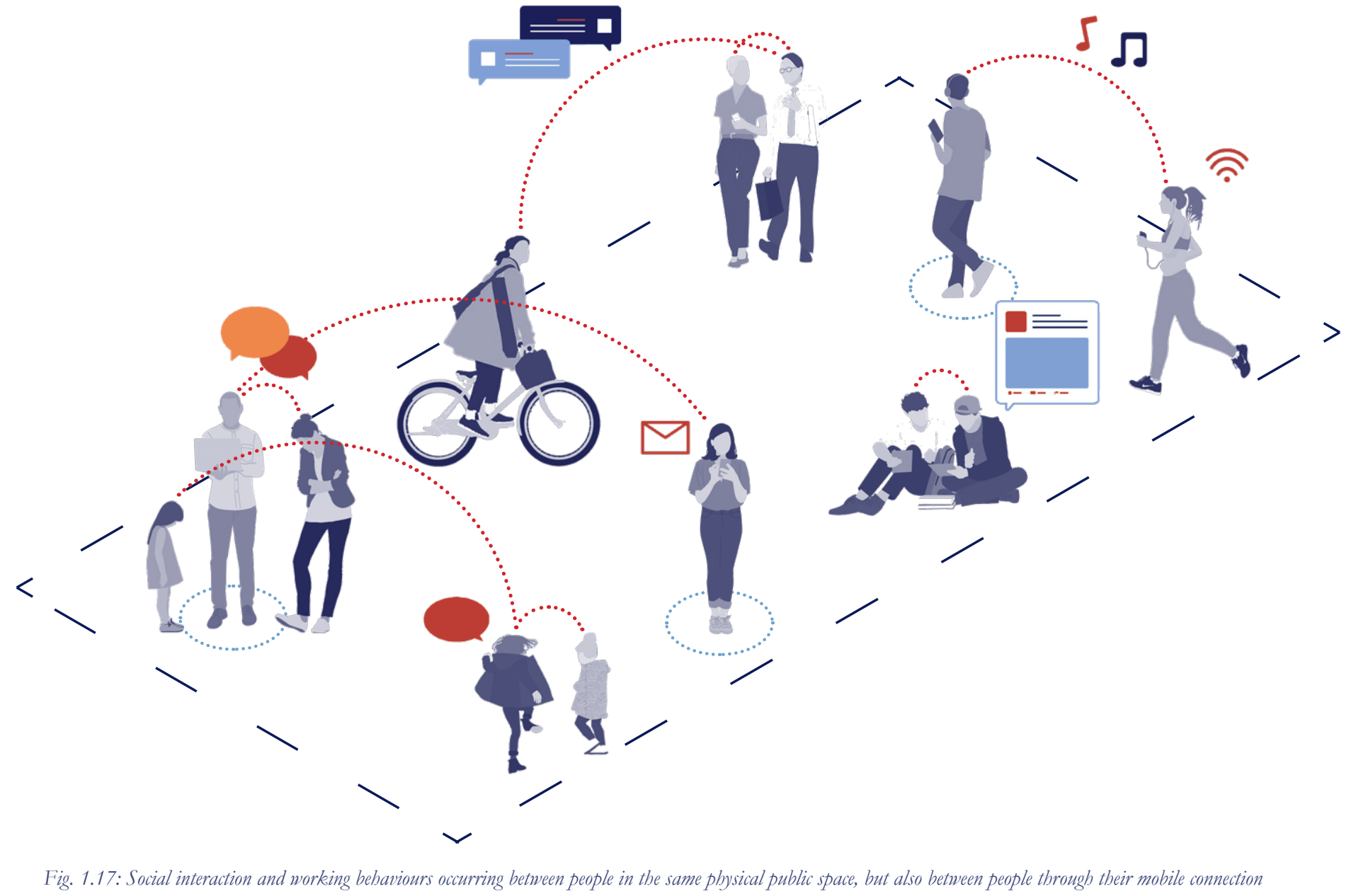




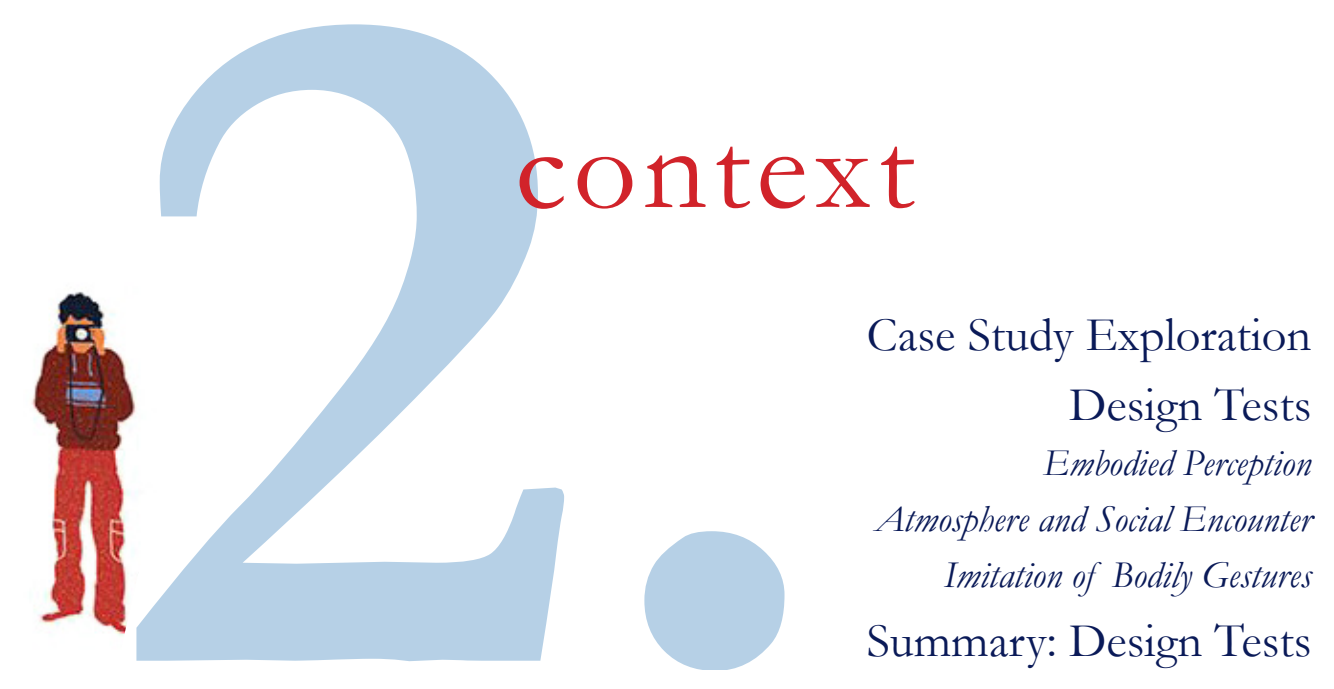

\section{$\square$}


Design/History:

Cuba Street

Cuba Street was named after the ship Cuba, arriving in Wellington on January 4, 1840 (Winter, 2013). It has existed since the early days of Wellington, being redesigned to various extents over the years;

to accommodate steam trams in the 1870s, and later electric trams (Winter, 2013)

Cuba Street is home to many historic buildings, and to this day retains its bohemian reputation

(Wellington City Council, n.d.). In the mid-1960s, the street was closed to remove the remaining tram lines, and pedestrians became attached to its use as a pedestrian-only street. Following public petition, in 1969 Cuba Mall was created, becoming New Zealand's first pedestrian mall - complete later that year with the famous Bucket Fountain Wellington City Council, n.d.)

\section{Willis Street}

Named after one of the directors of the New Zealand Company; Arthur
Willis, Willis Street has always been one of the main arterial streets in Central Wellington, over the year being home to many businesses (Irvine-Smith, 1948, p. 59). Today, the street is transformed residential to commercial; the lower block contains Wellington's two tallest buildings, and almost the entire block here is dedicated to businesses; largely retailers and offices (Irvine-Smith, 1948).

\section{Press Hall}

In 2016, development began on Community House to create Press Hall (Winter, 2018). A two-storey building was removed to make way for a laneway and courtyard space. Community House was formerly the heart of the Wellington Newspapers Group; the new food hall occupies The Evening Posts' press hall (Press Hall, 2019). The redesign of the site aimed to echo the precinct's style; a modern, dynamic site that celebrates the original form, structure, and heritage (McKee Fehl, 2018). The laneway is pedestrian access only creating a space where customer can linger to enjoy both the food and the architecture.
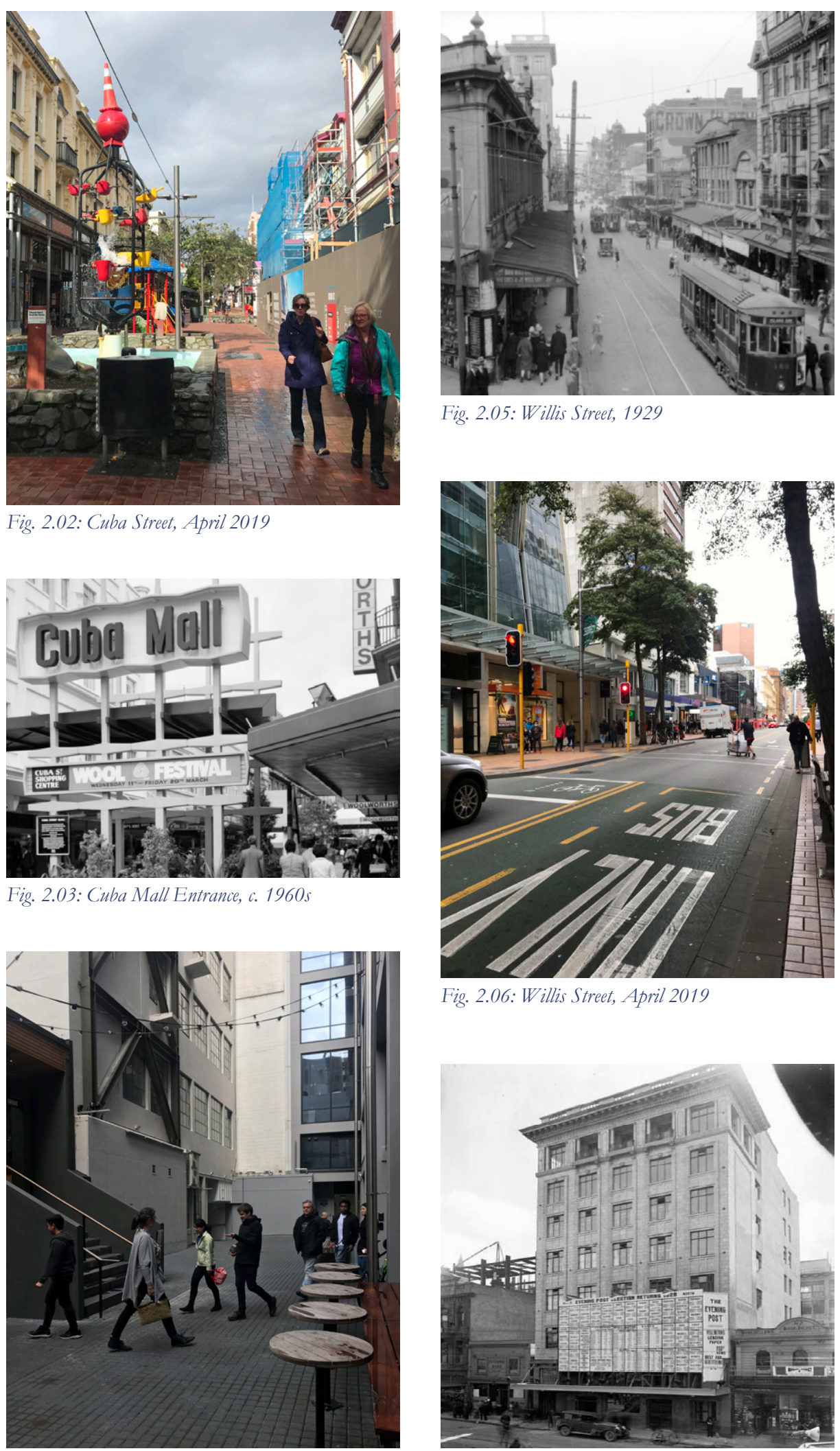

Fig. 2.04: Press Hall, April 2019
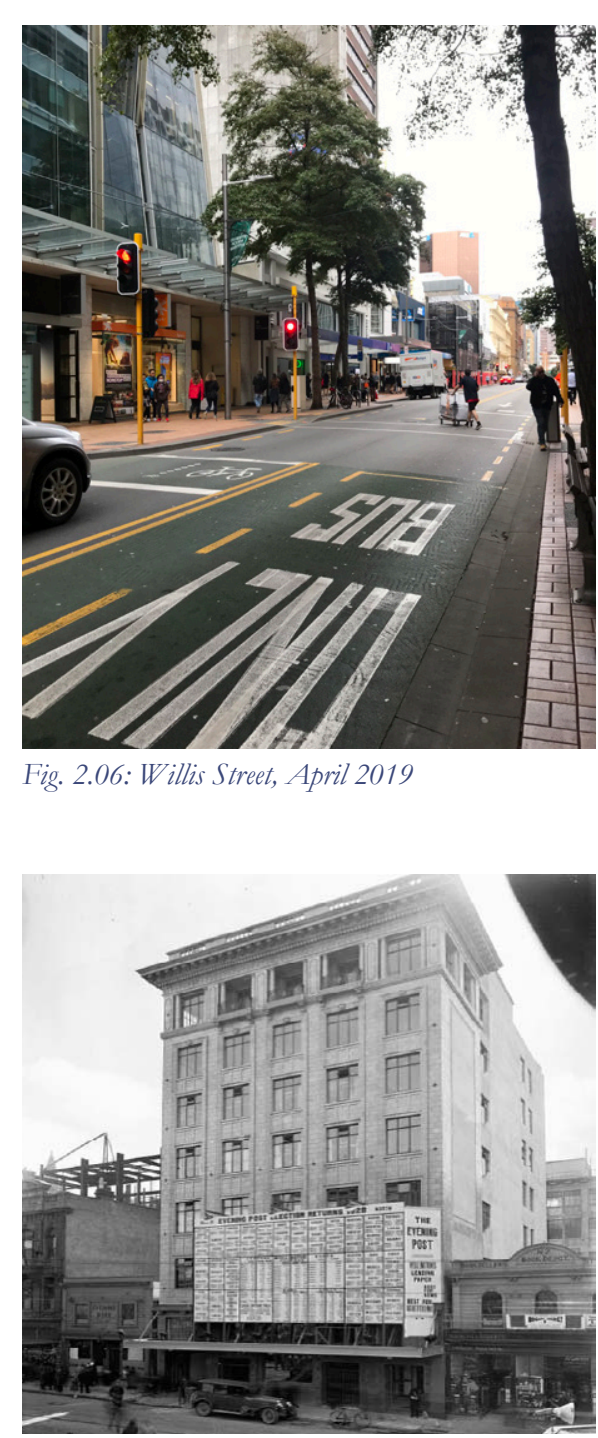

Fig. 2.07: The Evening Post Premises, 1928 
As we move through our daily lives, architecture acts as a backdrop it tends not to be something we consciously focus our attention on, but this does not mean we are not perceiving it. Peri Bader introduce a model developed by Gurwich and Arvidson; dimensions of attention (2015, p. 246).

\section{When architecture}

creates a disturbance within our perception it moves up to the focal dimension; theme

We absorb information through the two outer dimensions; marginal consciousness and thematic field, as we move through the world. When architecture creates a disturbance within our perception it moves up to the focal dimension; theme (Peri Bader, 2015, p. 248)

\section{embodied perception}

The case study sites are filled with affect-inducing objects, which are able to disturbance; generating an affective response. The testing introduces the sites and the architecture that builds them up through layers. As each layer is introduced, its disturbance on human movement is indicated.

Testing will explore existing and imagined elements that cause affective relationships that ripple out across the streetscape.

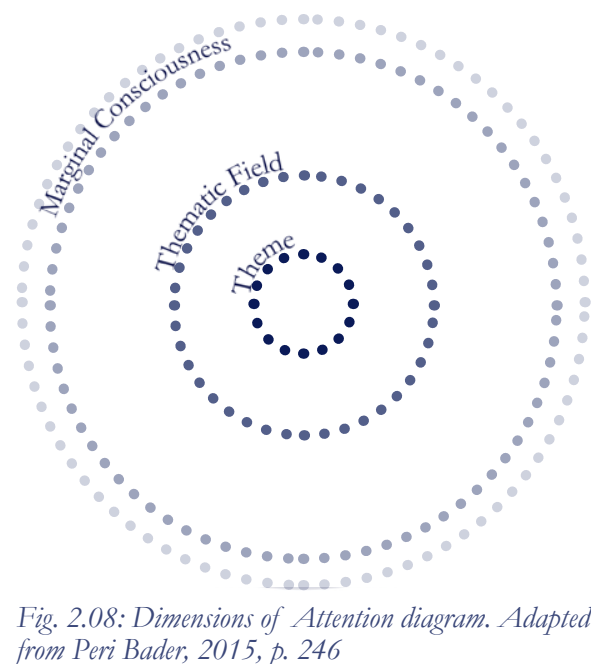
Fig. 2.08: Dimensions of Attention diagram. Adapted
from Peri Bader, 2015, p. 246

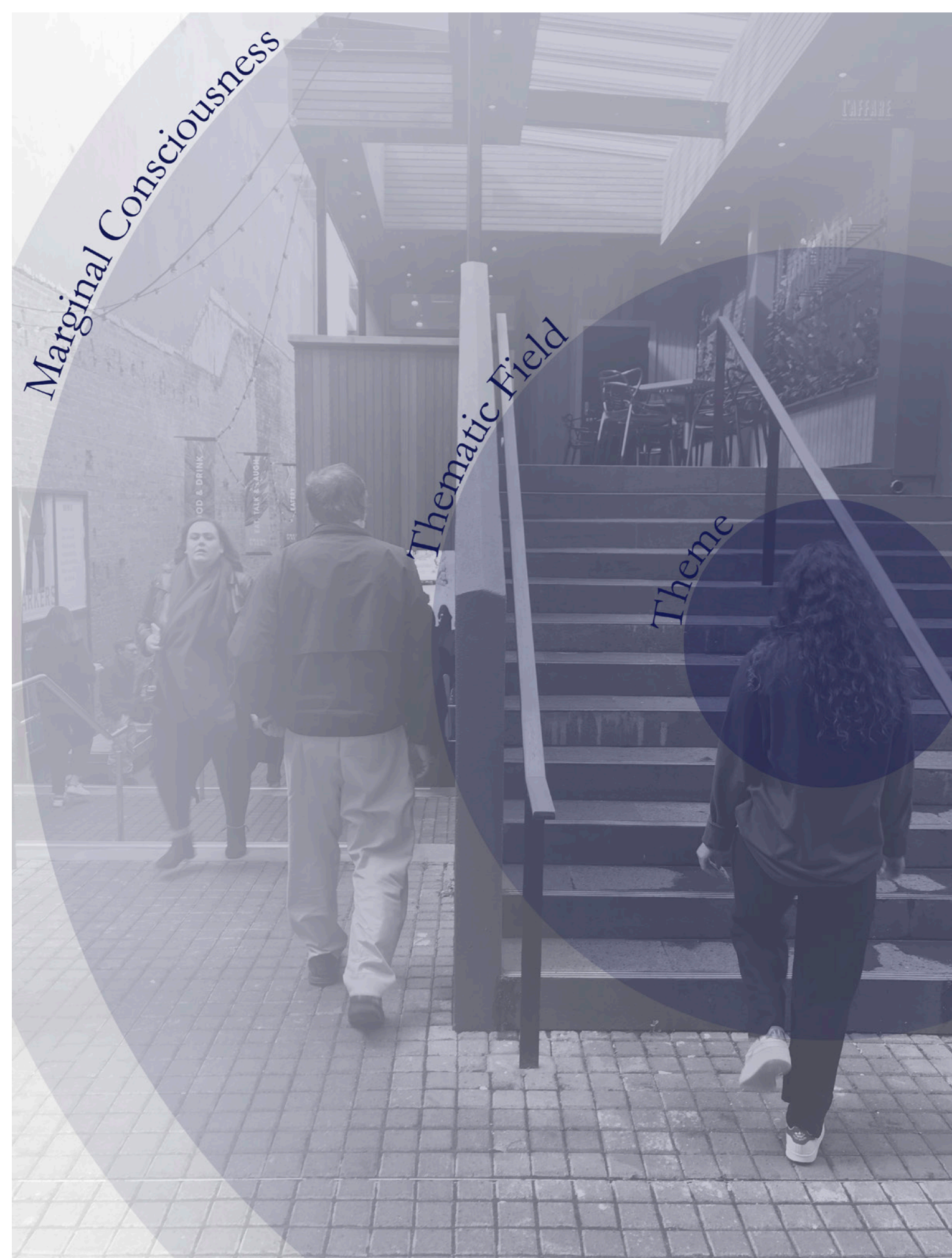

...the ability to cause an architectural disturbance; generating an affective response

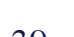




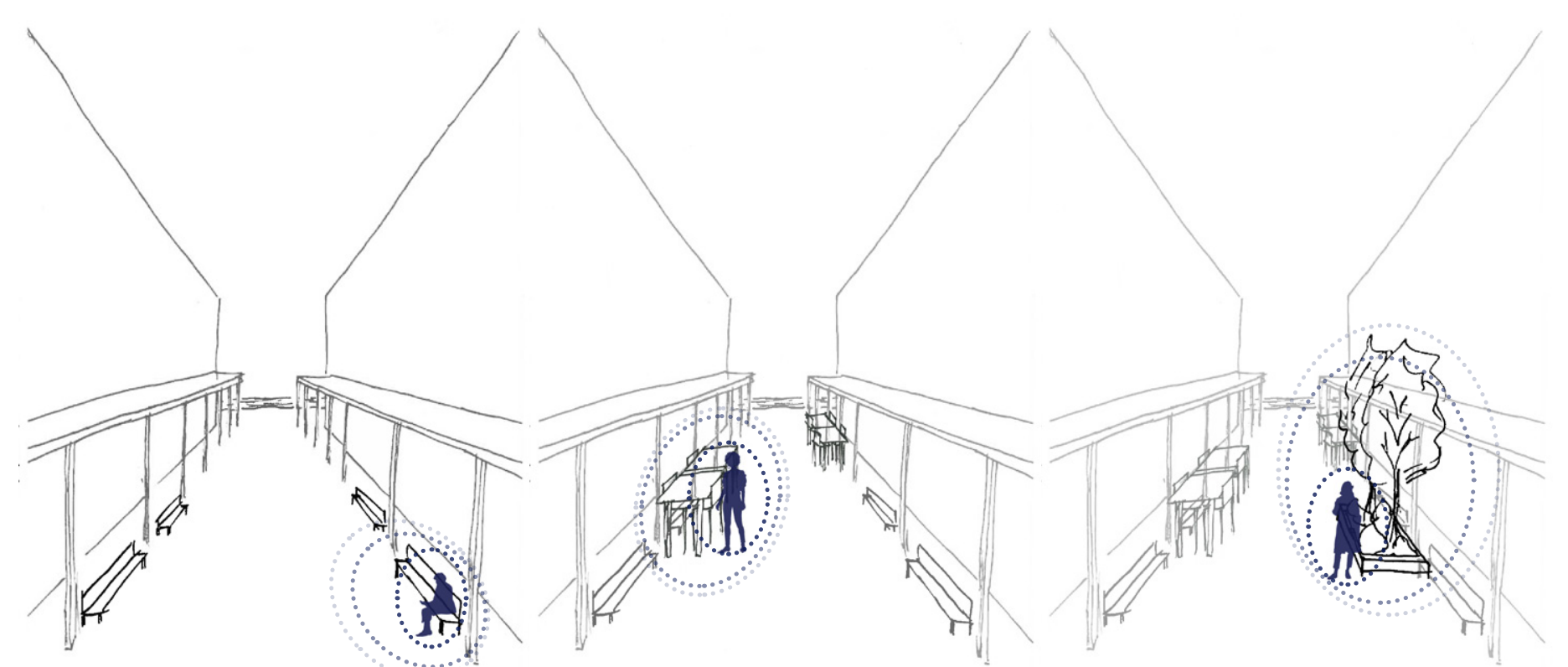

street furniture

café extrusion

planting

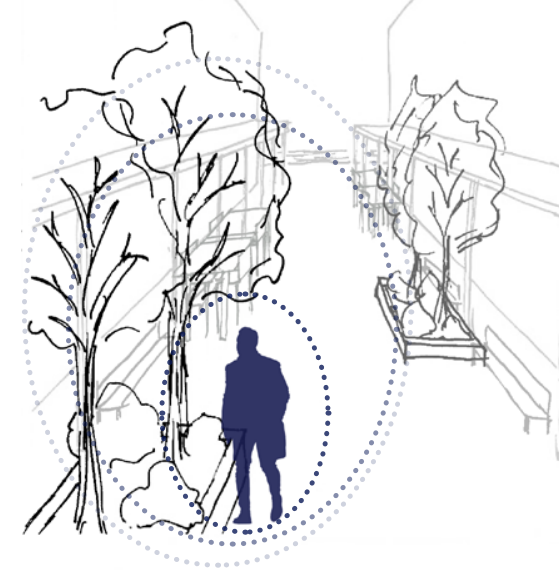

extensive planting

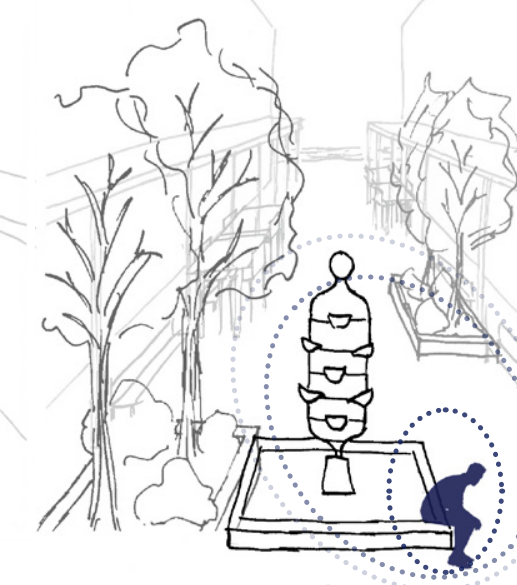

sculpture

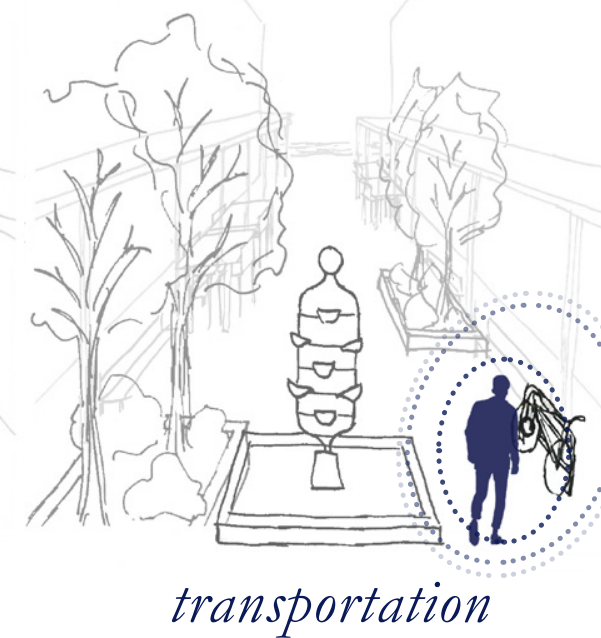

transportation

\section{embodied perception \\ cuba street / willis street / press hall}

Cuba Street is filled with overlapping spill onto the street. As one architectures and activities; places traverses the street, architectures to sit, interact, eat, walk, run, dance, move into the focal dimension play, perform... The edges of the theme, demanding attention. At each street are not defined by the walls of level, a critical moment occurs; an the buildings; café and bar seating, affect emerges and is experienced shelters and entertainment items (Massumi, 2002, pp. 32, 33).

Fig, 2.10 - 2.15: Test A, Cuba Street. Dimensions of Attention overlaved on lavers of the street 

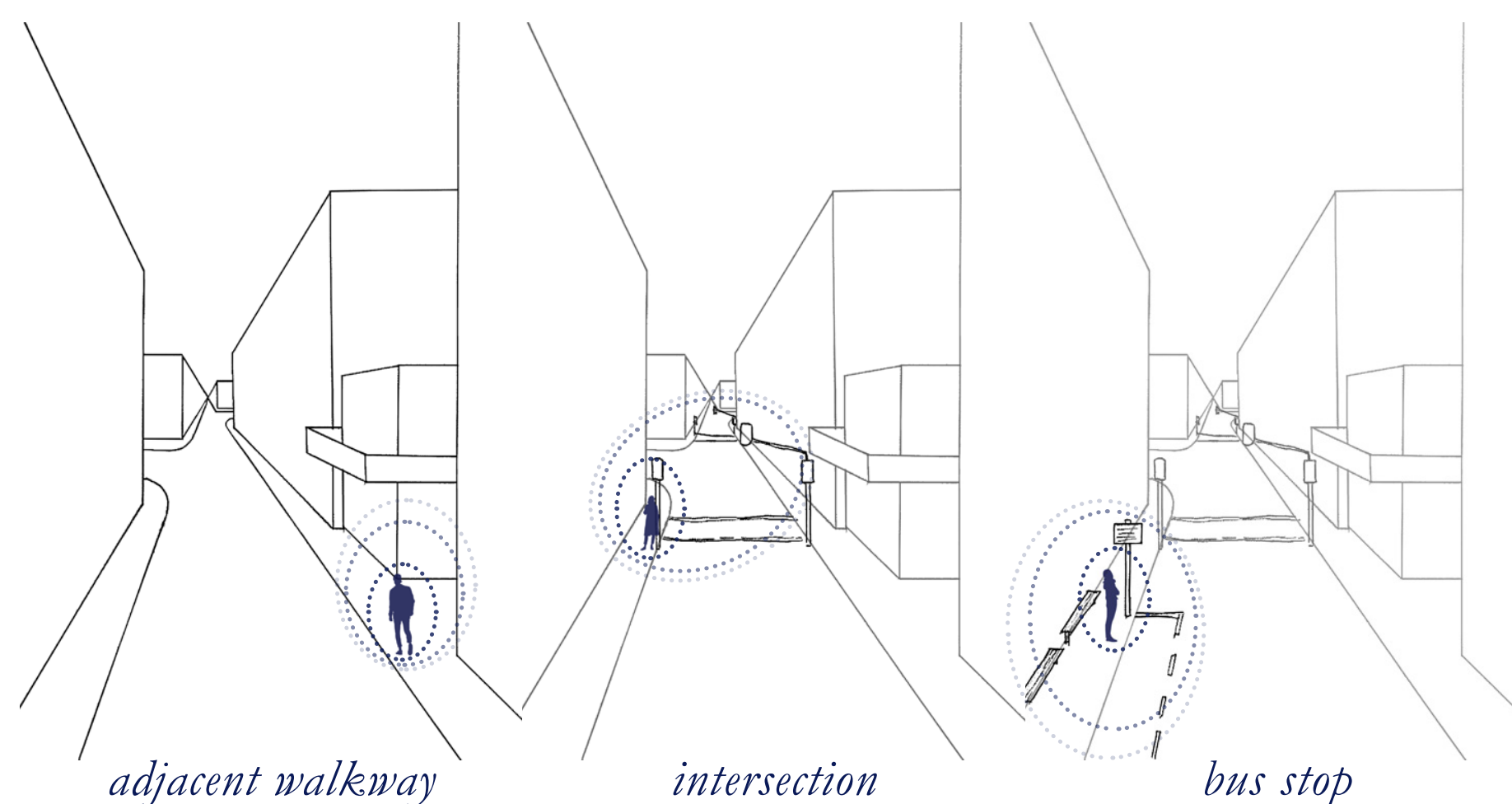

bus stop

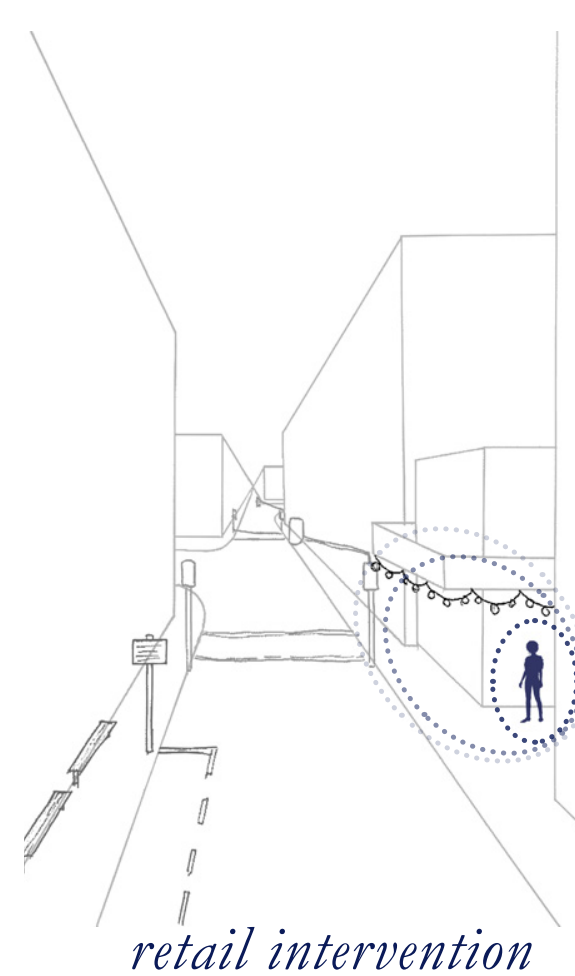

retail intervention
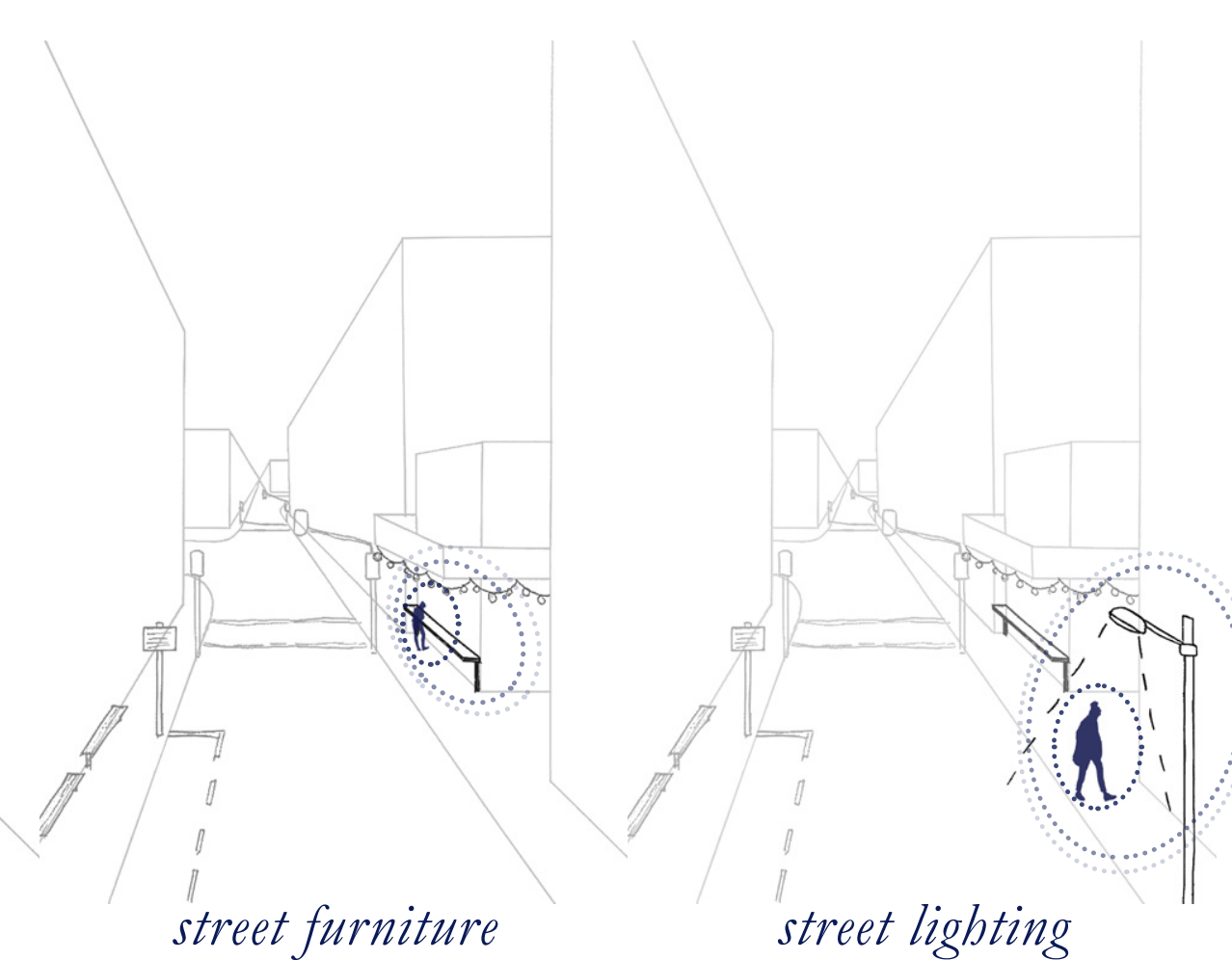

street lighting
Willis Street is the only one of the three case st access; the street is dominated by cars and buses. Because of this, the most regularly interacted with

architectures' are the street edges

where the footpath meets the

Fig. 2.16 - 2.21: Test A, Willis Street Dimencions of adjacent buildings, and the traffic lanes. Pedestrian space is limited, leading to significant interaction occurring amongst pedestrians and with the architectures that fill the space; intersections, furniture, retail spaces. 


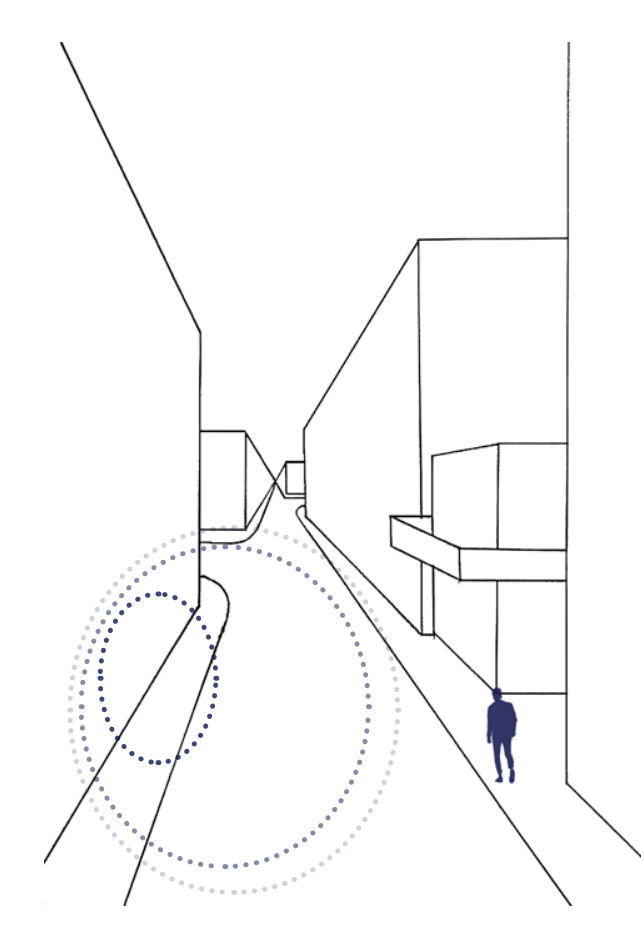

access

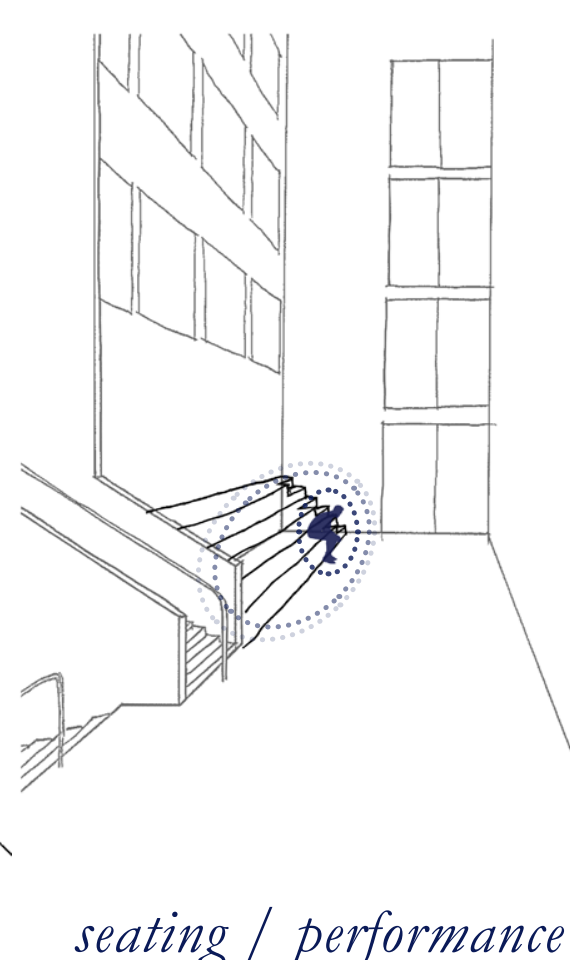

seating / performance

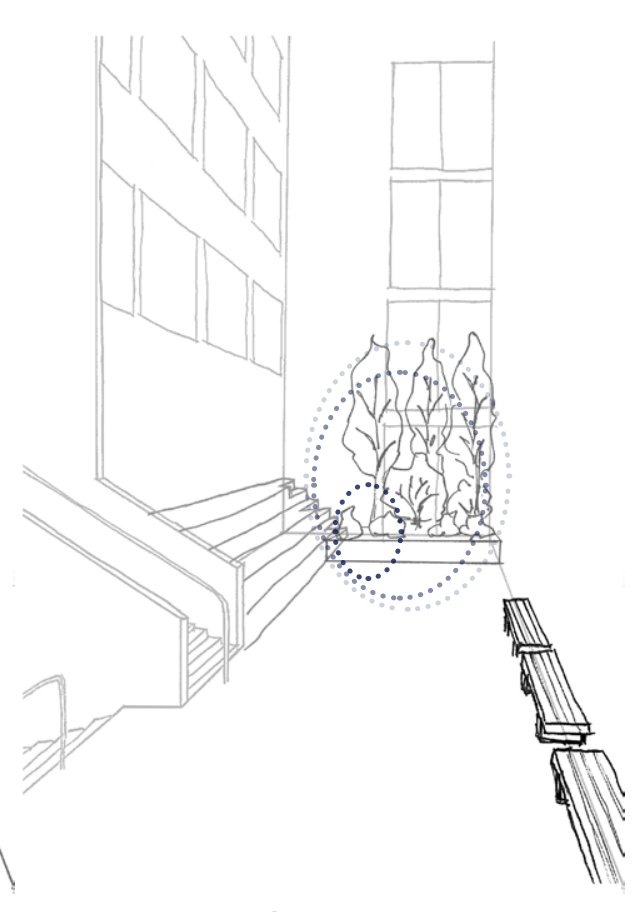

planting

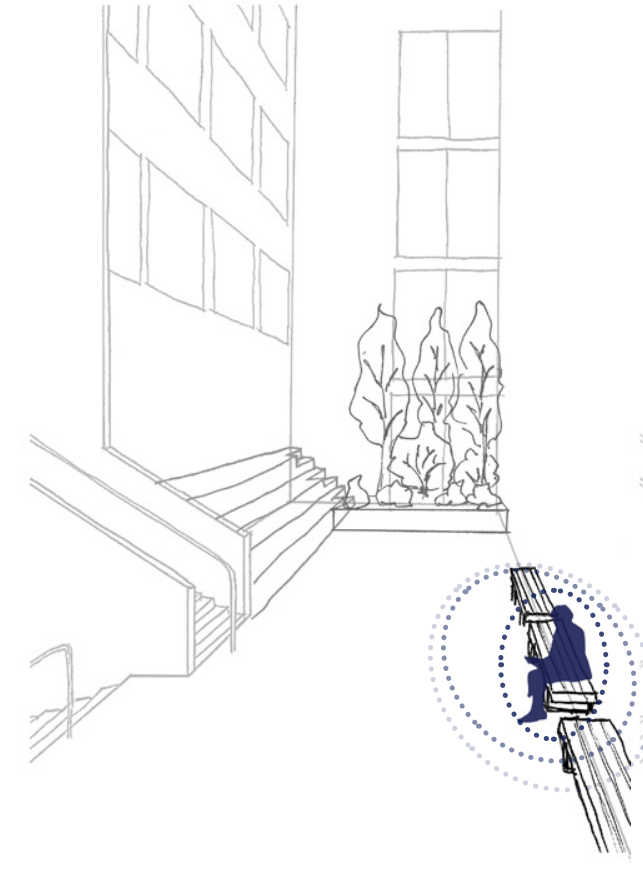

street furniture

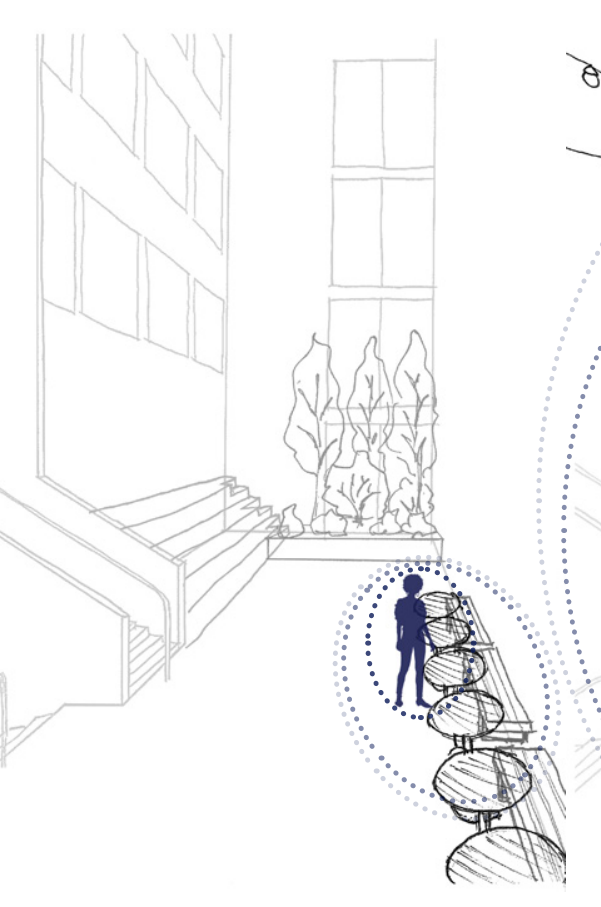

eatery extension
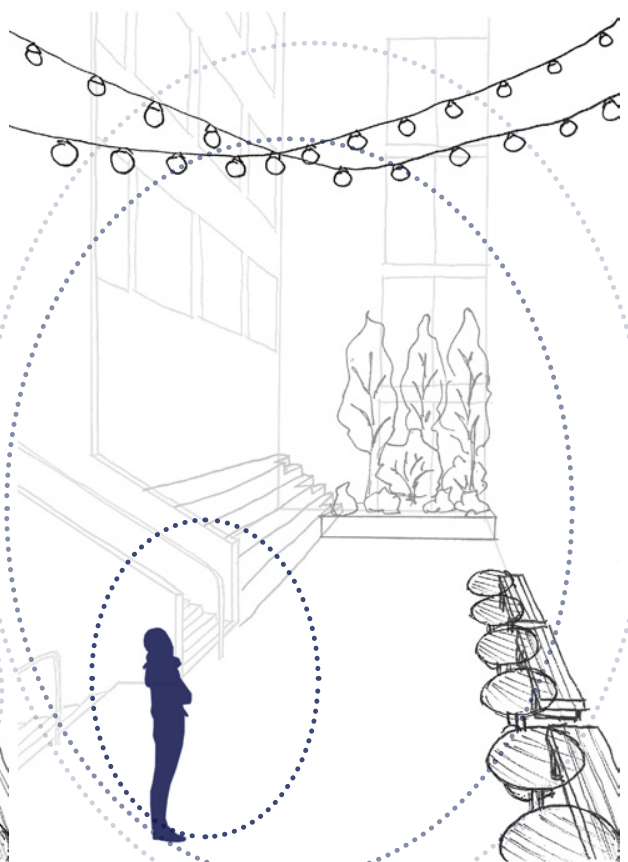

lighting

Press Hall was specifically designed the site fills, and possible affective as an access route and extension relationships become apparent. of the interior eatery. The existing The interventions explored were exterior is quite empty, so most of chosen to enhance opportunities the interventions here are imagined for moments of pause within the waysto enhancetheexperience of the site; to encourage people to linger space. As each object is introduced, and interact. 
Eliasson adjusts atmosphere; the sensory qualities of space, to invoke affect. This occurs through the manipulation of elements and dissolving of material; transparency, colour, light. He contextualises affect through transformative shifts; weather conditions and landscapes are not fixed in the spaces he creates, and their ever-changing nature teaches us to be subjects that recognise our subjectivity.

\section{"atmosphere is} inextricably linked

\section{with social encounter";} his work demands the visitor engages to create mutual transformation Frichot, 2008, p. 32

For Eliasson, "atmosphere is inextricably linked with social encounter"; his work demands the visitor engages to create a mutual transformation of space and person (Frichot, 2008, pp. 32, 33). We are

\section{test atmosphere}

reintroduced to our part in the world, "[passing] into the landscape as the landscape passes through us" (Frichot, 2008, p. 35).

Attempts to "dissolve material" will be directed through a testing phase. Use of interacting media will manipulate elements; using watercolour to draw affect from site photographs through the first test, and light and colour to explore affect, space, and threshold from the street context through the second test, using modelling

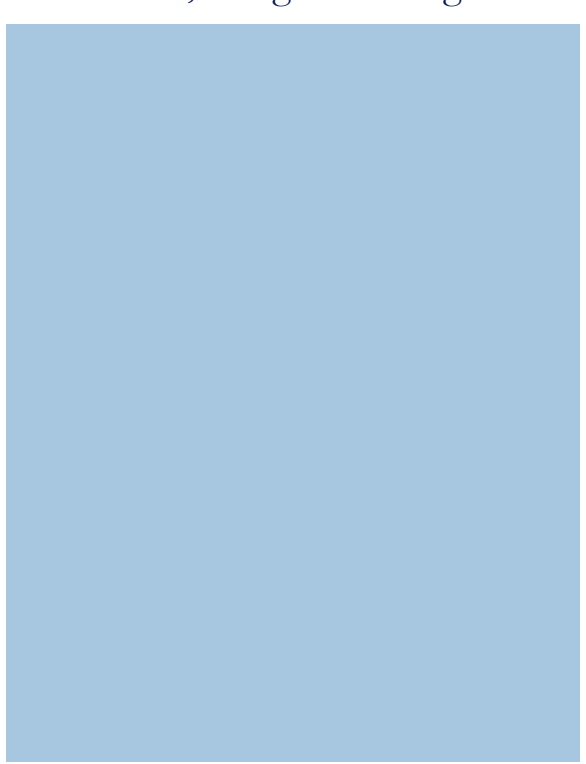

Fig. 2.28: The Weatter Project, Eliasson, 2003 ...dissolves material through manipulation of elements; colour, light, transparency.. 


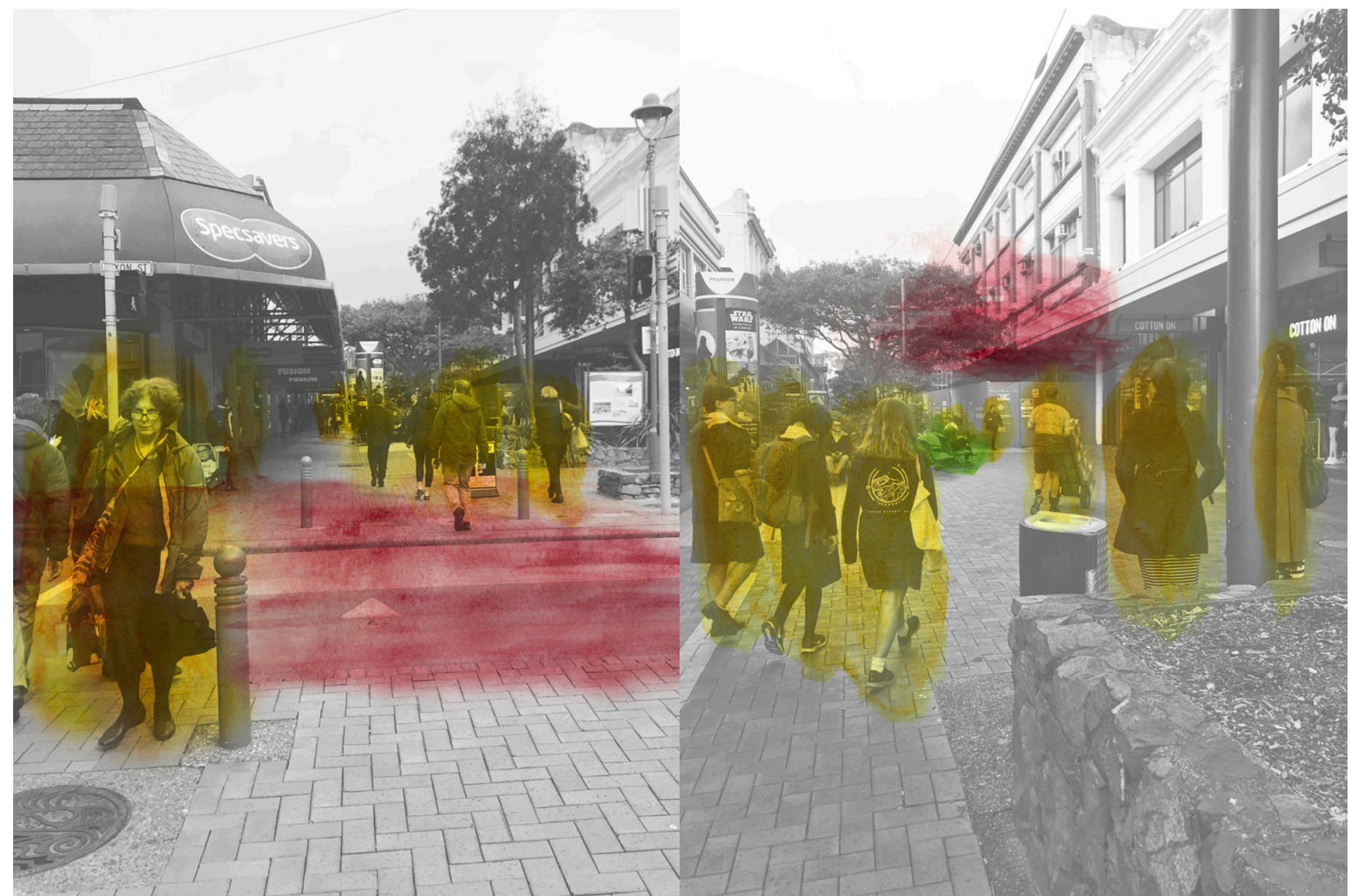

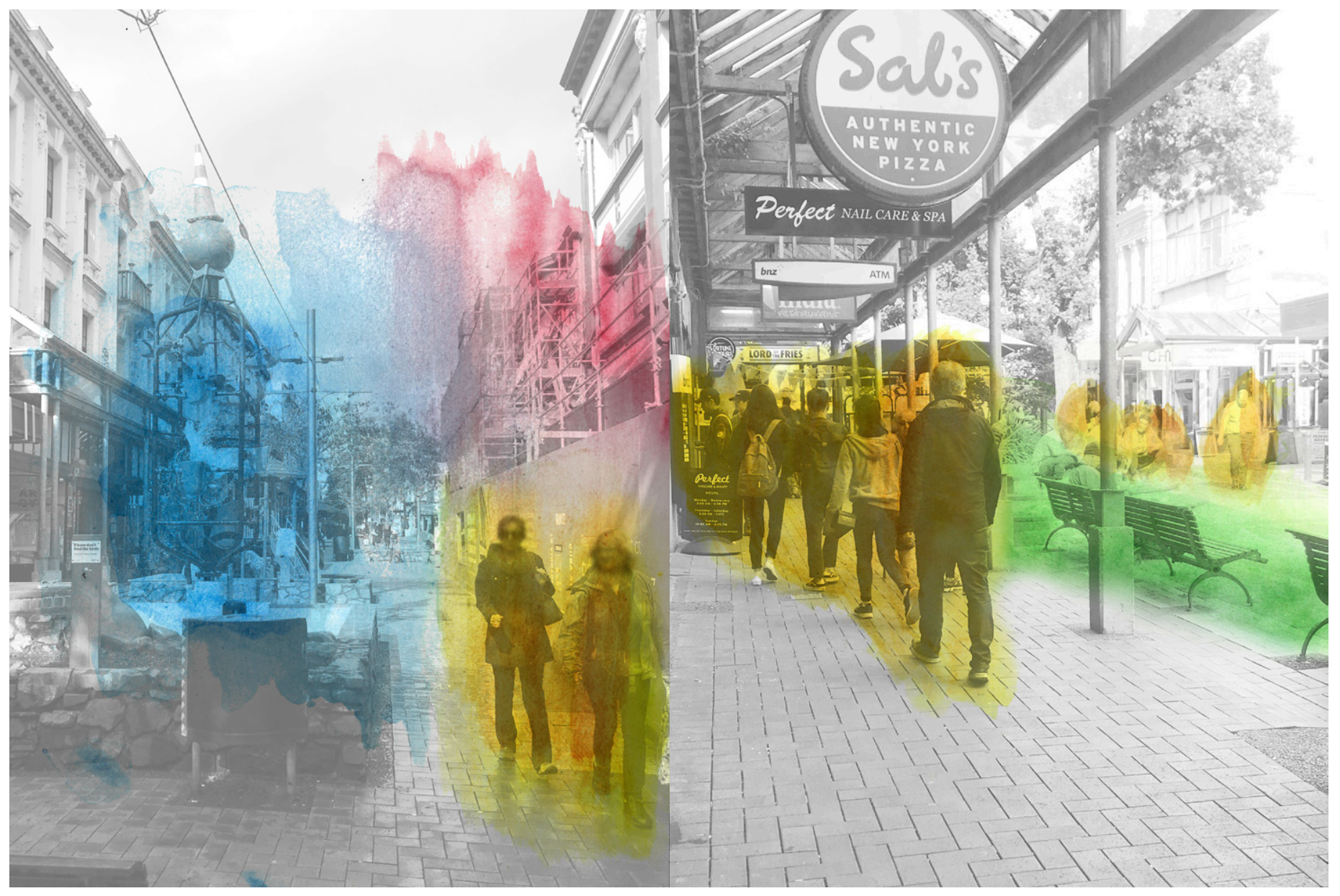

Watercolour has been applied conditions, lighting, and numbers to images of Cuba Street in its of people change, the relationships present condition to investigate the being formed within the space possibilities for affect from multiple constantly change. People are drawn possibilities for affect from multiple constantly change. People are drawn
personal and architectural elements personal and architectural elements to different spaces throughout the
to interact, creating ephemeral day, as the elements in the street can thresholds and relationships that be interacted with in multiple ways, constantly shift and change over fuelling opportunities for social time. Over the day, as weather encounter.

Fig. 2.31-2.34: Test B, Cuba She 


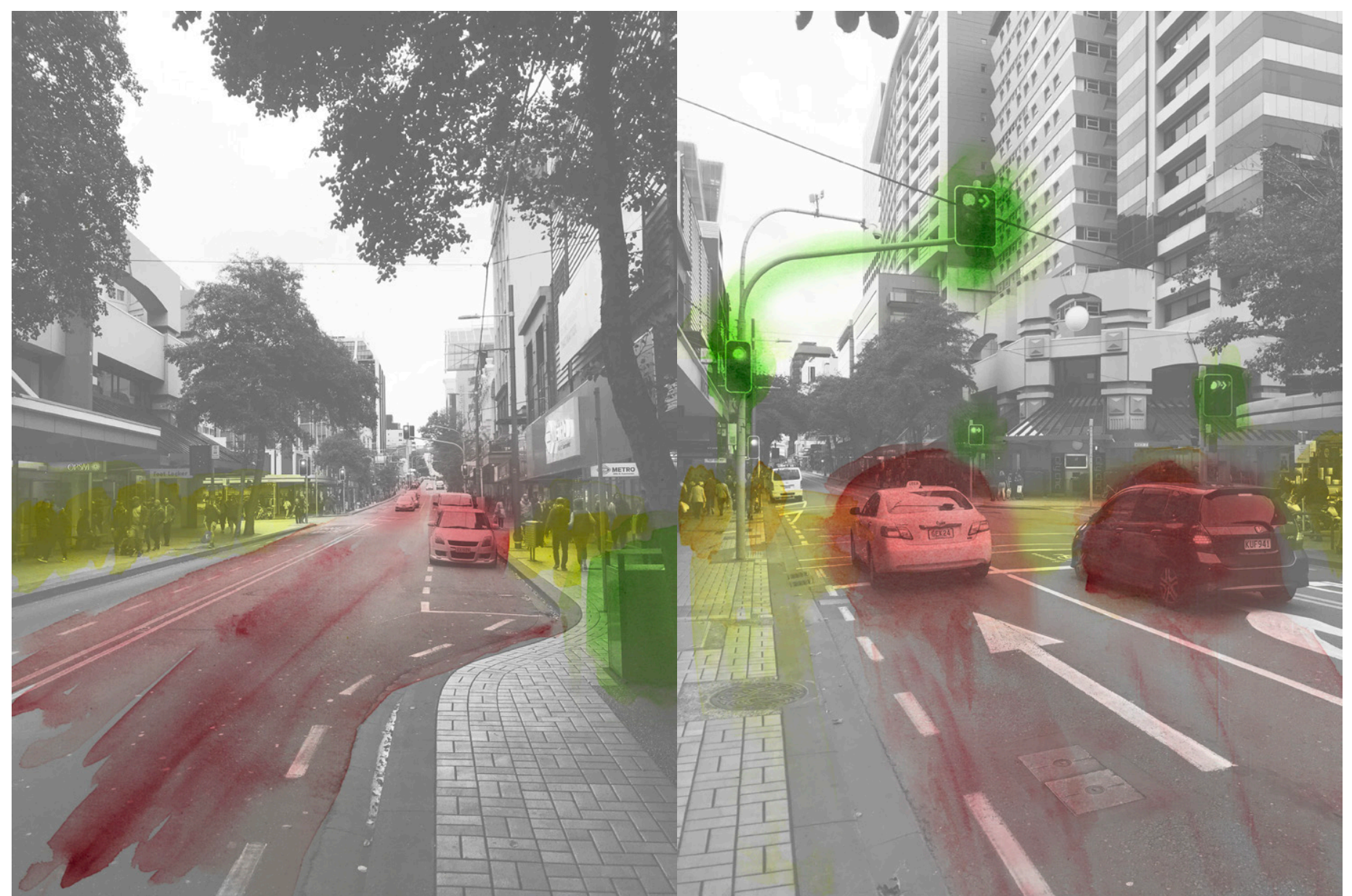

cuba street / willis street / press ball
Willis Street is dominated by the route for anyone accessing retail and vehicular condition; many of the office locations in the $\mathrm{CBD}$ area affective relationships occurring are Unlike Cuba Street, the condition of intertwined with the noise and rush Willis is not as ever-changing over of the traffic in the background. the entire day, rather it shifts from The busyness of the street is further being very busy, with a multitude of emphasised through the location; social opportunities in the day, to Willis Street is a popular pedestrian being very quiet overnight.

Fig. 2.35-2.38: Test B, Willis Street. Watercolour oven

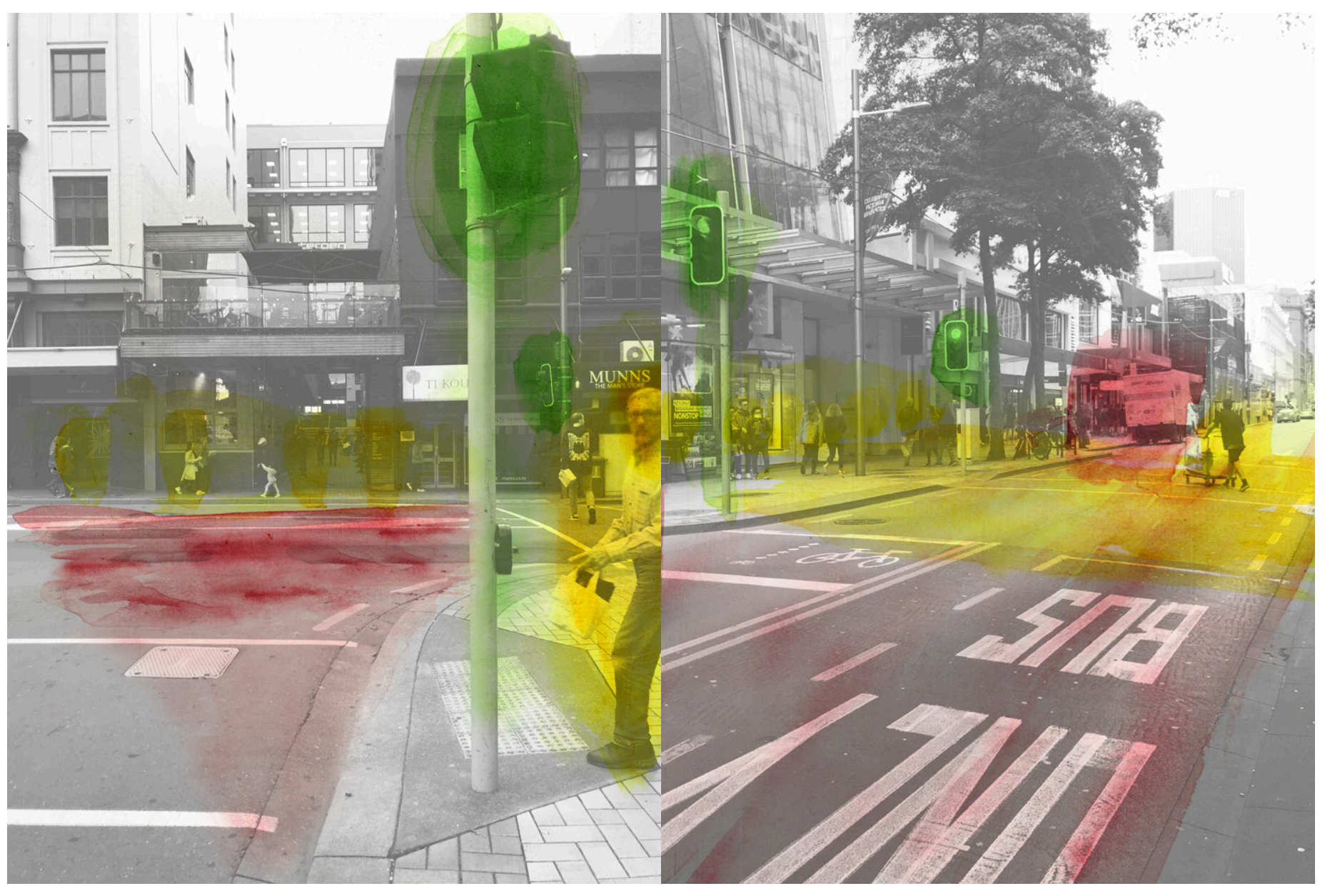



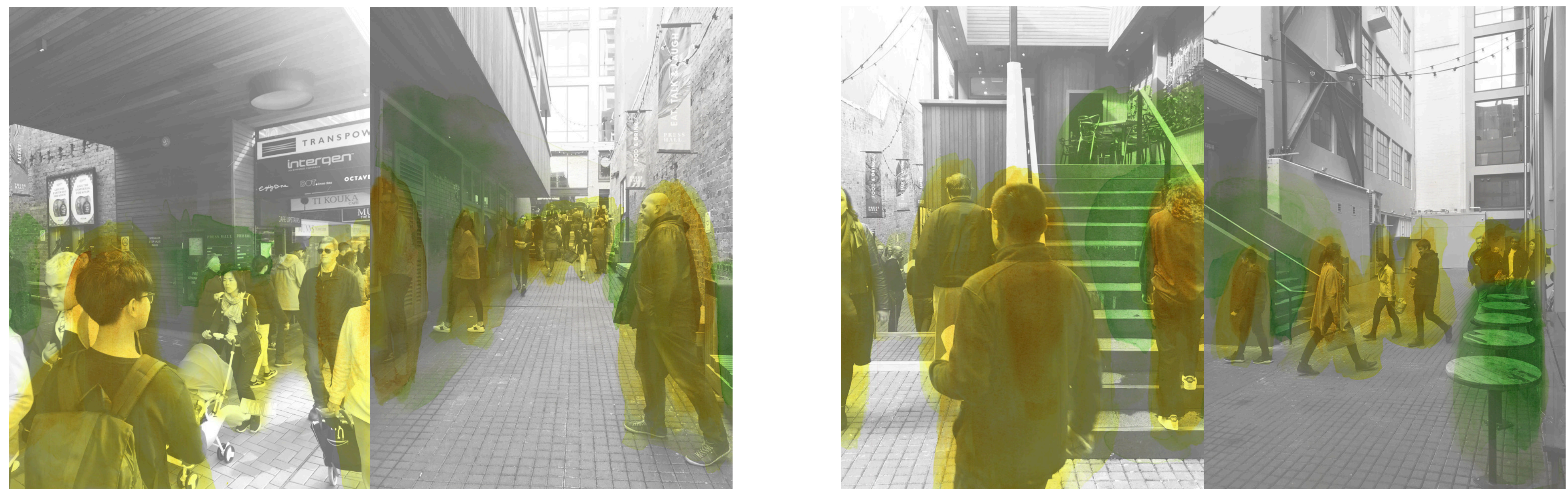

The design of Press Hall is simple, evening, meaning the space is and focuses on the relationship unused for many hours of the between the individual and the day. The architectural elements eatery destinations. The provision themselves do not provide much of seating encourages users opportunity for shifting affective of the space to pause, creating interactions; they are placed for opportunity for social encounter. specific purposes and tend to be The eateries close in the early used accordingly. 


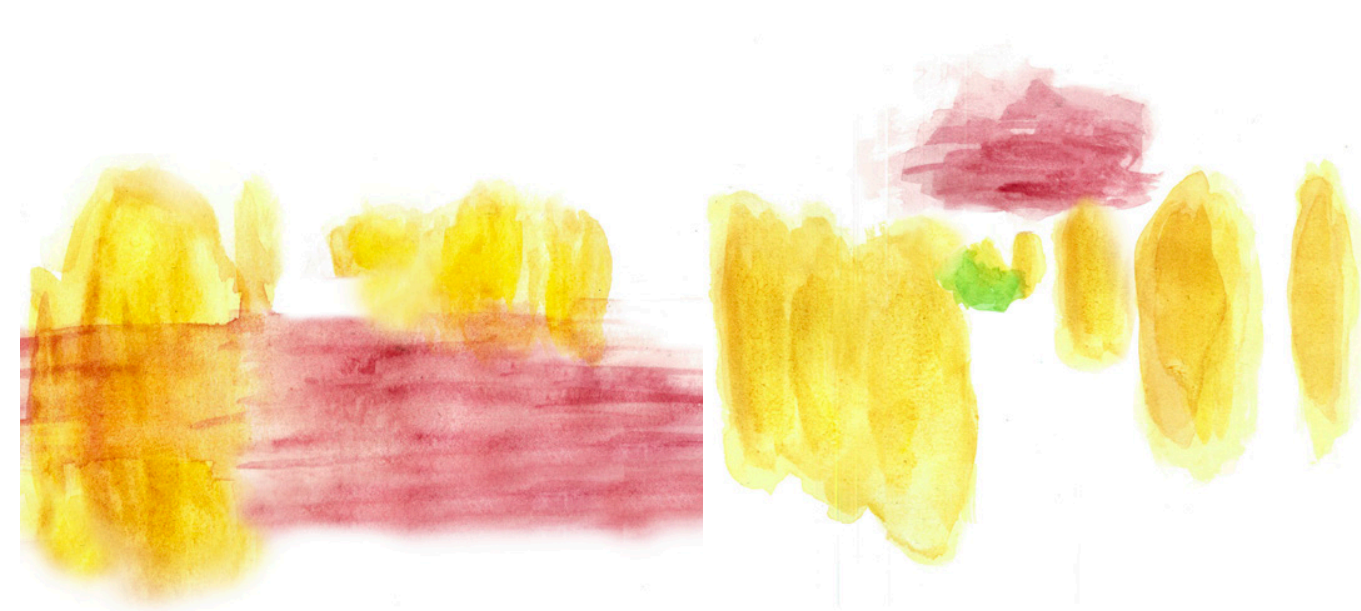

\section{cuiba}
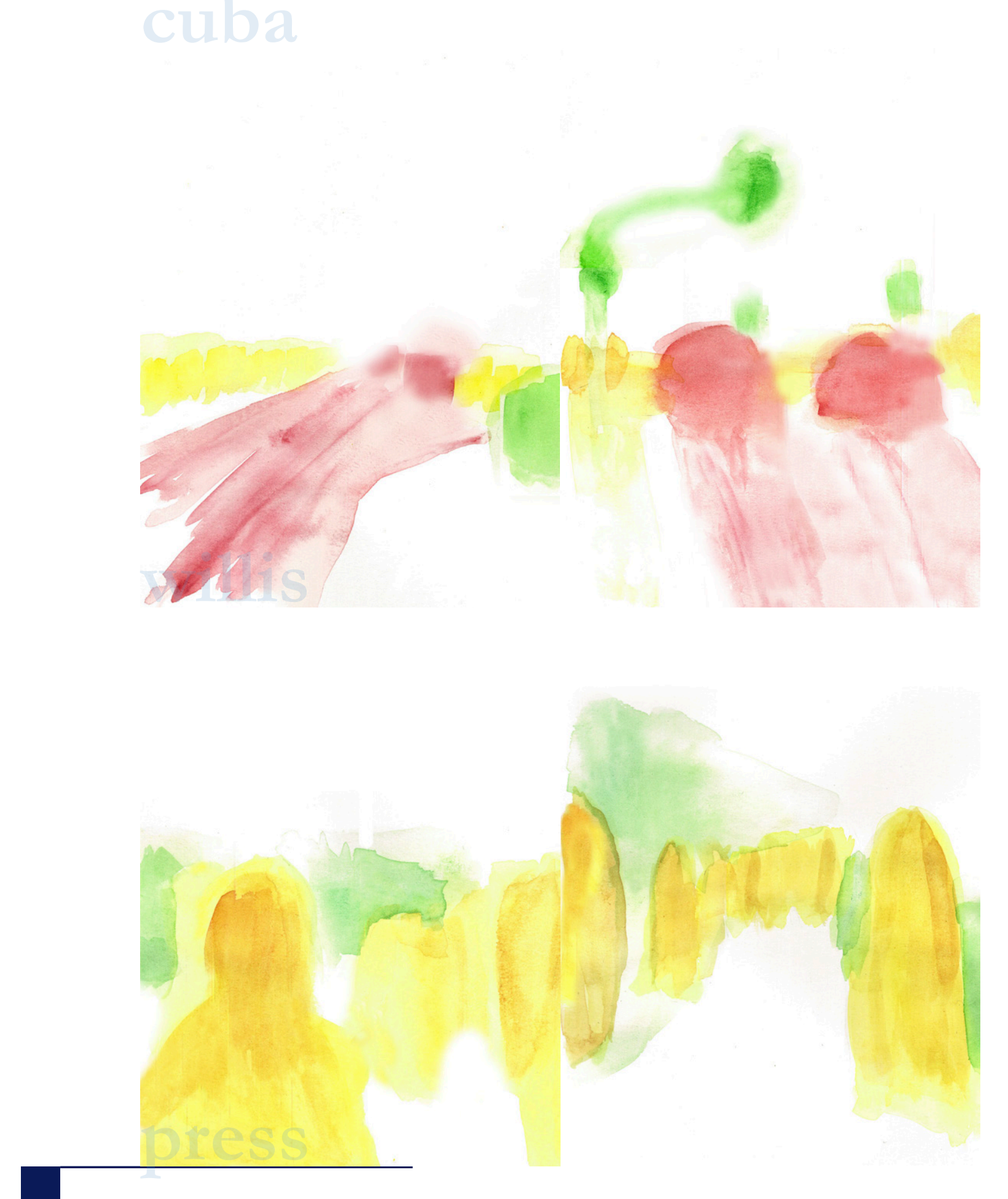

54 culba
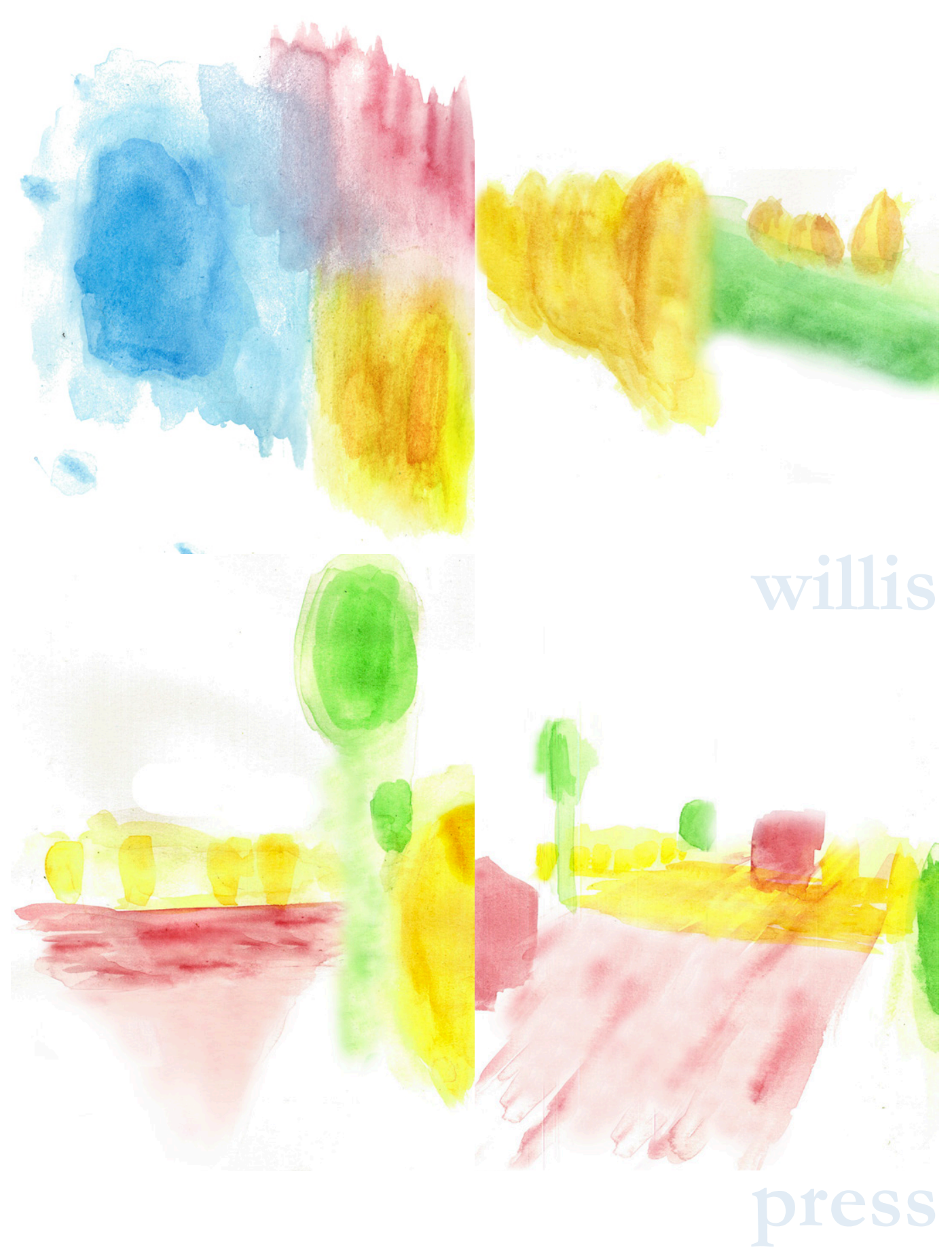

55

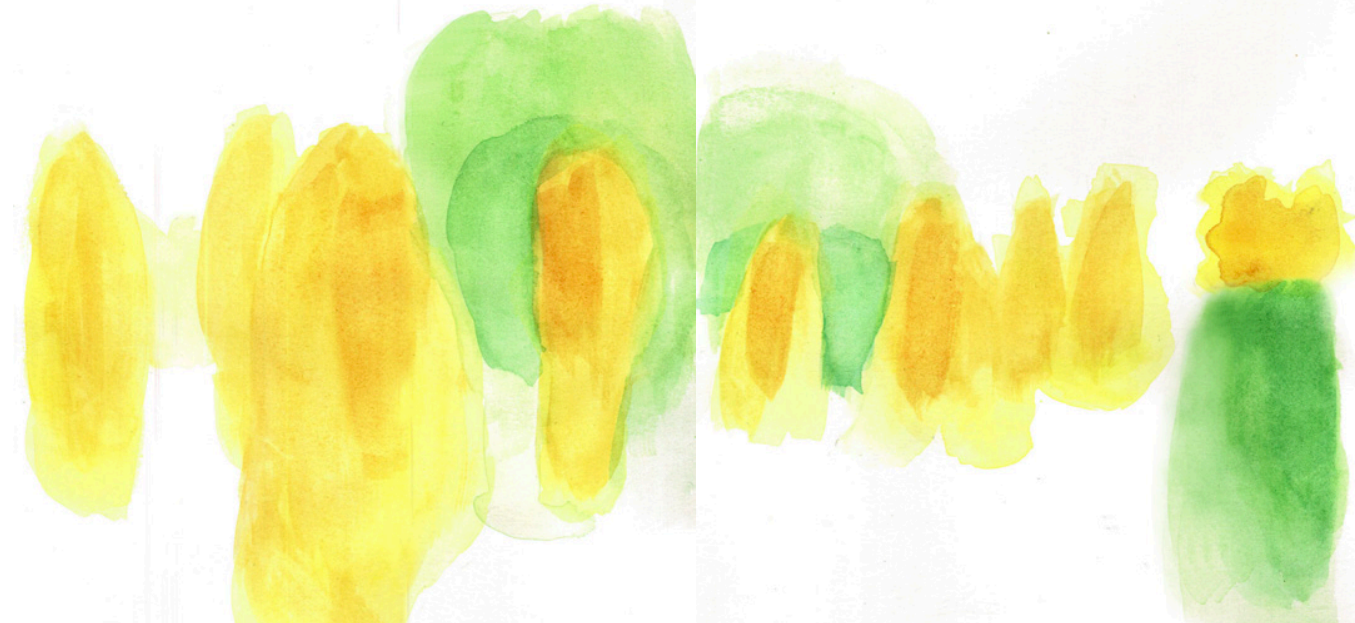

Fig. 2.43-2.54: Watercolour images created to indicate interacting affects on the Case Study streets 


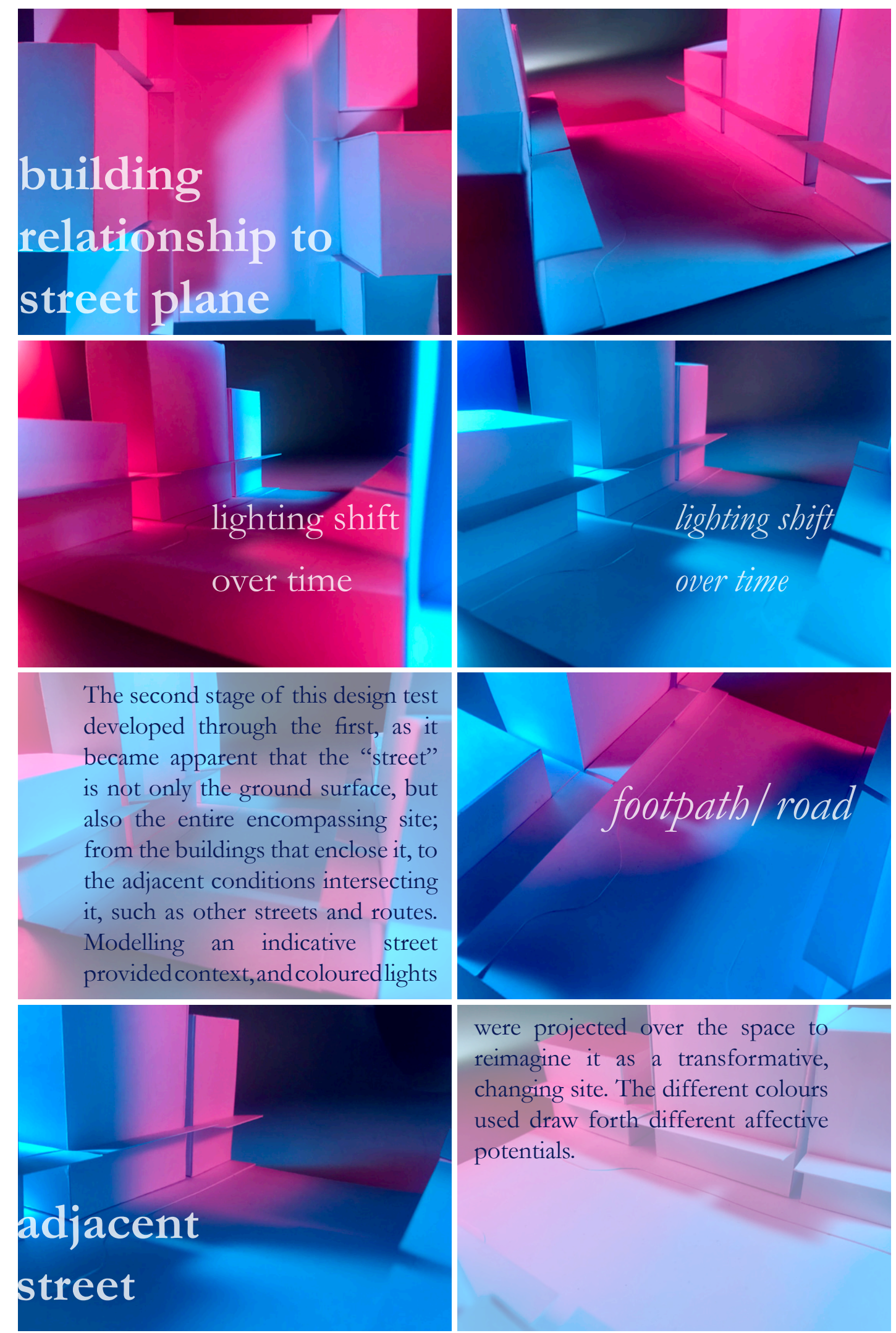

101 atmosphere
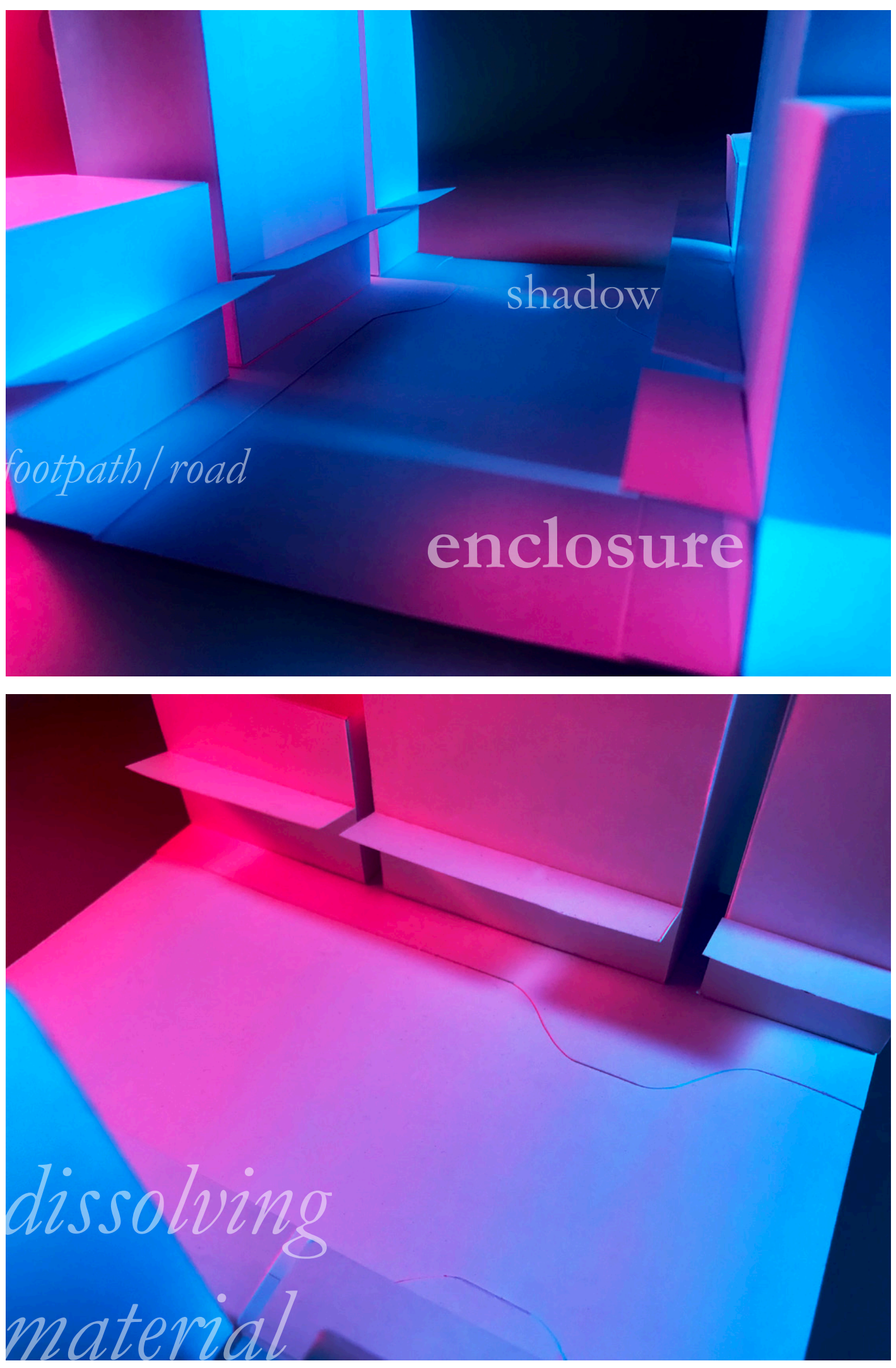

Fig. 2.55-2.62: Photographs of coloured light cast over indicative street model 

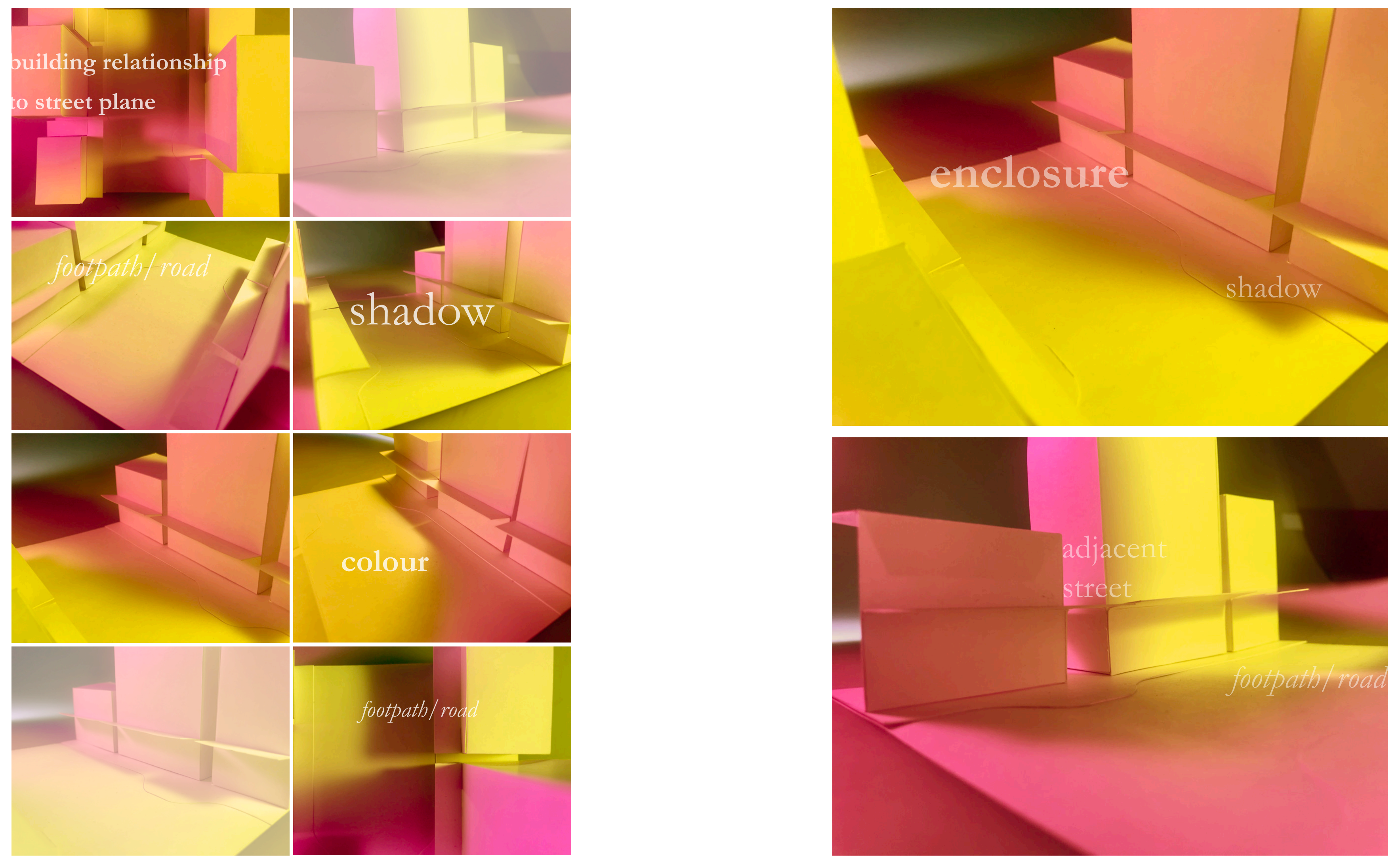

W 

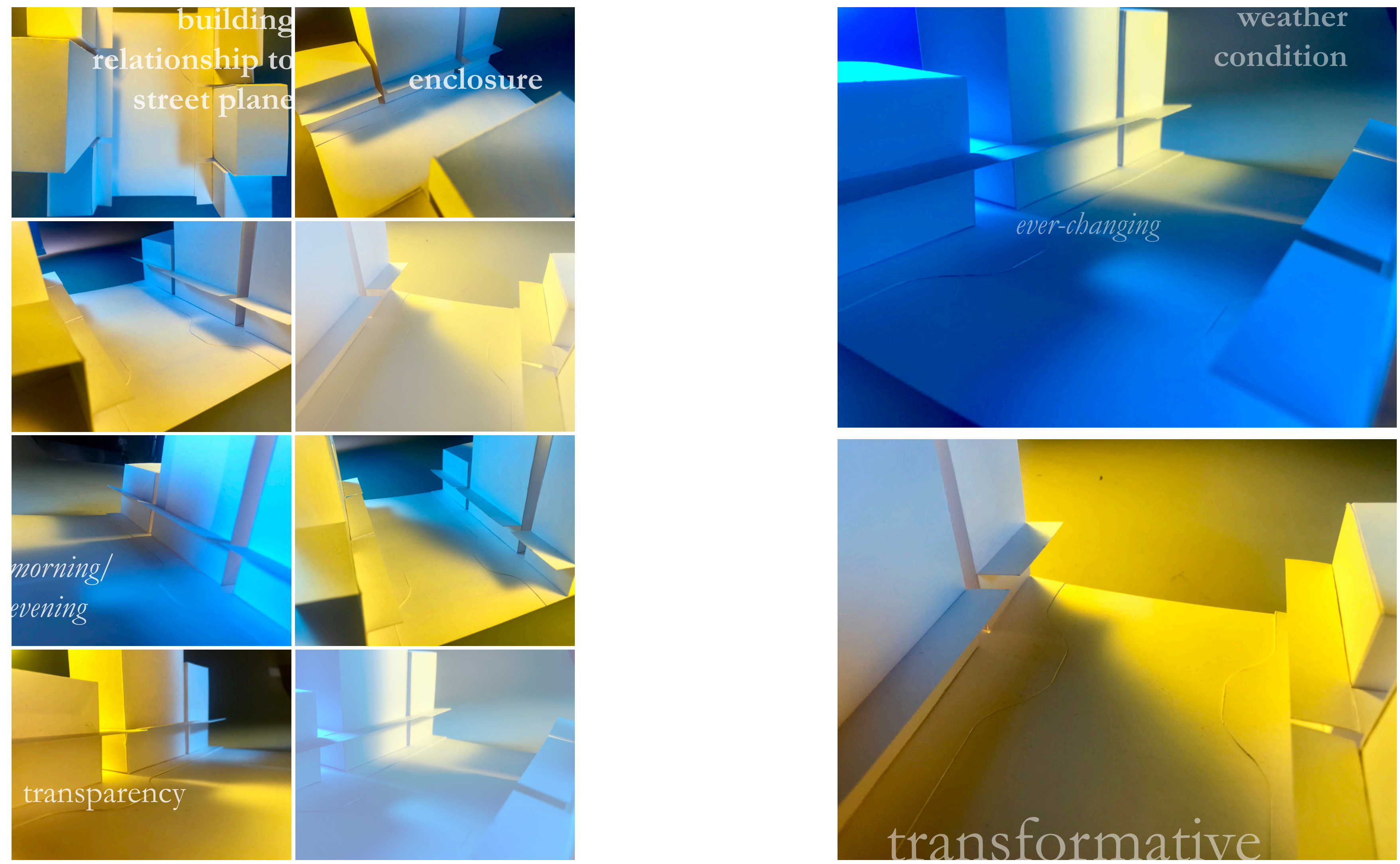

口 
Kraftl and Adey explore how affect can be created through architectural design decisions. They define affect as "a sense of push in the world", and discuss that bodies diffe in affect, and therefore feeling, emotion, activities, and action (Kraftl and Adey, 2008, p. 215).

\section{surfaces on the sites} will be manipulated

in response to

typical gestures and

movements

In the design of the Nant-y-Cwm Kindergarten, the architect took a focus on imitation of bodily gestures to imbue the architecture with "styles of bodily doing" (Kraftl \& Adey, 2008, p. 221). Enclosure through soft curves to architectural elements, and warm lighting, were used to generate a magical childhood sanctuary.

Inthedesign of anew AirportGarden and Prayer Room at the Liverpool

Airport, the aim was to create an

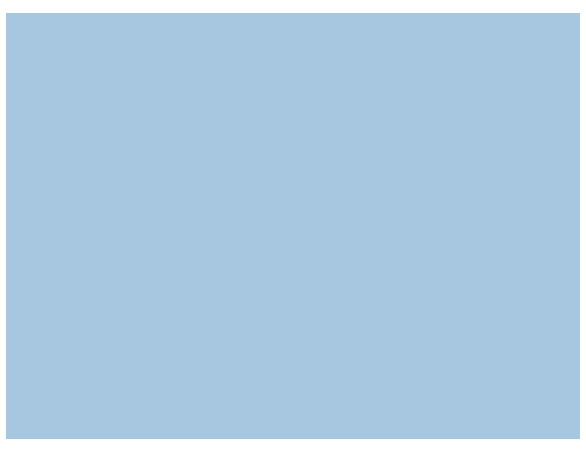
Fig. 2.79: Exterior of Nanty-Cwm School

affect of calm and relaxation. Affectual intensity of pressure, anxiety, and excitement perpetuates the rushed environment often experienced in airports. The garden and prayer room are spaces that now employ calm and serenity, affecting an "oasis amongst chaos" within the rushed airport environment (Kraftl \& Adey, 2008, p. 225).

Architectural interventions can either enhance existing affect conditions through gesture, or be employed to create a new affectual environment, mitigating unwanted affects and enhancing new emotions and charges. The testing will focus on designing at the scale of human gesture. Through this study, surfaces on the sites will be manipulated in response to typical gestures and movements of occupants.

\section{...bodies differ in affect, and therefore feeling,} emotion, activities, and action 


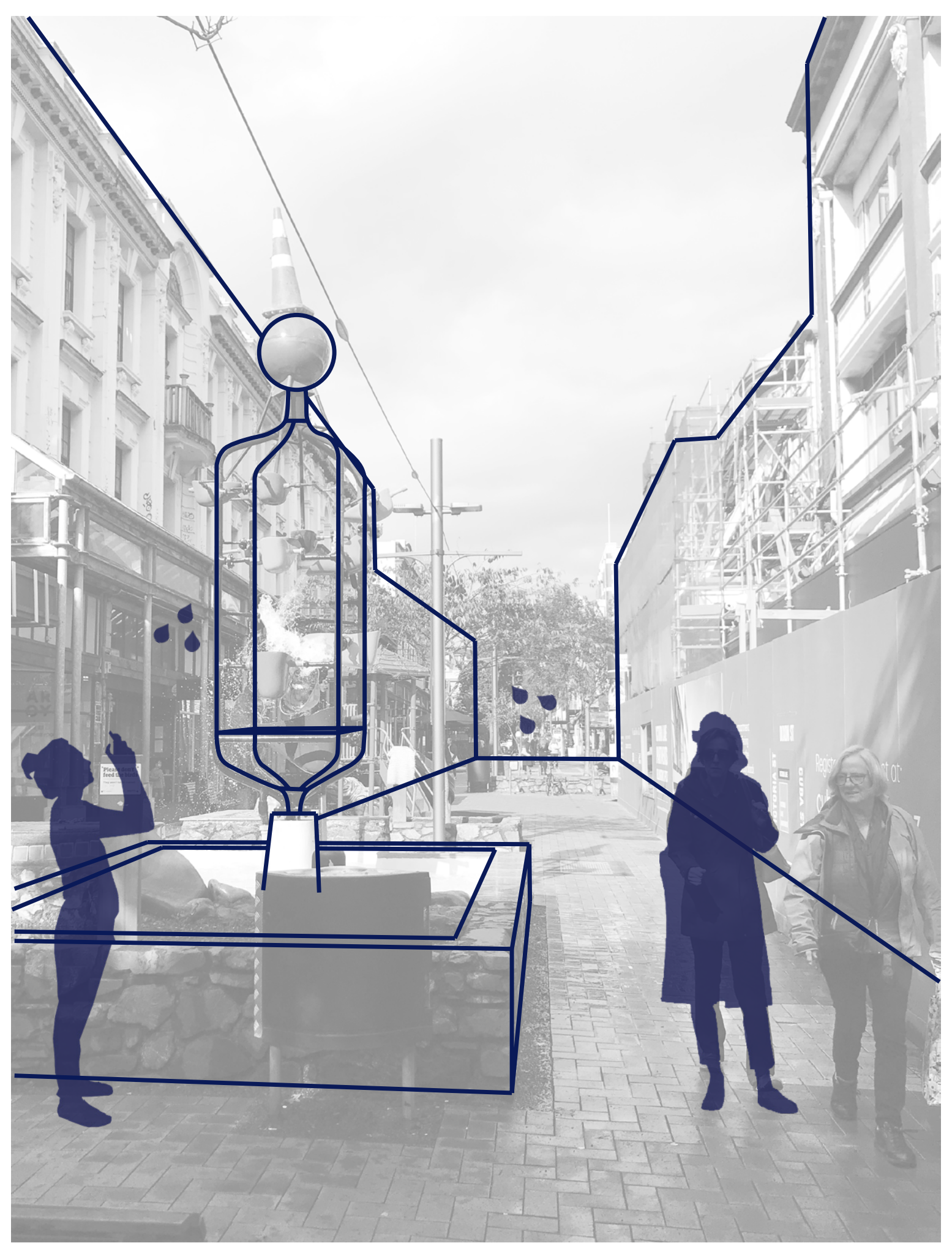

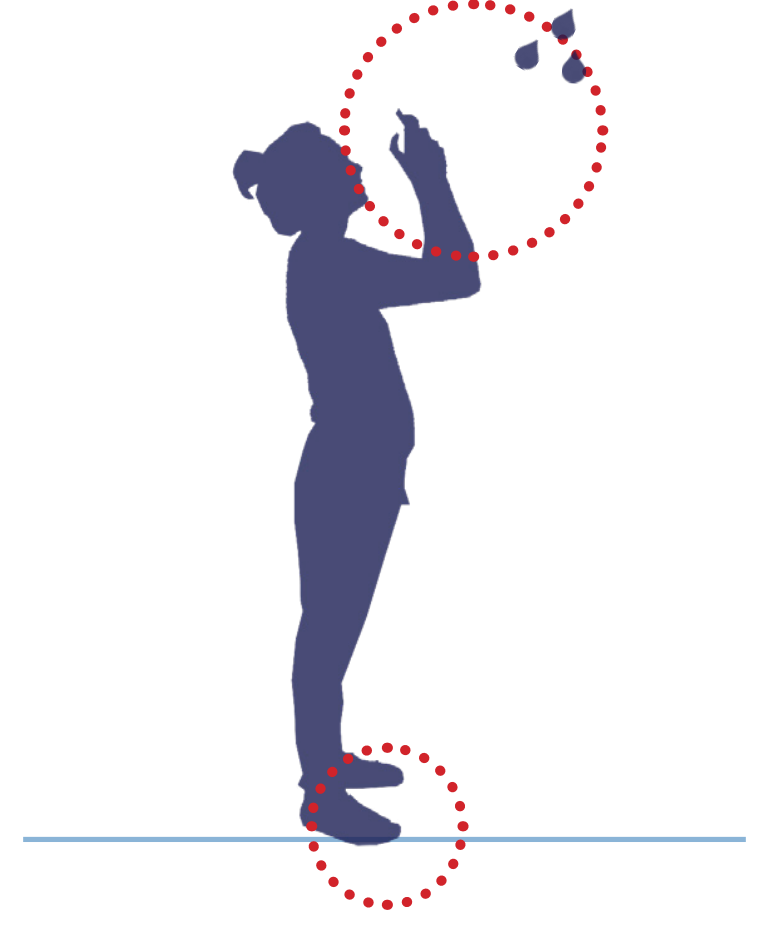

photography

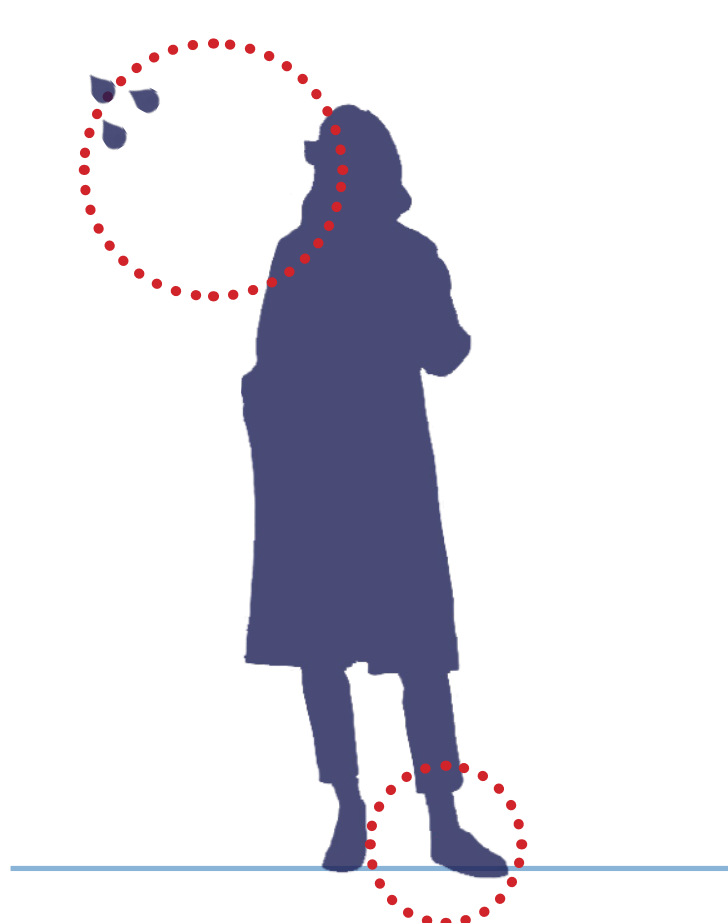

access route

The previous two tests interpreted defined by the gestures of the body various affects present on the become apparent. Currently, the case study sites at the scale of Bucket Fountain is a focal point on the street and at the scale of the Cuba Street, a space where people human body interacting with already pause in their motions. architectural elements. Zooming The fountain and its surroundings in, as the human body moves, suggest opportunity for change to potential to recreate architecture as enhance the affective experience. 


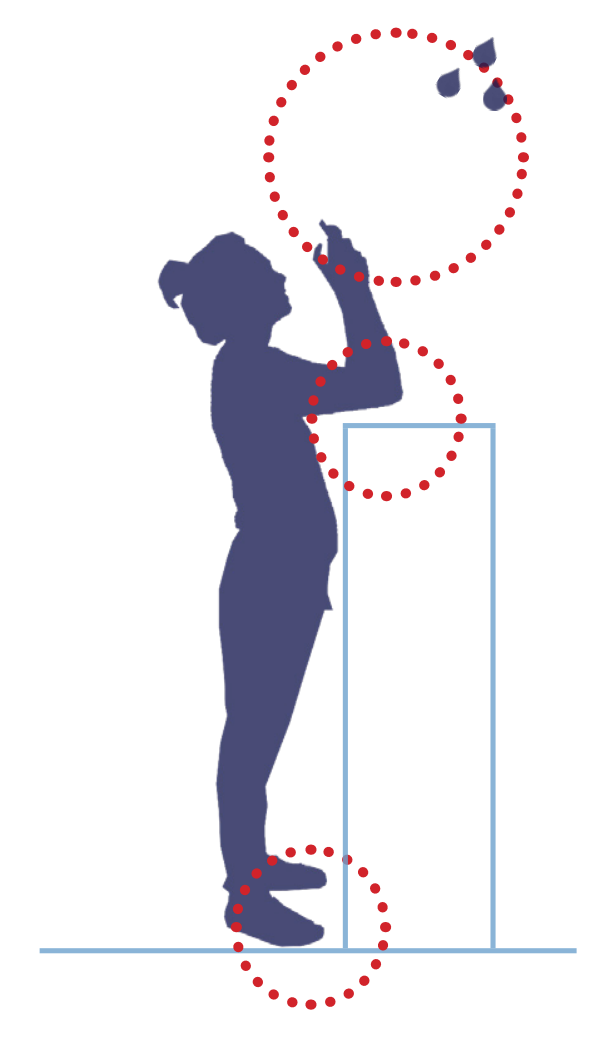

photography

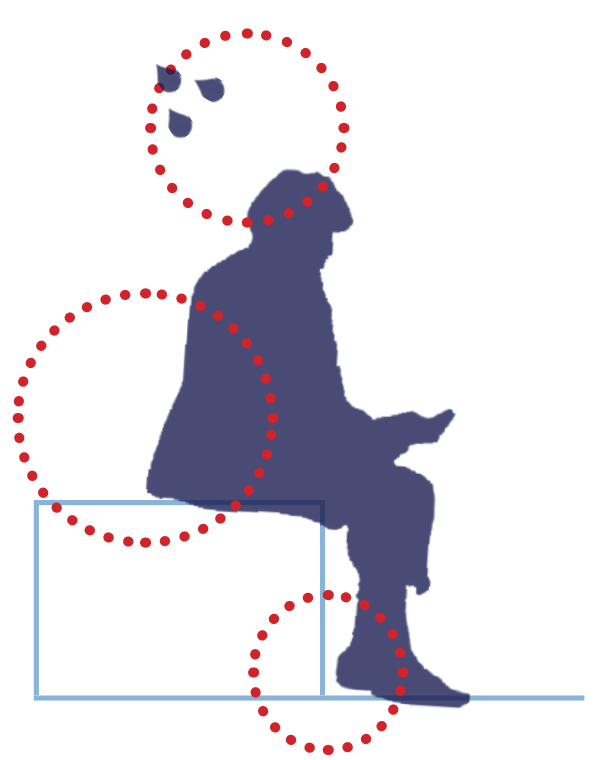

seating; conversation, read, use phone

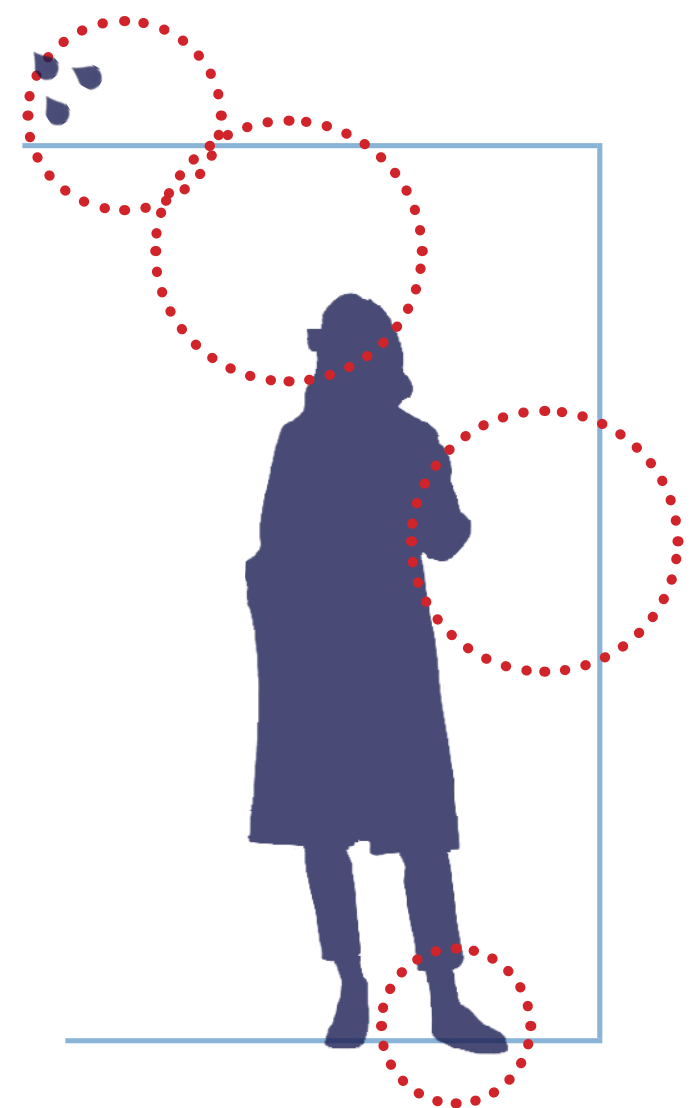

covered vs uncovered walkway - access

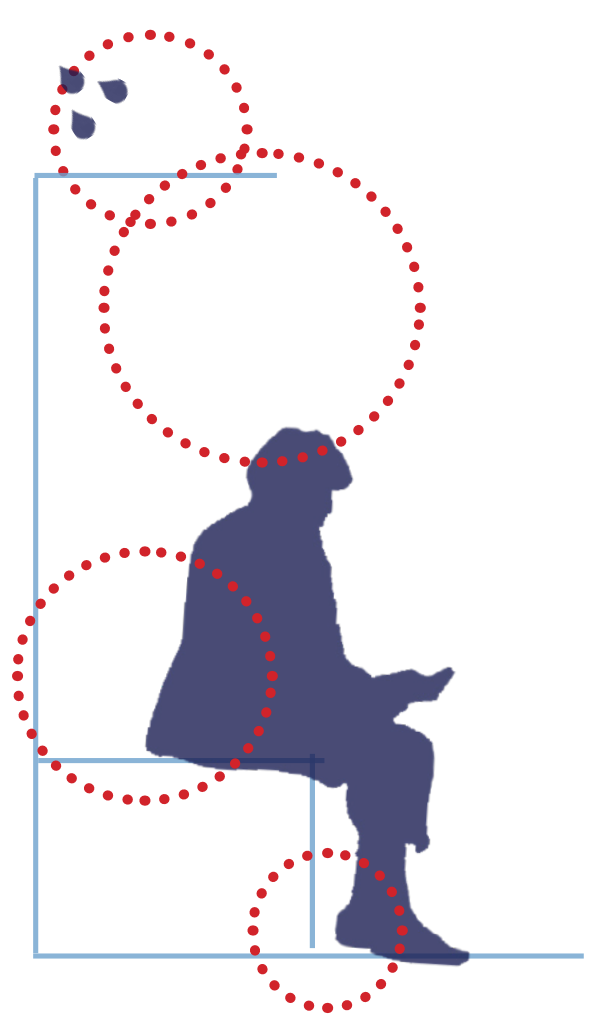

covered seating

Surrounding the Bucket Fountain, insertions may encourage a different affective relationship in the age of mobile technology. Covering adjacent spaces removes the current affective relationship; the possibility

of becoming part of the sculpture 

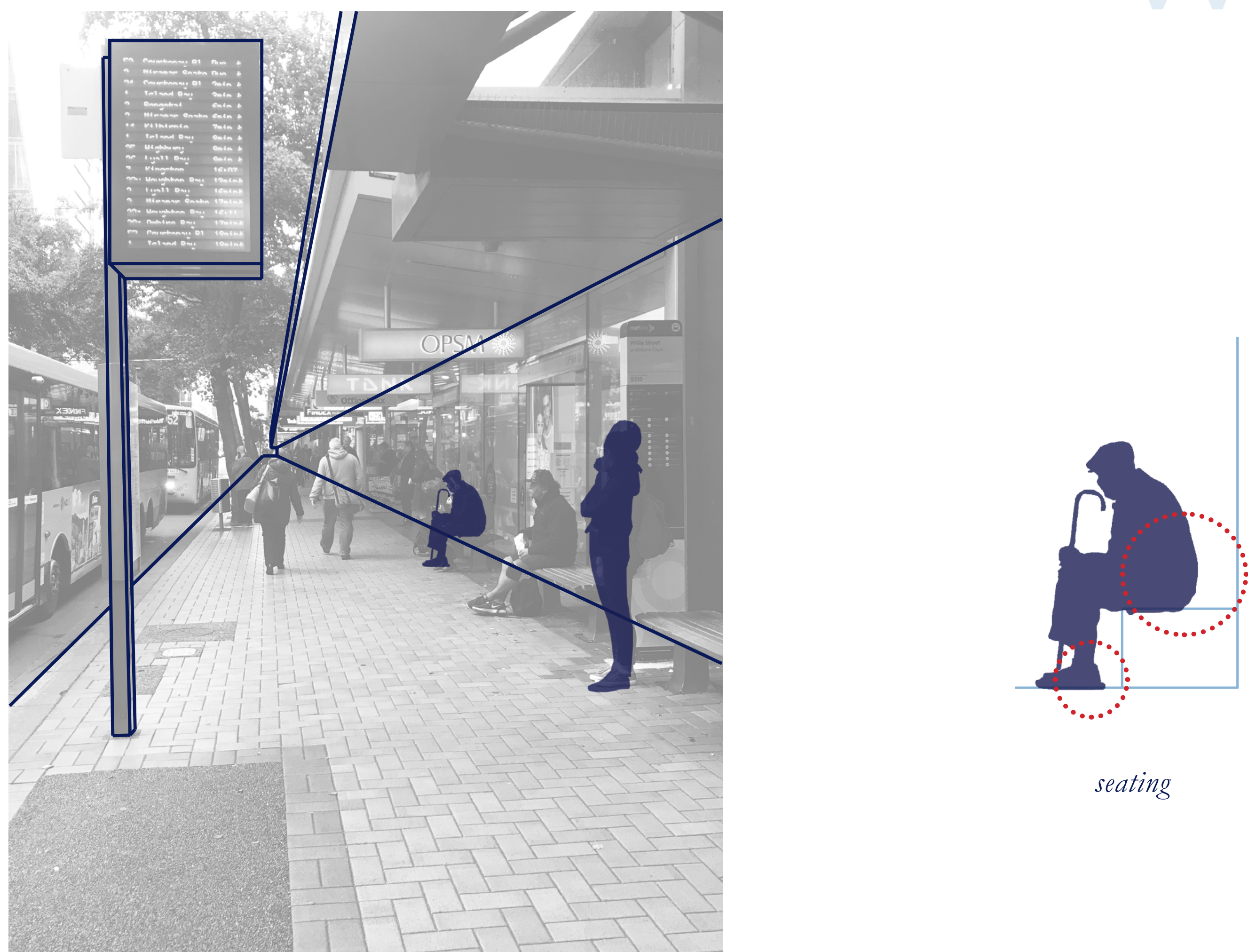

seating

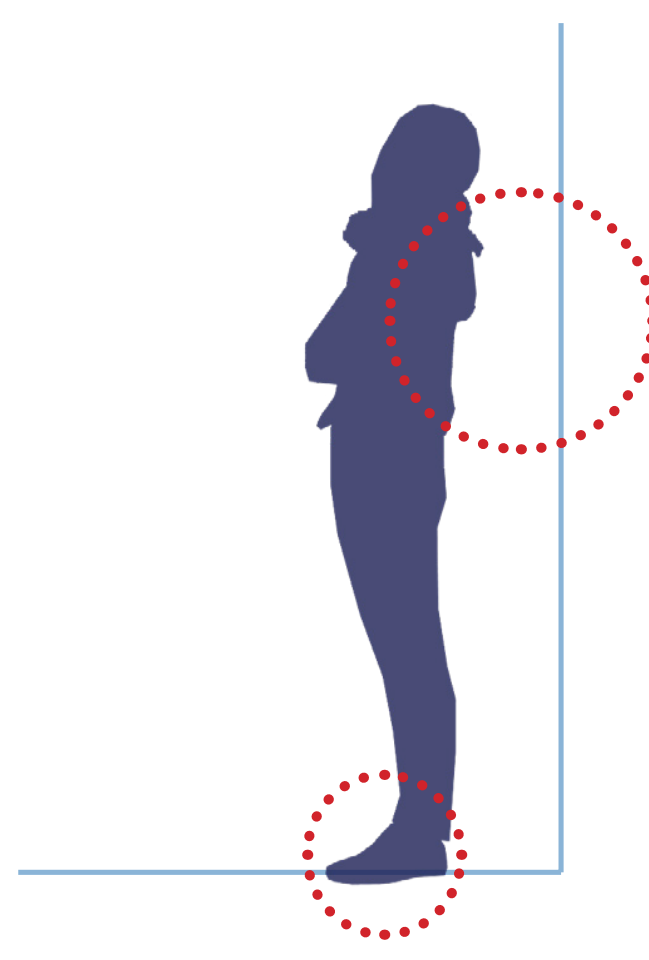

wall condition

The programme of a bus stop encourages a moment of pause by its very nature. The current architecture, however, does not provide many opportunities for bodily pause; most people waiting

during busy times are required to 


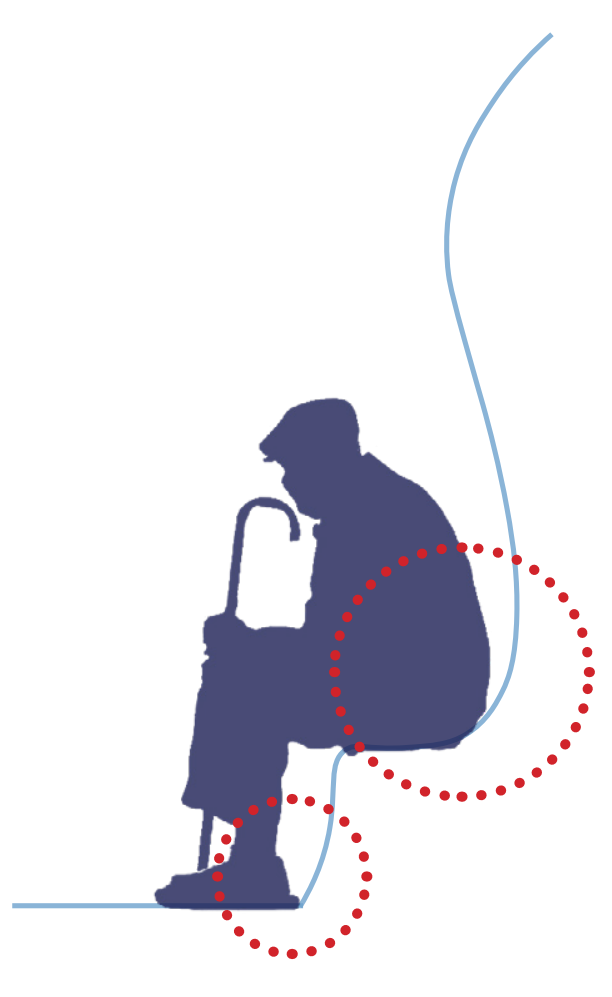

seating; read, use phone

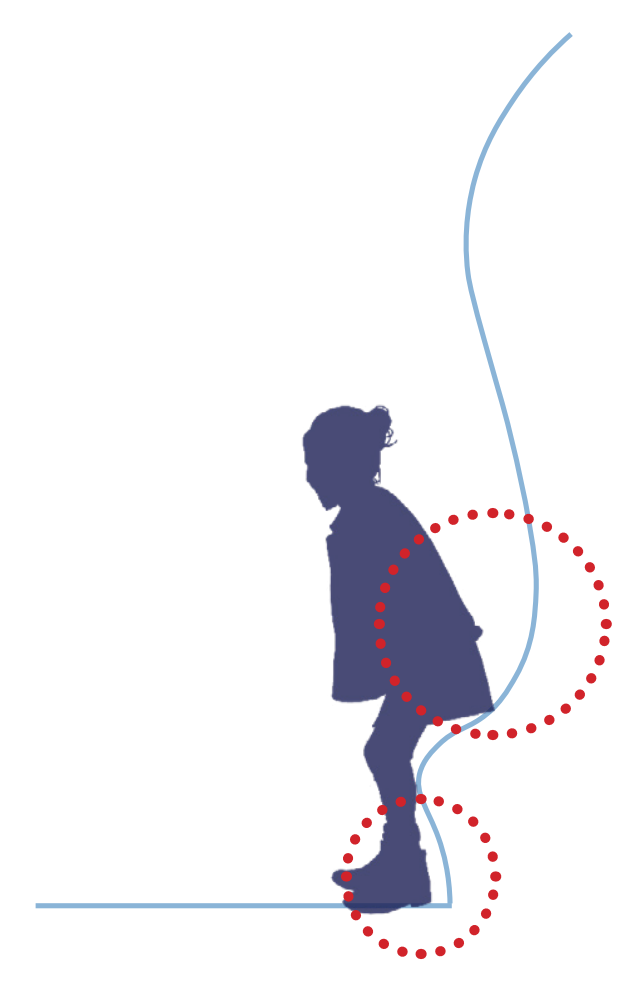

lower seating / leaning; children

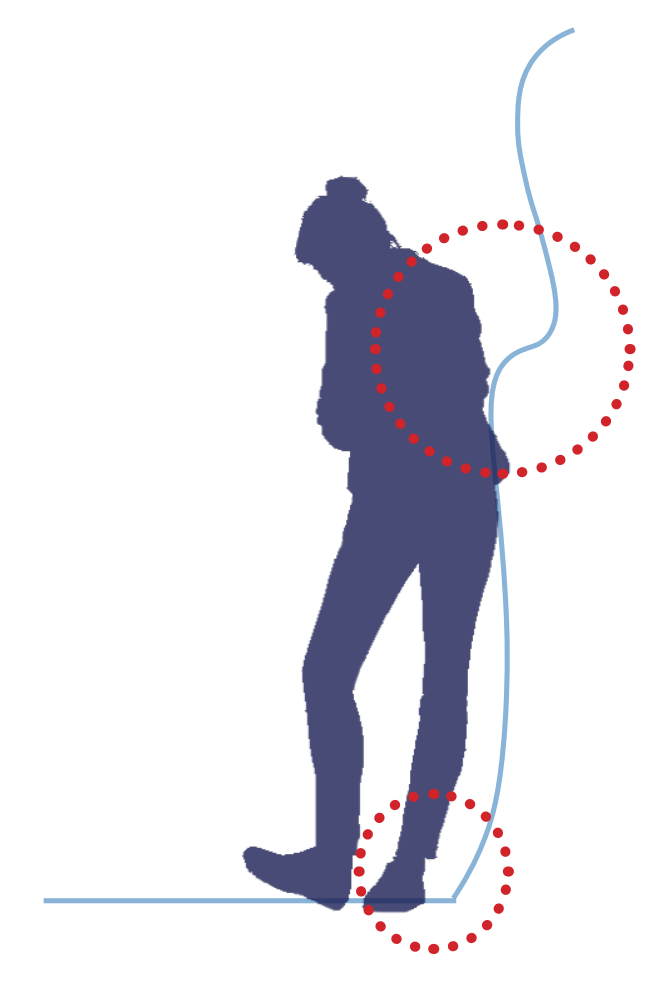

leaning; use phone, conversation

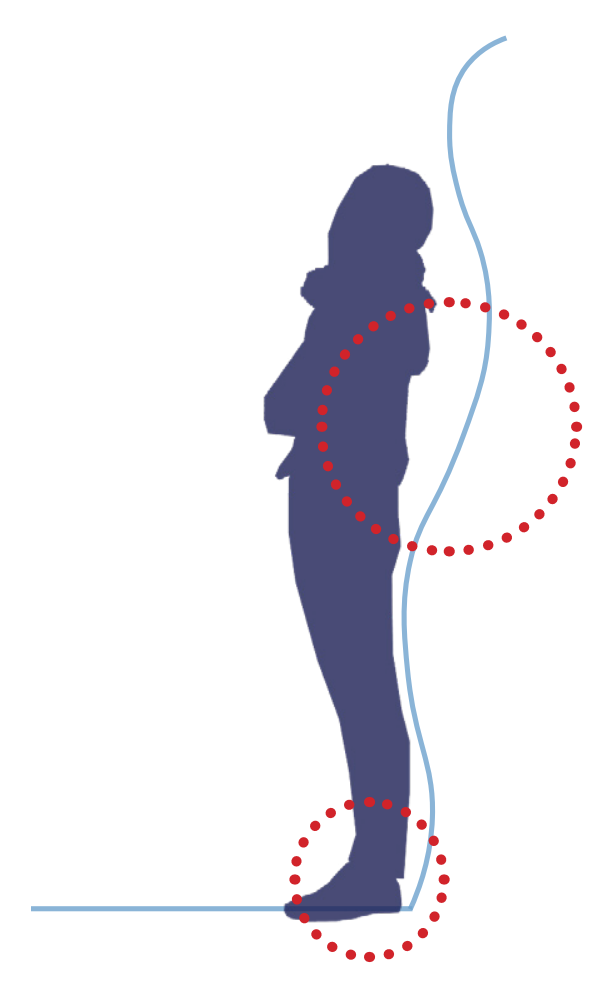

leaning; watch for bus, meet colleague

The relationship between the wall and the human body has the opportunity to fluctuate, when typical gestures of the users are considered. The wall becomes a key part of the urban surface in

this space; joining the ground in a continuous responsive plane. 


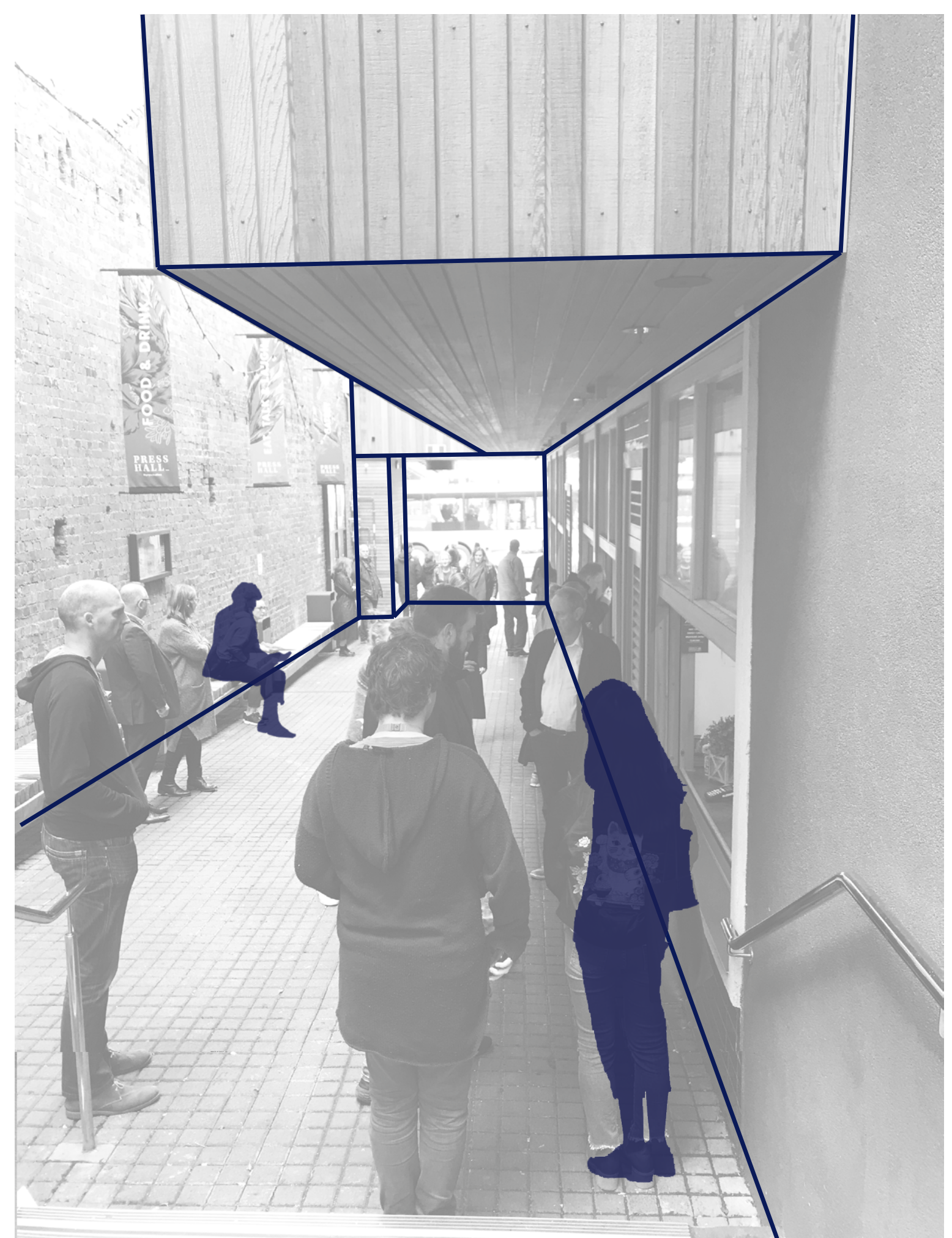

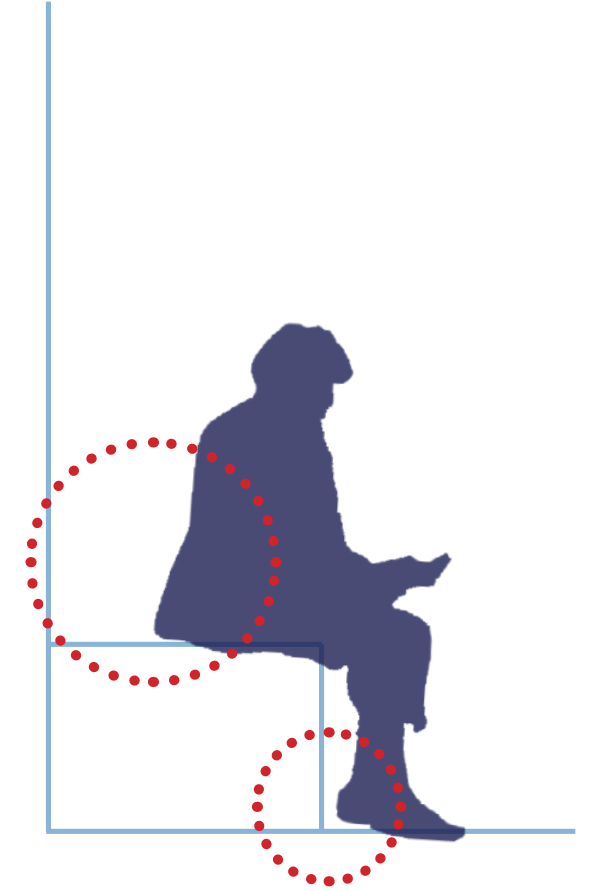

seating; waiting for order

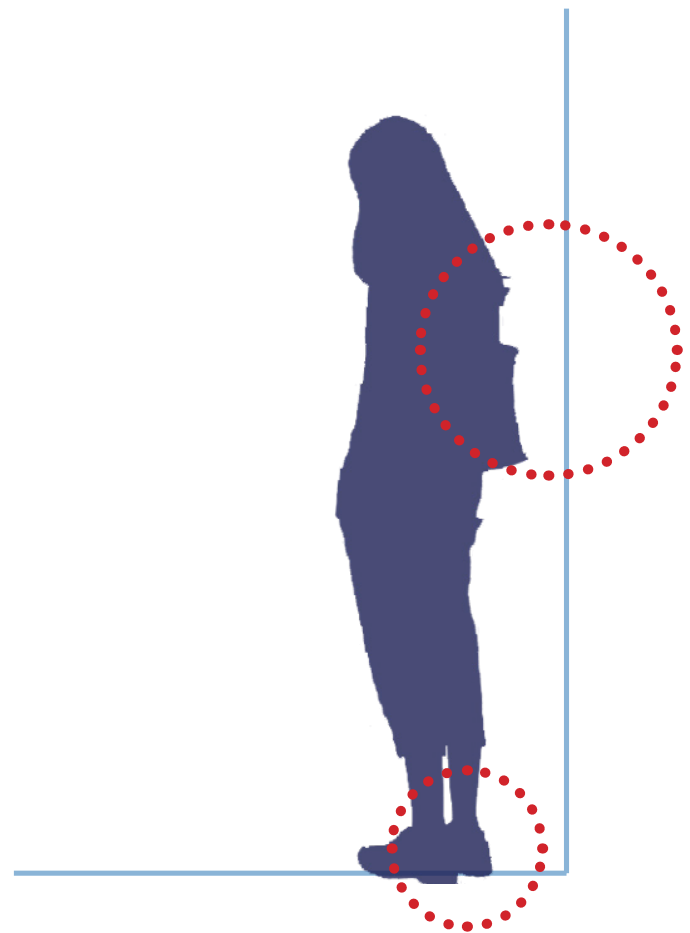

wall; opportunity for leaning
Press Hall, similarly to the bus stop on Willis Street, encourages pause through the programme, as pedestrians occupy space to wait The current architecture hints towards this, but similarly, it is not actively encouraged throughout the entirety of the space. 


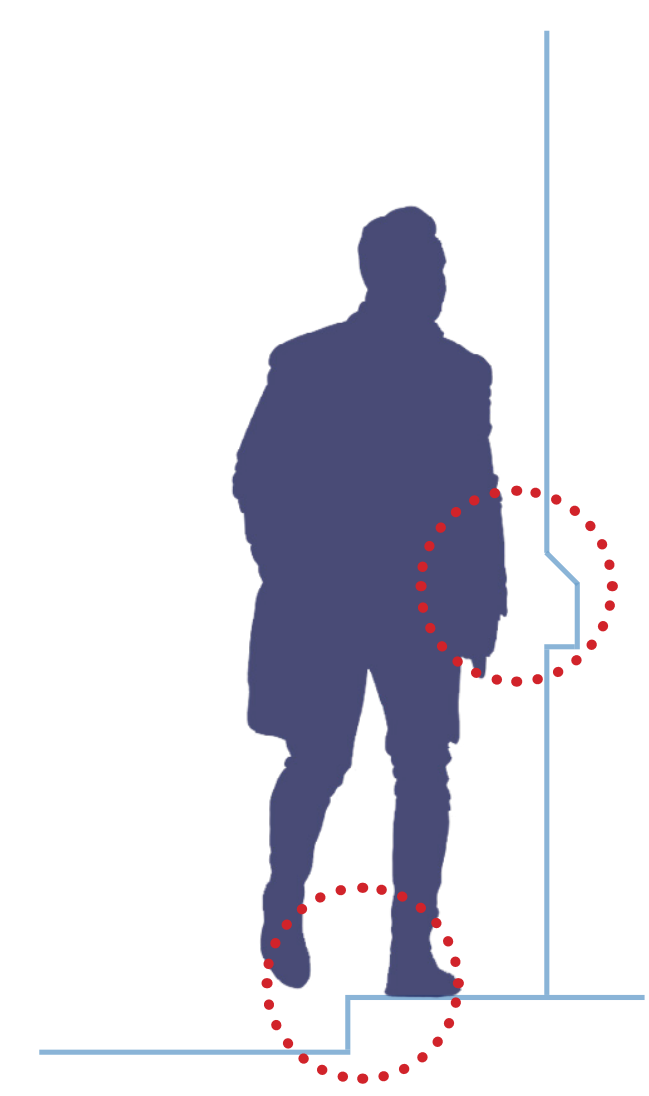

steps; access

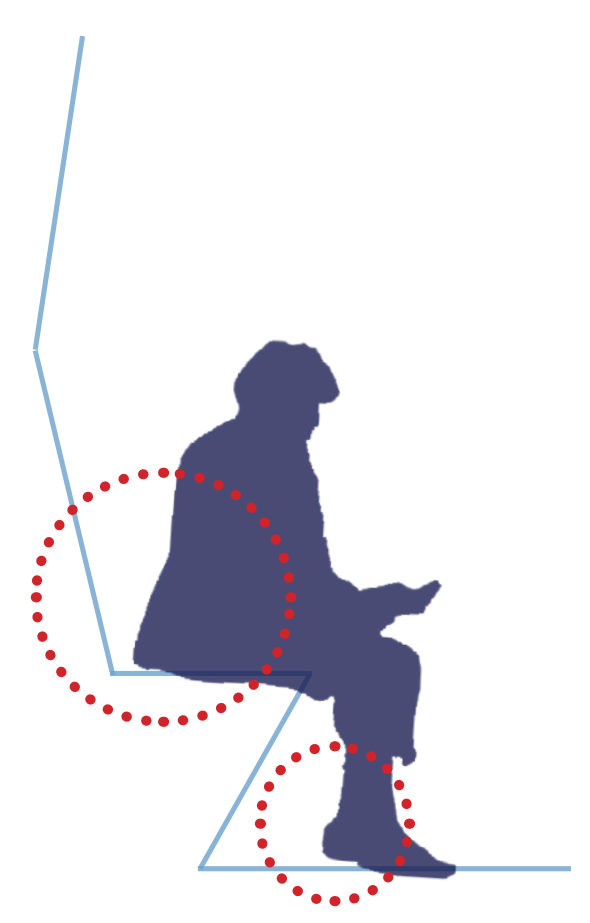

seating; waiting for order

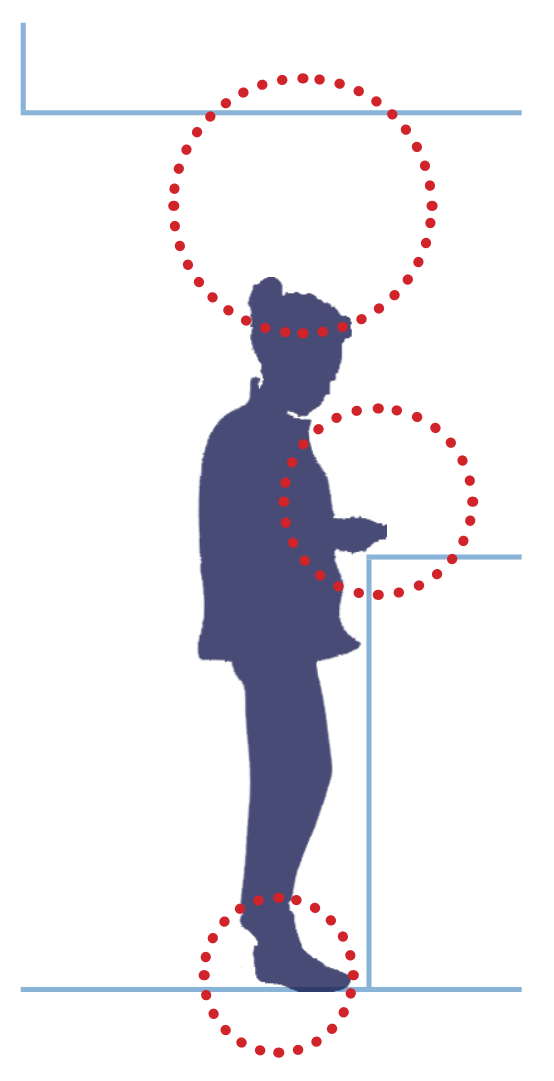

ordering

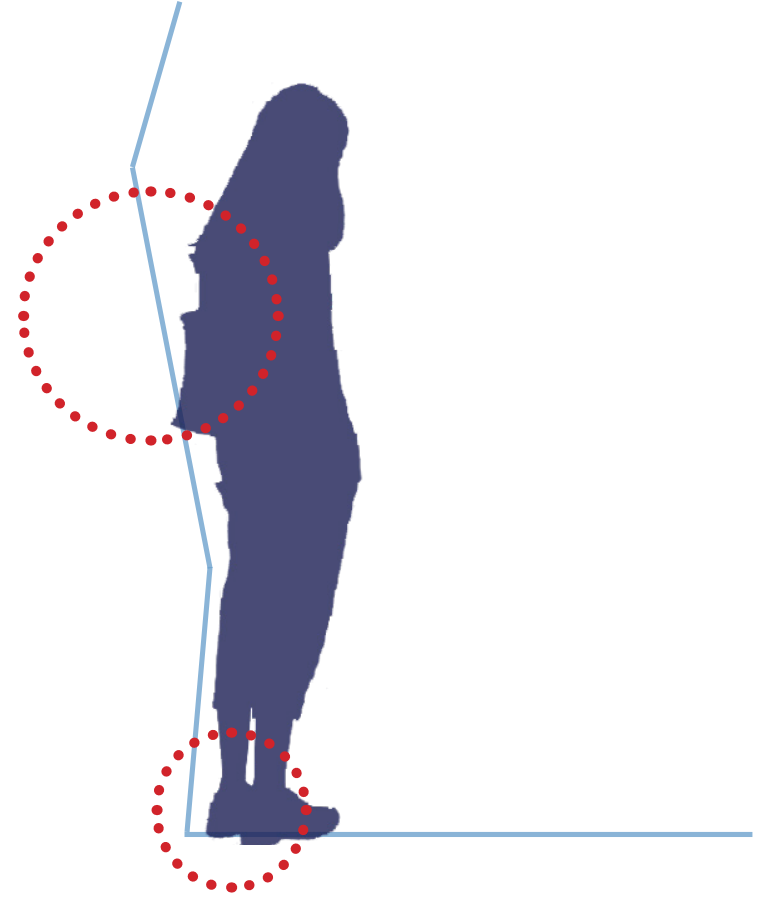

leaning; waiting for order

The wall and floor can meet with various intersection, providing moments to pause through seating and leaning. At moments of movement, such as the stairs and ordering counters, similar architectural interventions at the closer scale can mimic these. 


\section{summary}

design tests / phase 1

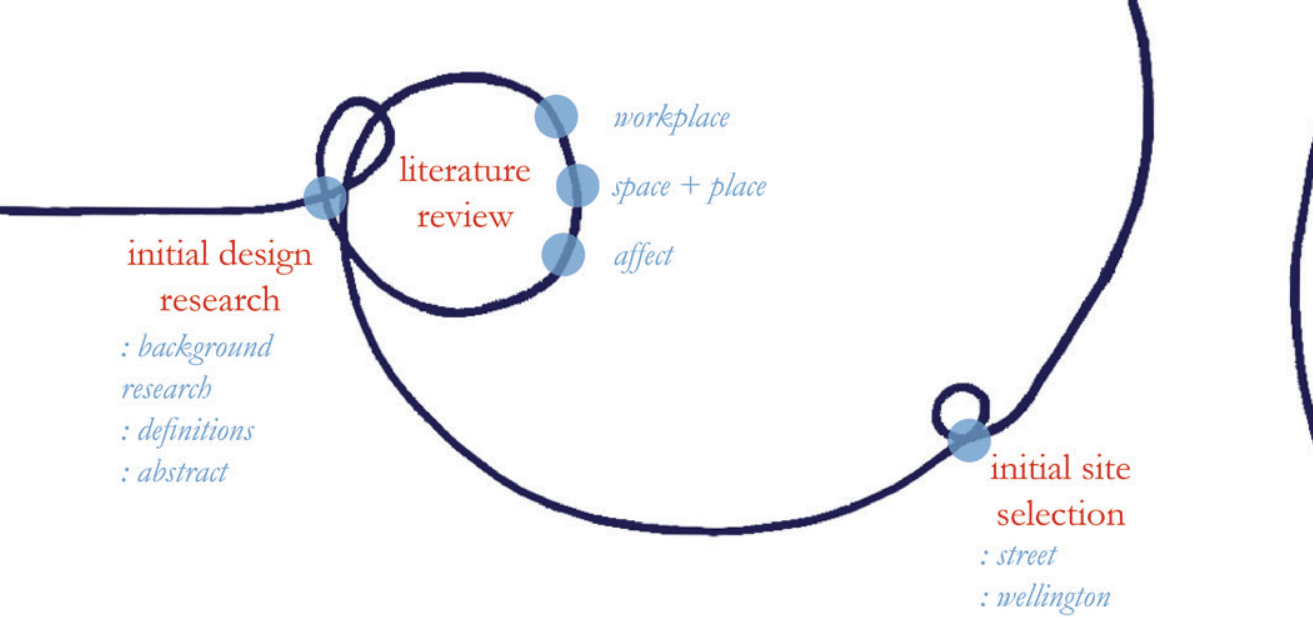

: street

The first design phase utilised Case Studies in Wellington city to explore existing affective relationships within the street. The three streets selected were Cuba Street, Willis Street and Press Hall, due to their various qualities being indicative (each in different ways) of typical street life in Wellington today.

The sites were explored through three design tests, adapted from key texts in relevant literature. The aim was to analyse the sites from the street scale to the human scale, seeing how different affects came into play as a pedestrian interacted with the architecture of the street

Test A began at a street-wide scale, layering architectural items in the street, seeing how they may distupt the movement of a pedestrian he me, and nature. Though the streets have some similar current and imagined interventions, their organisation within each site leads to vastly different streetscapes, with seemingly endless possibility for changing affective encounters as the disturbance affects different pedestrians in differing ways.

Test B began with highlighting different items within the street through an imagined affective "aura", spreading out from the physicality of the object itself, and blending with other affects across the streetscape. The defining parameters placed the objects into "types", but upon reflection, these are very limited. Any intervention within the street can serve multiple purposes - it may not be being used primarily in the way it was intended to be, thus it is possible that the affect contributed to the stree environment may be unexpected. From the findings of the second stage of Test $B$, the porosity of the street needs to be further considered. Where does the "street" condition end and an adjacent space (such as the interior of a building, or another exterior space) begin? This "edge" is unlikely to be defined. On Cuba Street, the socialising spaces of bars spill onto the street, causing pedestrians to travel between them, moving into a space that may belong more to the bar than the street as they do so. The colours cast onto the streetscape in this test bleed together, indicating the ephemeral nature of thresholds.

Test $C$ was established due to a need to $c$ into the human form, relating the architecture to the body of the pedestrian through gesture and movement. The key finding from this test is the existing surfaces manipulate, ripple, and change to meet the gesture of the human form as it occupies space. The two preceding tests highlighted the affective relationship between pedestrian and street; that as one moves through the street, they cannot help but disturb the existing architectural condition, therefore being disturbed themselves. In the design sense, Test $C$ exposed the possibility whis disturbance to chance the form the architectural interventions themselves take. Overall, the architectural idea exploration. Creation of a dedicated workspace in the street quickly leads to ideas of a place to stop and work for a while, which loses the perpetual nature of being a pedestrian - the relatively consistent movement that occurs as the typical nature of interaction with the street. Each of the design tests highlighted the impact of movement on affect; both at the scale of the pedestrian traversing the street, and the human being simply adjusting a limb in space. 


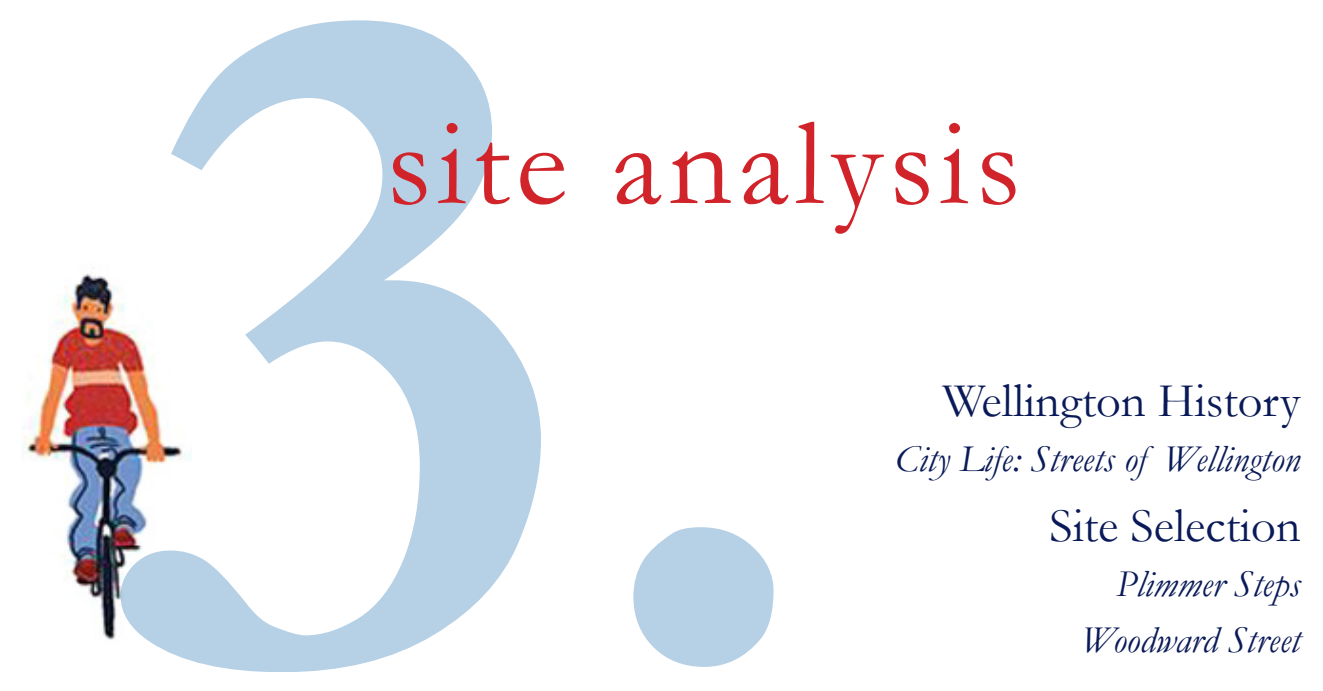

\section{-}


Wellington, the first city of New Zealand, was initially settled on the foreshore in 1840. Towns and cities have been integral to the development of New Zealand, as they are places where organised culture develops (Schrader, 2016, pp. 14,15$)$. In early Wellington, preexisting Maori paths were used until surveys were completed for the first plots to be assigned to immigrants, and the first streets laid. It took a the curve that Lambton Quay follows was the foreshore (see fig. 3.01) (Thomson, 2013). Lambton Quay was originally called Beach Street; an example of how the names of many places in Wellington were derived from the configuration of the land, or characteristics of the place (Irvine-Smith, 1948, p. 117). The southern end of Lambton Quay is now commonly known as Dawson's corner, but was previously referred to as "Clay Point" "Windy Point". This harks back

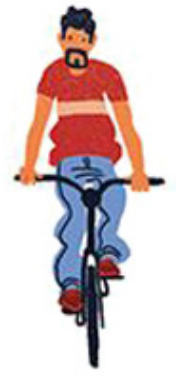

\section{city life: streets}

\section{of Wellington}

a history of the development of the street as we know it in

New Zealand, focusing on Wellington's CBD

\section{Towns and cities have been integral to the} development of New Zealand, as they are places where organised culture develops

the Wellington of 1842 , there were only a few places where attempts had been made to build houses in a straight line (Schrader, 2016, p. 90). The dirt surfaces of the early streets made travelling difficult in many weather conditions. In summer, dust would swirl, and during wet winters one may have found themselves calve-deep in muddy slush.

Prior to the Wairarapa earthquake of 1855 , and any land reclamations, to the early days of the settlement where, as points along the coast, it was nea impossible to pass in high seas or strong northerlies (IrvineSmith, 1948, p. 117). The Terrace was originally named Wellington Terrace, due to it being exactly as the name states - a terrace along ridge atop the cliff behind Beach Street (Irvine-Smith, 1948, p. 119).

In the early years of Wellington as a settlement, the inner-city stree
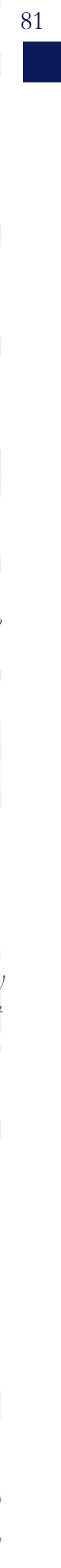


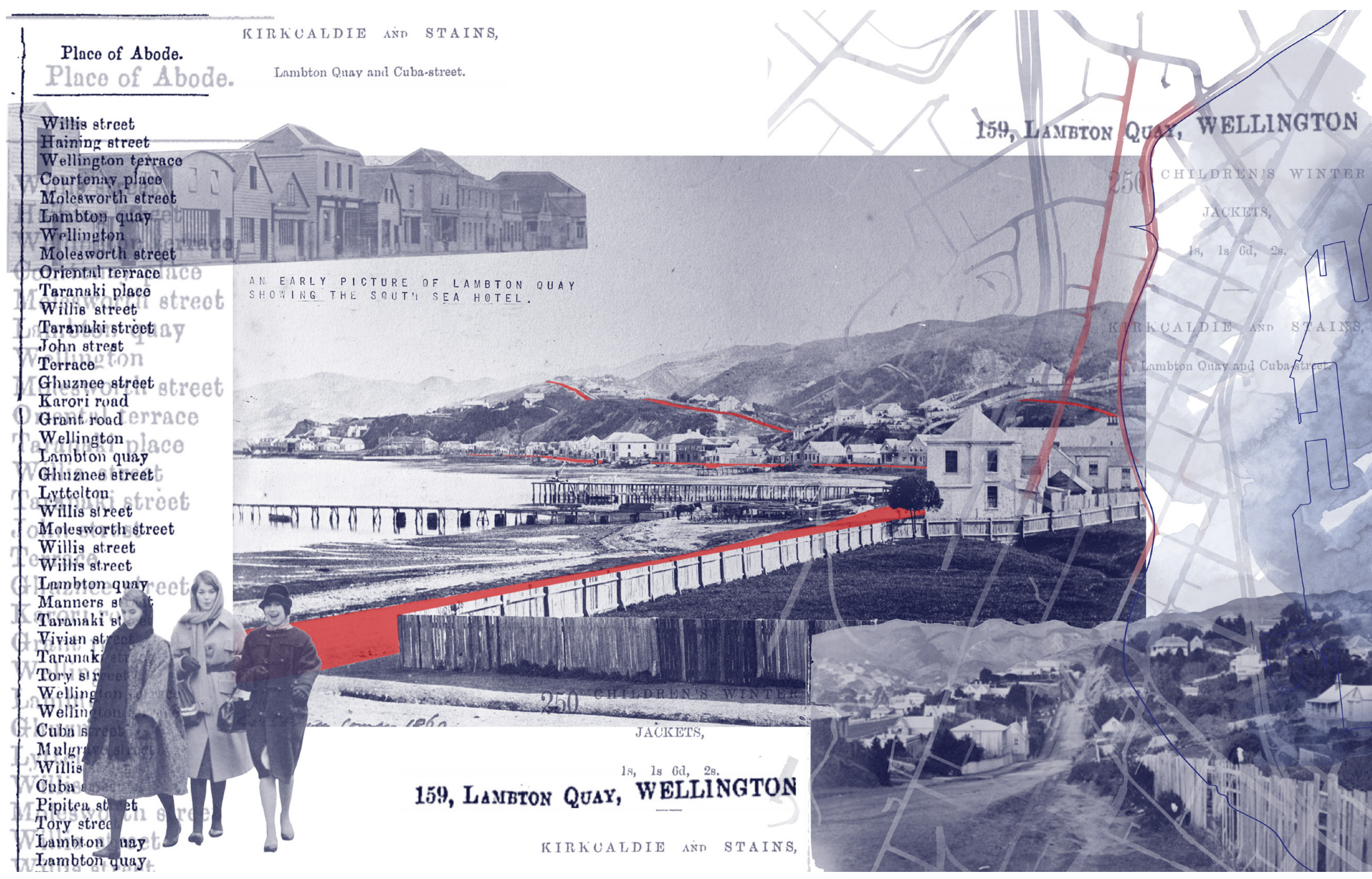

The names of many places in Wellington were derived from the configuration of the land, or characteristics of the place 
were vibrant, busy places. The vehicles of the time were horses and carriages, and the street space was shared between them and the pedestrians and traders (Schrader, 2010). The street was often used as a place to socialise. Old photographs and paintings indicate people passing time on the streets; chatting, trading, and playing.

Lambton Quay had a dubious reputation in its early years; haunt for layabouts, drunkards, and prostitutes (Schrader, 2010). However, it soon transformed into Wellington's main street. Day to day, streets were busiest in the late afternoon as women met husbands and boyfriends to "walk the block" before heading home (Schrader, 2010). Late night shopping was introduced on Saturday evenings, where shops remained open until $10 \mathrm{pm}$ that Wellington could be imagined to be a city ten times larger at these times.

\section{Old photographs and} paintings indicate people passing time on

the streets; chatting, trading, and playing

In the early 1900 s cars were introduced, and vehicle use led to the street being used in completely different ways. Initially, cars were expected to move very slowly to allow safety for pedestrians, but soon, separate lanes were introduced; those walking had to keep to footpaths (Schrader, 2010). The idea was that streets would be more efficient this way; city authorities had started to argue that city streets were chaotic, requiring civilisation (Schrader, 2016, p. 262).

Street activities were separated, creating spatial order. This change reduced the number of places for people to gather on streets, and overall they became less used as social places, and more used for transportation (Schrader, 2010) This was enhanced further by council restrictions on where traders could sell goods, and where other street performers and personalities could continue to work and entertain

In sum, these modernising force changed the spatial charge of the street. The street "moved from being a pluralistic space, encompassing many functions and activities, to one that privileged traffic" (Schrader, 2016, p. 262). Many social groups were targeted directly or indirectly through these changes; through regulation or even attempted banishment. The street became the stage for an argument between the representations of space; through planning and conceptualisation, and representational spaces; of resistance and struggle (Schrader, 2016, pp. 262-263).
This change reduced the number of places for people to gather on streets, and overall they 
Lamblon ouay an

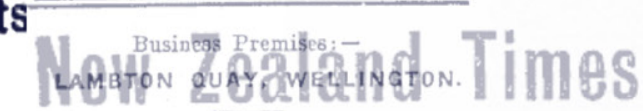
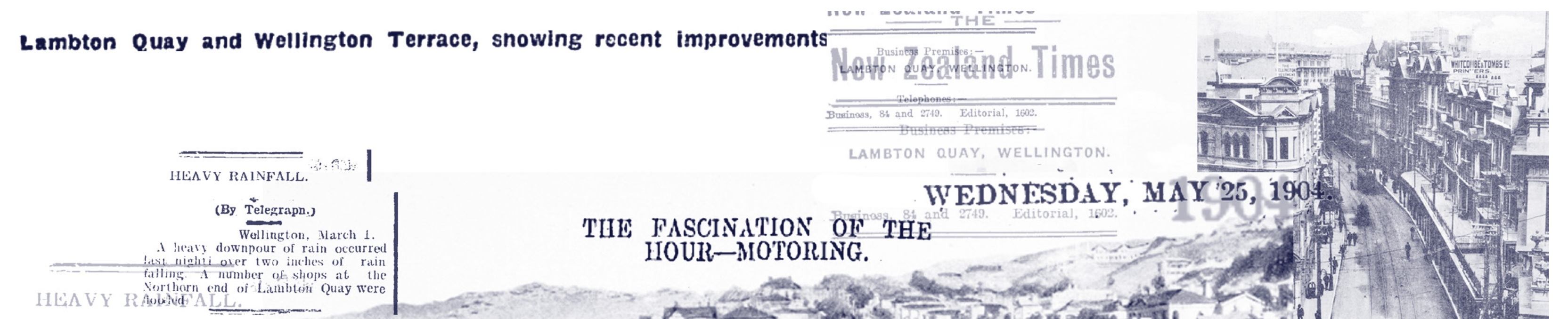

WEDNESDAY; MAY'25, 190

THE FASCINATION OF THE HOUR-MOTORING.

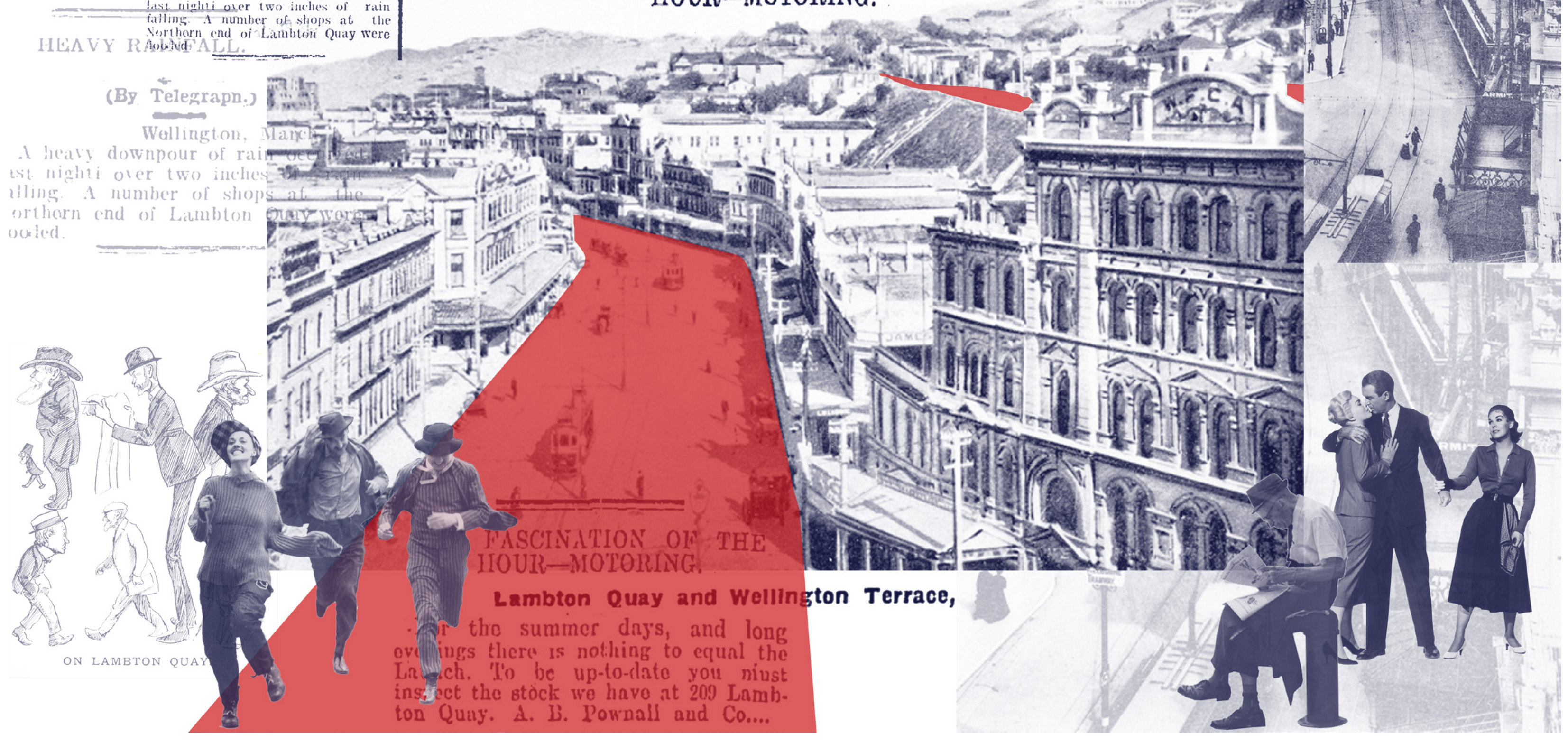

The street was often used as a place to socialise... Wellington could be imagined to be a city ten times larger at these times 
Following these changes, the pursuit of street design picked up. Despite having footpaths, pedestrians needed to cross intersections and streets often, and this was still a safety risk (Schrader, 2010). When pedestrian crossings were first introduced they were often ignored. The government encouraged their use by declaring vehicles must give way to pedestrians at these points.

Around the same time, the city was expanding, and more people moved to live in the suburbs, taking away further livelihood from the inner city streets. This was particularly evident in the evenings, as pubs closed at $6 \mathrm{pm}$, so after that everyone was at home, leaving the central city empty. Street life became that of suburbia; children playing, cars revving, and the sounds of motor mowers and power drills in sheds and gardens.

Throughout this era of quieter city life, the streets were still lined with various groups of people - many of whom were working, the street their workplace; pie and coffee cart traders, newsboys, streetwalkers (prostitutes), and the homeless.

Cuba Mall became the first street mall in New Zealand when it was established in 1969 (Wellington City Council, n.d.). This coincided with other changes that also enhanced street life again, including cafés and bars being allowed to stay open later, and

have seating areas that overlapped with footpath spaces. The street expanded as its edges became more porous again, and adjacent spaces

The street expanded as its edges became more porous again, and adjacent spaces started to interact, as they had in the past

started to interact Professionals and students saw the allure of living centrally; many moved into the inner city, popularising living in high-rise apartments, which further boosted street life.

Throughout this time, street carnivals and festivals were introduced across the country, and urban designers focused on further improving city spaces to be more attractive to pedestrians. Lambton Quay was remodelled in 2008 to widen footpaths, lower speed limits, and provide more street furniture (Schrader, 2010).

The reintroduction of design solutions such as shared spaces was to encourage a city designed for people. New Zealand saw 100 years of streets being used primarily for passage of traffic, but now people are rediscovering the social and recreational opportunities provided by the street. 


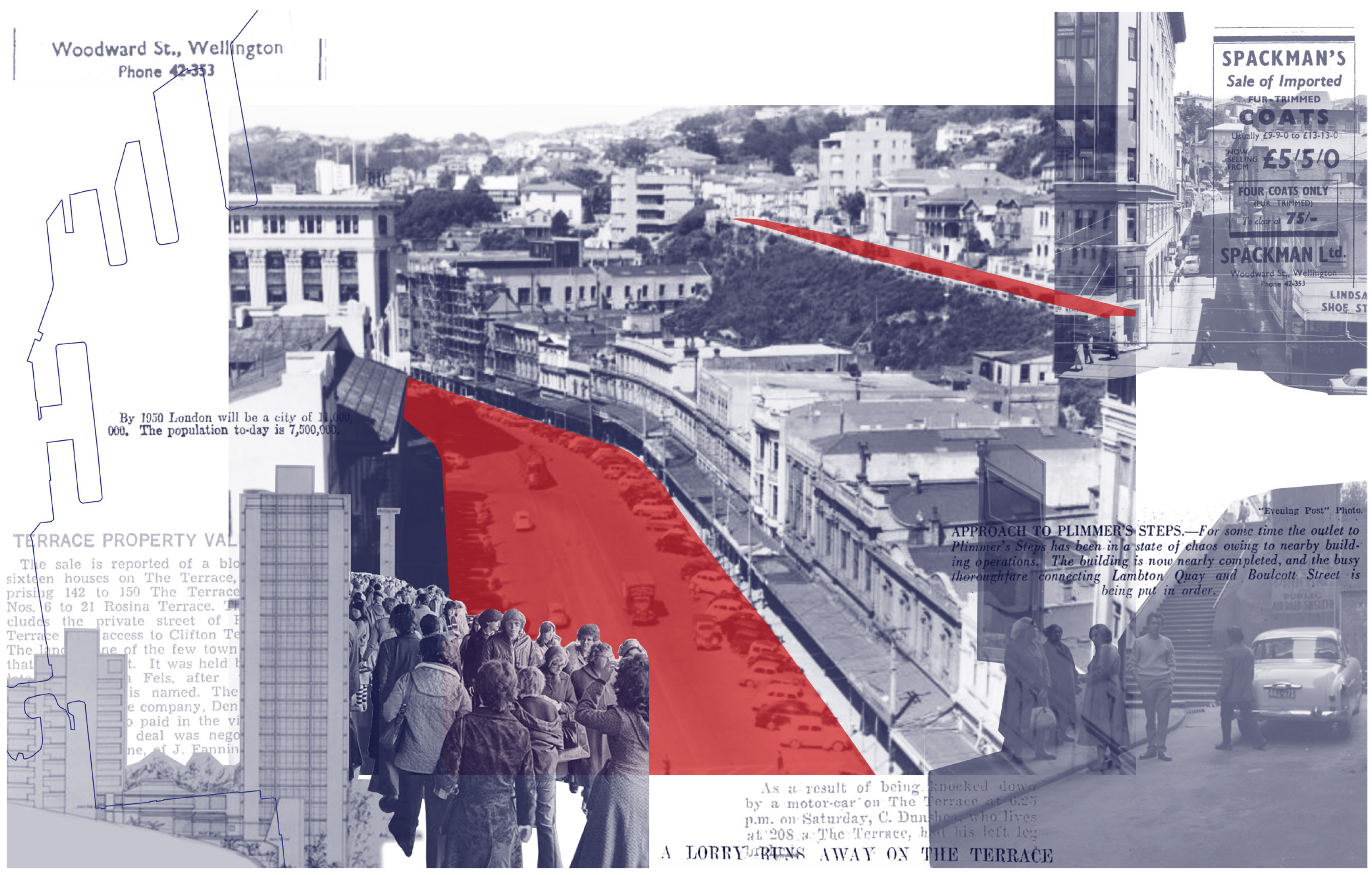

The city was expanding, and more people moved to live in the suburbs, taking away further livelihood from the inner city streets 
The sites selected have been repressed by the significant considered thoroughly prior vertical language provided by to beginning a comprehensive the development of high-rise site analysis to explore multiple architecture. For over a kilometre, contexts, including historical, the only access between the two on earlier research; including site reach up through the buildings. A analysis of Wellington City, case these points, the compression of studies at selected sites, and research the high-rise buildings, the narrow into the history of street life in width of the routes, and the steep New Zealand, it became apparent grade all create pedestrin "street" that specific "street" sites within conditions that are rich with Wellington's Central city needed to affective relationships.

be selected to provide grounding for further design research.

Lambton Quay and The Terrace are both significant streets in the Central Business District of Wellington City; Lambton Quay is home to much of Wellington's premium retail space, and both streets provide access to many significant office buildings.

Lambton Quay was previously Wellington's waterfront; prio to significant land reclamation over the past 180 years. Behind this, a cliff rose, and The Terrace wound its way along the ridge. The difference in topography reaches over 30 metres at multiple points along the block. The cliff condition has, over time, become somewhat

Two of these routes have been selected as sites for further design exploration and research; Plimmer Steps and Woodward Street. They are located $400 \mathrm{~m}$ apart along Lambton Quay and have some similarities in language, but also many differ are exemplary of the "periphera site" condition; they are narrow pedestrian access streets that may previously have been considered as little more than the space between buildings (Wall, 1999 p. 234). There is a critical intersection of physical access and working behaviours occurring; any exploration needs to consider common activities being performed on the street today, taking into account the mobility technology has provided us.

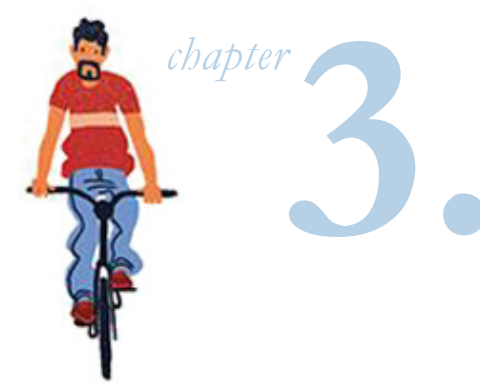

\section{site selection}

streets of the Wellington CBD

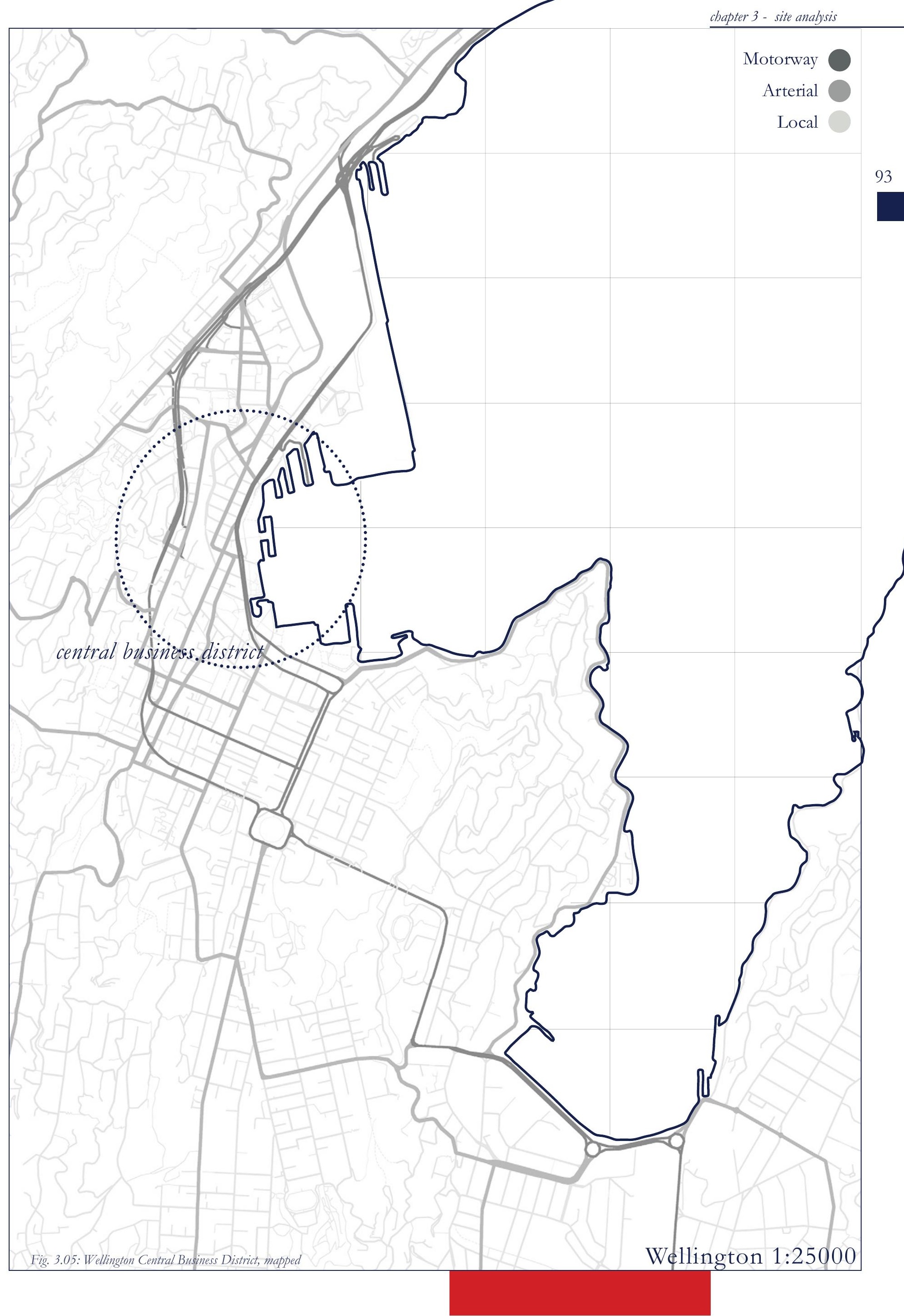




\section{the pedestrian workplace}

(1.) mitidesy

94 से 1 है।

ह 3 䝠 1 . - $153+1$ - 1 -

aly, $5 \times 1$ 2)

2. $45,1<$.

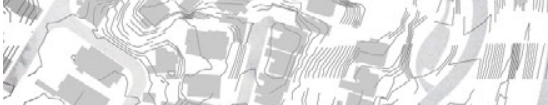
(2) $3(1)=12$

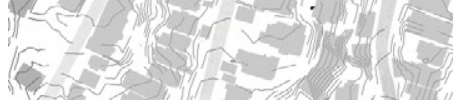
( - (1) j.

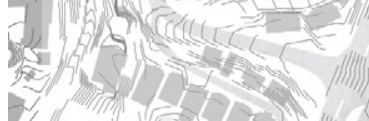

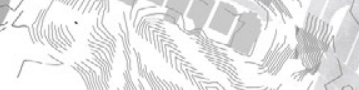
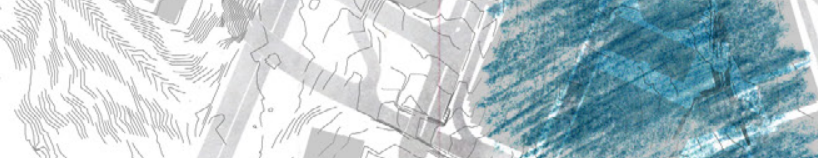
if(3) 1 (I) (II)

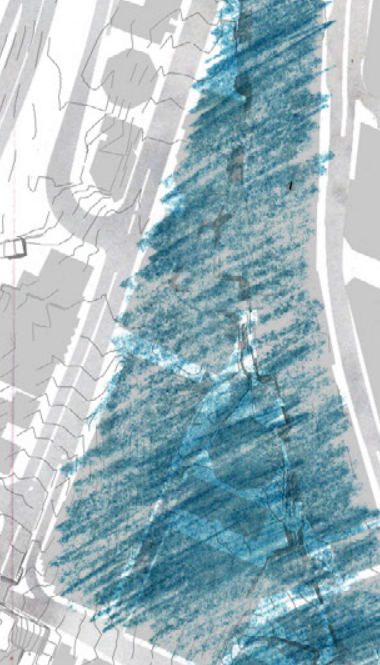

Sin 1 Y i n

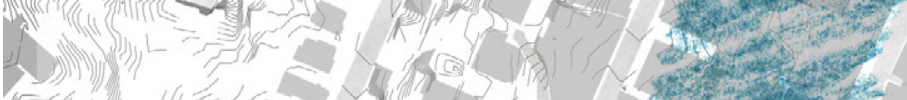

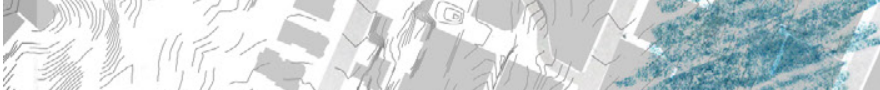
y.

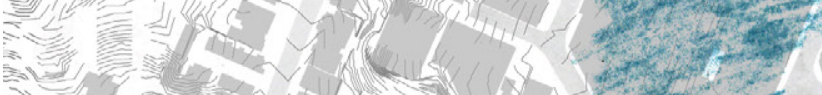

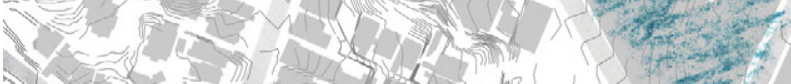
a. a

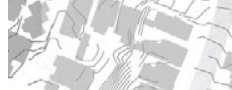

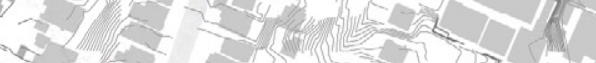

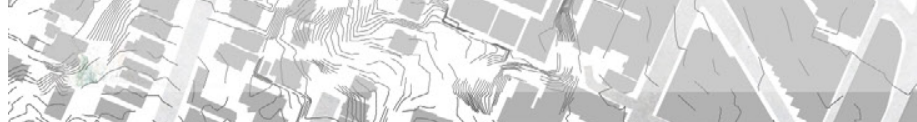
cultural, historical, and geographica features of the extended site. Here, the block contained by The Terrace to the west, and Lambton Quay to the east, is indicated. From the north to south corners, the buildings fill over one kilometre where there is no vehicular through-route.

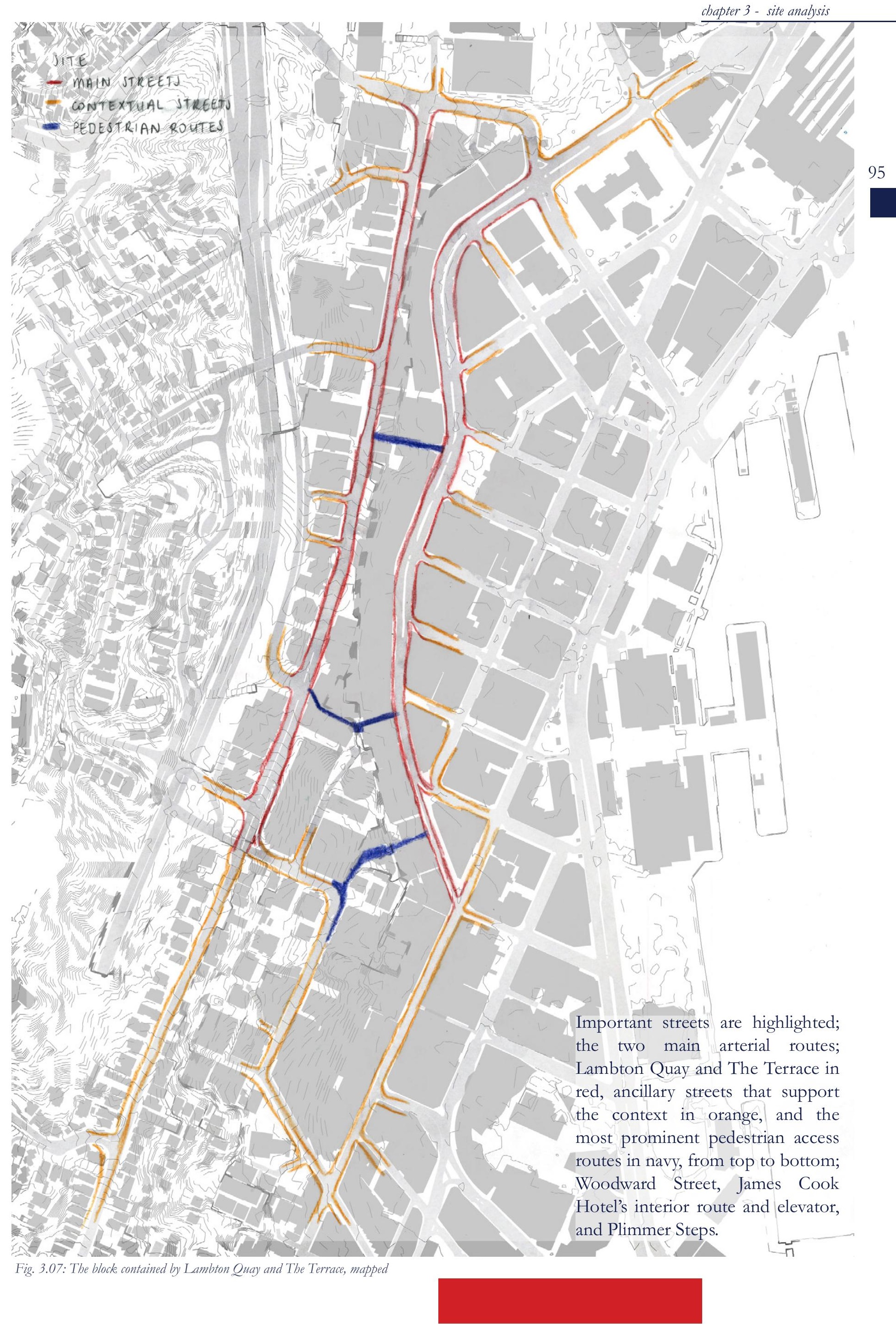




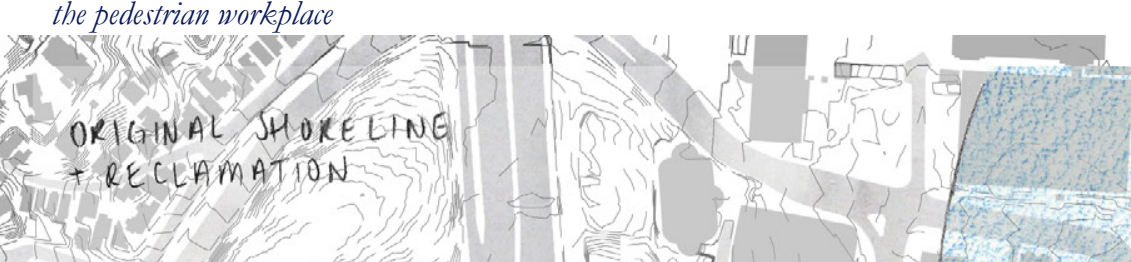

96 जो

3 ,

10 .

s.t.

- $21-23+10$

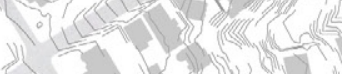
sin $(2,10$

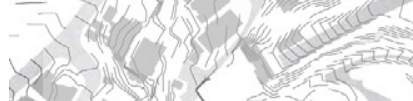
A

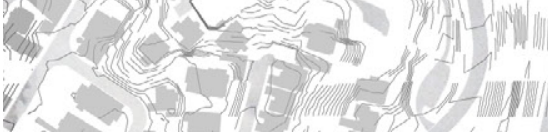
(3) $3(1,-1)$ R-

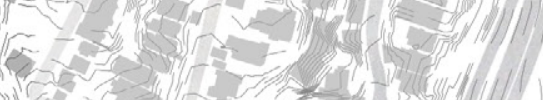
n

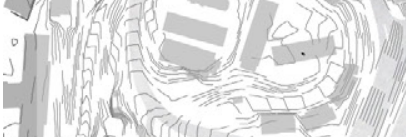

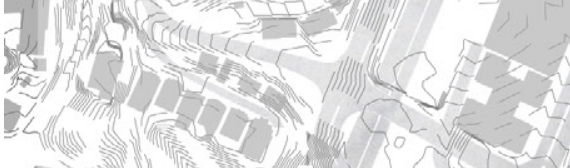
$(-1)=$

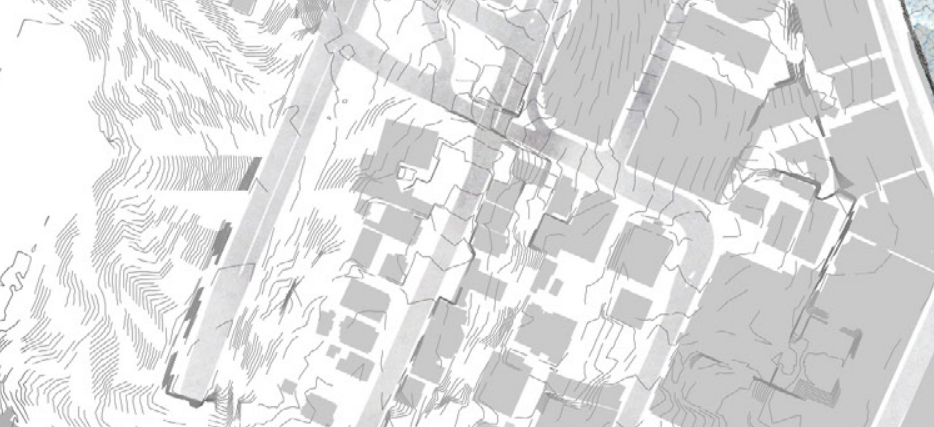

(i)

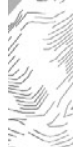
(u)

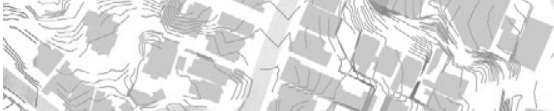

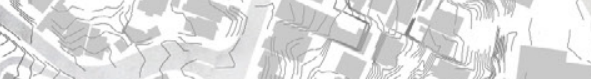

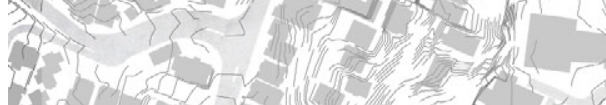

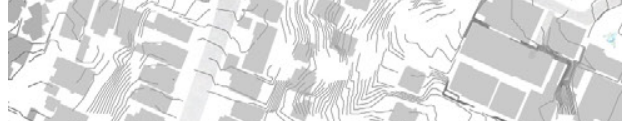

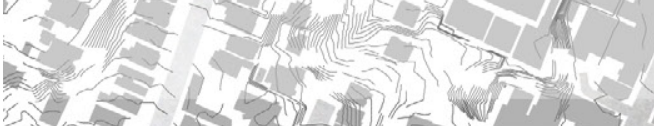

$5.2 \times 14$ M.

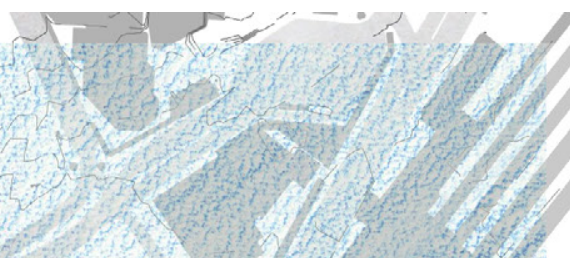
P. (2.5.

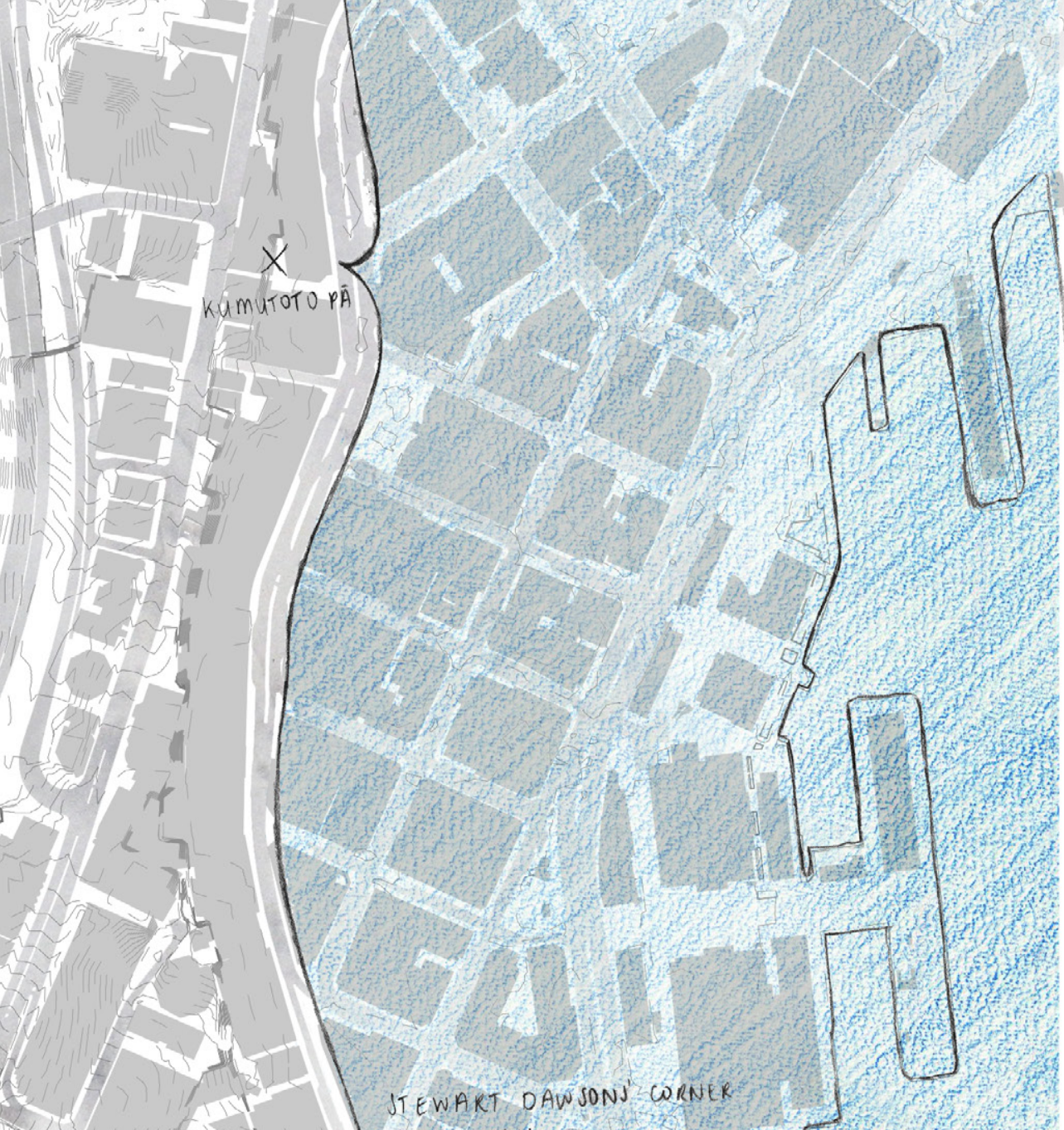
PREvTOUJLY POINT Or
WINDY PINT CLAY POINT

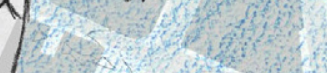
the years. The original shoreline followed the curve of current day's

Lambton Quay, with a cliff rising sharply to the Terrace, where the pedestrian routes are today. The corner where the street meets Willis Street earned its name as it was difficult to traverse in high northerly winds, which occur often in the city. Fig. 3.08: Toddgys sho

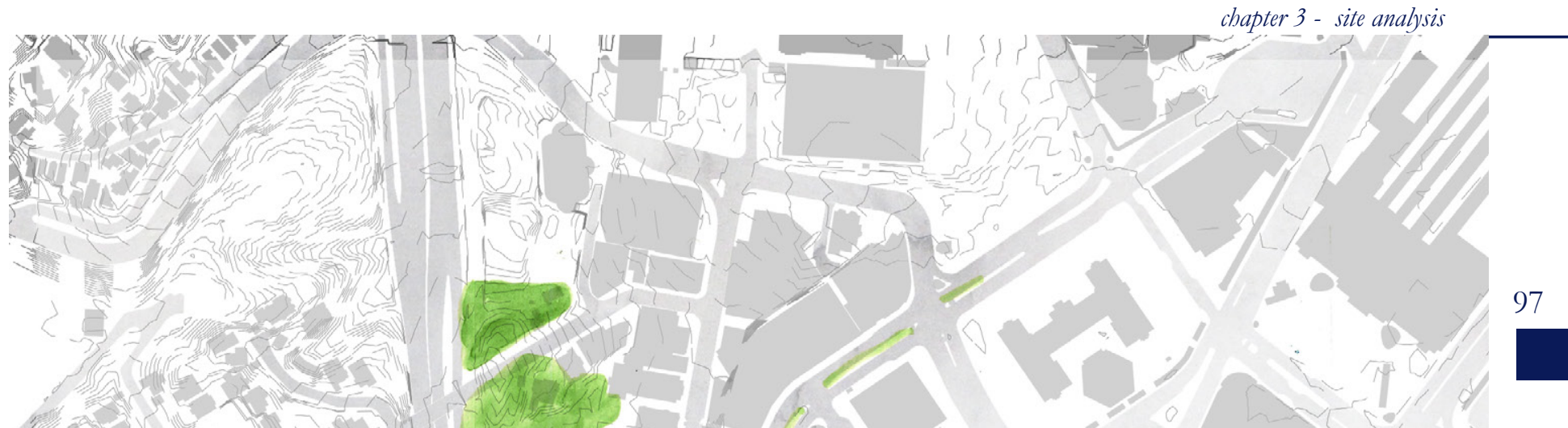

玹

s. 1 (1)

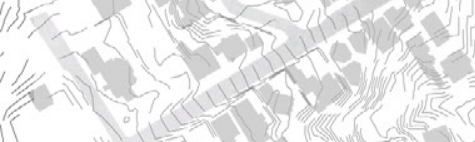

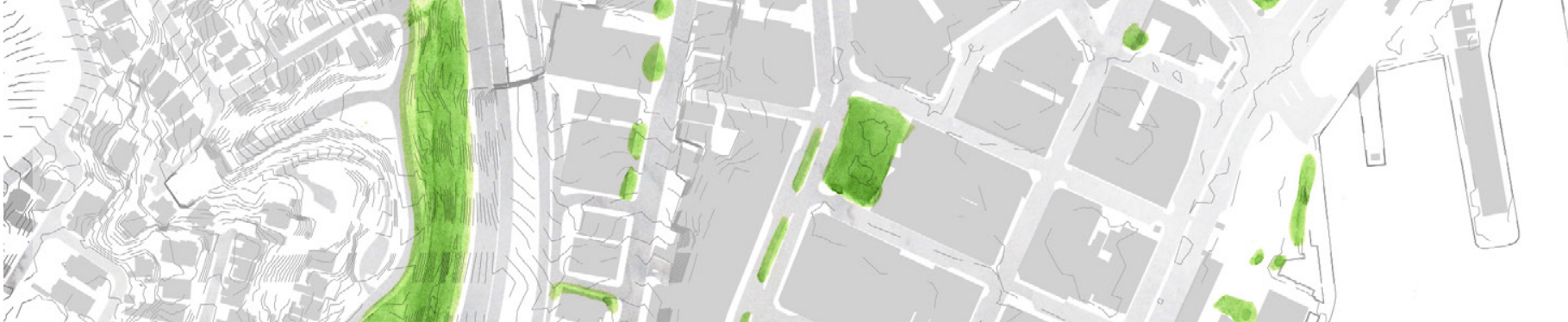

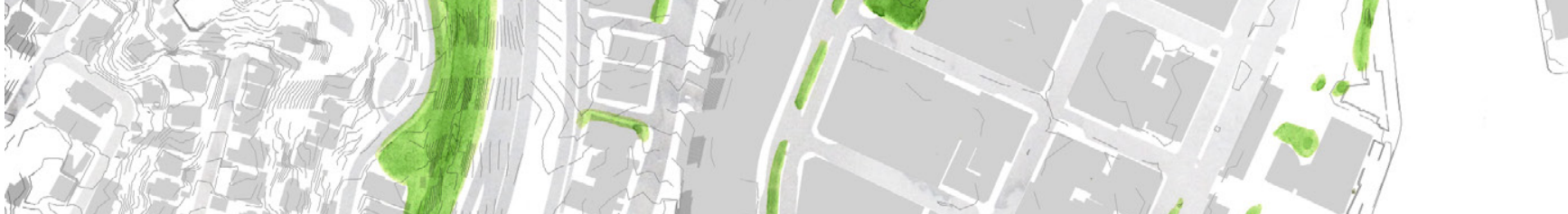

(e)

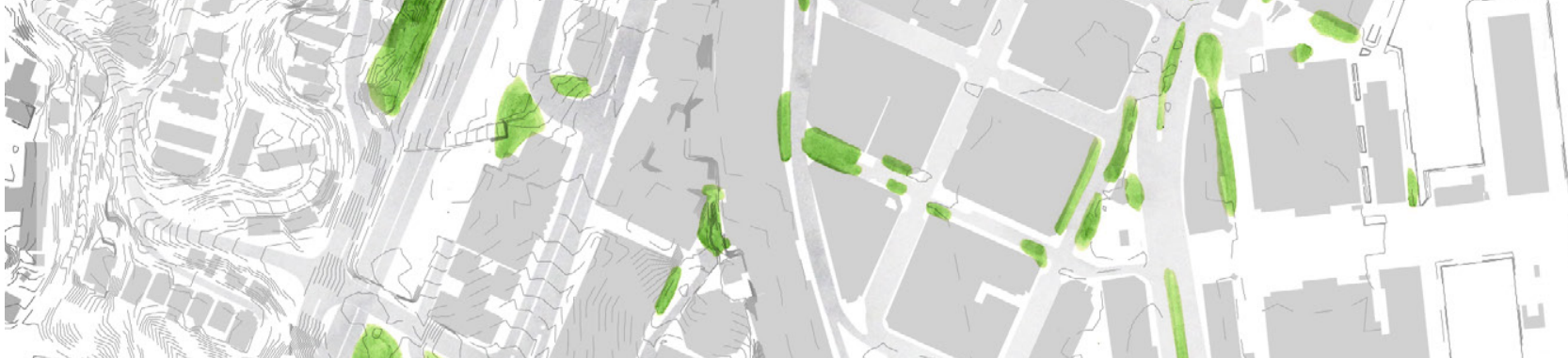

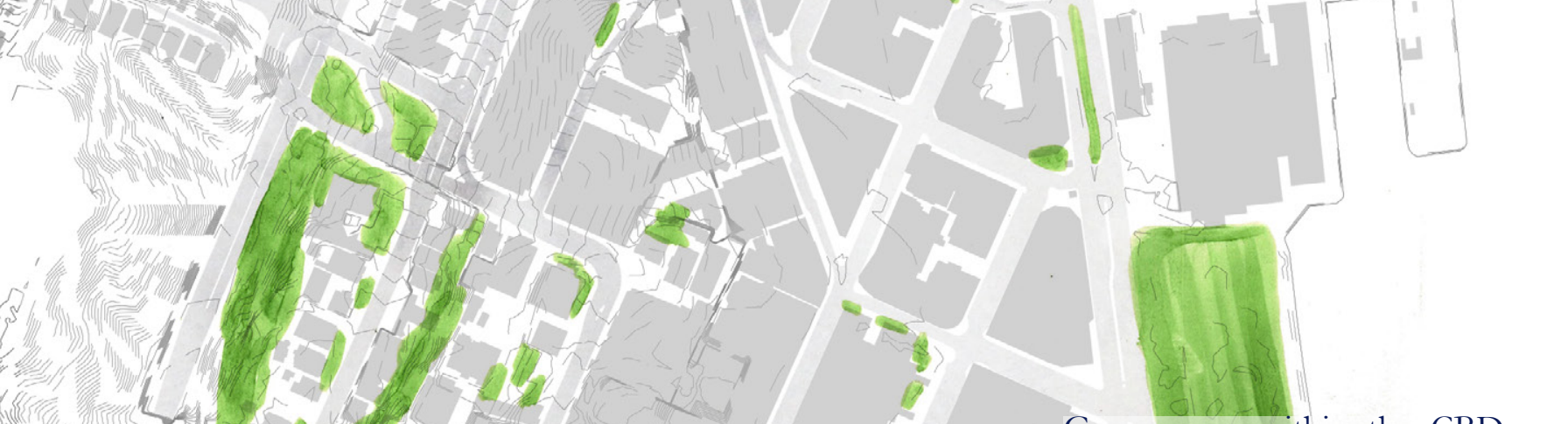
(1) Green areas within the CBD are

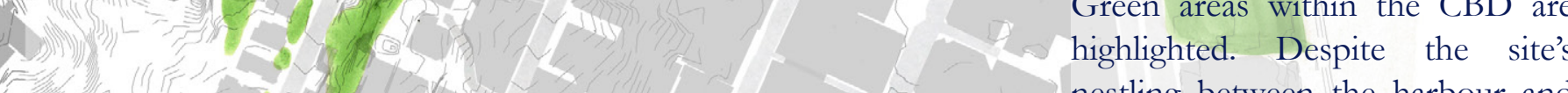
nestling between the harbour and the town belt, thereis little greney,
so including planted areas within any

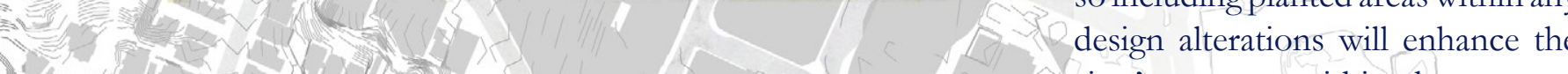
N. 4 - 7 (sites' presence within the context, and promote frequent use, relating a th

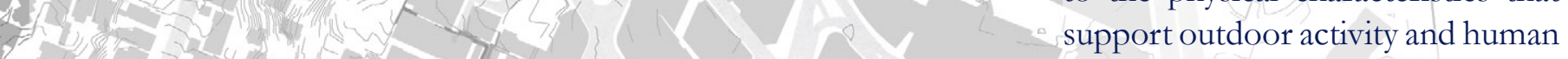
2 - interaction (Mehta and Bosson,

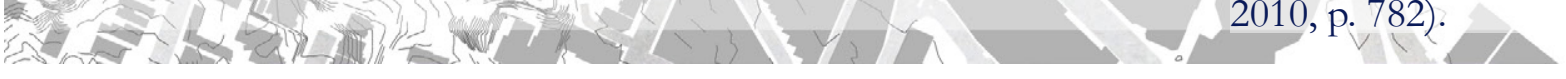
$\tilde{r}$ 


\section{the pedestrian workplace}

(1) 1 is

1 private

Nuth public

개: th th

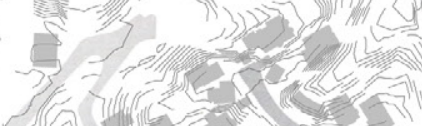

on

Ny n

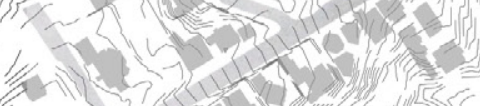

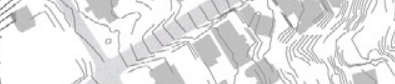

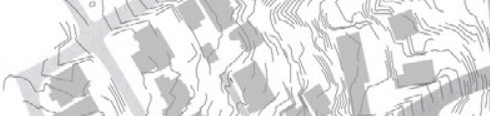

b.

(3) 3$)$

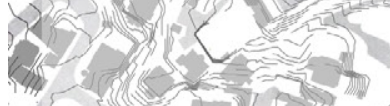

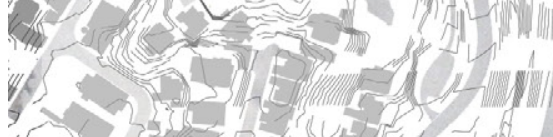

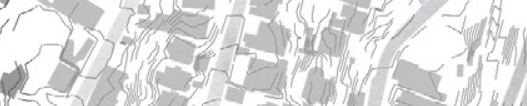

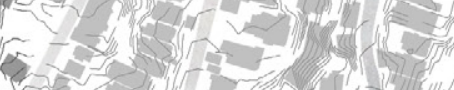

(

- 1 ( )

j.

等伿

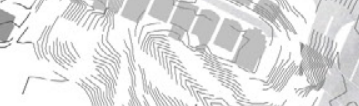

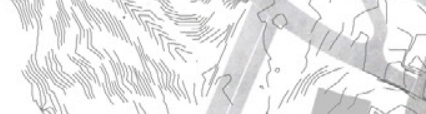

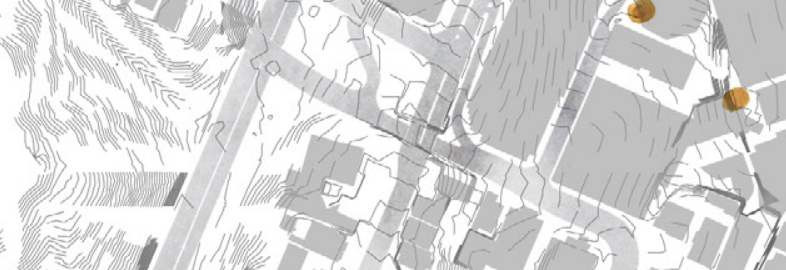
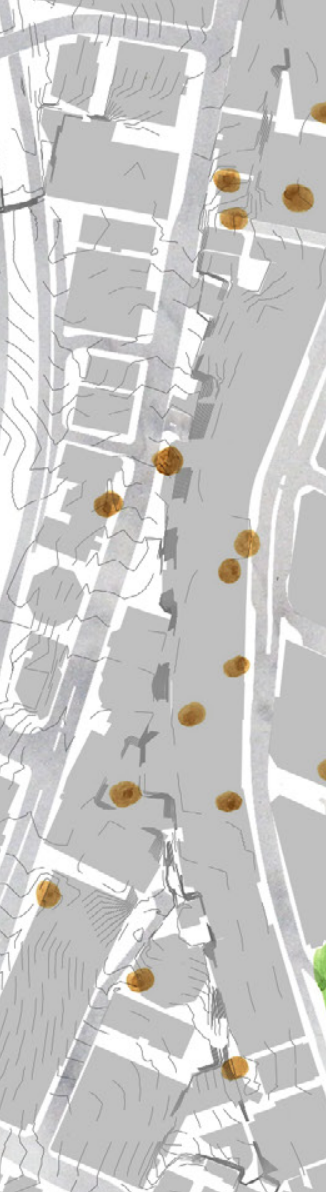
(

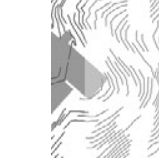

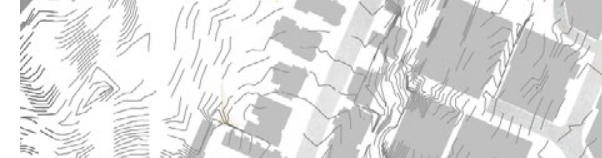

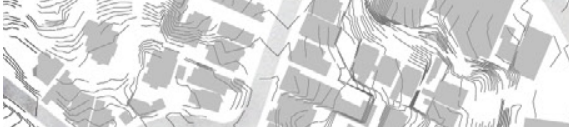
a.

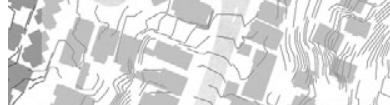

n 1 -

SA
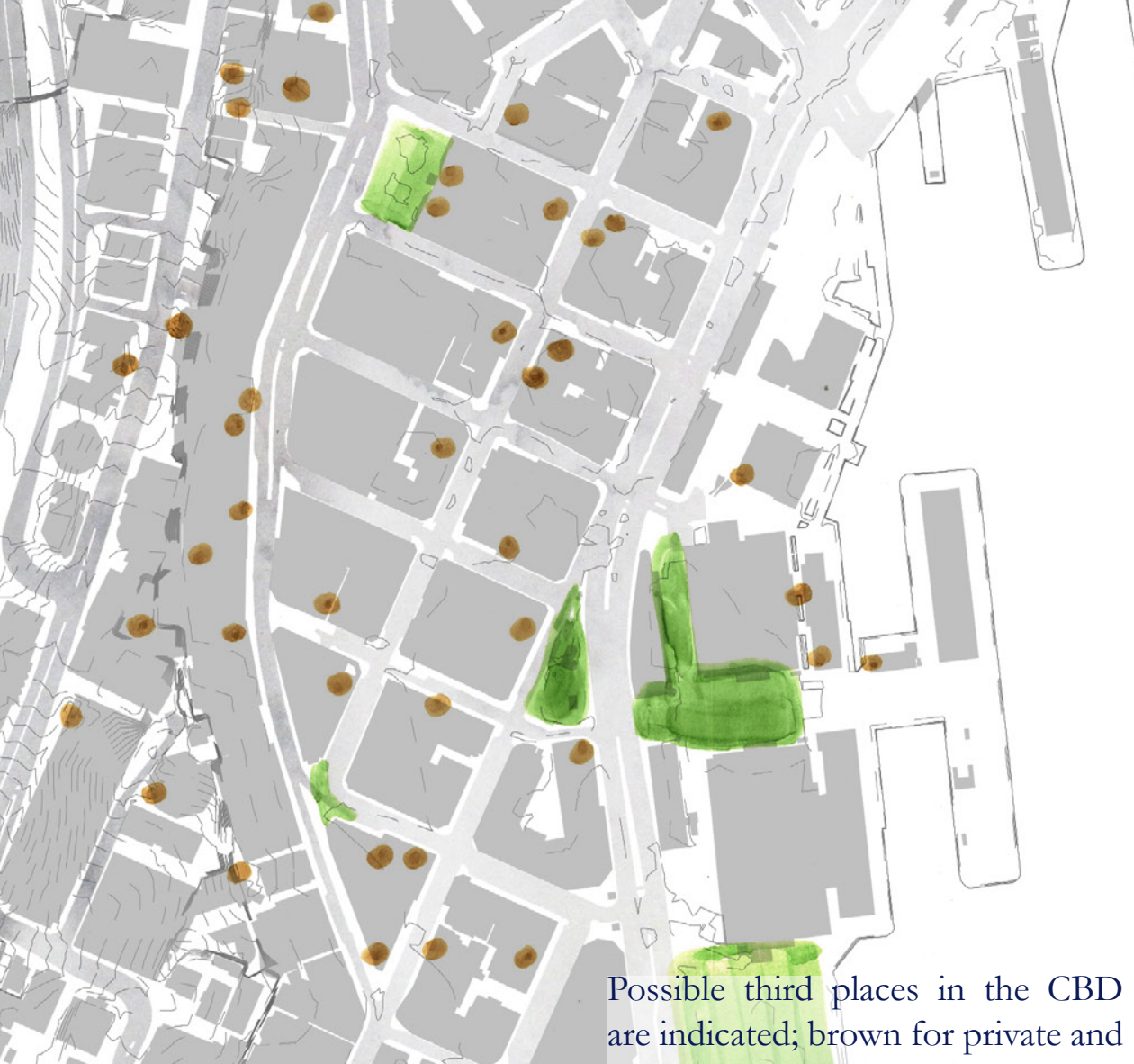

test
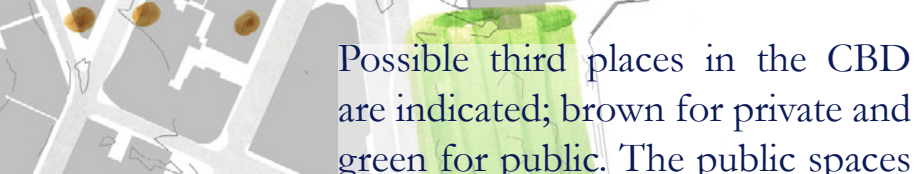
green for public. The public spaces tend to be larger, open, outdoo spaces, typically with a park or ho garden typology. Most of the privatised spaces are eateries. These private spaces can promote social interaction through their connection
to the street (Mehta and Bosson, 2010, pp. 780, 781). However, truly
"public"; inclusive, neutral, space is "public"; inclusive, neutral, space is
essential to supporting the "feel" essential to supporting the "feel" of a place, giving the city it's own character and culture (Oldenburg, 1991, p. 2).

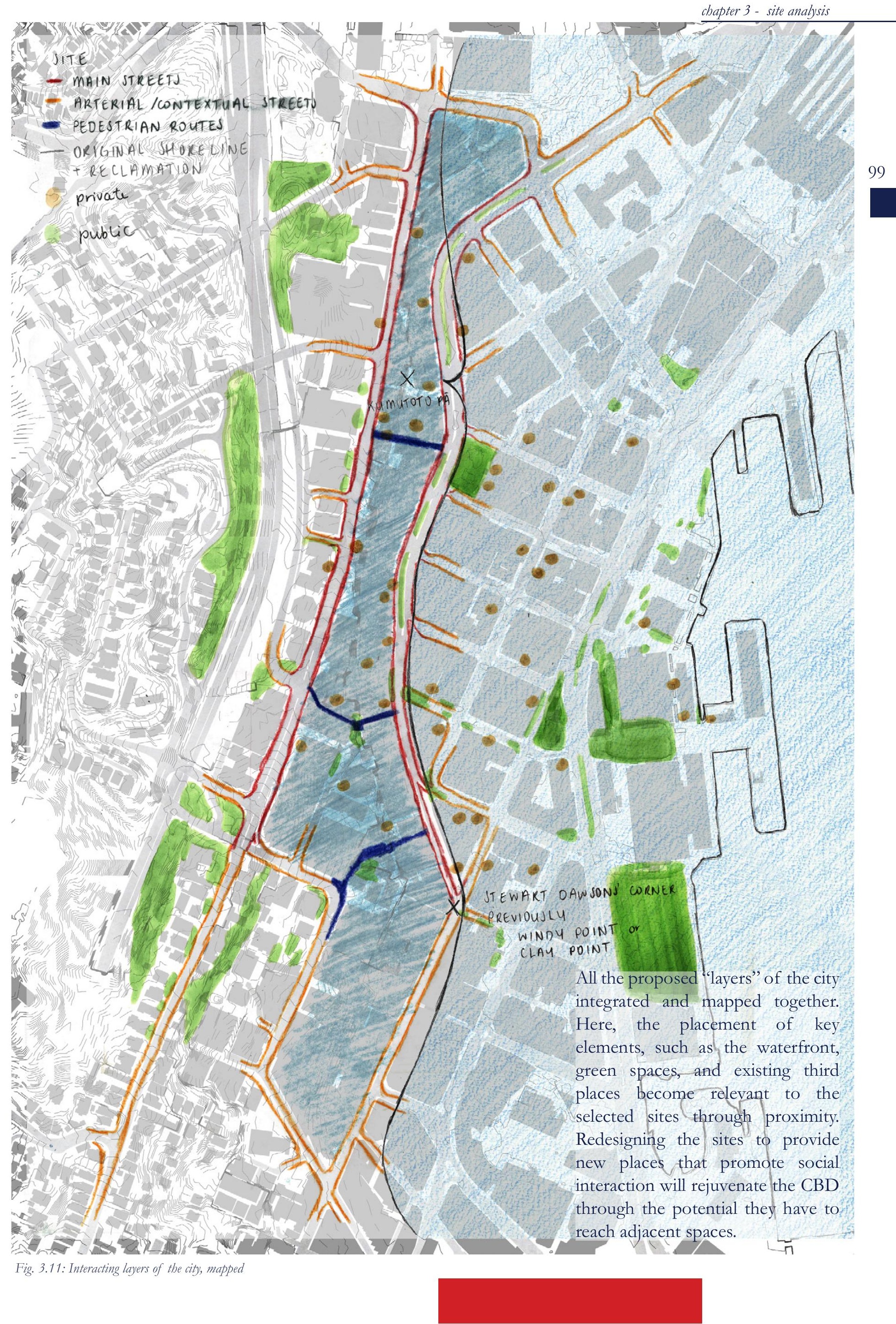


Fing

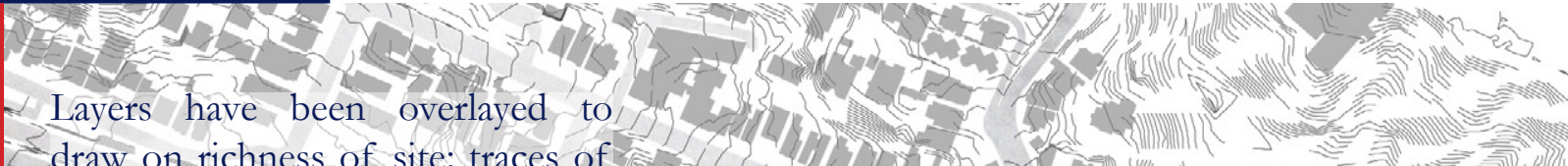

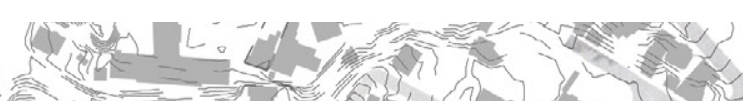

chapter 3 - site analysis

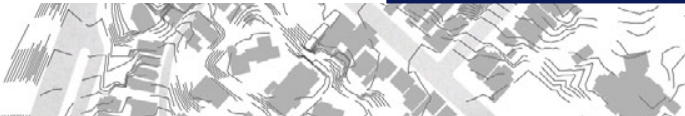

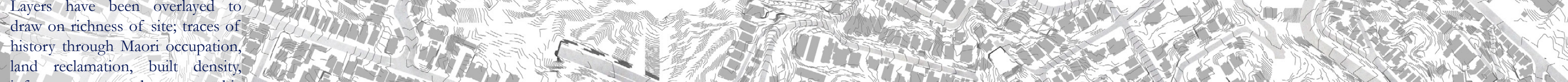

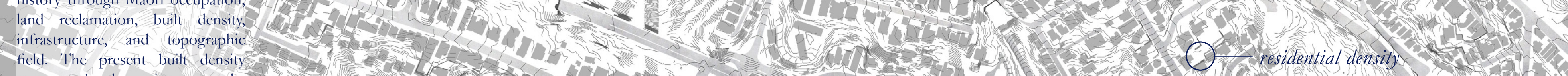

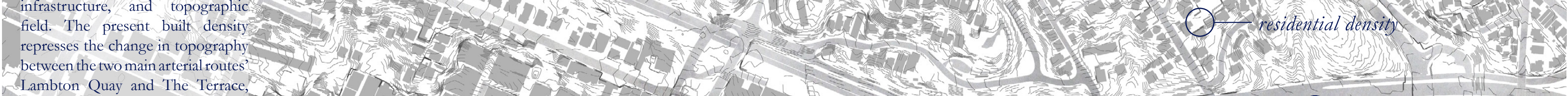

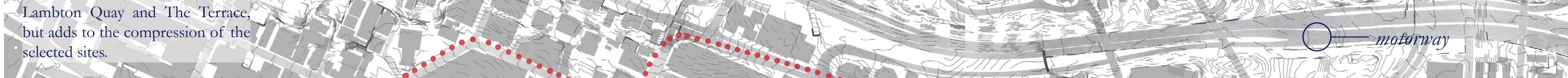

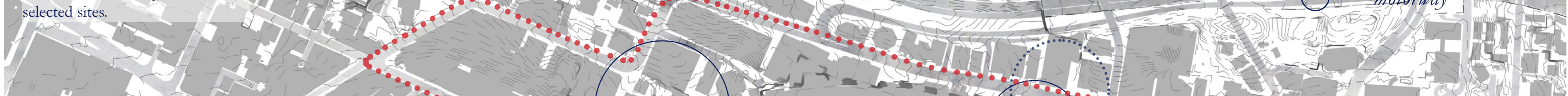

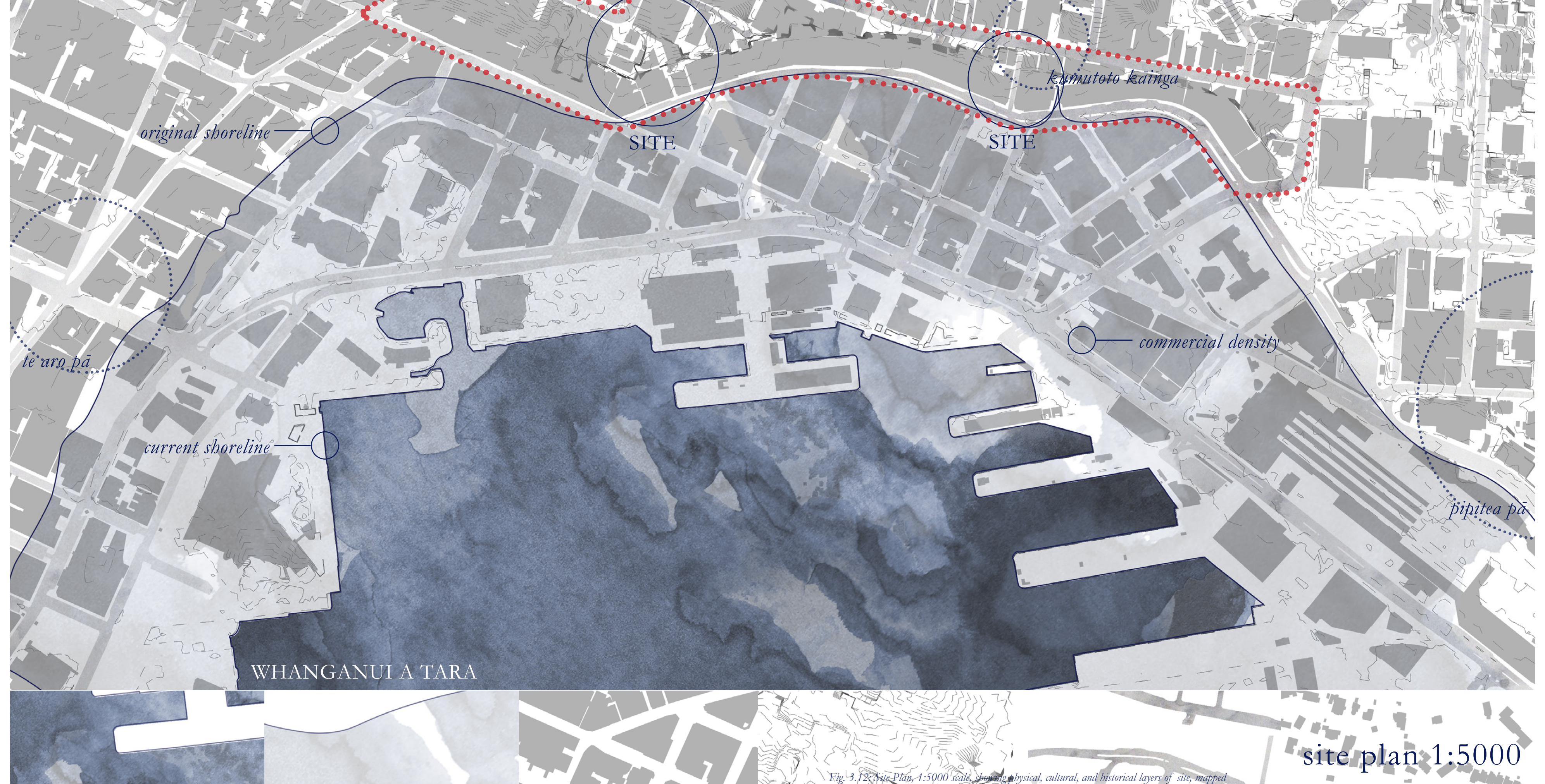



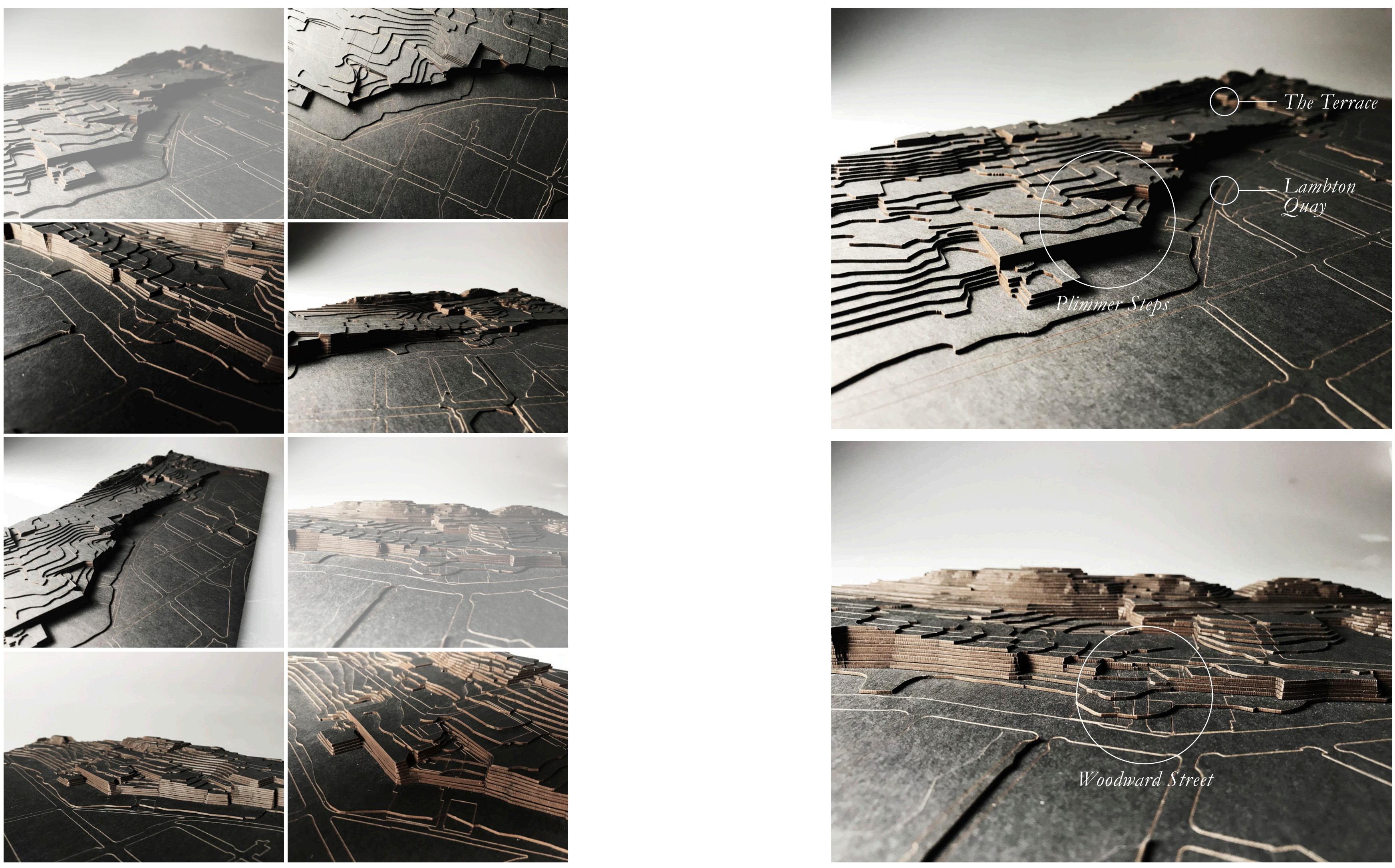

口 
With his keen foresight and press campaigns, Plimmers' impact on the development of Wellington City was lasting

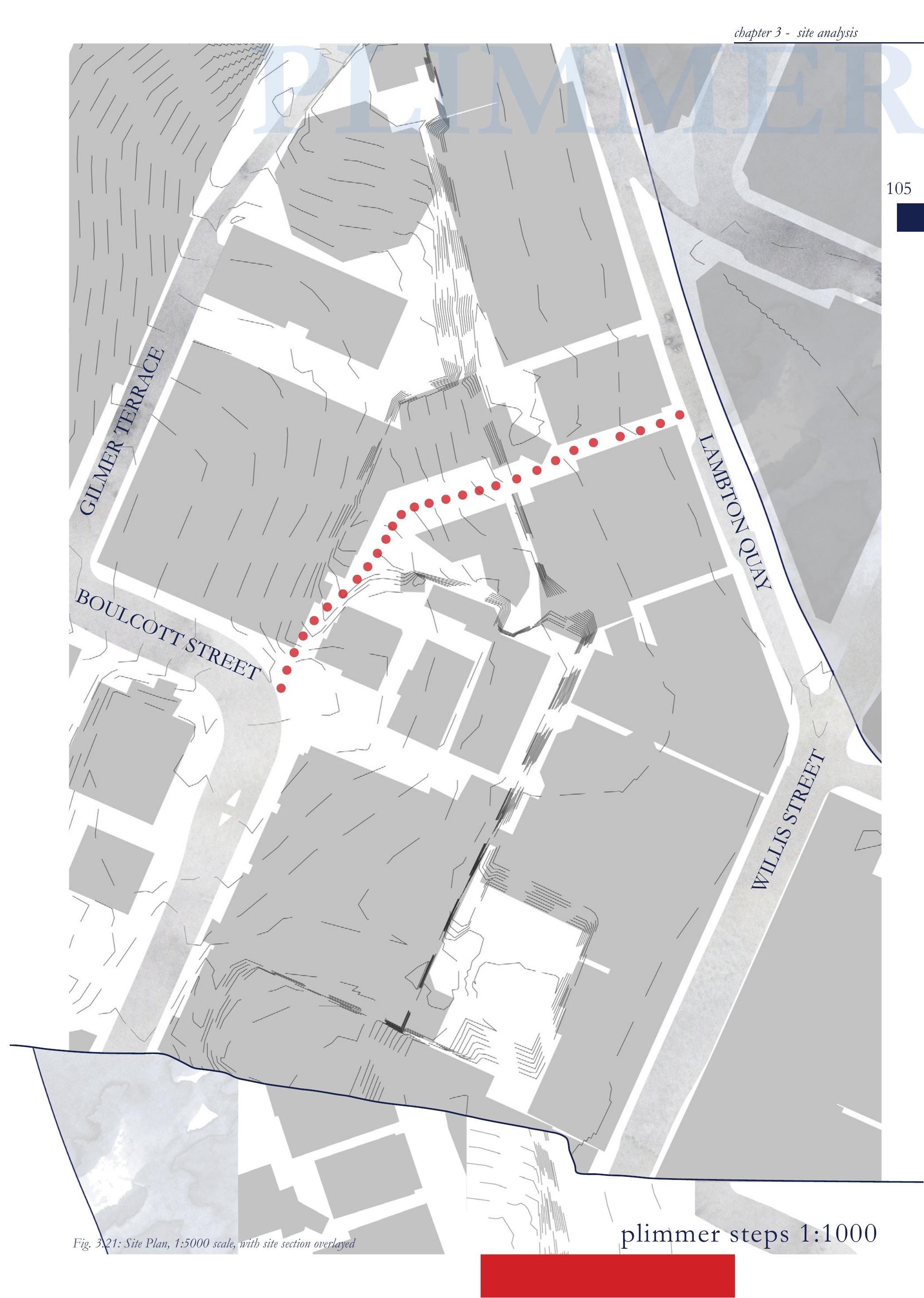




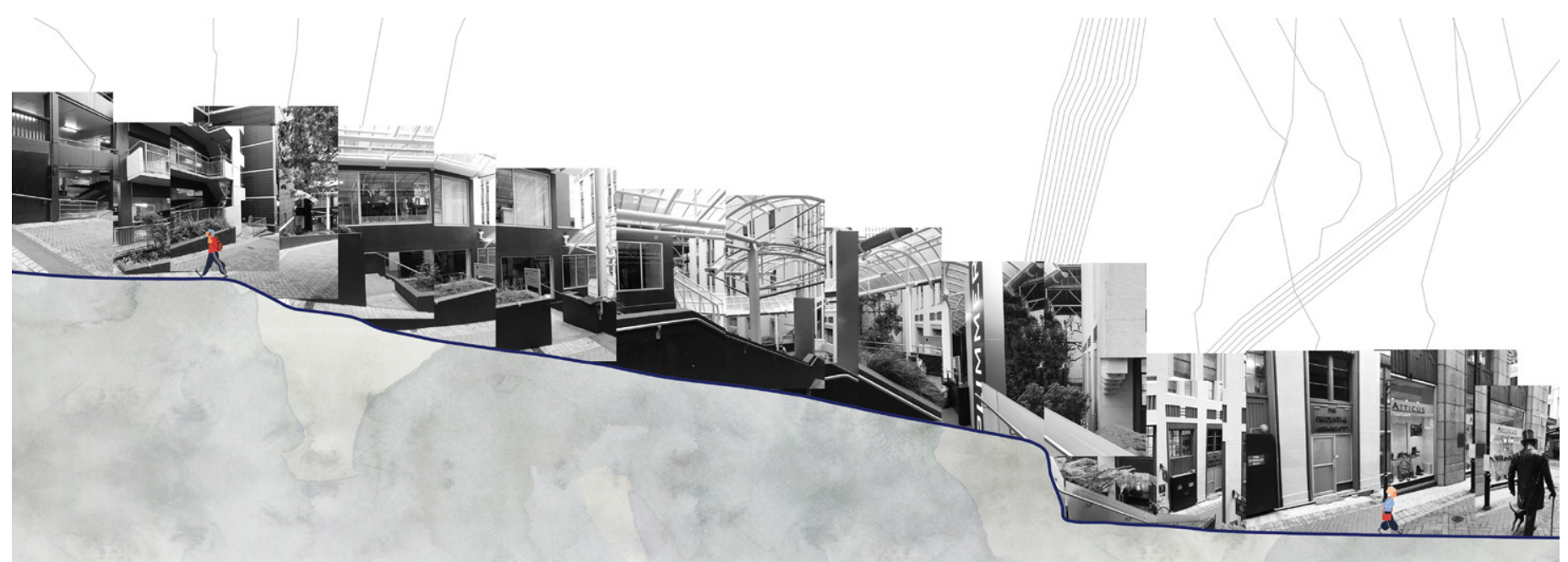

unfolded section: right

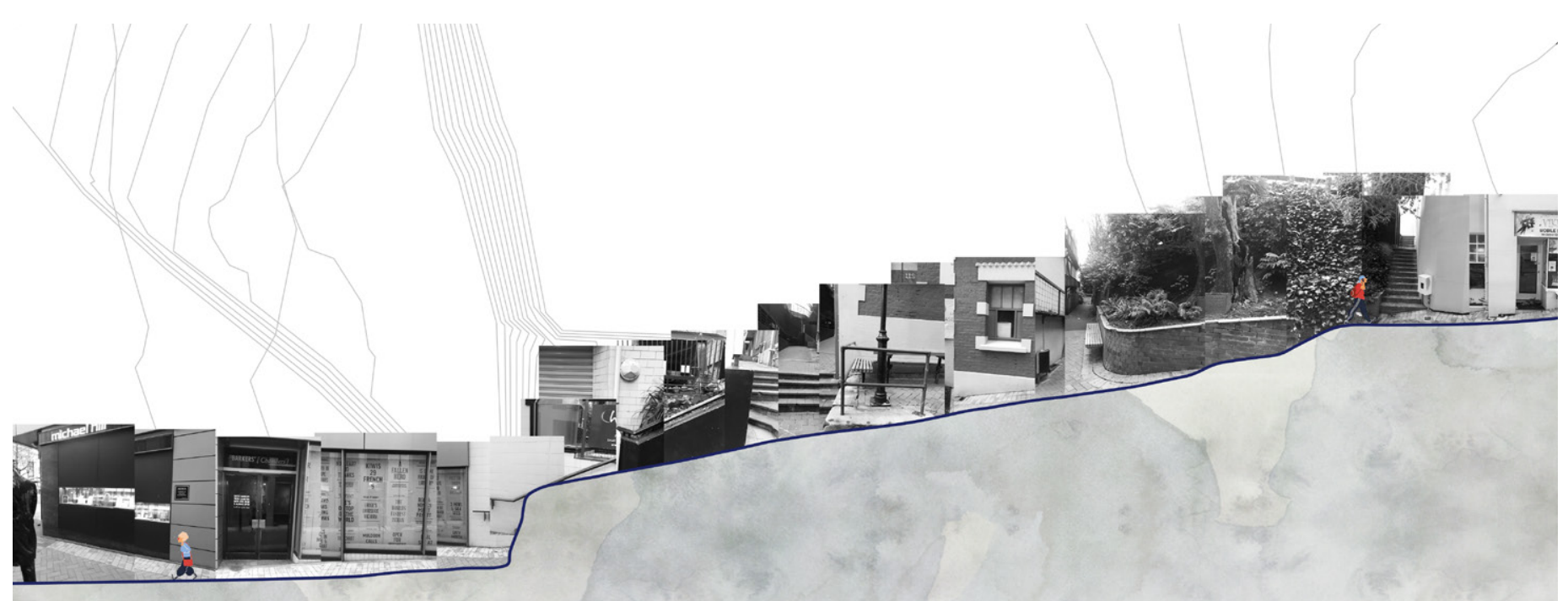

unfolded section: left
John Plimmer arrived in Wellington on the Gertrude in October 1841 (McLintock, 1966). Trained as a master builder and plasteret, Plimmer purchased the wrecked ship Inconstant and towed it from Pencarrow Head to the Lambton foreshore, which at the time, followed the present-day route of Lambton Quay (Mclintock, 1966 He converted the hull into a wharf, warehouse, and space for business offices, named Plimmer's Wharf, and it soon became popularly known as "Noah's Ark" (McLintock, 1966).

Much of Wellington's commercial and political development can be attributed to Plimmer's significant influence on the early settlement He invested money profited from his "Ark" back into local public companies, as well as his building and contracting business, which he fully devoted himself to in the aftermath of the 1855 Wairarapa Earthquake (McLintock, 1966).

John Plimmer has regularly been referred to as "the Father of Wellington', due in part to his longevity, and also his responsibility to the city - although Colonel Wakefield may more correctly have claim to this title (Gattey, 2015; McLintock, 1966).
With his keen foresight and press campaigns, Plimmers' impact on the development of Wellington City was lasting. He advocated for railway developments in the region, as well as waterfront reclamations and improvements to harbour facilities (MacLean, 2015)

\section{Plimmer resided}

near the present-

\section{day Plimmer Steps,}

giving the walkway its' moniker

Plimmer resided near the presentday Plimmer Steps, giving the walkway its' moniker. He planted the still-standing oak tree in his garden in the mid-1800s (Gattey, 2015).

The steps are a pedestrian shortcut between Lambton Quay and The Terrace, via Boulcott Street, but the "steep paths and sharply rising steps" are challenging, limiting foot traffic (Gattey, 2015). The main attraction is the statue of Plimmer with his dog Fritz stepping onto Lambton Quay; which was voted the most popular artwork in the city in 2013 (Gattey, 2015). 
Kumutoto Kāinga was a known boat landing site and flax collecting area; for many years it was a central point amongst a network of flax stations throughout the North Island

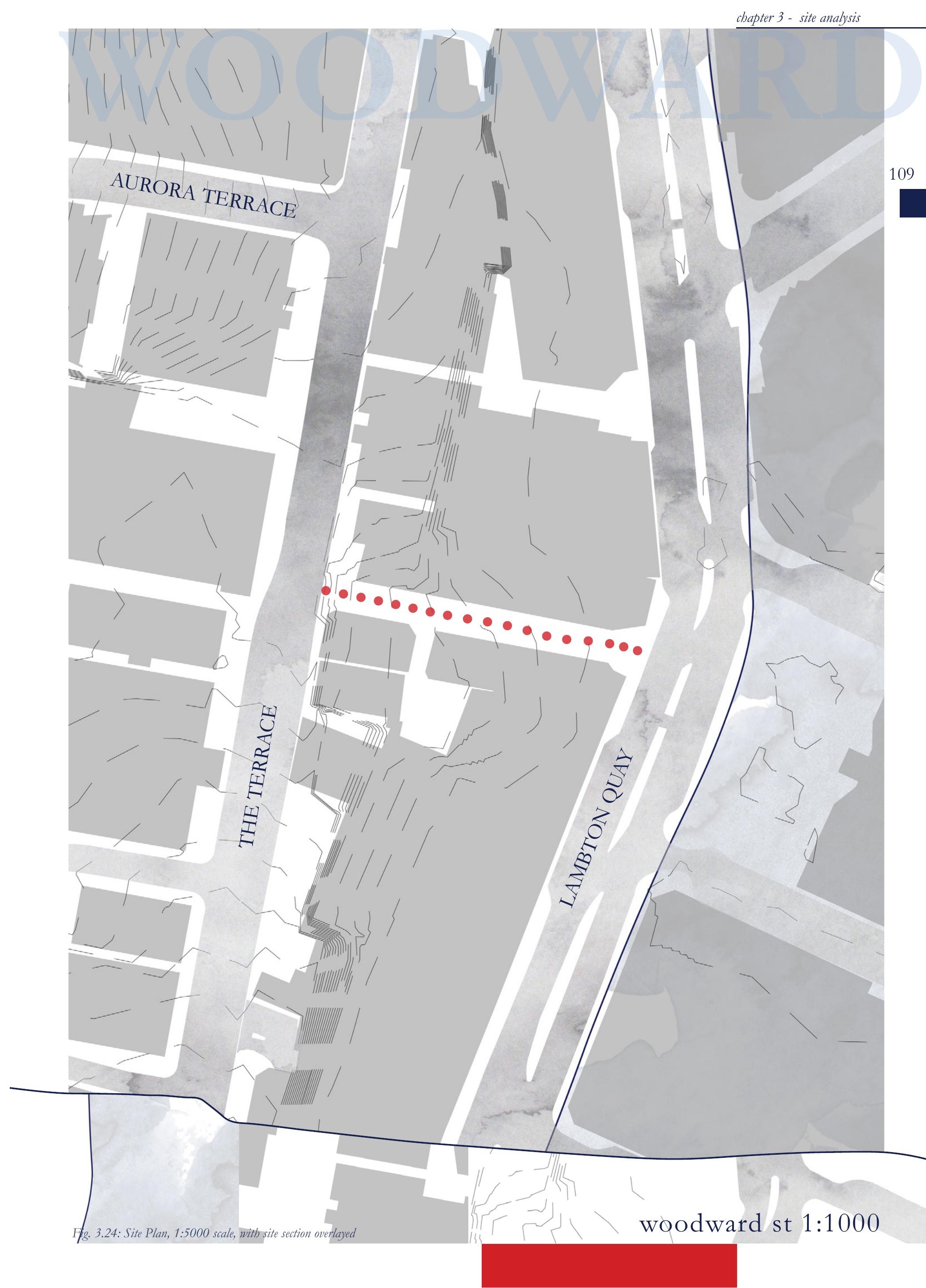



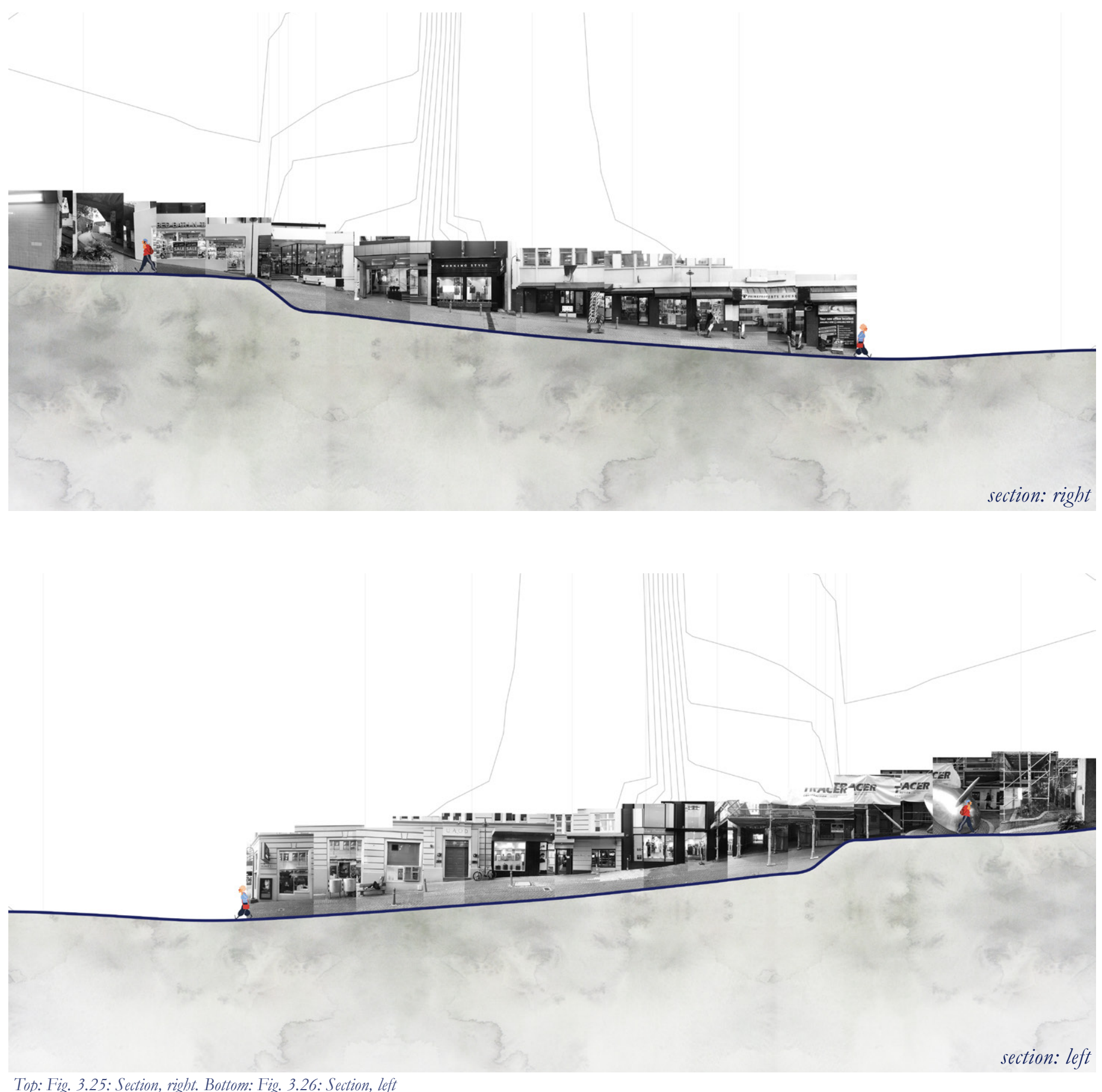

As Lambton Quay follows the original shoreline of Wellington, the original intersection of Lambton Quay and Woodward Street was where the Kumutoto Stream entered the harbour.

Up until 1853, Kumutoto kāinga; a Maori fishing village, was located at the very mouth of the stream (Wassilieff, 2006). On the ridge above the street, which is now The Terrace, Kumutoto Pā once overlooked the stream (Holder, 2014). The kāinga was a known boat landing site and flax collecting area it was a central point amongst a network of flax stations throughout the North Island (Love, n. d.). The site ceased to exist as an occupied kāinga following the departure of Wi Tako Ngatata in 1853, the Te Atiawa Chief (Love, n.d)

The present name; Woodward Street, was selected to honour Jonas Woodward, an English settler who arrived on the Clifton in 1842 (Holder, 2014). Woodward was a strong presence in the administrative activities of early Wellington.

In 2014 a sound installation project by Wellington artist Kedron Parke was installed to allude to the previous presence of the stream.
The art installation is still present, sampling sounds of local birds and running streams, creating an imagined environment reminiscen of the sites' rich history (Holder, 2014). Kumutoto Stream still exists, but is culverted beneath the streets to an outlet at Kumutoto Wharf it was the first stream in Wellington to be culverted, in 1866 (Holder, 2014)

\section{sounds of local birds} and running streams, creating an imagined environment of the sites' rich history

Currently, Woodward Street still houses a potaka; spinning top sculpture by Robert Jahnke. This design references both Maori and European histories in the area through the hieroglyphics included (Holder, 2014). The spinning top also nods to the former turntable that was installed in the 1970 s to help motorists turn in the narrow cul de sac. Nowadays, the street is closed to motor vehicles, but is home to multiple popular eateries and retail locations. 


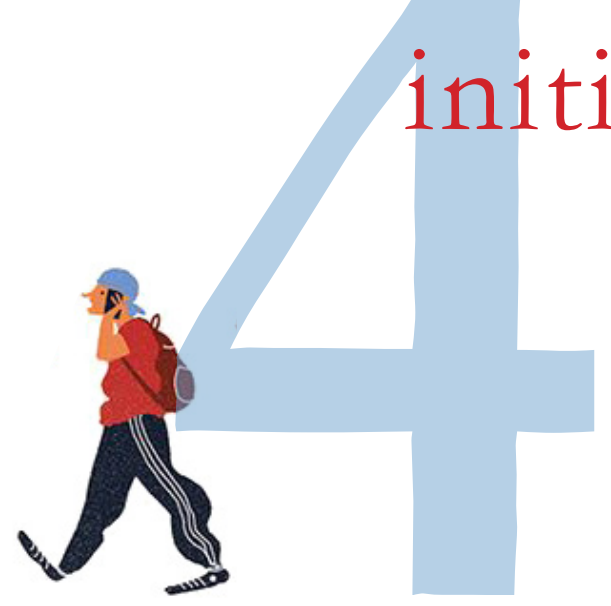

Design Tests Embodied Percestion Atmosphere and Social Encounter Imitation of Bodily Gestures Peripheral Sites

Initial Design Responses Summary: Initial Design

\section{-}


246). The test visually adapts the three dimensions; marginal consciousness, thematic field, and theme, introducing architectures to a human figure as it moves through the street (Peri Bader, 2015, p 248). Existing and imagined elements explore the disruptions they cause that ripple out across the streetscape, transforming the entire site as one experiences it.

Test 2 has been adapted to be a step forward from the two parts performed at the case study stage. For the selected sites, imagery from the second part of the earlier test is collaged over existing site photos to dissolve materials, drawing affect from the existing condition. Thi imagines how the site could morph into something new, with intensified affective charges. Through the affective charges. Through the
transformation created on the sites, we are reintroduced to our part in the world, "[passing] into the landscape as the landscape passes through us" (Frichot, 2008, passes through us" (Frichot, 2008,
p. 35). The collages explore space, threshold, colour and light.

Test $\mathrm{C}$ intervenes at the closer scale of the human body and gestural movement. Through this, surfaces on the sites are manipulated in response to typical gestures and movements of occupants. Here, affect is of push in the world", where individual gestural actions can inform architectural design (Kraft and Adey, 2008, p. 215). 


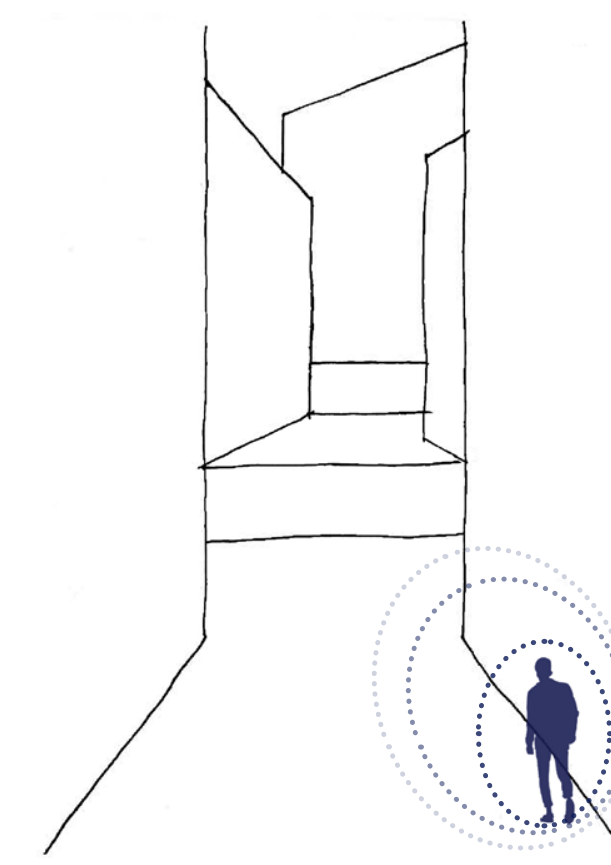

laneway enclosure

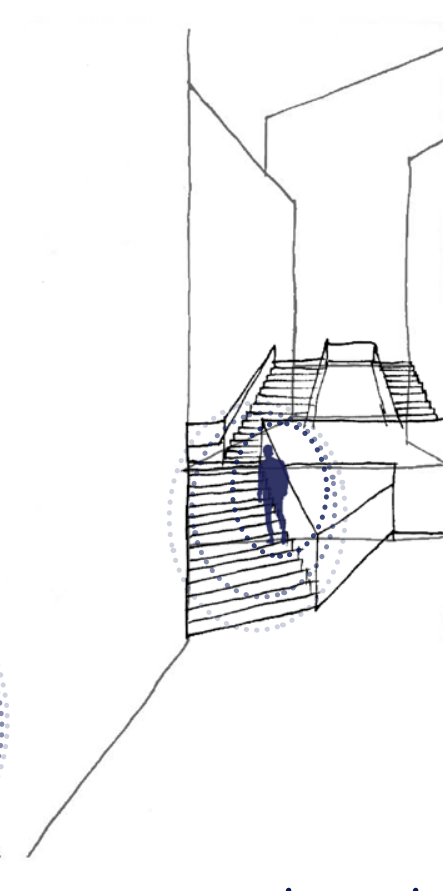

access via stairway

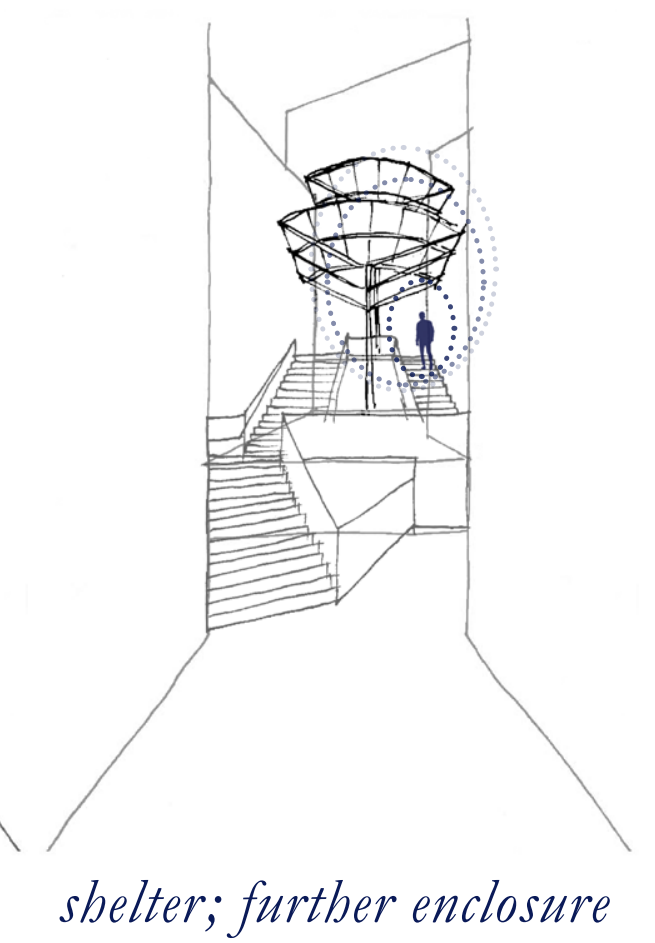

shelter; further enclosure

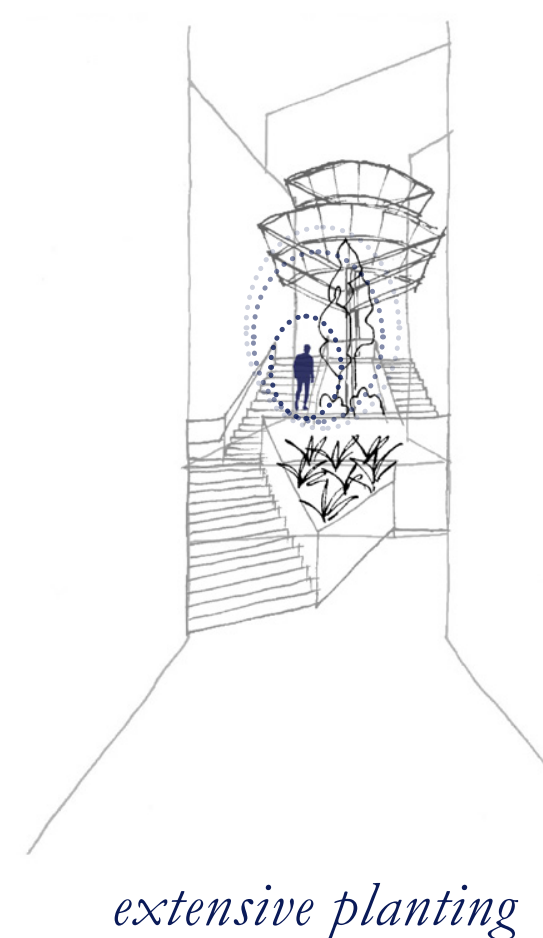

extensive planting

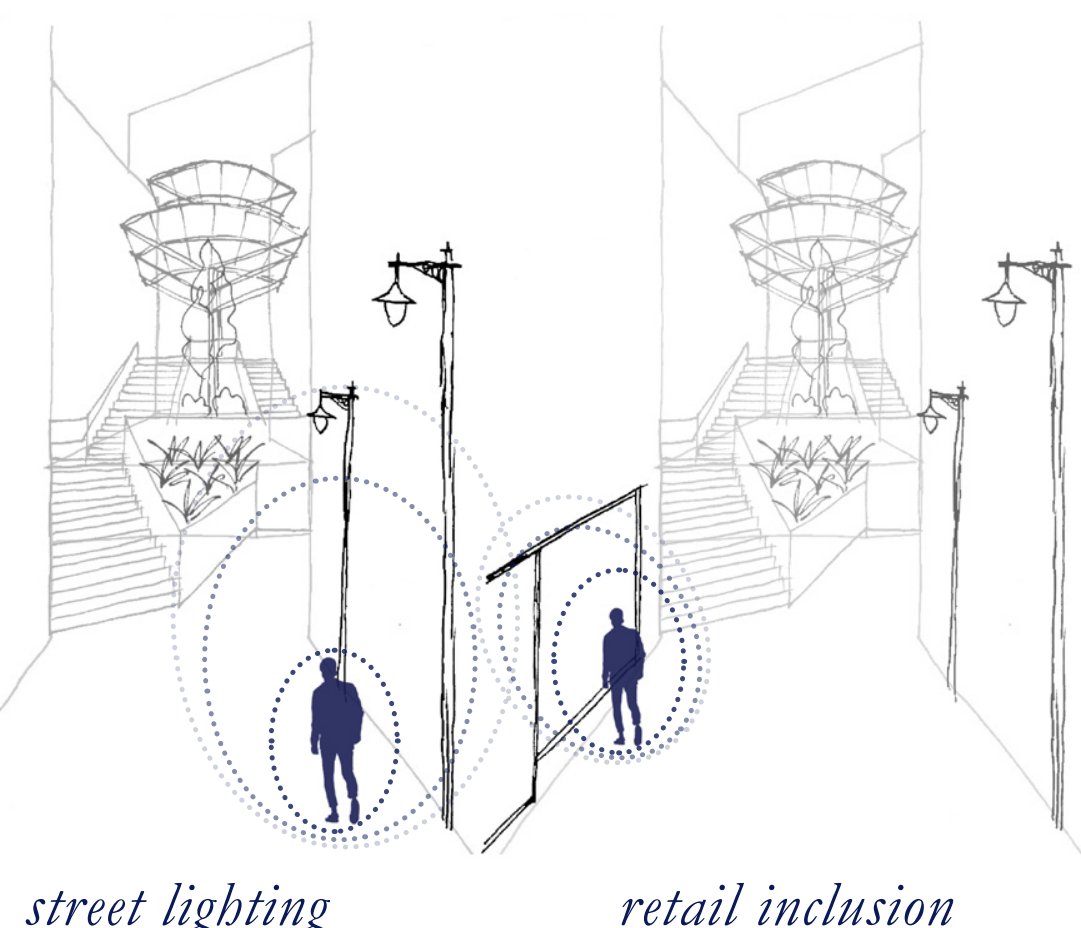

street lighting retail inclusion
1C embodied perception
The architecture of Plimmer Steps is characteristic of a laneway, with a narrow access route ranging from $4 \mathrm{~m}$ to $11 \mathrm{~m}$ in width. The current design includes access via stairs and sloped walkways, planting, shelter, and access to businesses, where

Fig, 4.01 - 4.06: Test A, Plimmer Steps. Dimensions relevant architectures interact with the main thoroughfare, creating some porosity. As one traverses the access route, countless architectural elements move into the focal dimension theme, demanding attention and affective interaction. 


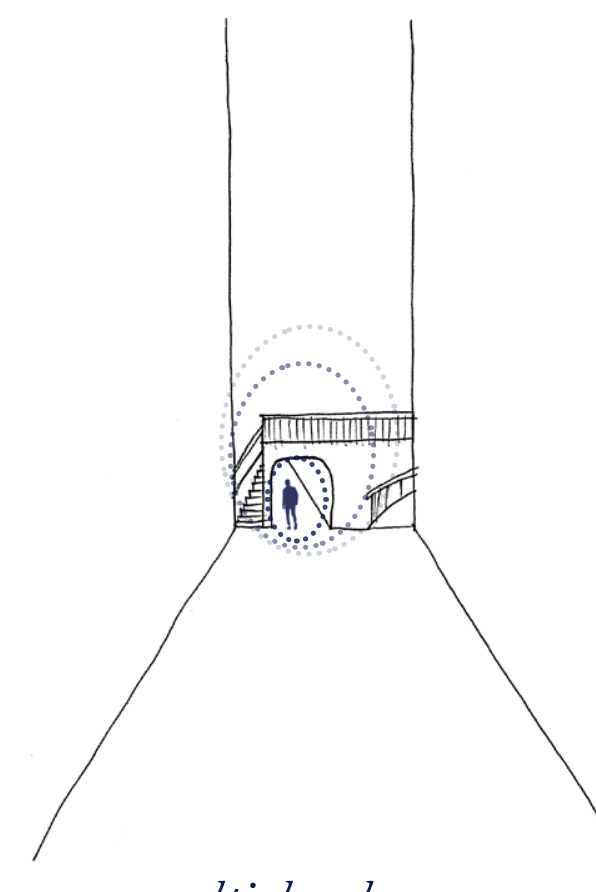

multi-level access

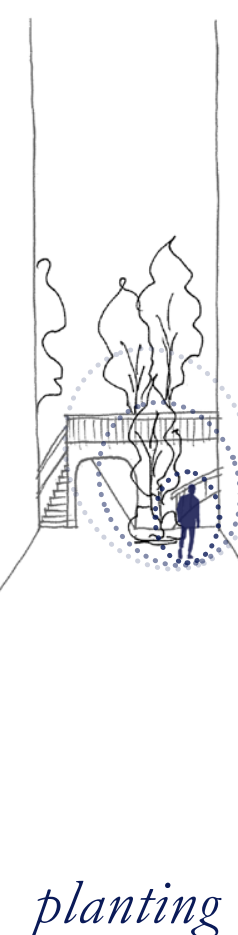

planting

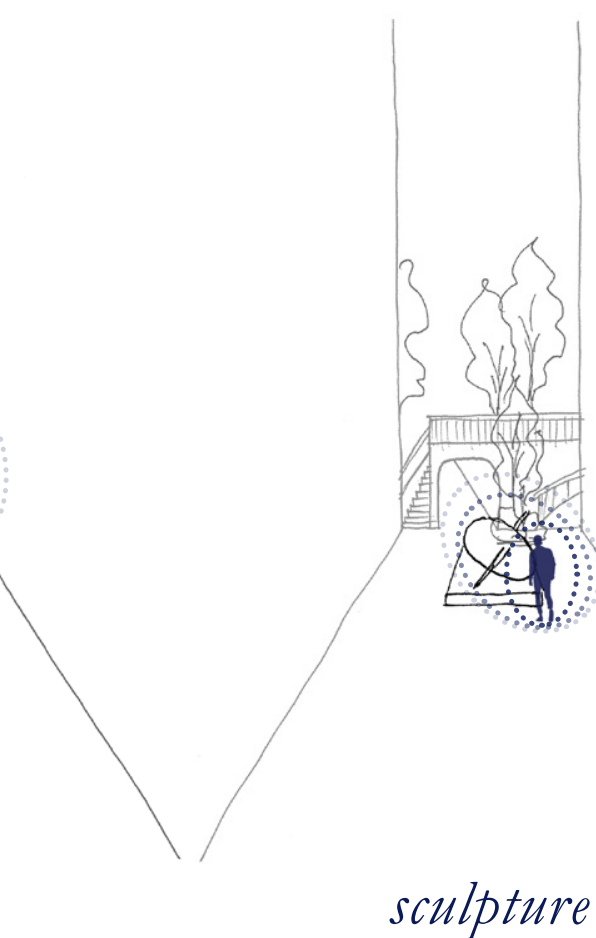

sculpture

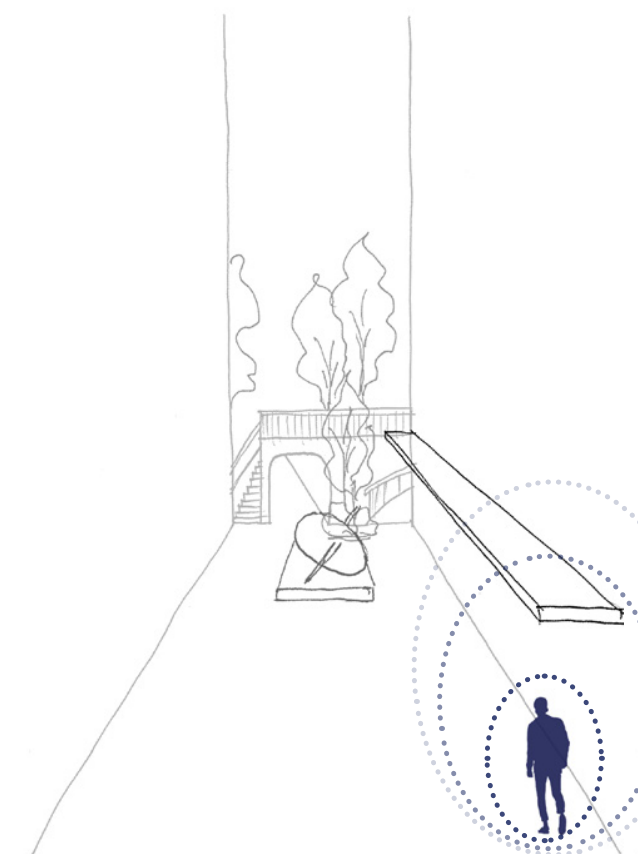

shelter; business interaction

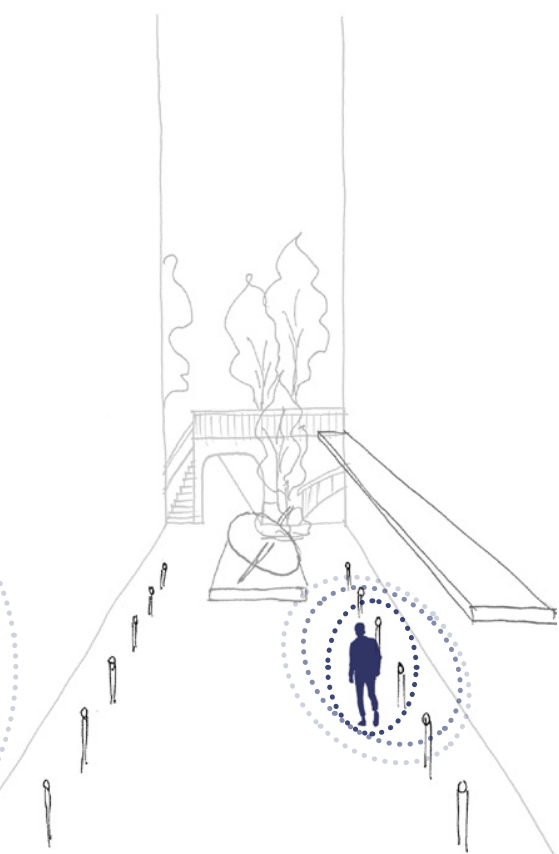

spatial separation

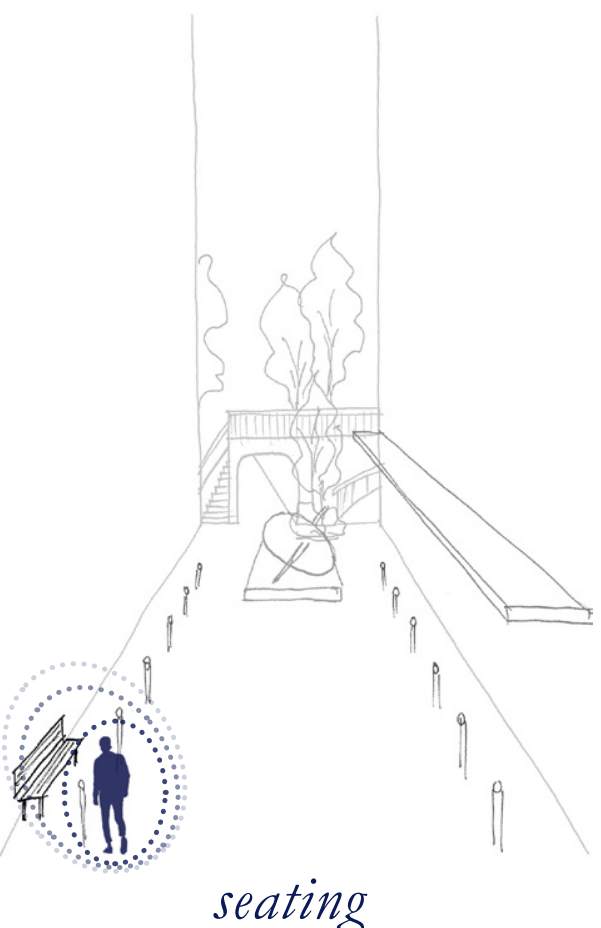

Woodward Street tends to be more populated that Plimmer Steps; its gentle slope is more inviting, and it is shorter and more direct. Similarly, many businesses line the edges, encouraging a porous characteristic that juxtaposes the enclosed feeling

Fig, 4.07 - 4.12: Test A, Wooduard Street Dimensins of created by the height of the buildings lining the street. Architectural items of similar natures; sculpture, planting, seating, shelter, occupy this street, causing similar affective relationships, but overall affecting a differing character. 
Collaged overlay reveals opportunity for intervention; physical, ephemeral, lighting, colour. Possible affective relationships start to be drawn forward.
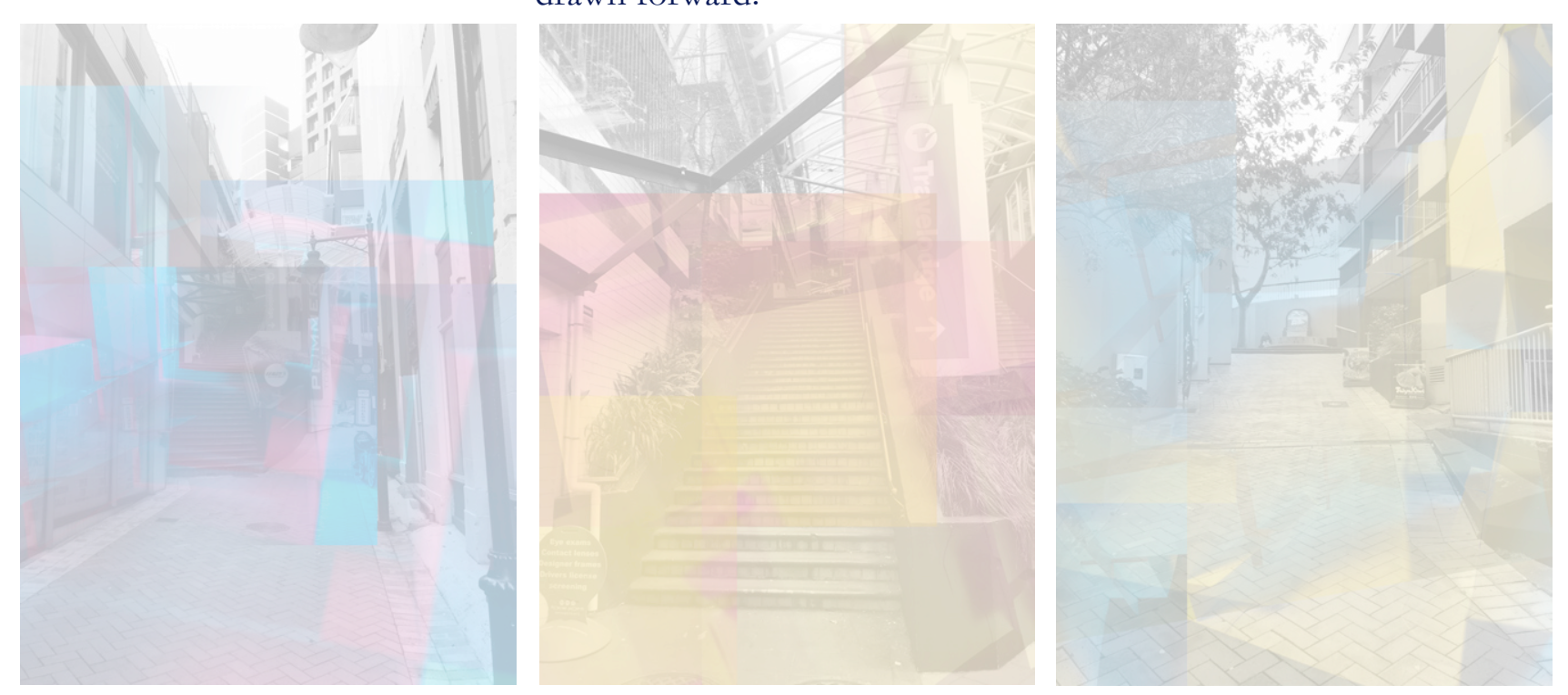

Directly off Lambton Quay, the approach to the steps is a very gentle gradient. The narrowest point of the site; there is still space for possible intervention along the walls to provide shelter and seating.
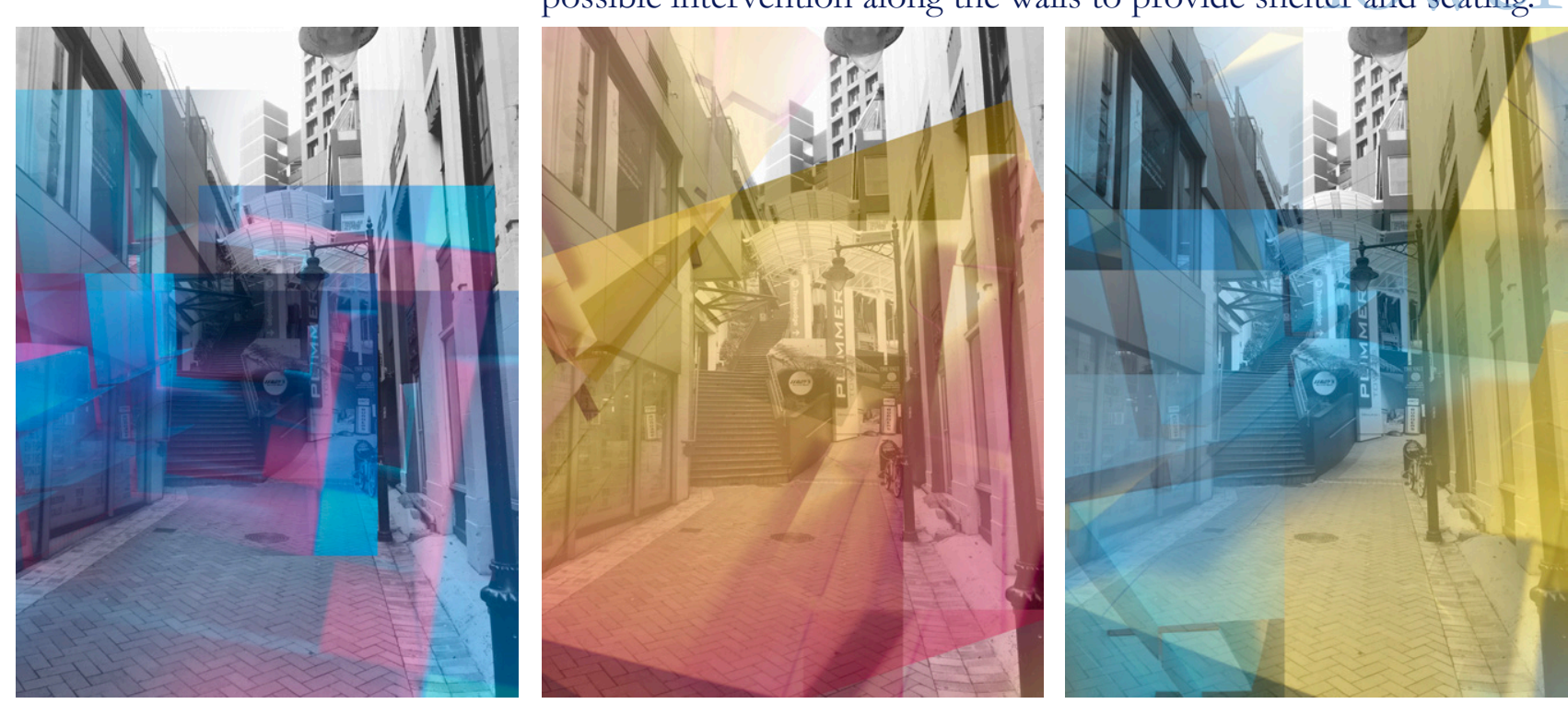

The main existing intervention at the middle point of the site is the stairway. Overlays indicate moments for lighting, colour, or physical intervenion the facitates mome of pase

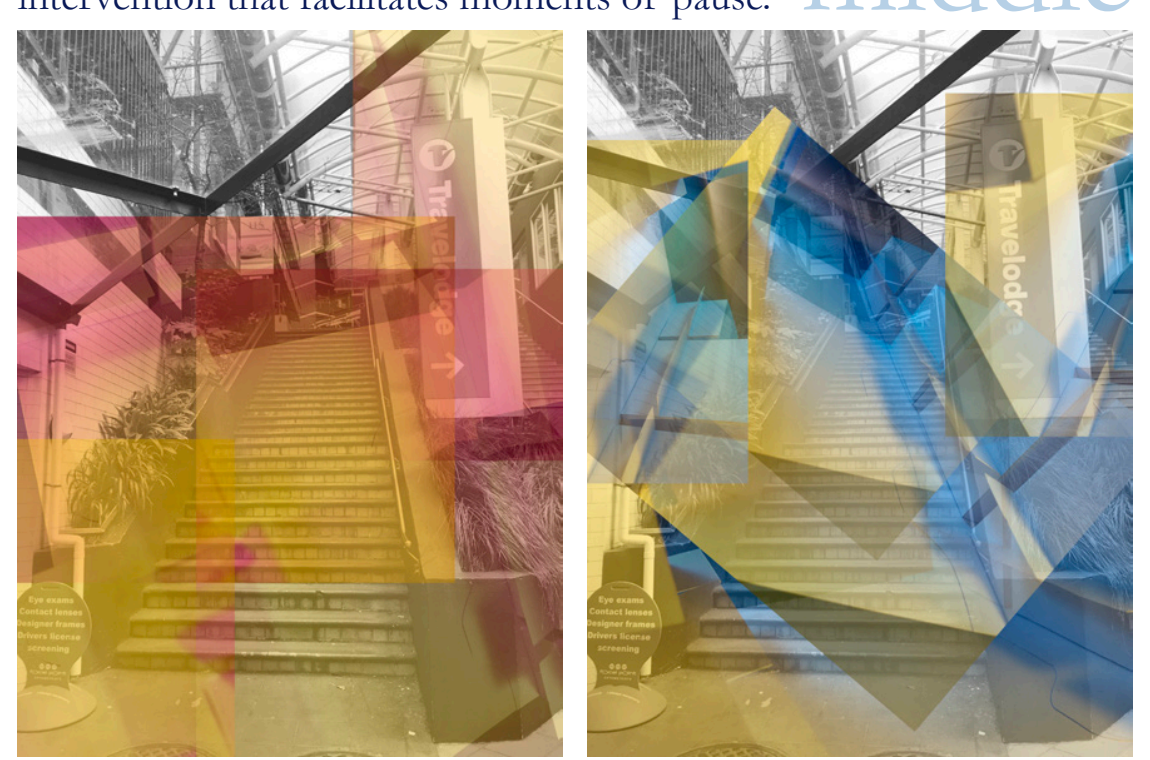

At the top of the site three businesses face the blank wall of a carpark building; intervention of colour or light could create interest. Despite the enclosure through the buildings there is a lack of shelter.

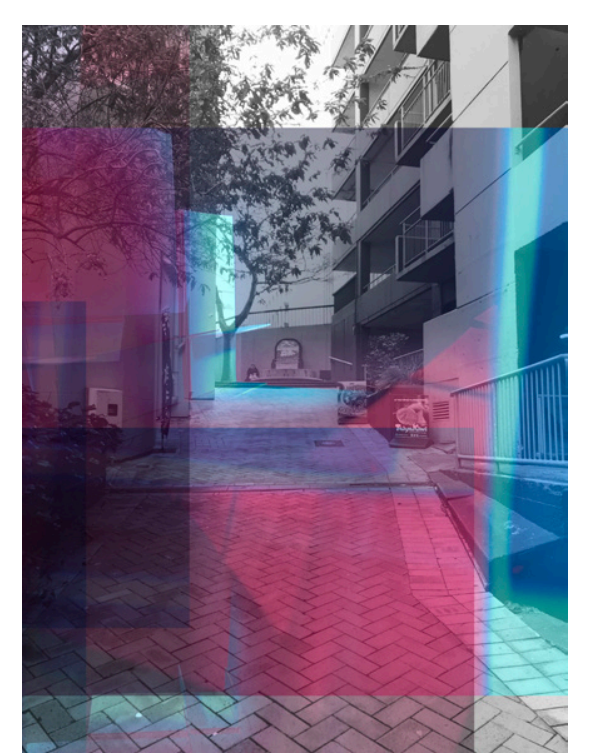

121
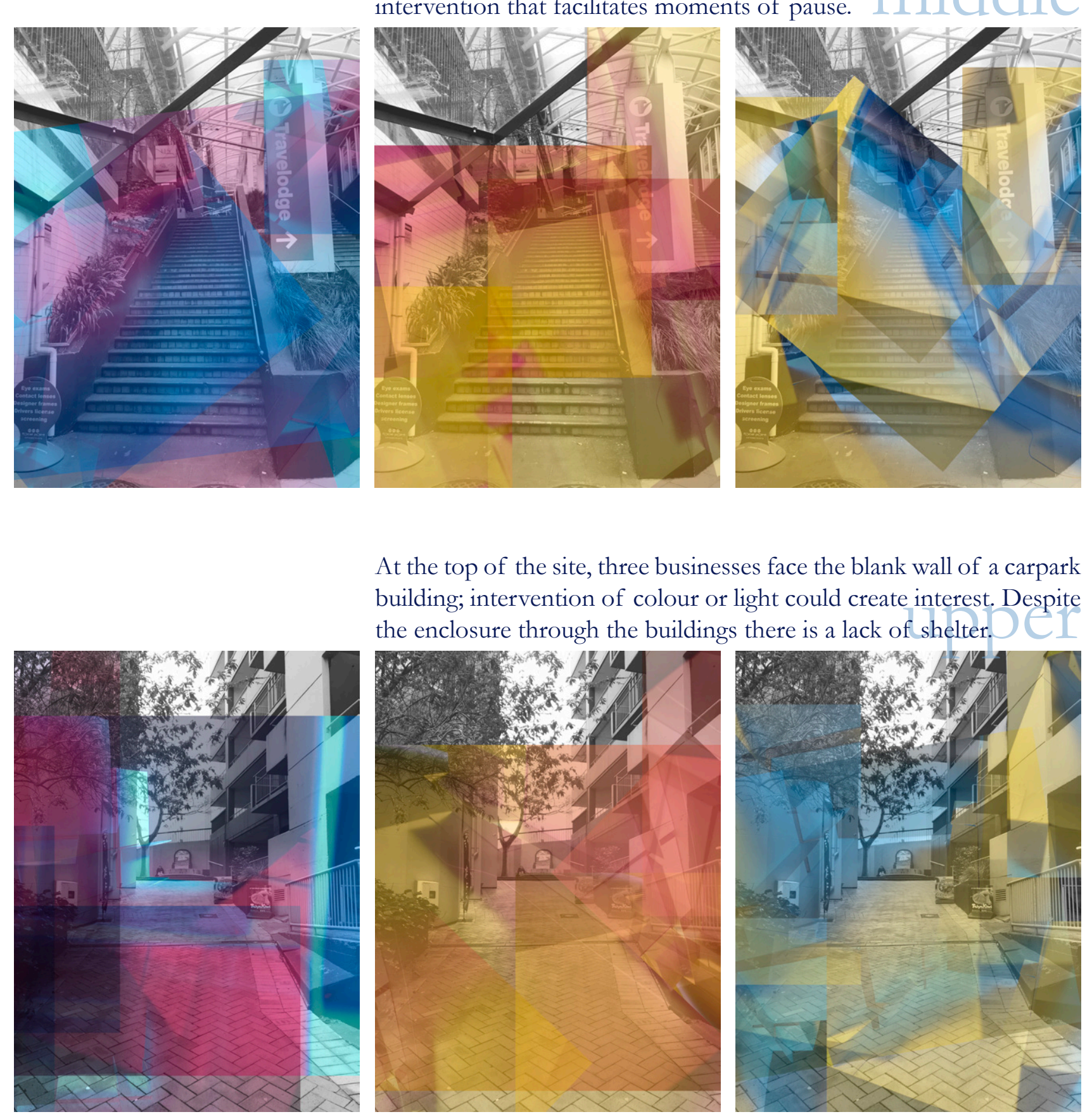
LCSt Dlimmer steps/, woodward street 
Collaged overlay reveals opportunity for intervention; physical, ephemeral, lighting, colour. Possible affective relationships start to be drawn forward.
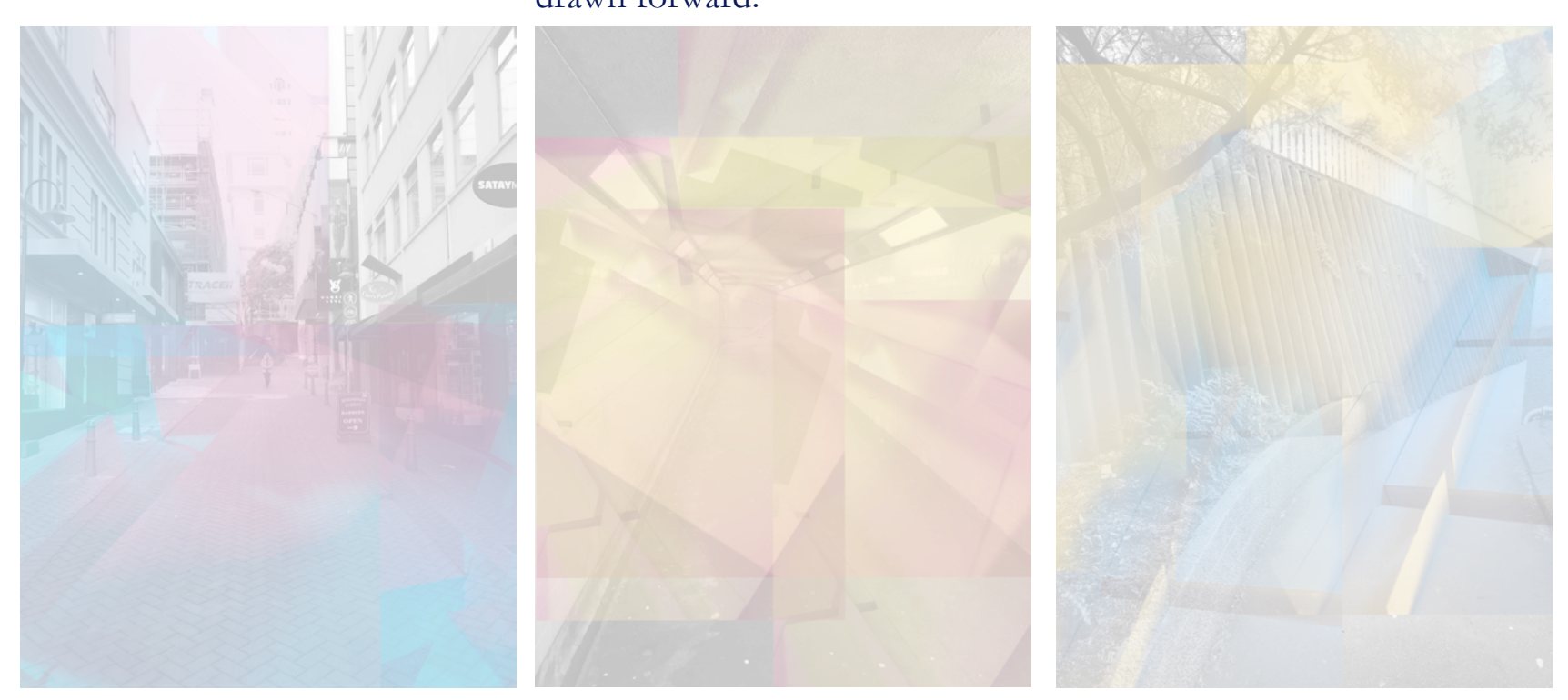

The street appears to be wide and open, and has a mostly gentle gradient. To slow the flow of foot traffic, colour highlights possible places for interventions that facilitate social interaction. LCC C
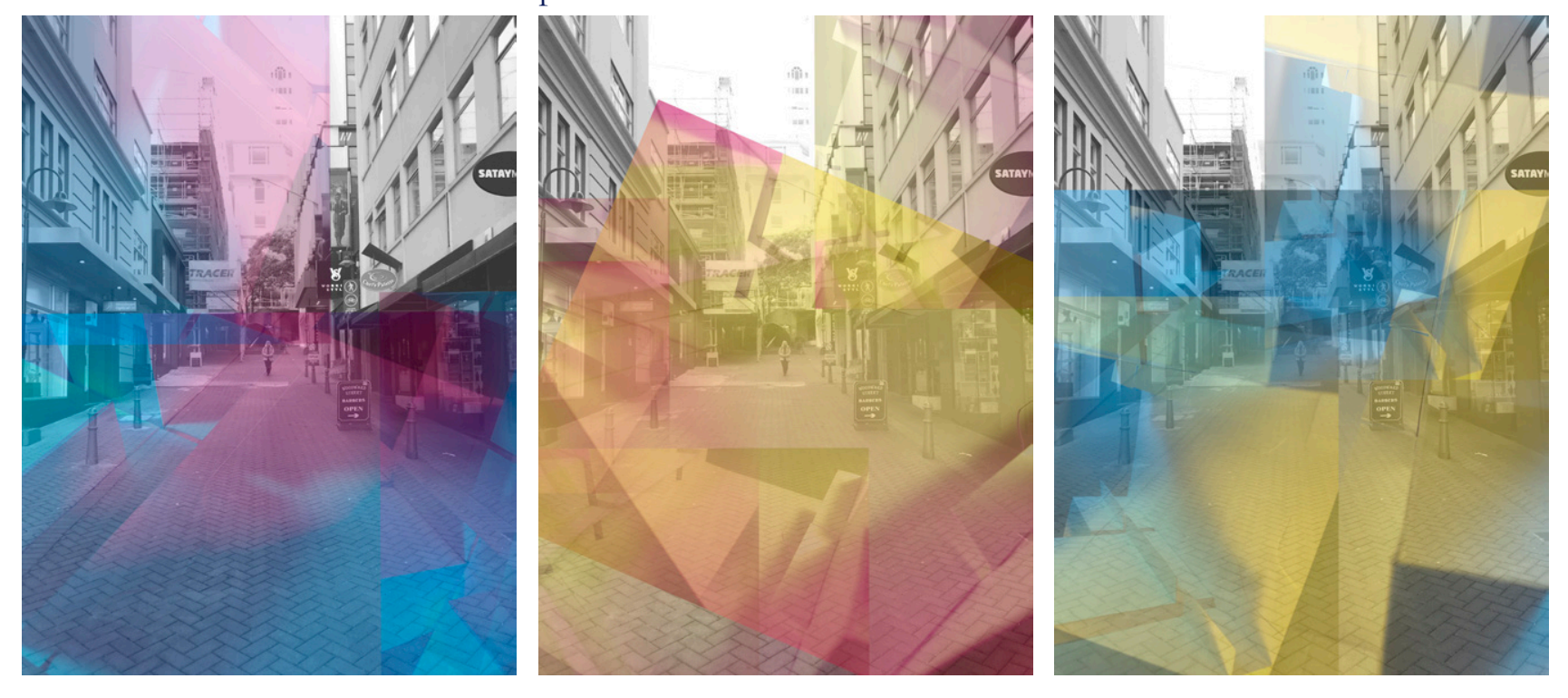

The tunnel is currently narrow and long, with a lack of visibility at the opposite end. There is little space for physical intervention. The colour overlay starts to effect atmospheric possibilities; lighting, sound. CI
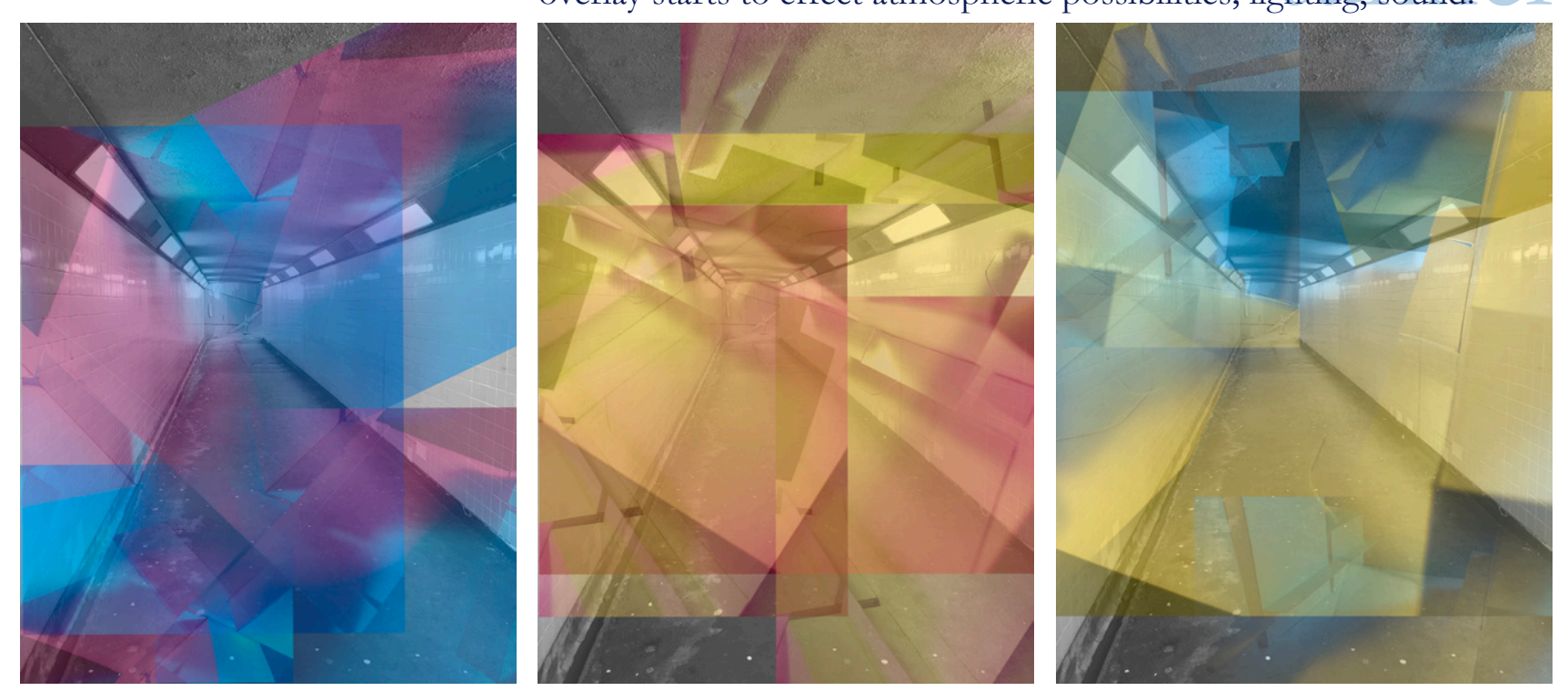

Here there is clearly an opportunity to bring the sloped wall surface and ground surface closer together in their interaction; through use of colour, materiality, manipulations to the surfaces... C C CIO1
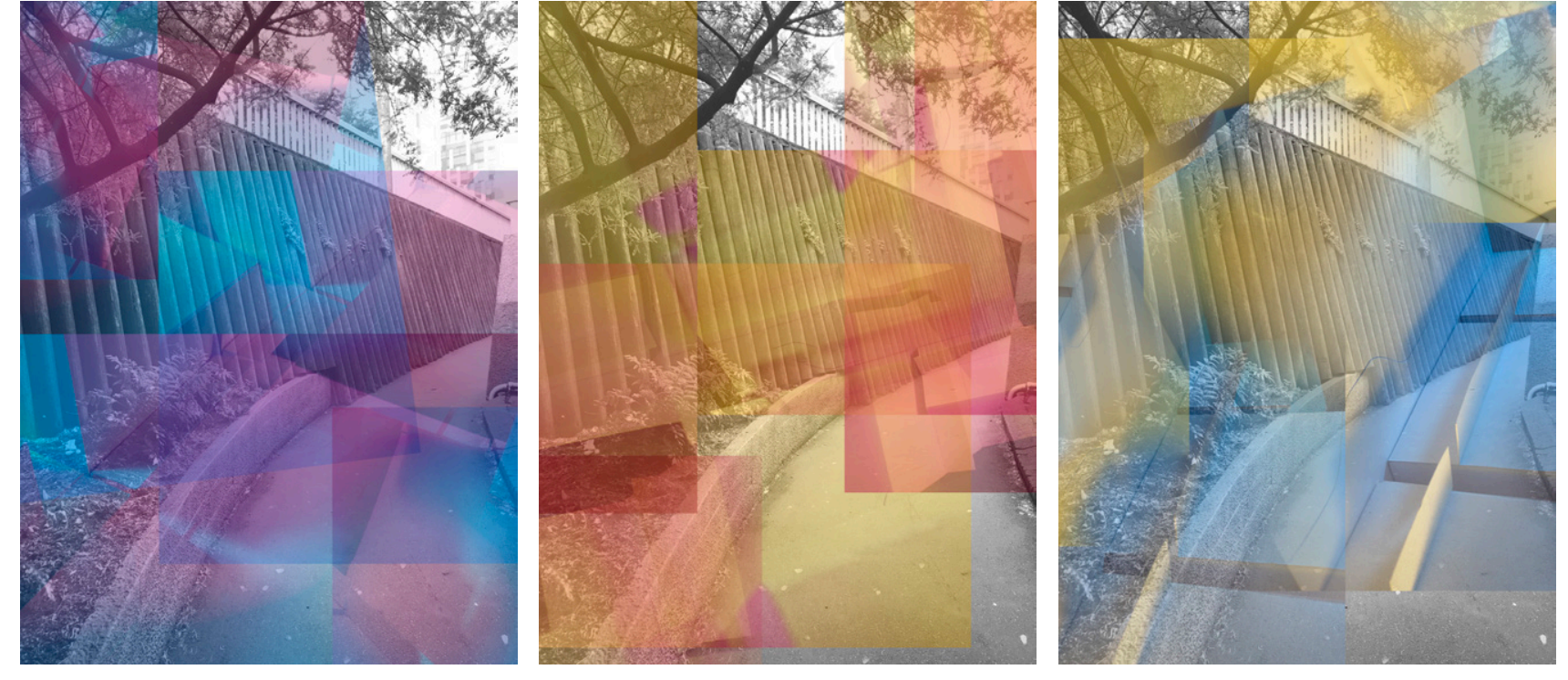

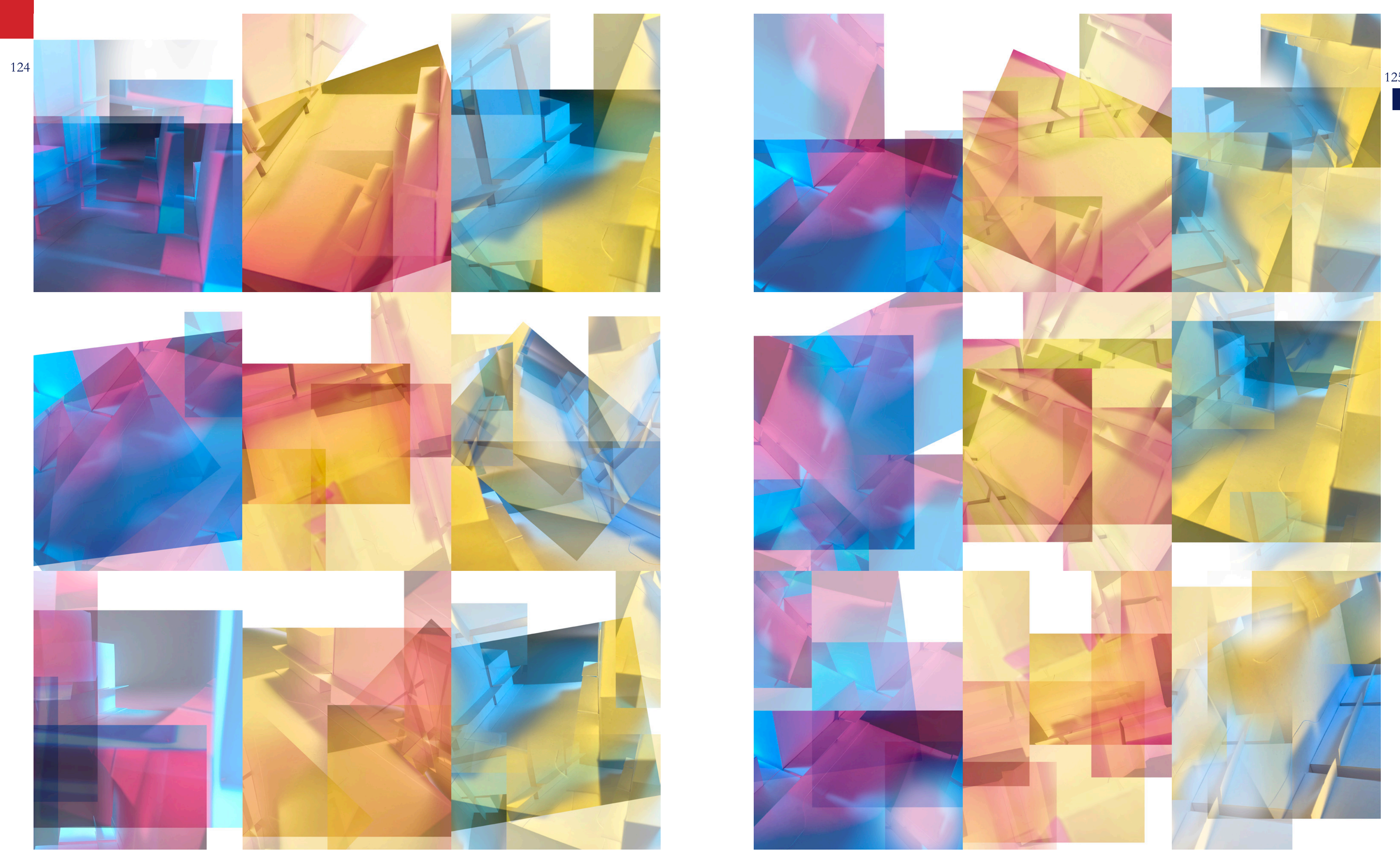

\section{a}

Fig, 4.31-4.48: Test B. Photographs of indicative street model with lighting application, collaged. 


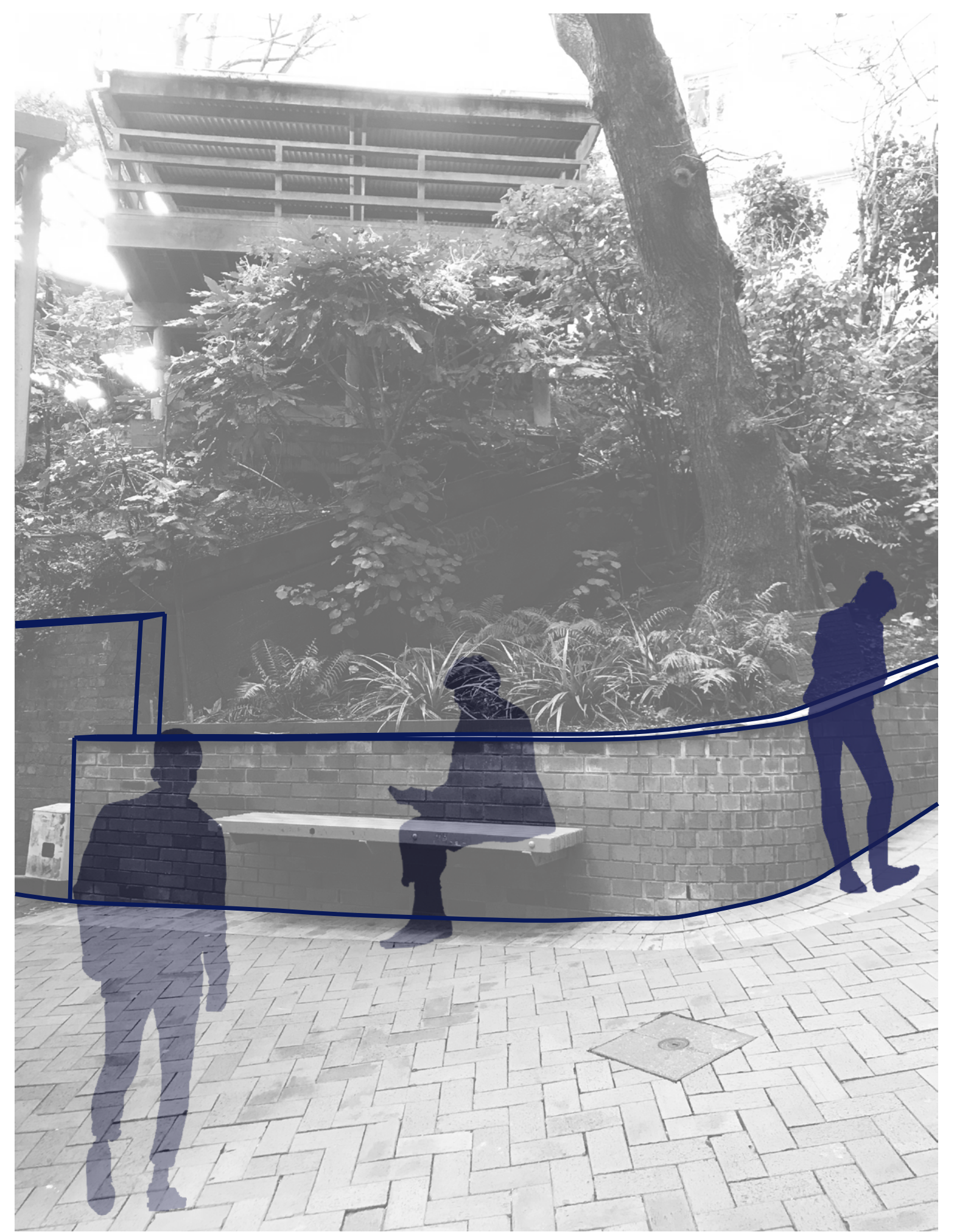

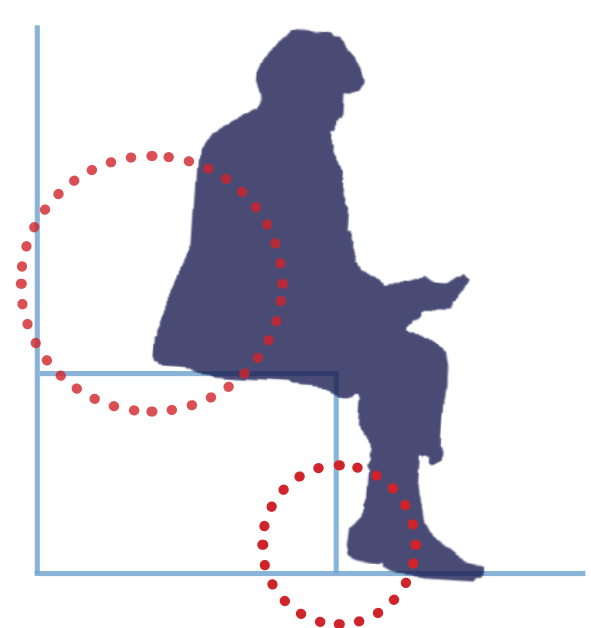

seating

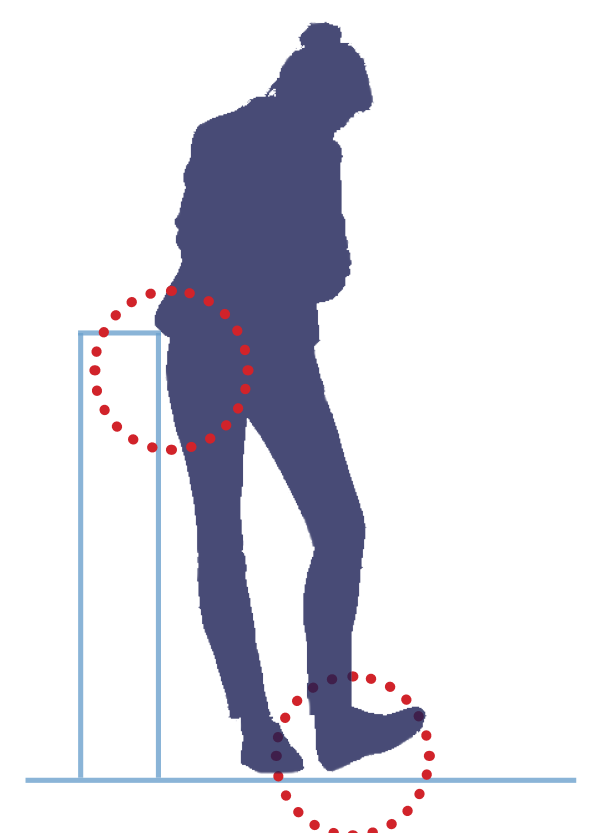

low wall; invitation to lean
Currently, Plimmer Steps presents

some small key moments where the

scale of the human body becomes

apparent, and is essential to the

possible design decisions. Partway

up, the planted area is retained by

a low wall, with one small bench provided. 


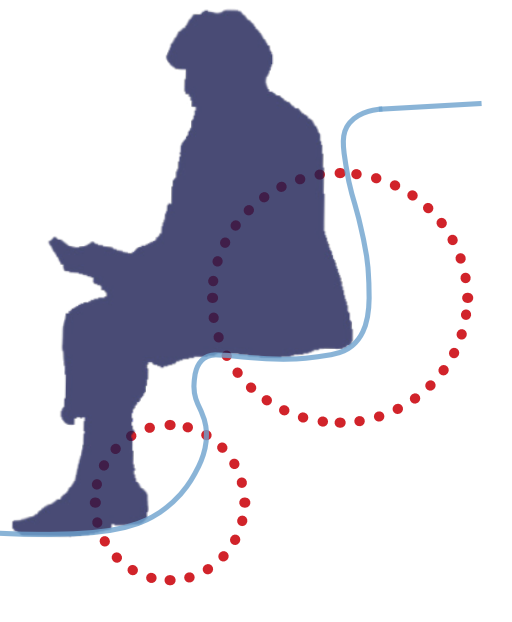

seating; read, use phone

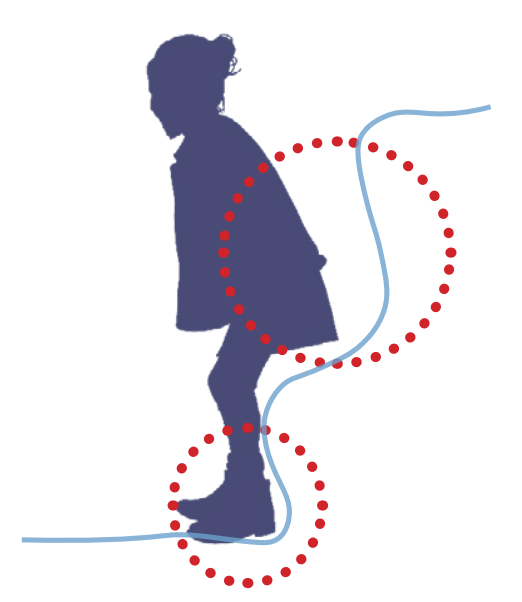

lower seating / leaning; children

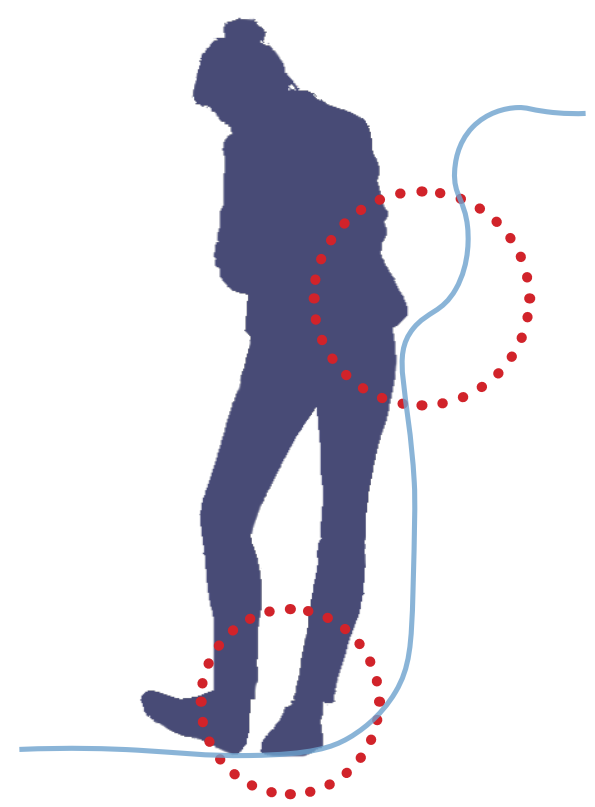

leaning; conversation

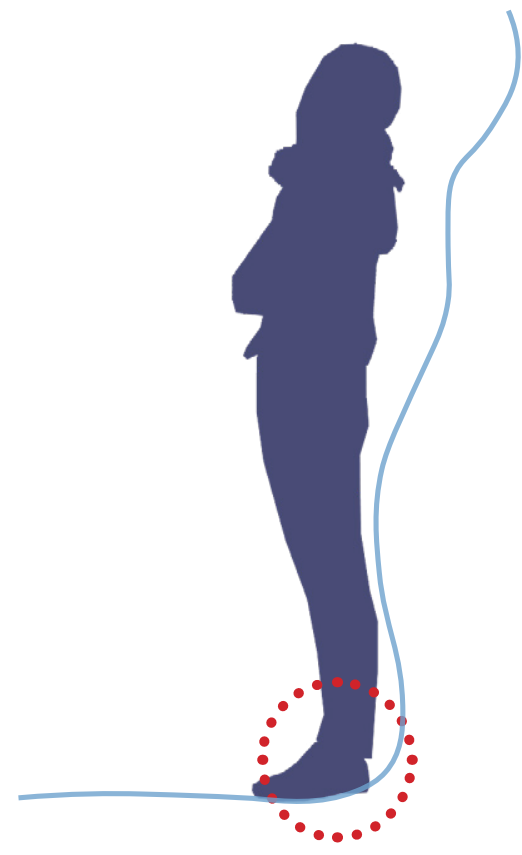

leaning; social interaction, meet colleague

Here, the ground surface, wall, and seat are very separate architectural surfaces, with little interaction. Reinterpretation of the surface as one unfolding opportunity opens up the possibility for places to stand,

lean, sit, recline, play, move... the gestural possibilities seem endless.

129 


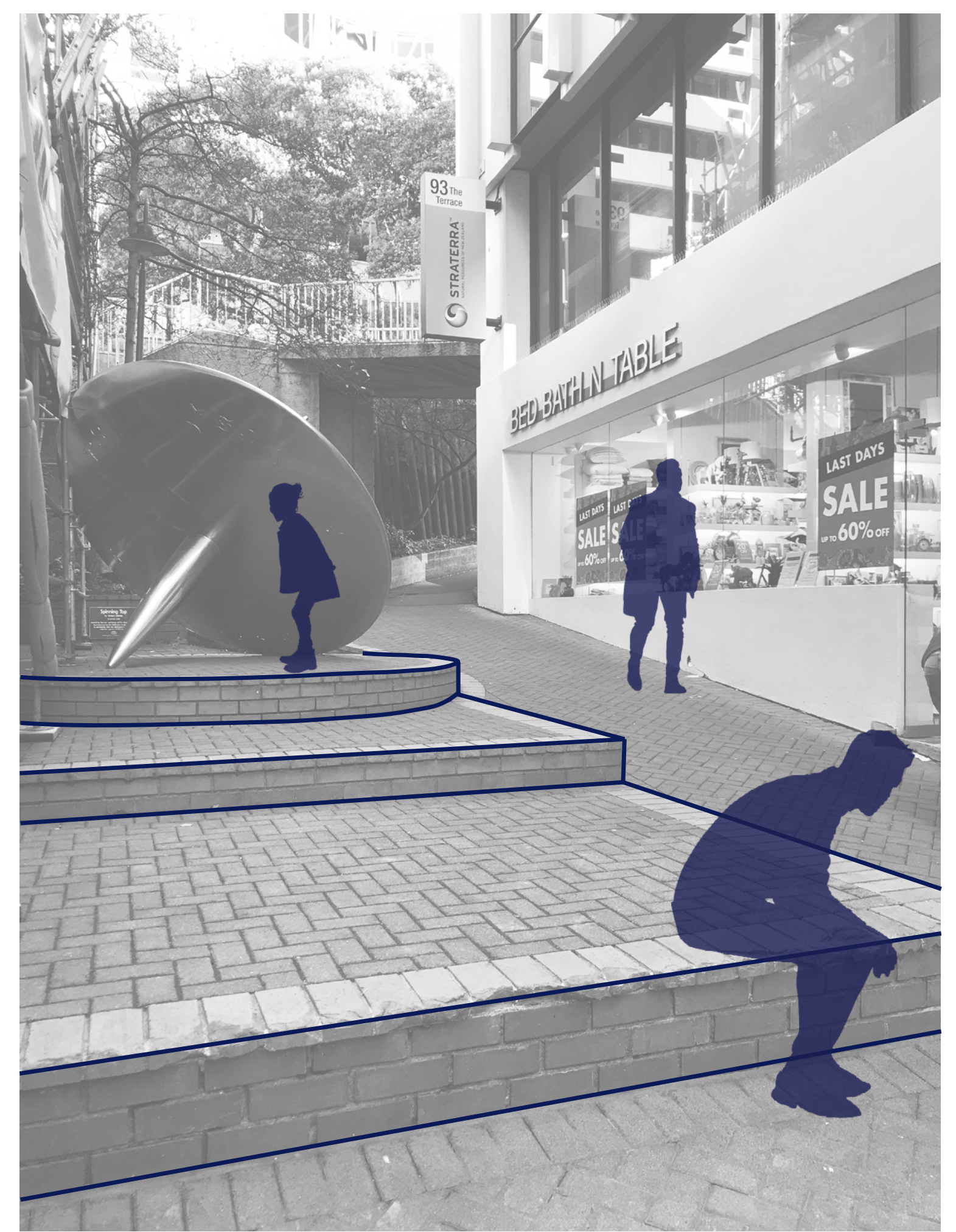

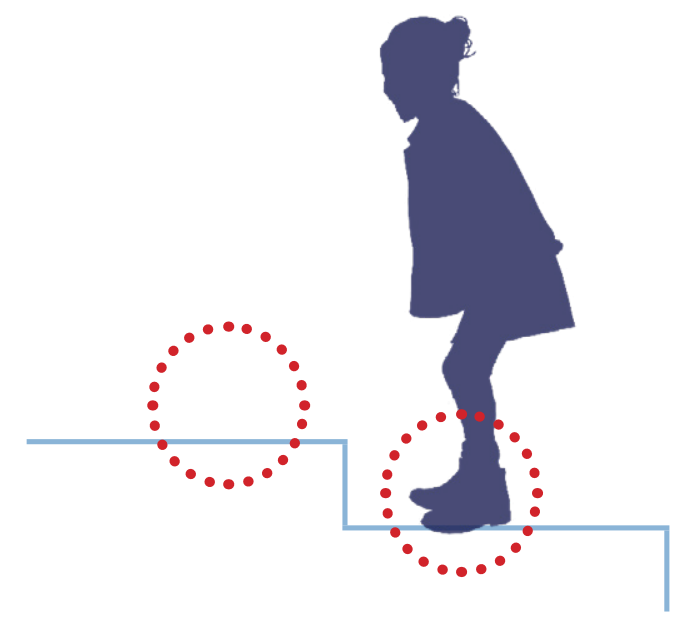

steps; access, play

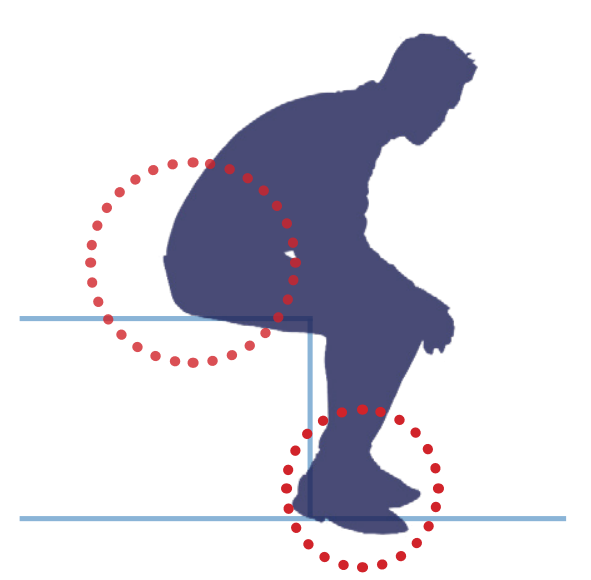

step; opportunity to sit
Near the top of Woodward Street, the steepness of the slope increases slightly, and the centre of the street changes to a stepped terrace area. This provides an alternative access possibility, but is less direct, due to the placement of the sculpture, so is more of a social space. 


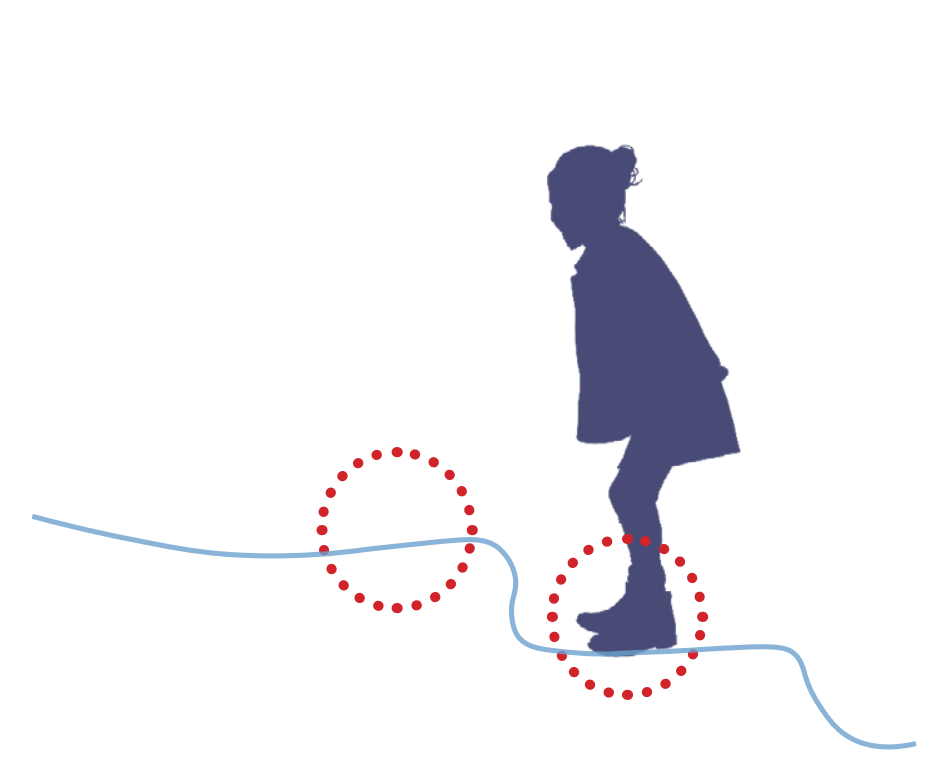

manipulated stepped surface; play

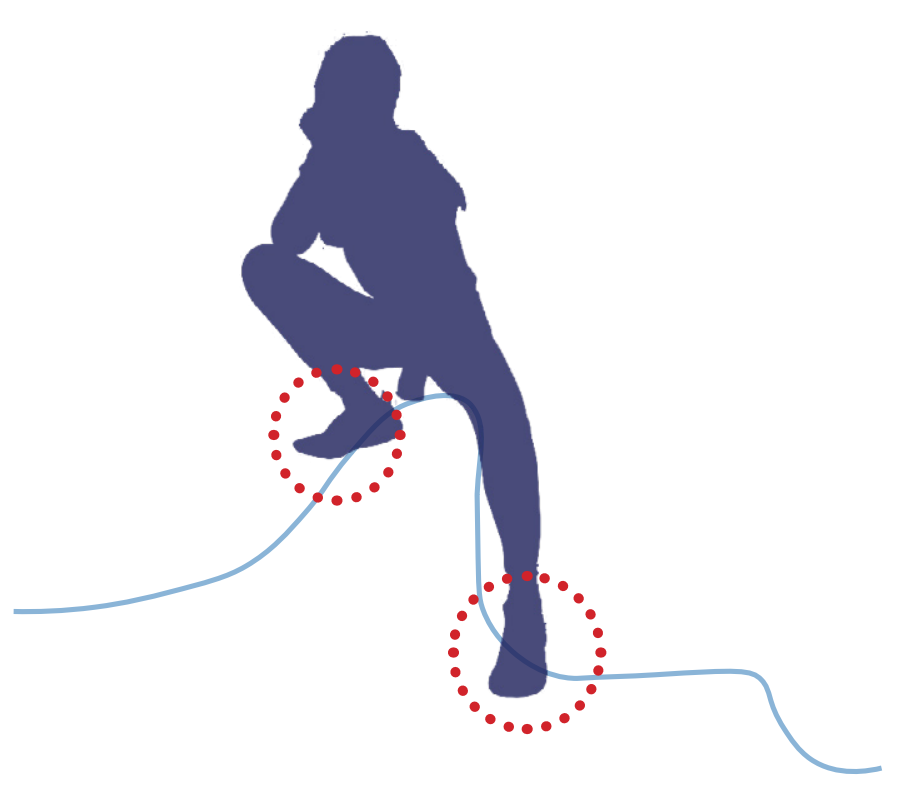

warped 'wall'; seating, leaning

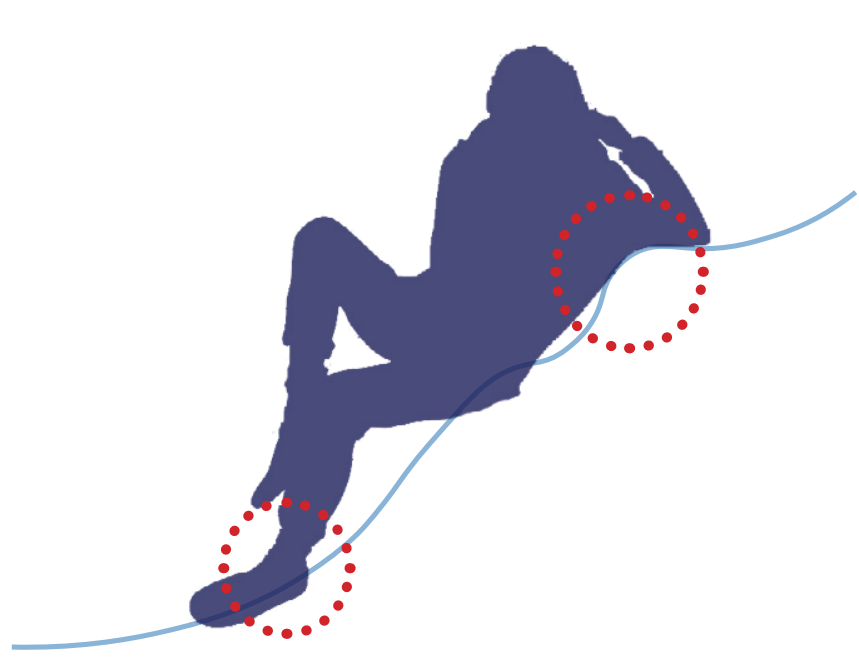

sloped surface; reclining

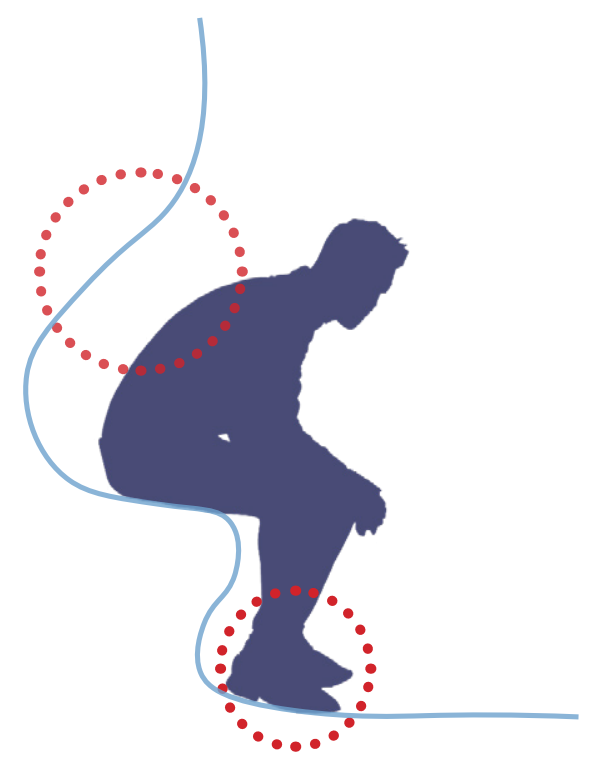

enclosure; seating

Rather than direct steps, a more manipulated surface can be provided that still gradually steps up the site, providing some flat spaces, amongst various curved and warped surfaces that encourage various activity, as the surface has been manipulated based on possible bodily gestures. 
Like all streets, Plimmer Steps and Woodward of overlapping networks of communication, transportation, production, and consumption. This "web" experience has led to the importance of flow and overlap over static spatial boundaries.

\section{These are seemingly} peripheral sites, but are in fact the spaces where people actively live; they are social spaces

A shift in the professions of landscape and urban design from the 1960s led to the consideration of the landscape as an active surface (Wall, 1999, p. 233). The urban surface, when considered this way, becomes dynamic, unfolding, and responsive; interactions between various elements are supported, and conditions that promote new relationships are formed.
Spaces that have risen in importance include the "ambiguous areas that are caught between enclaves" (Wall, 1999, p. 234). These are seemingly peripheral sites, but are in fact the spaces where people actively Pere actively he spaces (Wall, 1999, p. 235)

For the new town of Melun-Senart in France, OMA and Koolhaus flipped the "formal and structura roles of figure and ground, building and open space", giving importance to voids over buildings (see figure $\mathrm{X}$ ) (Wall, 1999, p. 238). The condition of each void slid over one anot allowing for future adaptive change.

The selected sites are exemplary of ambiguous spaces; they are pedestrian access routes, defined the architecture that encloses them. For this design test, each site has firstly been analysed to discover the overlapping spatial relationships over time, and then been considered as an active surface that may be manipulated to find moments for intervention.

\section{tes peripheral sites}

The urban surface becomes dynamic, unfolding, and responsive

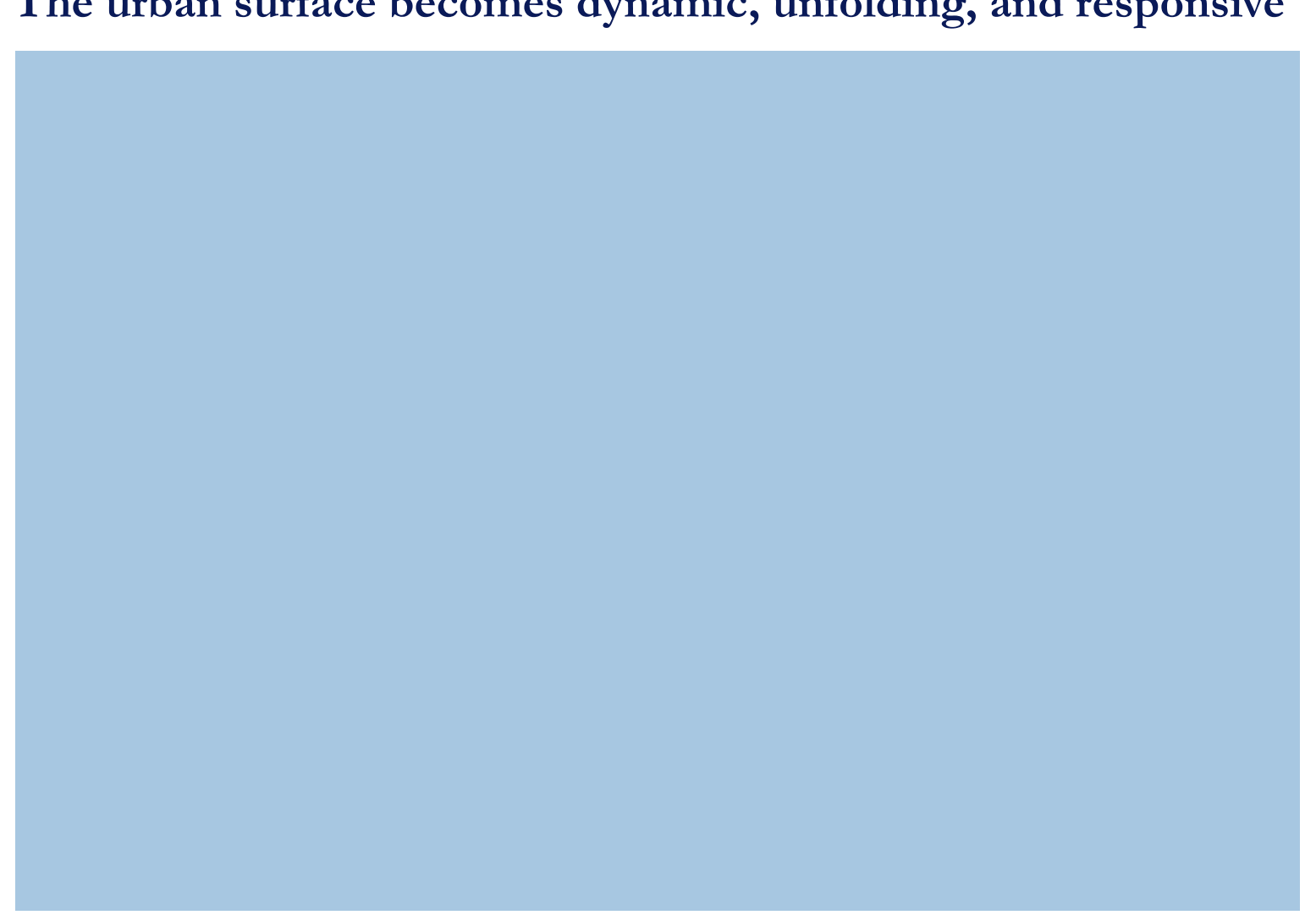


136

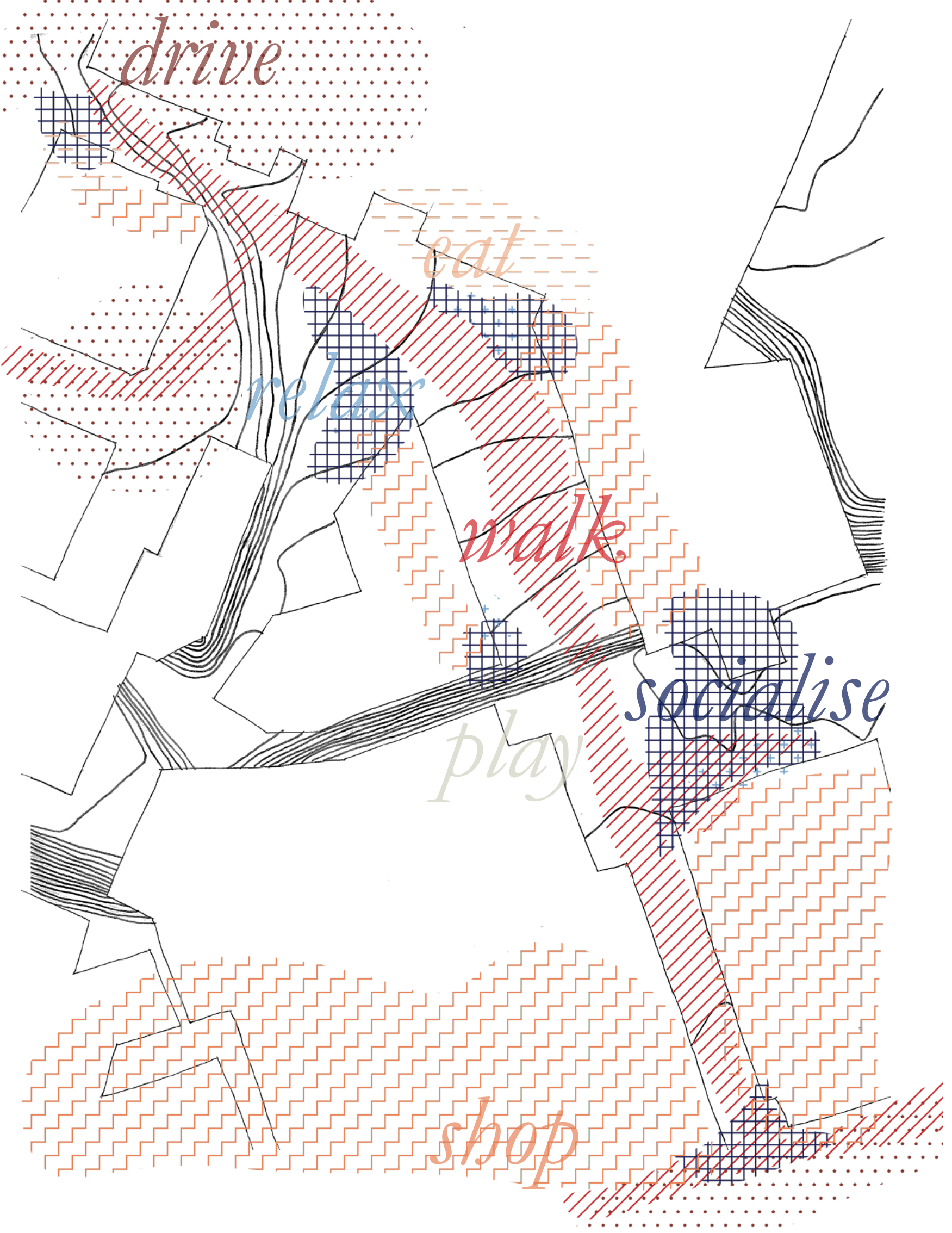

1 peripheral sites

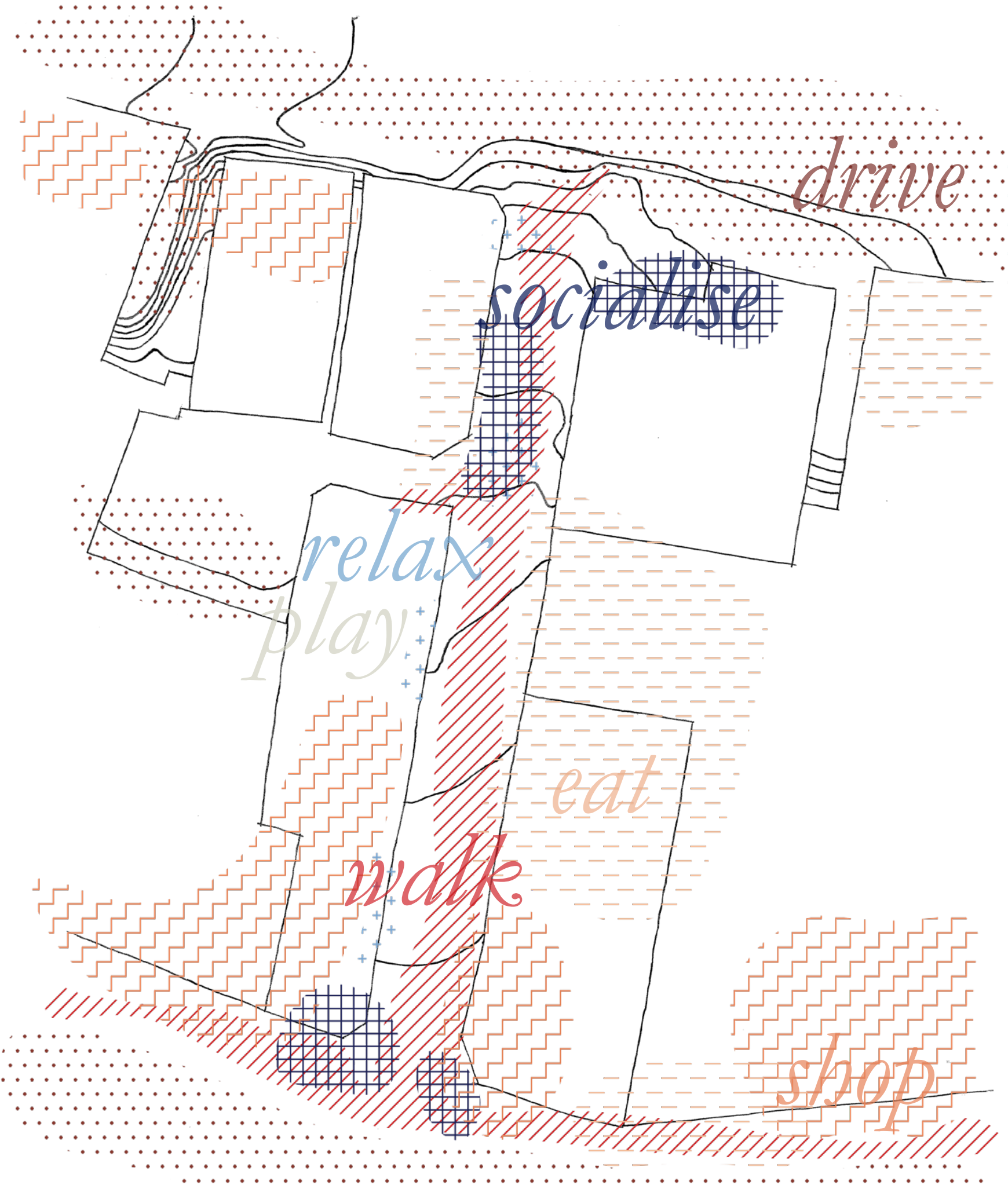

Across both sites - interaction conditions accomodating activities between multiple $\because \cdots$ activity $\because$ that can occur simultaneosily with conditions currently occur (Wall, or adjacent to, work, are presented 1999, p. 233). The ground surface This highlights potential for supports a network of activites; changes to the site that could alter both fixed and changing. Here, the space currently "assigned" to on each site, overlapping spatial each activity. 


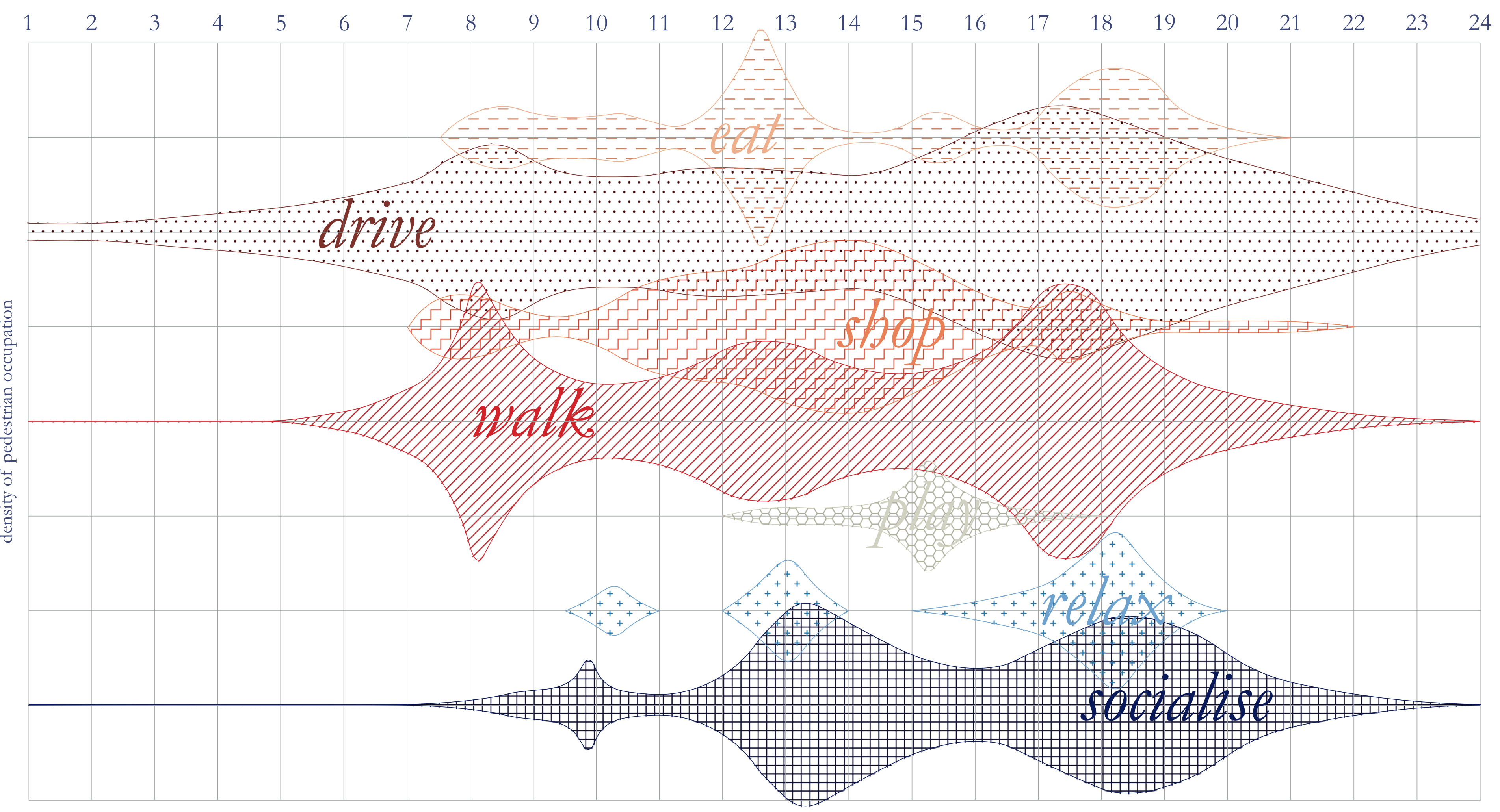

Here, a timeline is presented, bulk of activity occurs during the indicating the occurrence of day, supported by $9-5$ working hours. activities over a typical 24-hour day. Design changes to the sites that As the sites are located in the $\mathrm{CBD}$, support a responsive, dynamic, everwhere work is the main supported changing urban condition may alter activity, and the activities analysed the times activities are occurring, as are occurring alongside work, the well as the spaces they take place in. Fir. 4.67: Activities on the selected sites, matped over the 24 hours of the 


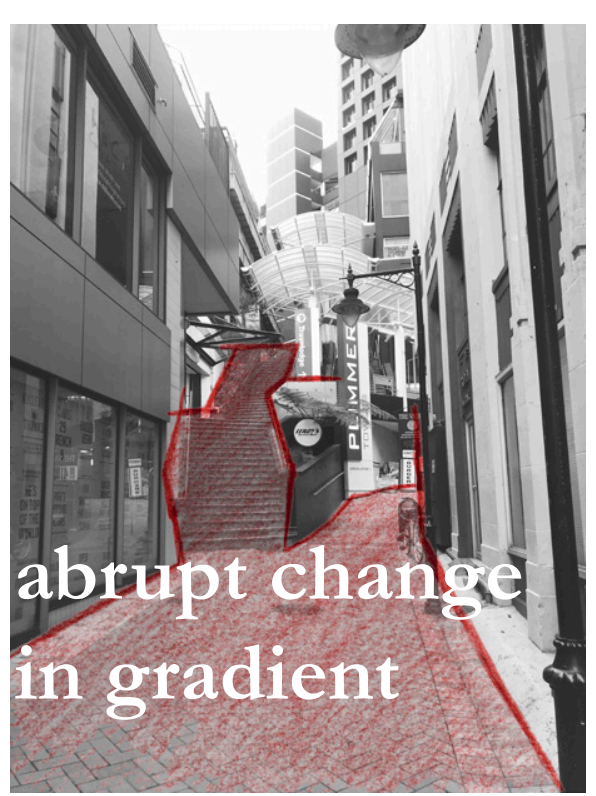

The urban surface has three key conditions across the Plimmer Steps site;

- Narrow, low gradient at the bottom

- Wider, significantly steeper, and less enclosed through the middle of the site. A feeling of enclosure is created through use of shelter and narrow staircases separated spatially.

Wider, curving and sloped from the middle There are more spaces separated out here that indicate a possibility for activities; social or working.
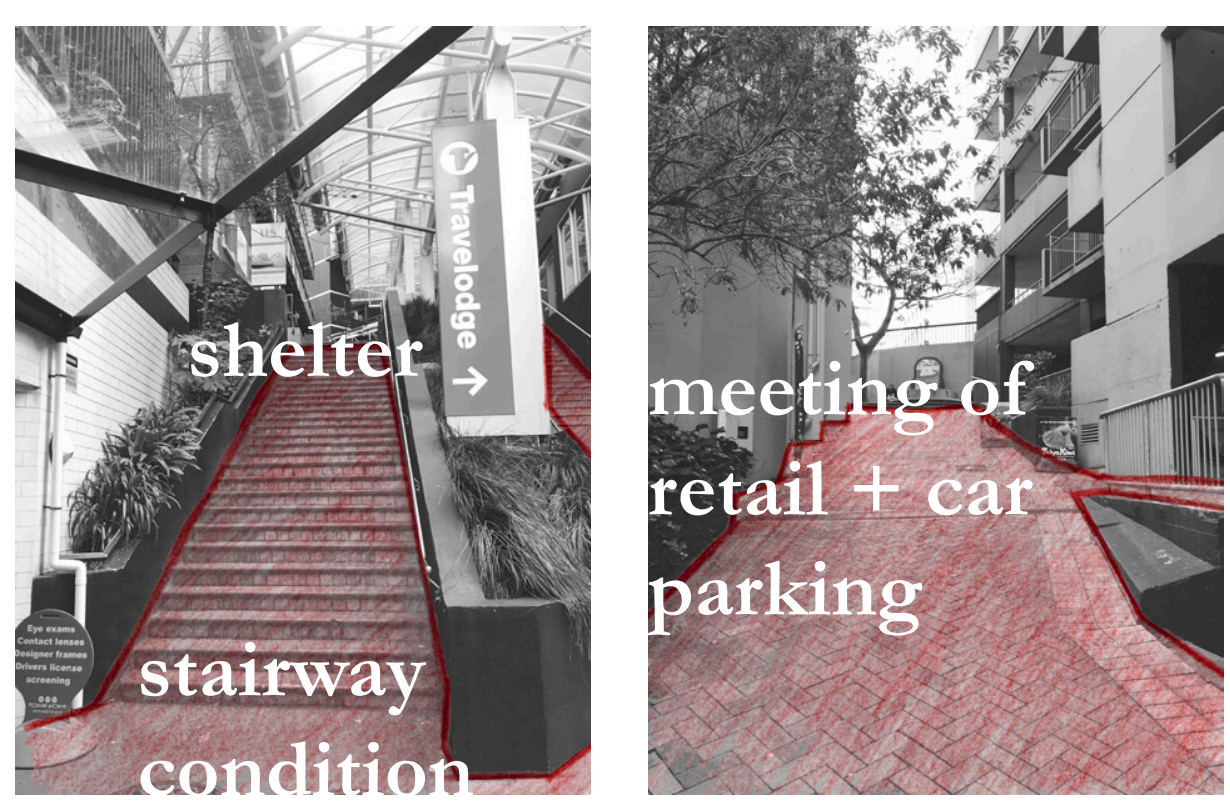

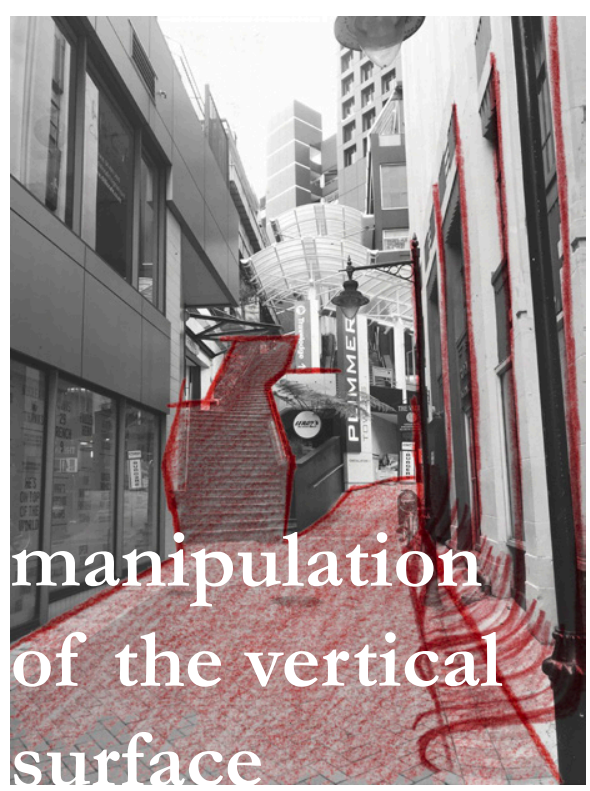

their current condition, the bottom and middle sections of the site clearly prioritise access. Intervention could emphasise the existing enclosure; utilising the walls and stairways to provide small moments of pause that promote social interaction.

At the top of the site, opposing the retail spaces, a wall treatment system could brighter up the space, and furniture and shelter could be provided to further support possibilities for various activities; social or working.
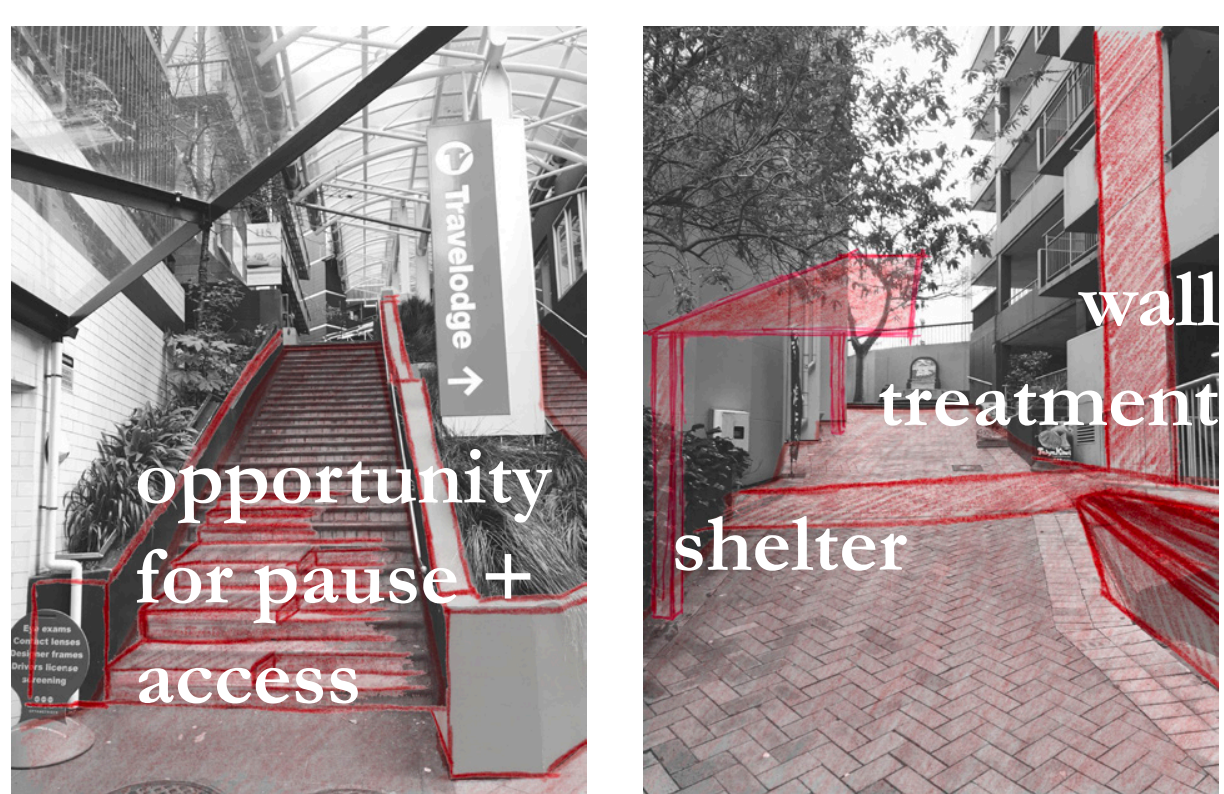


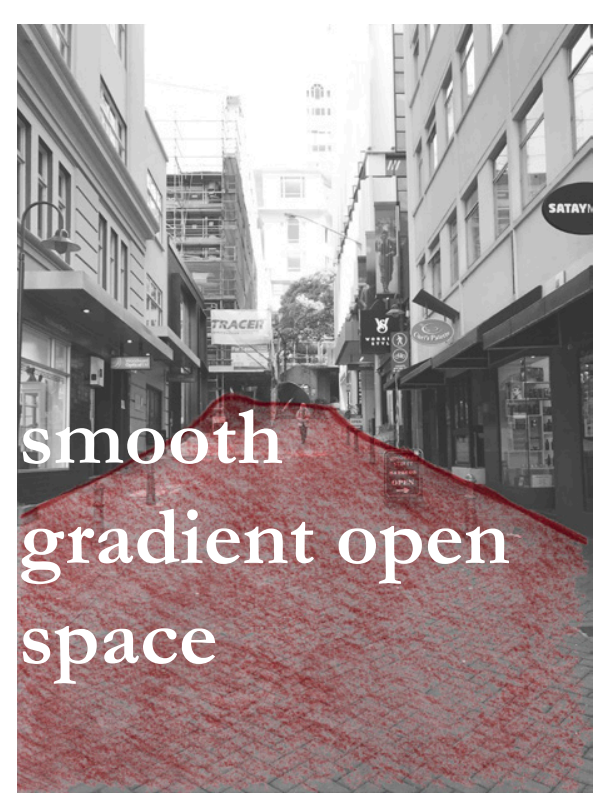

The urban surface has three key conditions across the Woodward Street Site;

- The main street space is wide, sloping, and enclosed through the height of adjacent buildings.

- The connection to The Terrace

requires a change in condition,

either through a tunnel, up a

staircase, or, up the ramp

- The ramp connection to The

Terrace is narrow and enclosed.

Both the ramp and the tunnel have

a lack of visibility, and contribute

to a complicated series of access

connections.
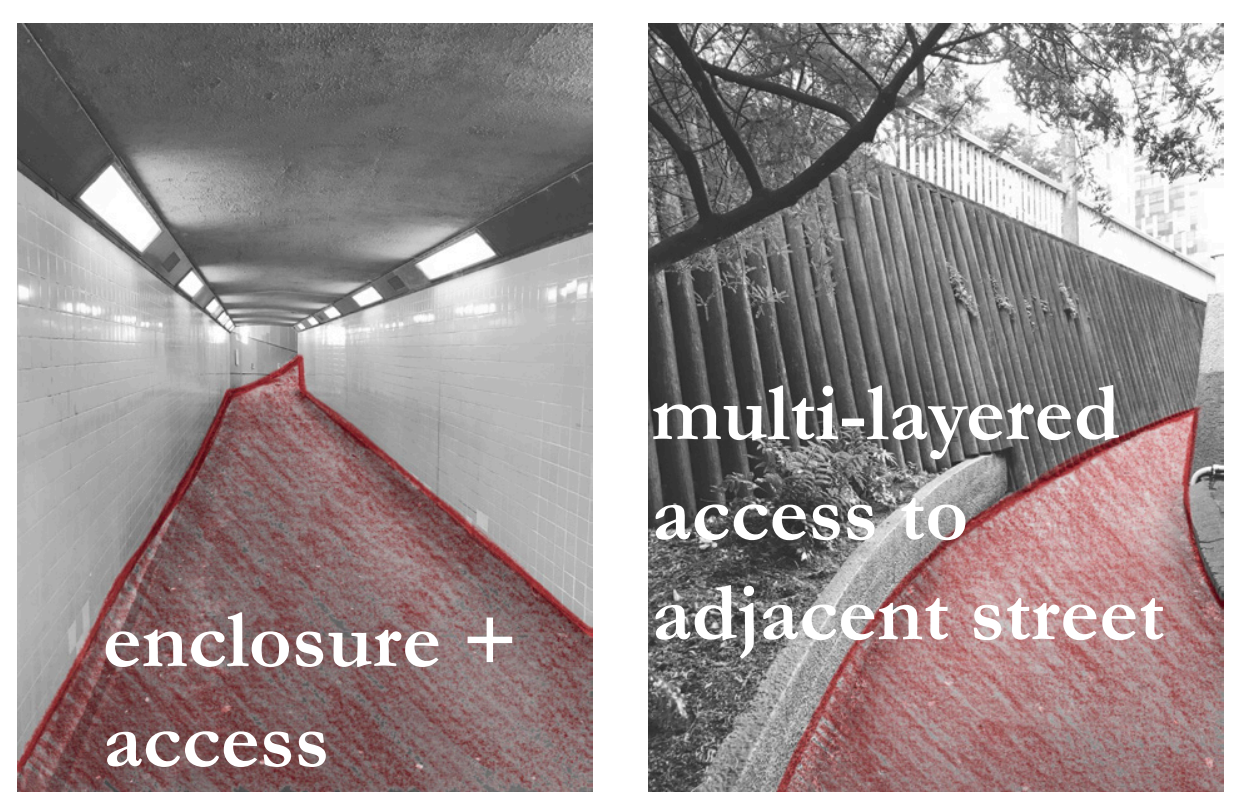

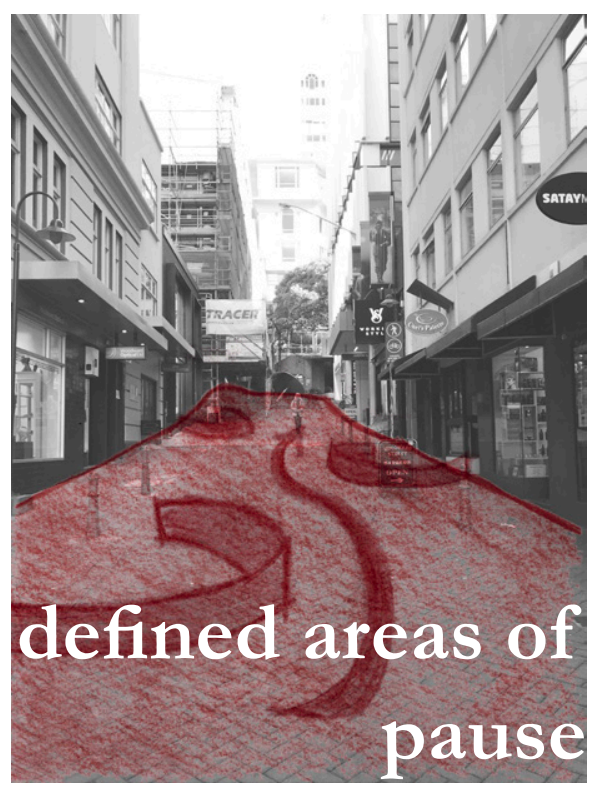

Altering the main street space through intervention like street furniture, supports social interaction (Mehta and Bosson, 2010, p. 782). Manipulating the surface of the street in this way changes the urban condition to one that is dynamic, unfolding, and responsive; supportive of future change (Wall, 1999, p. 233).

The tunnel indicates the possibility for atmospheric change, rather than physical; through lighting or sound installation, as is existing, alluding to the sites' history (Holder, 2014).
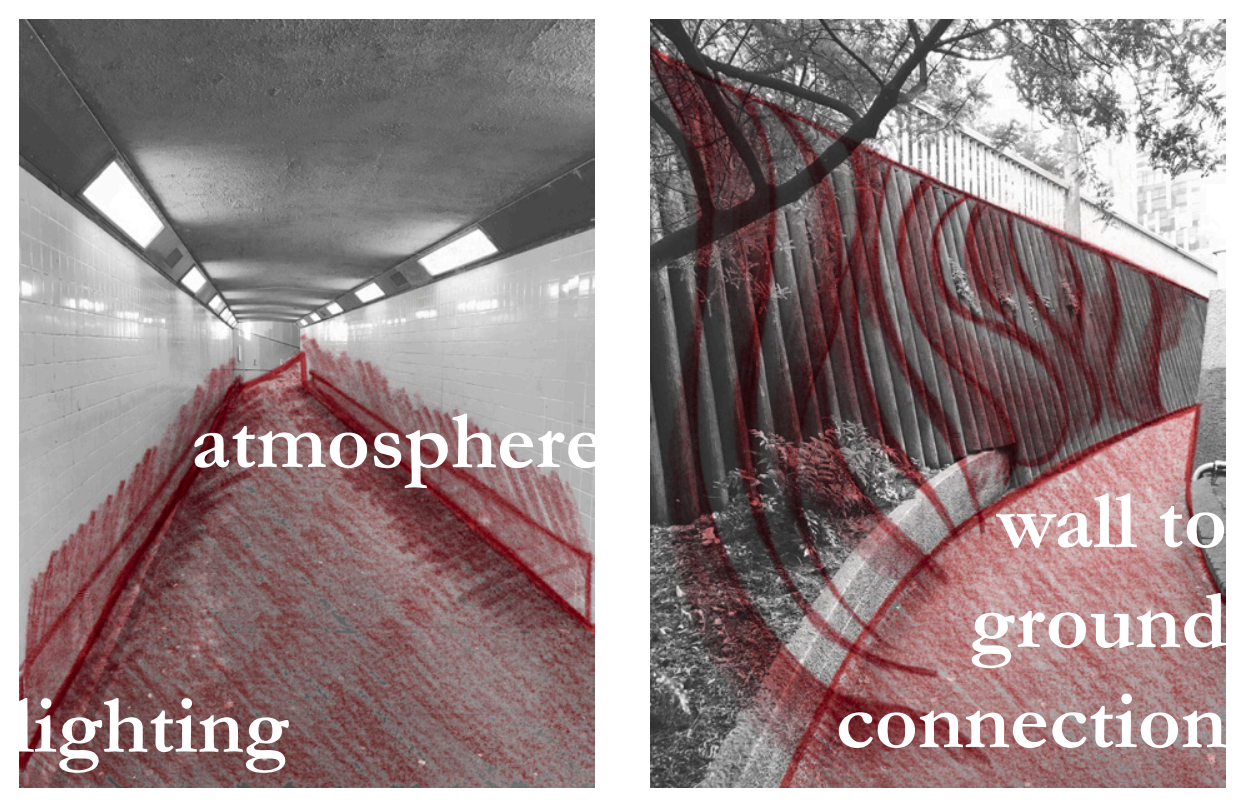
Initial design responses

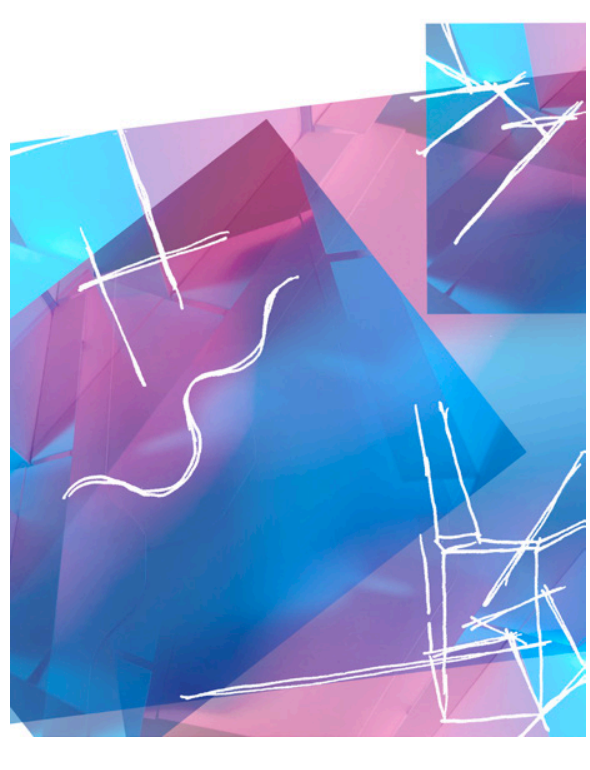

interventions / sketching
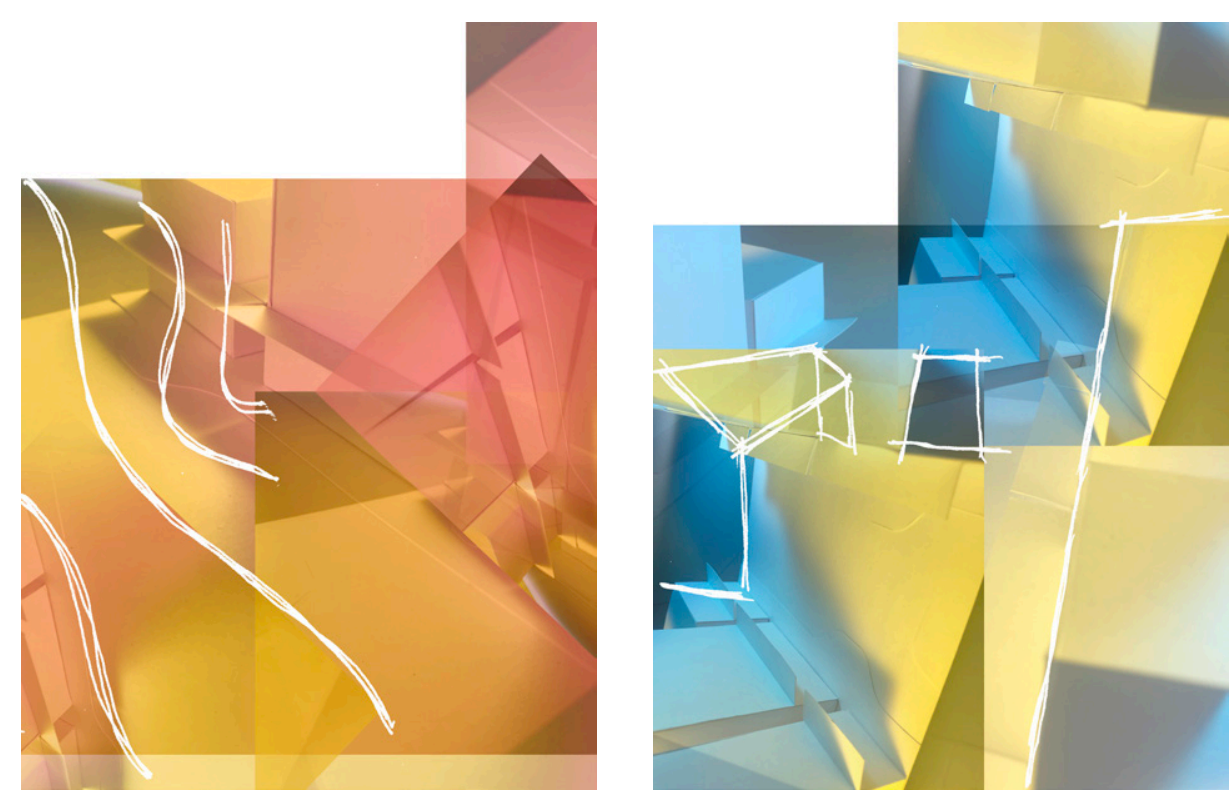

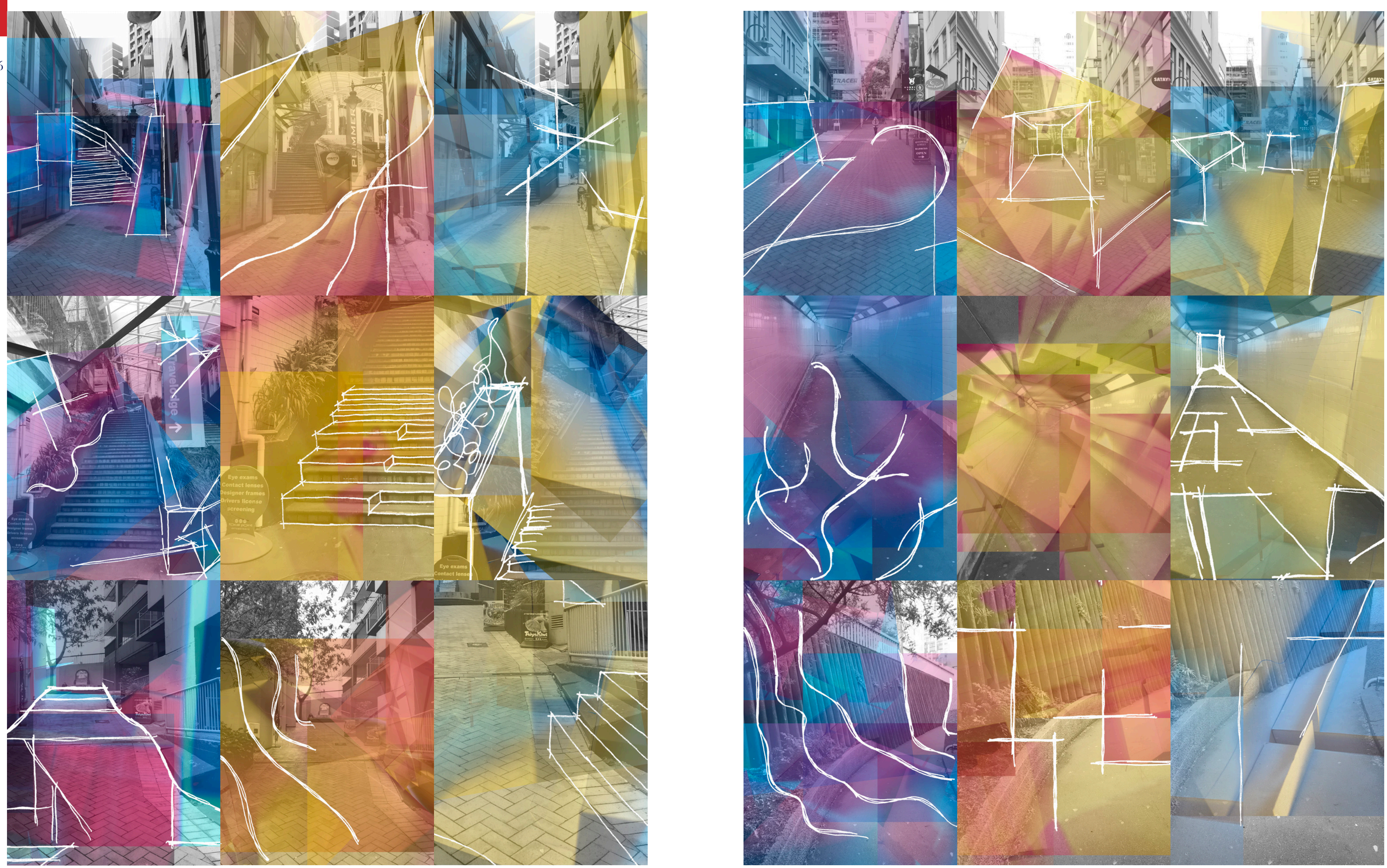

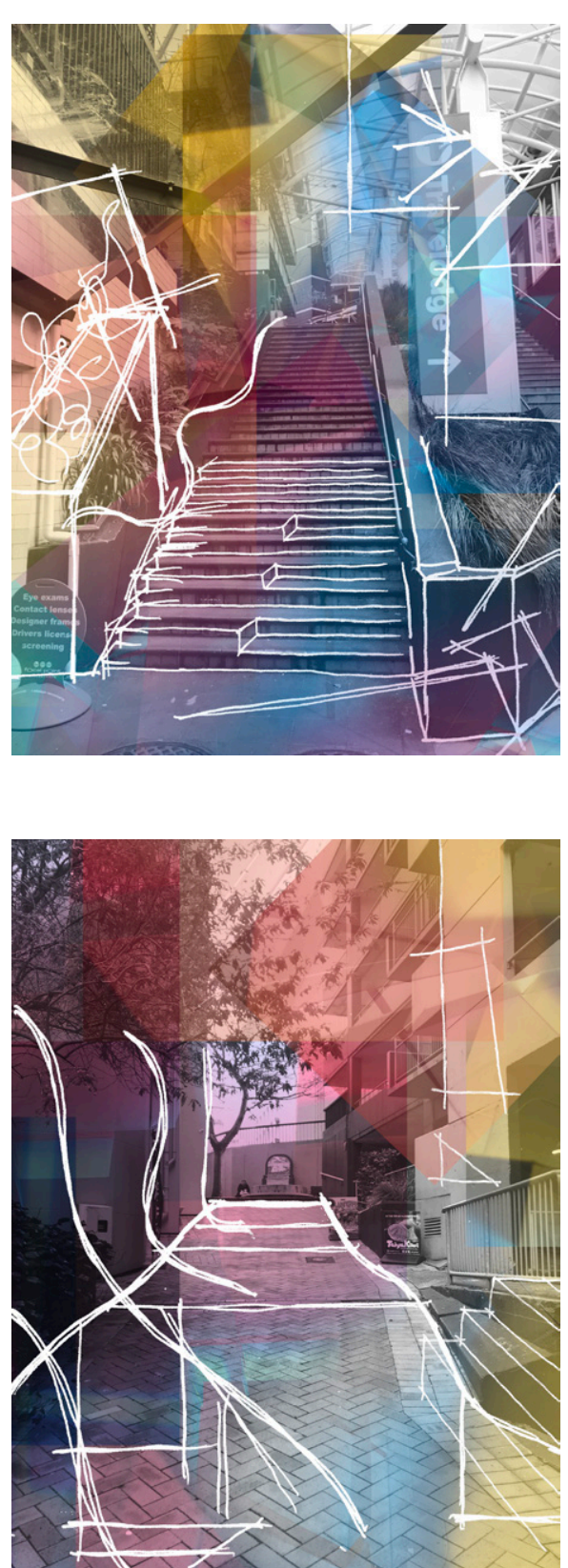

The most successful sugrested interventions still promote the access that here created to provide, but integrate possibilites for other activities to occur alongside the main access routes

Indications of this include;

Street furniture, particularly seating:

The opportunity to pause extends the time pedestrians are likely to spend in a given location, and offers the chance to consume food and drink; an activity associated with socialising (Mehta and Bosson, 2010, p. 782). Furniture also provides the opportunity for working behaviours to occupy the site, supporting work that is "merging of leisure and obligation", mobile work (Idenburg, 2013).

Shelter:

Shade and shelter are as necessary as orientation to receive sunlight, as considering these accomodates changing weather conditions, creating a comfortable outdoor space (Mehta and Bosson, 2010, p. 782).

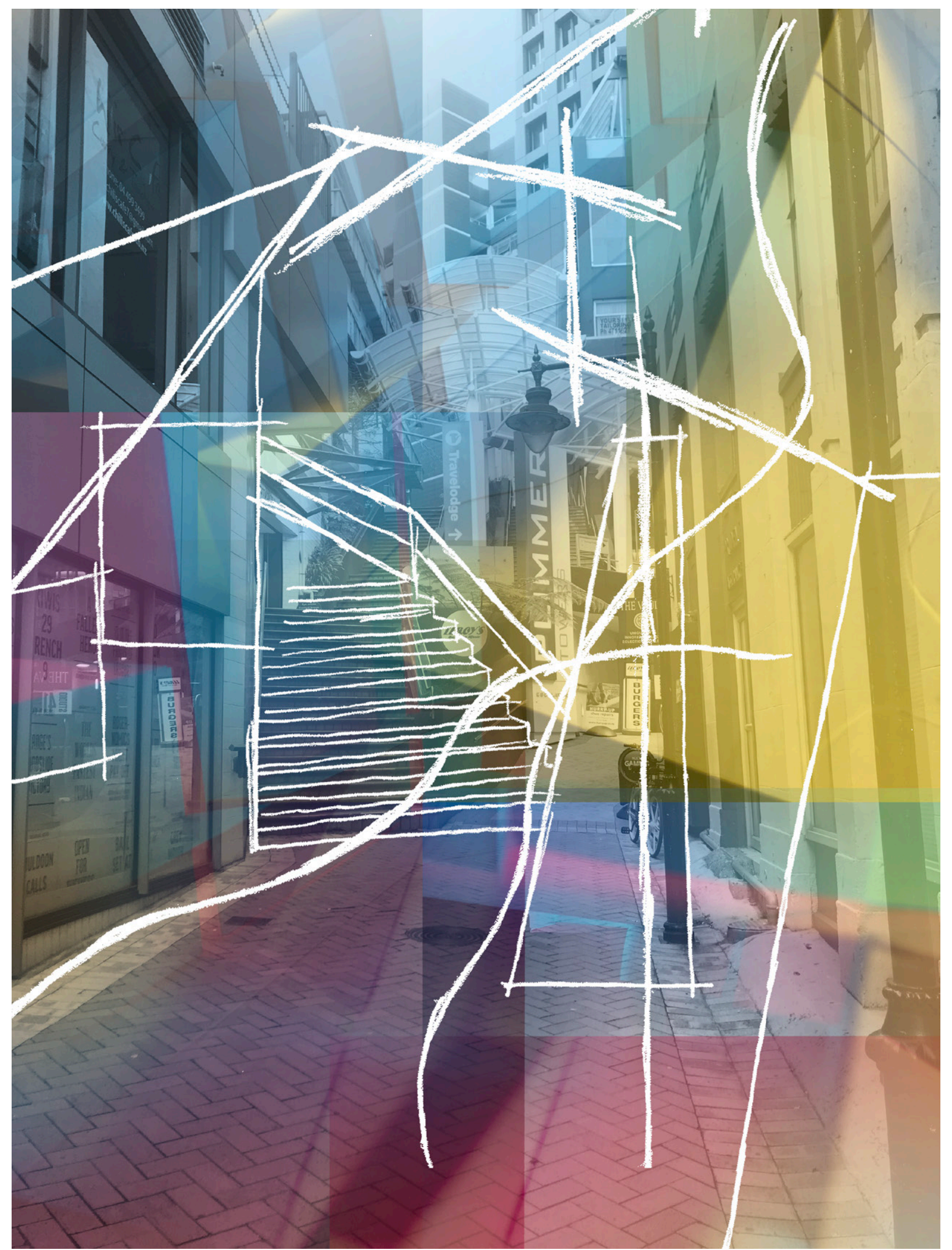

149 


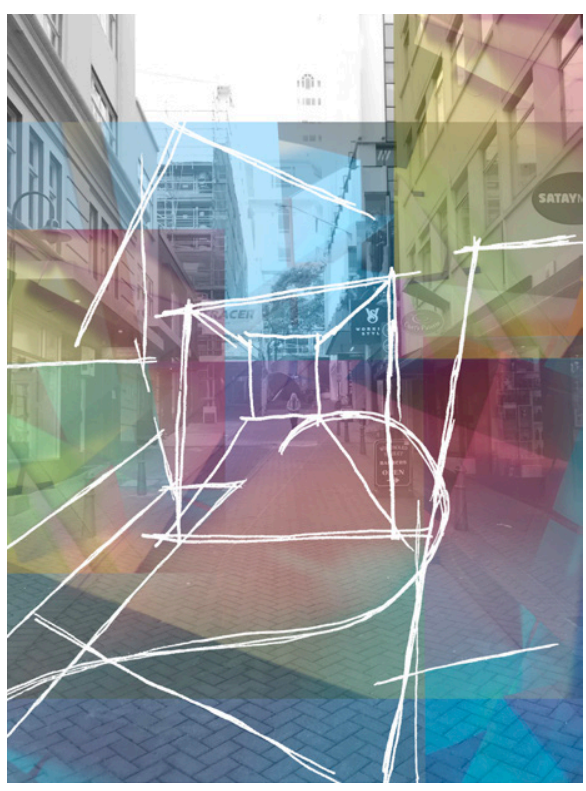

Manipulation of the urban surface

Creating spaces that aren' completely defined by activity allows for personalisation, which aids in promoting place attachment through creation of identity (Oldenburg, 1991, p. 2; Mehta and Bosson, p. 781). Undefined elements also allow for spatial boundaries to overlap, promoting a dynamic and responsive urban environment, that can adapt to future change (Wall, 1999, p. 234)

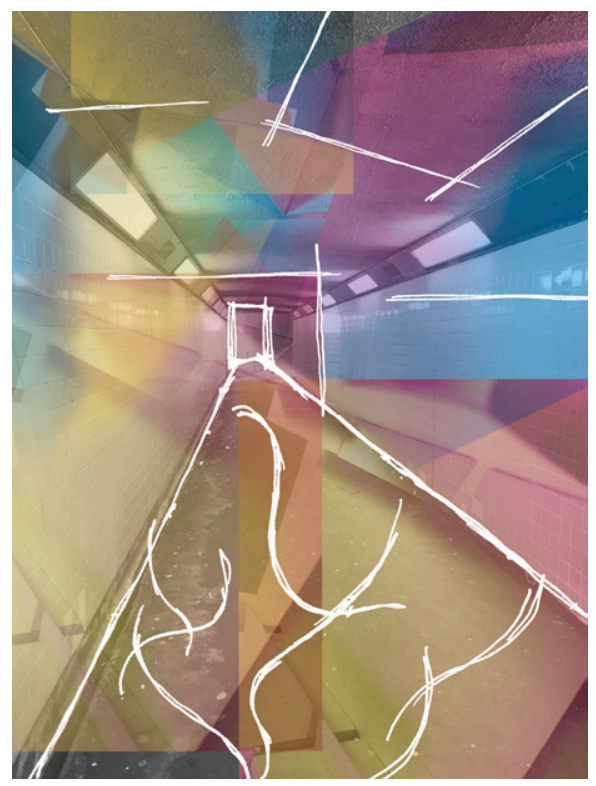

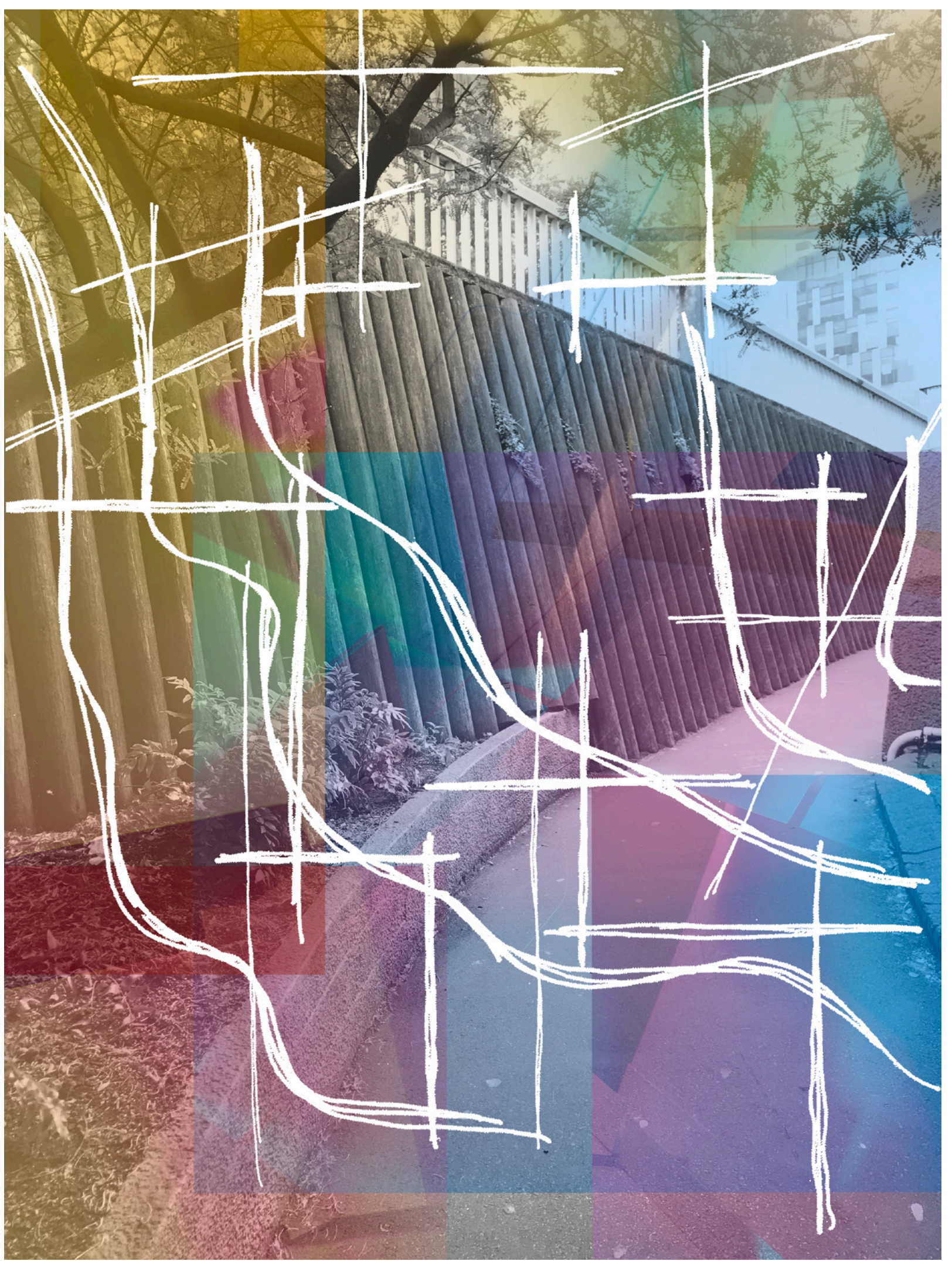




\section{summary \\ design tests / initial design responses / phase 2}

Extending from the first design phase, the second phase began with site analysis. Firstly, research into the history of streets in Nev Zealand cities, and specifically Wellington, provided grounds to make site selection on. Based on the literature reviewed, the case study design tests, and this research, the sites selected were Plimmer Steps and Woodward Street.

Each site was analysed at a broader scale, to highlight their relationship (1) one another to Wellington's Central Business District, and to Wellington City overall. Following this, specific history and context research was presented for each site, along with physical analysis.

To adjust to the site selection, the three design tests performed on the Case Study sites were reinterpreted for the selected sites. Tests A and C remained very similar, but Test $B$ was adapted to more specifically draw affect from the new sites. The key focus of these tests was to discover how the information collected could be reinterpreted into an initial design phase.

Test $B$ was adjusted in response to the critical reflection after Phase 1; that the "categories" assigned to the architectures existing on the Case Study streets were limiting; pedestrians may not use the street in expected ways, therefore each object has endless possibility for its use, and how it may be reinterpreted to accommodate desired activities of the individual. In response to this, no categories were assigned, and rather the photographs of the street model with coloured light applied (from Test B.2) were collaged over images of the sites as they currently exist Through this approach, colour and light applications could interact in more ways, drawing out existing qualities of the architectures, and imagining new possibilities. This enhanced the idea of there being seemingly endless possibility for changing affective encounters as the disturbance affects different pedestrians in differing ways.

Test $\mathrm{D}$ was developed from Wall's Programming the Urban Surface, the created test focused on Wall's discussion of the urban landscape being an active surface; at the first layer, all the surfaces are one surface that can be manipulated to support a changing range of activities. The surface becomes dynamic, unfolding and responsive; primed for changing interactions and possibilities. Through this test, some initial design interventions became apparent; surfaces across the site could be manipulated to create spaces that are ambiguous and filled with interactive possibility.

The initial design response began as a secondary stage to Test B; sketching over the collages to indicate possible interventions that became apparent through overlaps and interactions. Many of the initial designs suggested here were influenced by the design moves initiated in the other three design tests; in particular the considerations of what the surface could become that was inspired by Test $\mathrm{D}$, and the possibilities for gestural manipulation initiated in Test C. The most successful responses were combined, along with their collages of colour, to show a conversation between physical architectural intervention and the affective qualities that would be incidental to these design changes on site.

The design development (Phase 3) needs to show how increasing opportunities for social interaction enhances the affect of the site, allowing positive place attachment to occur. To do this, pedestrian activity needs to be prioritised; activity that varies from movement, to socialising, to working. The development will follow the process of suggesting interventions design with this facilitation considered, then moving into redesign of each of the sites to support the desired outcome. 


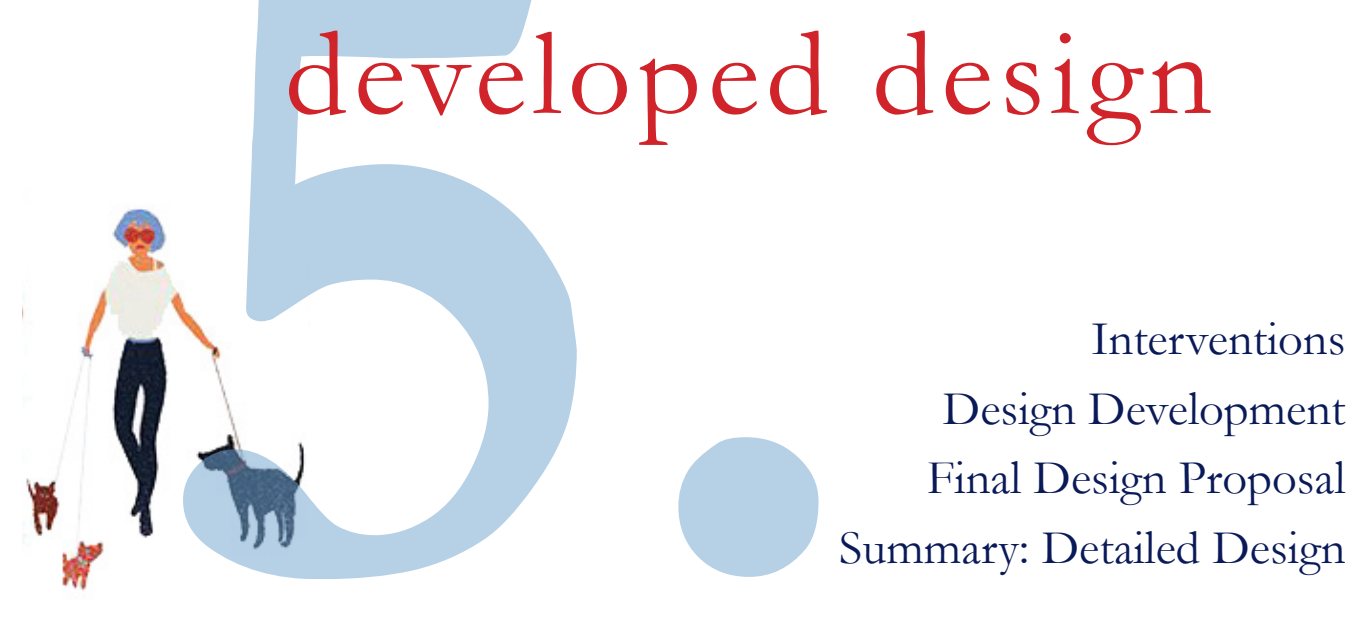

\section{$\square$}




\section{interventions}

design development description
The initial research used tests created from literature to explore existing and imagine affective spatial relationships on case study sites in Wellington City.

Influence pedestrian movement and activity, with the intention of facilitating place attachment through the generation of affective relationships between pedestrian and site.

The next phase interpreted these tests onto the selected sites Plimmer Steps and Woodward Street - and interpreted this research into initial design interventions.

The design development phase demonstrates the synthesis of

site and intervention; developing possible design responses into a cohesive redesign of each site.
This focus is achieved through the development of proposed intervention and site redesign.

The development is presented as a series of key design moves, altering the site moment-by-moment. The moves are informed by the earlier site analysis and contemporary theories as interpreted through design testing. 


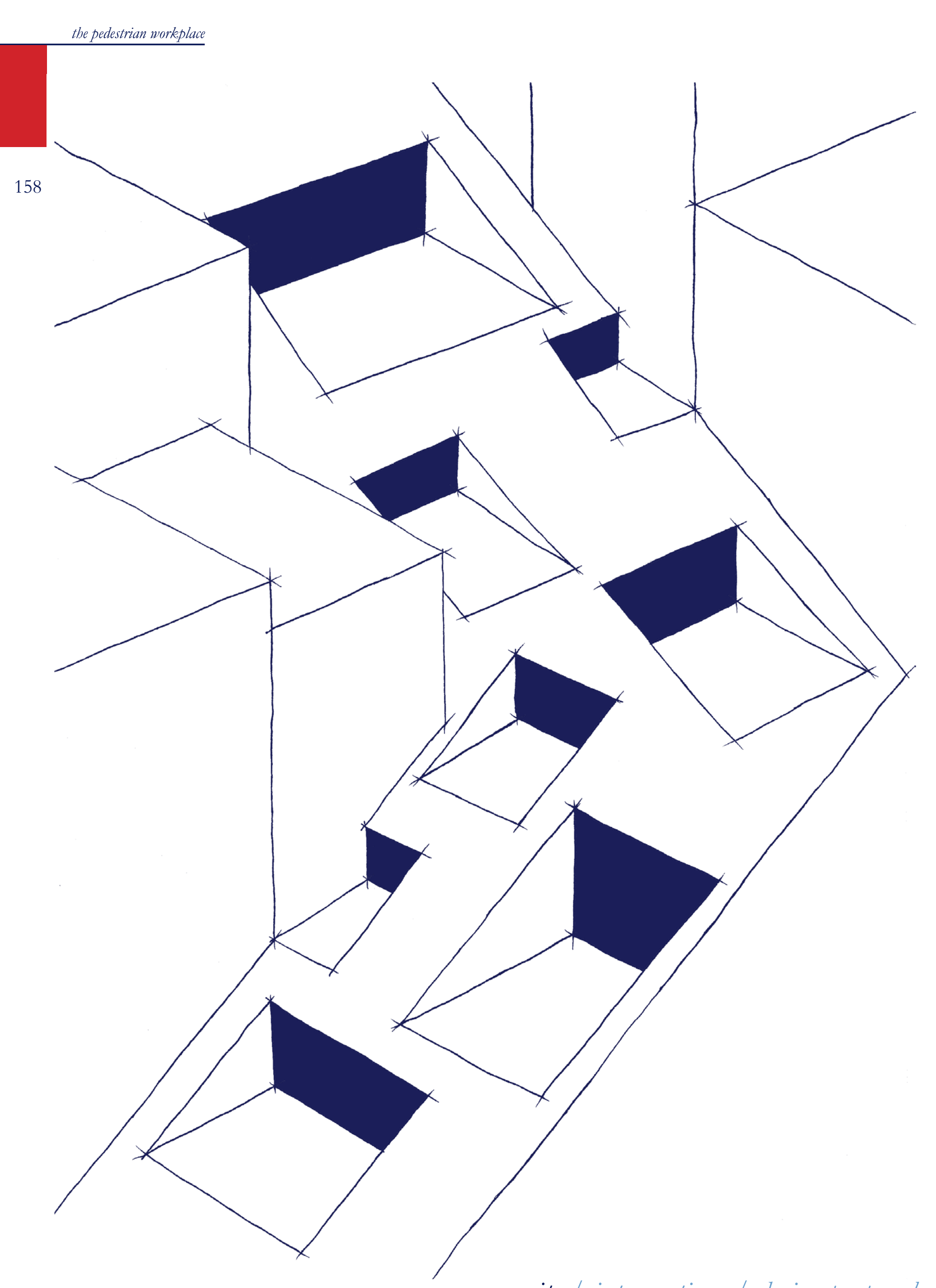

site / interventions / design proposal

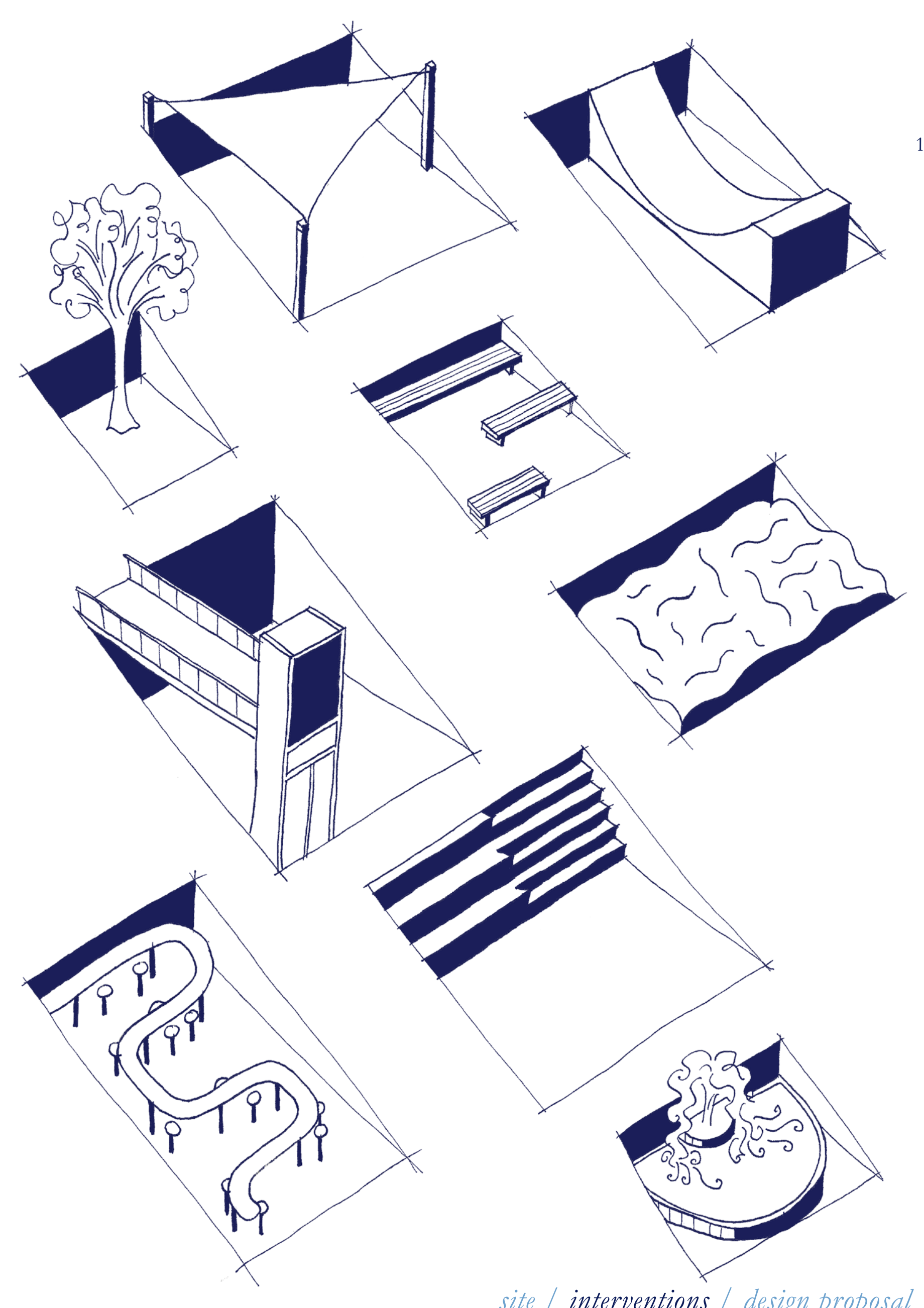


Indicative of the design process followed, this initial series of images follows the process of

1. Existing site consideration

2. Proposal of possible

3. Synthesis of site and

intervention to redesign the site

and create a cohesive final design proposal.

The series was created to sugges interventions suitable to the site.

The interventions fit into the

following categories;

- Access/movement

- Greenery

- Art installation/sculpture

- Furniture; shelter, seating.

workspace
The categories were considered The literature, early desion testing and existing site experience. Mehta and Bosson suggest green spaces, street furniture, seating, and shelter to be supportive of social interaction (2012, pp. 780, 781). Access is the current primary use of the two sites, and each site currently has artistic installation to indicate histories.

The selected interventions shown here create an initial imagined moment of the final site; that the interaction between intervention and site may alter the existing site topography, and that many activities have the possibility to be supported.

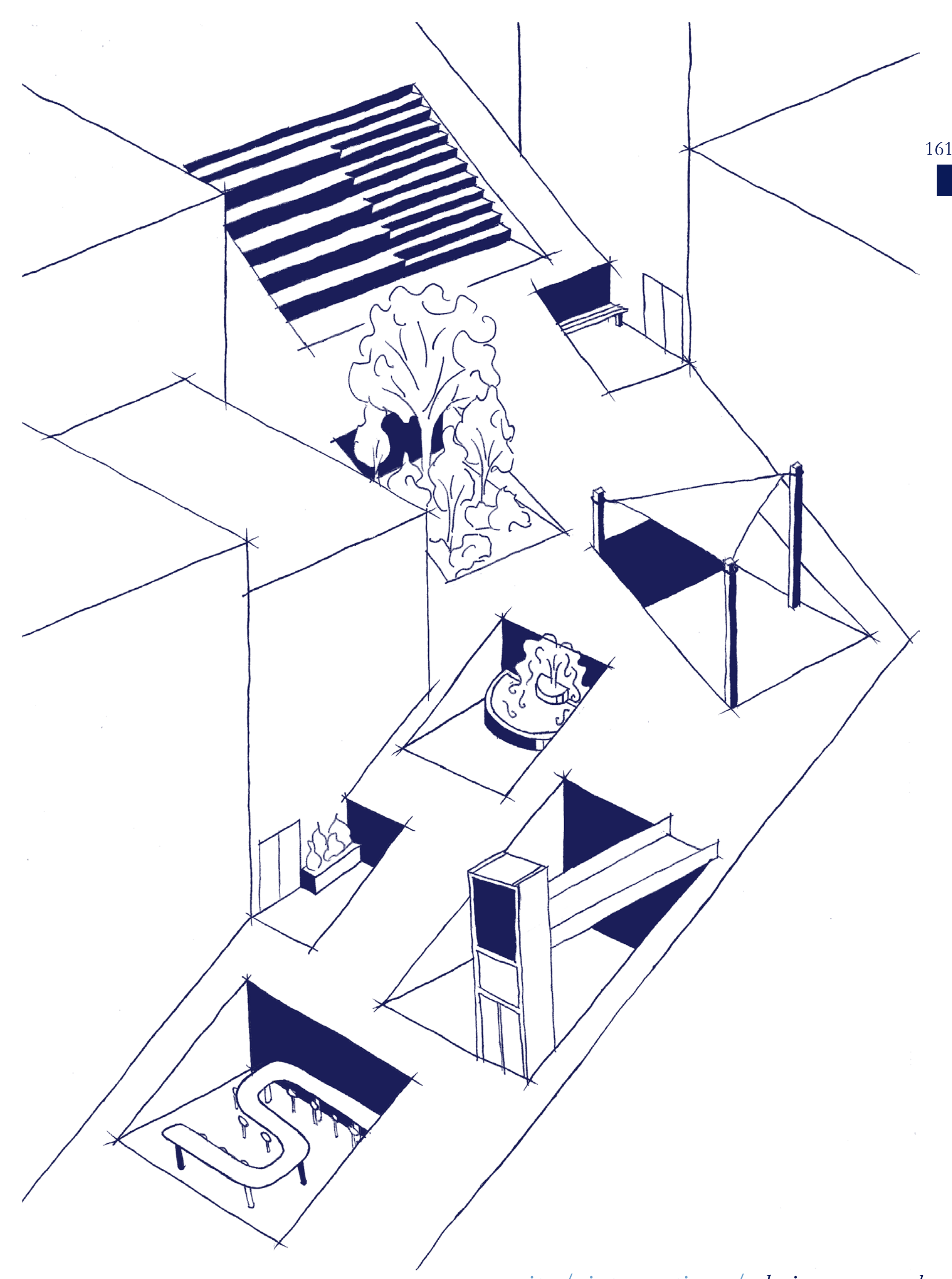

site / interventions / design proposal 

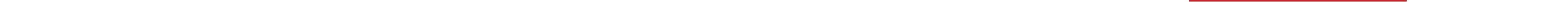


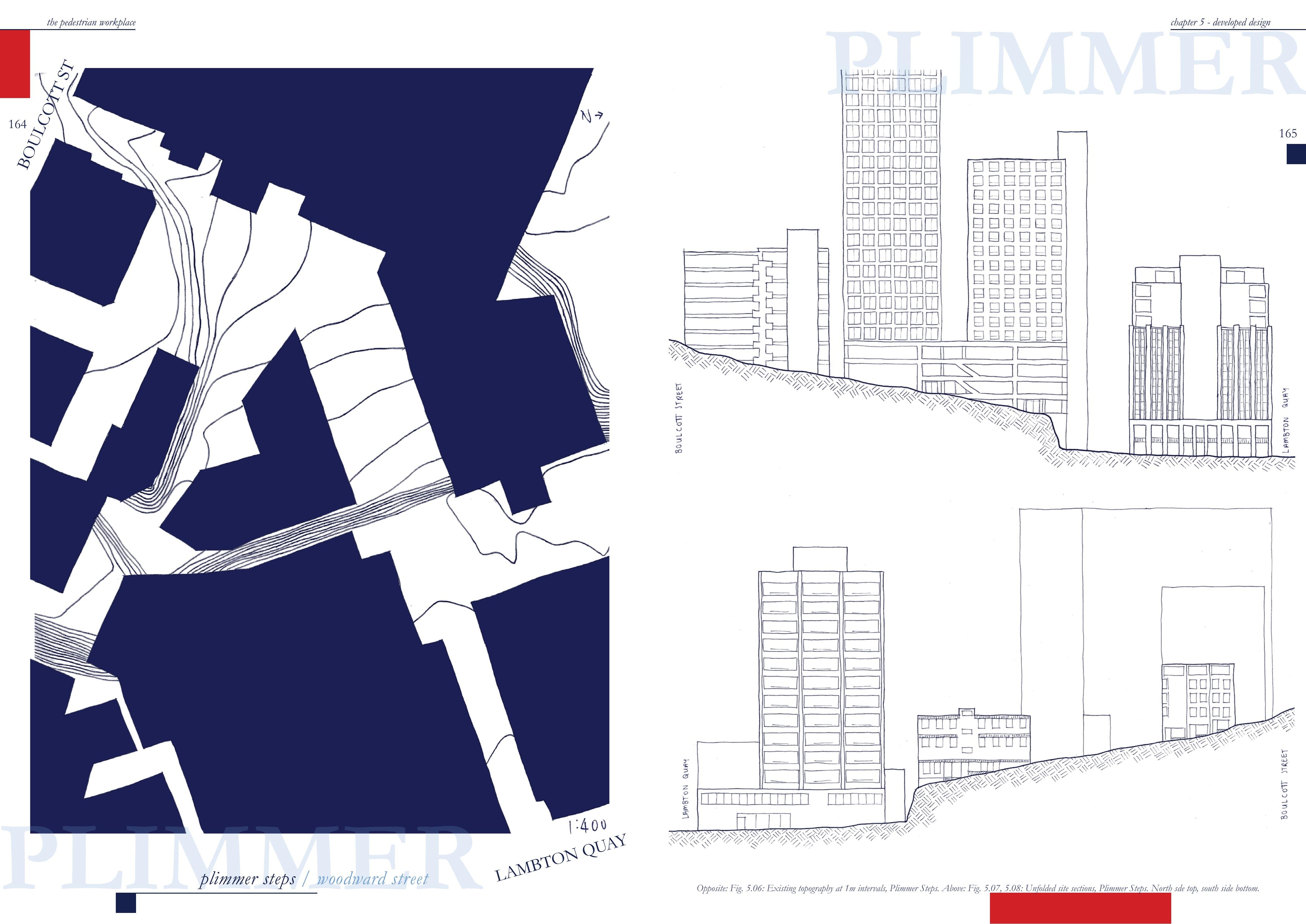




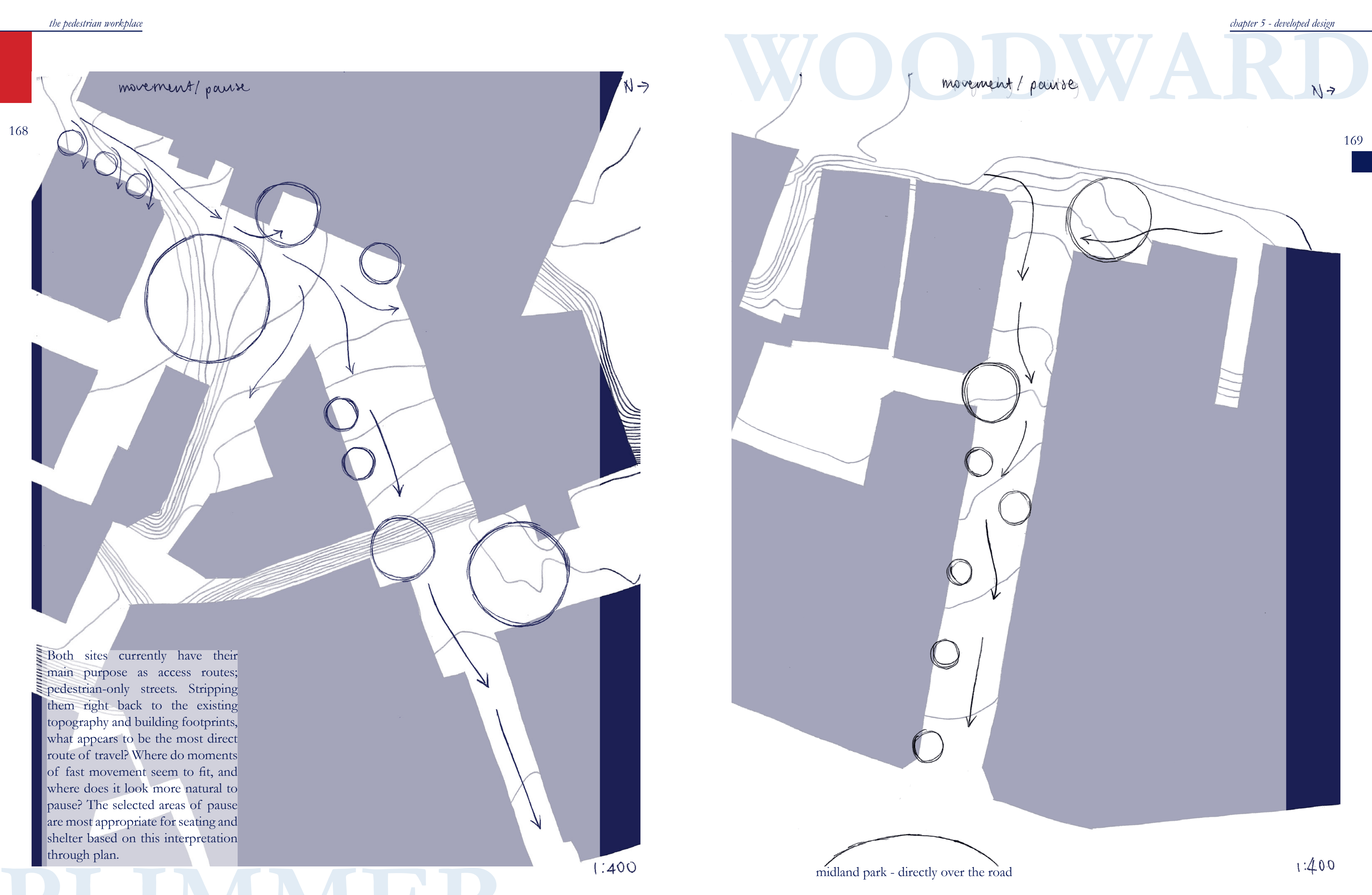



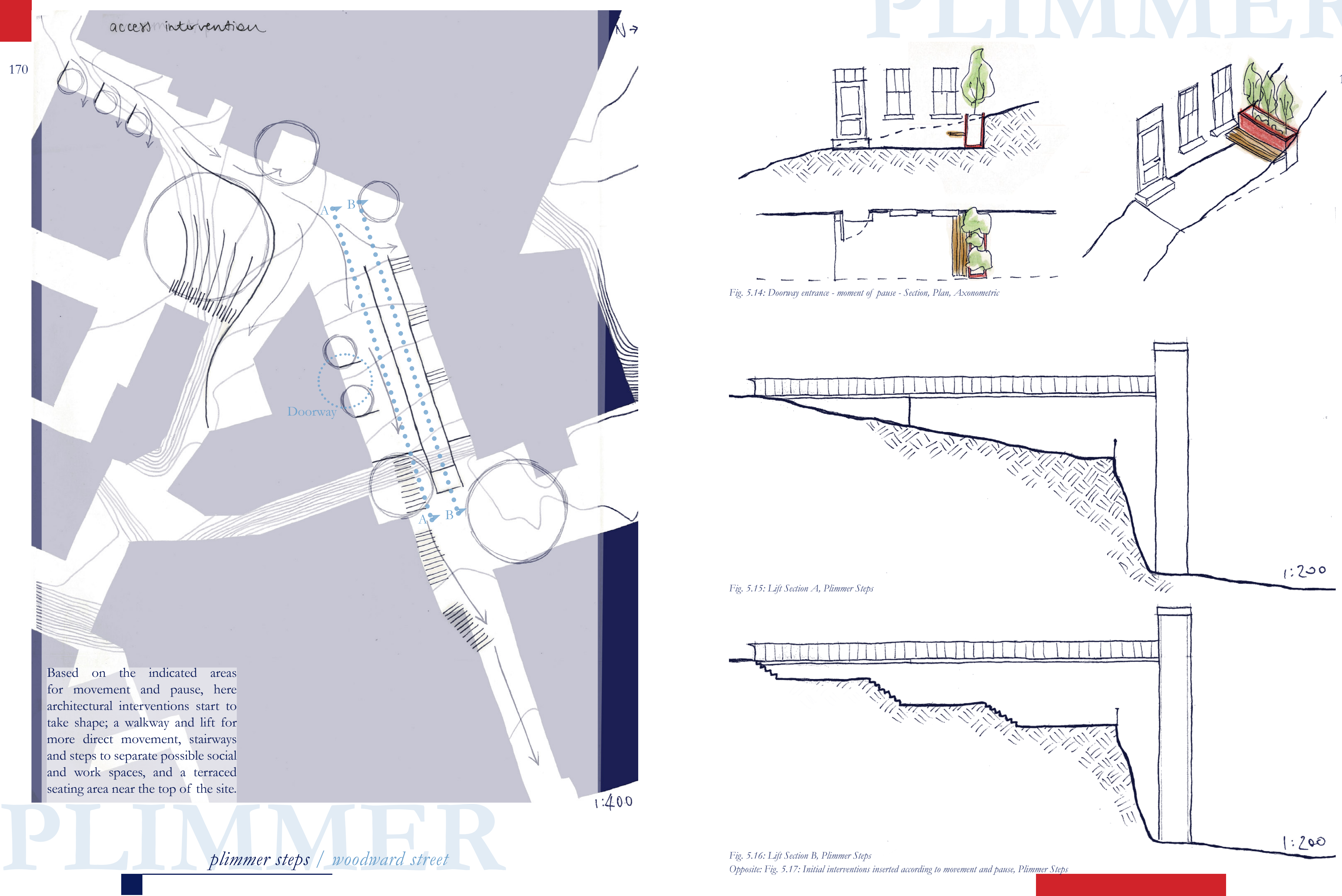


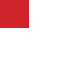

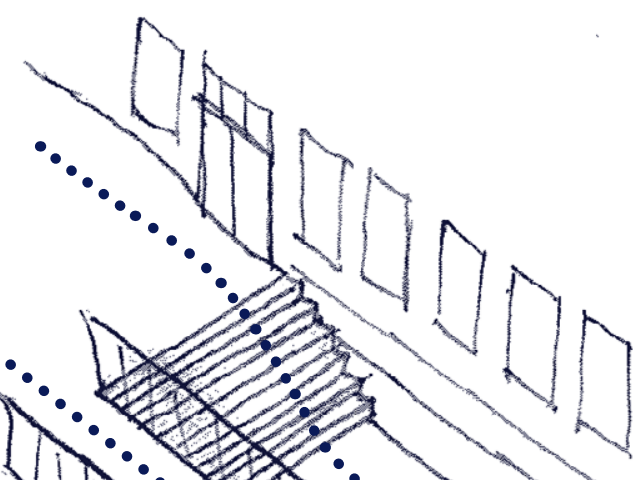

- social

- working

- movement

The intervention of a lift creates accessible movement on the currently steep and treacherous Plimmer site. The raised walkway provides direct movement, and the additional benefit of sheltered spaces underneath. The space underneath provides moments for pause, and could contain furniture that accommodates social and working behaviours. This would also be an interesting design intervention on the Woodward site.
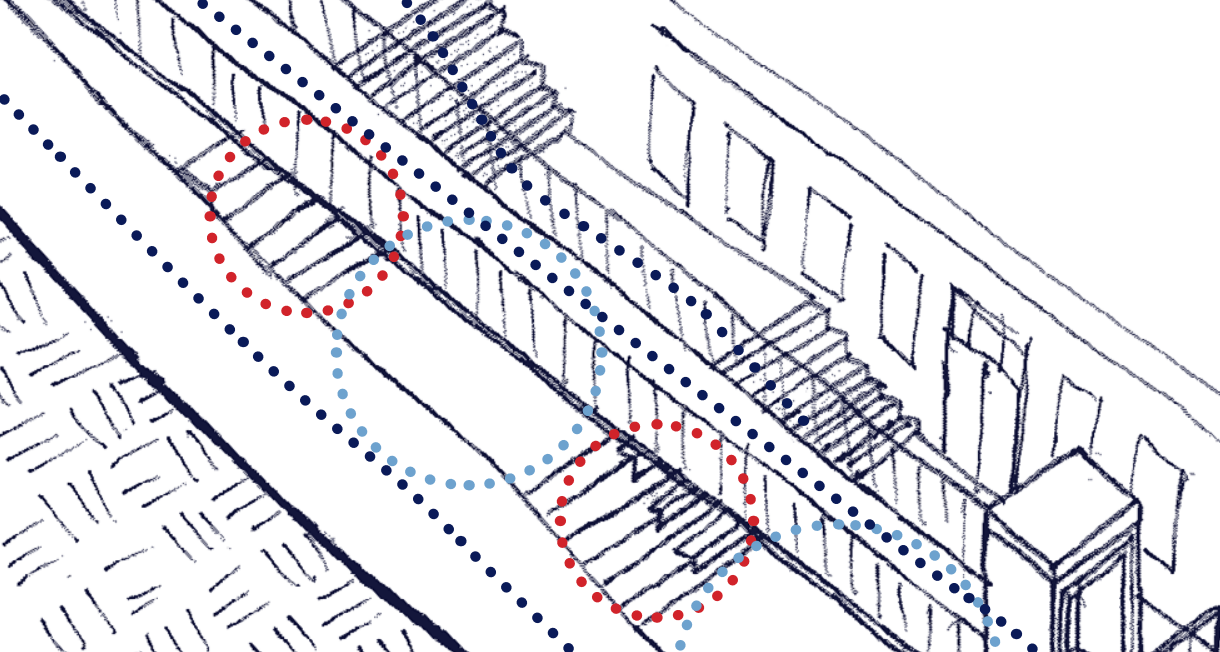

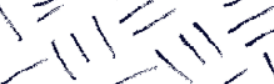
$11=11=$ (I) $=41$
$=41$
$=11$

$=0$
$=11=$
$=11=11$

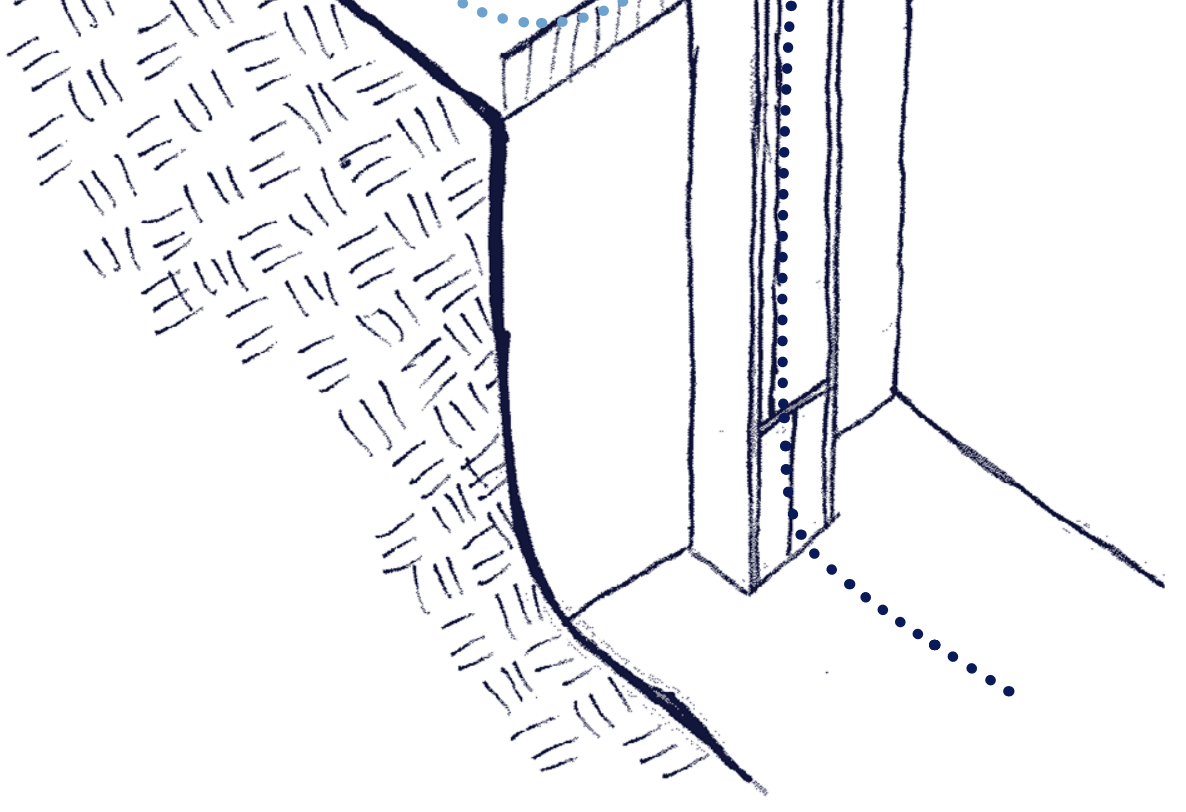

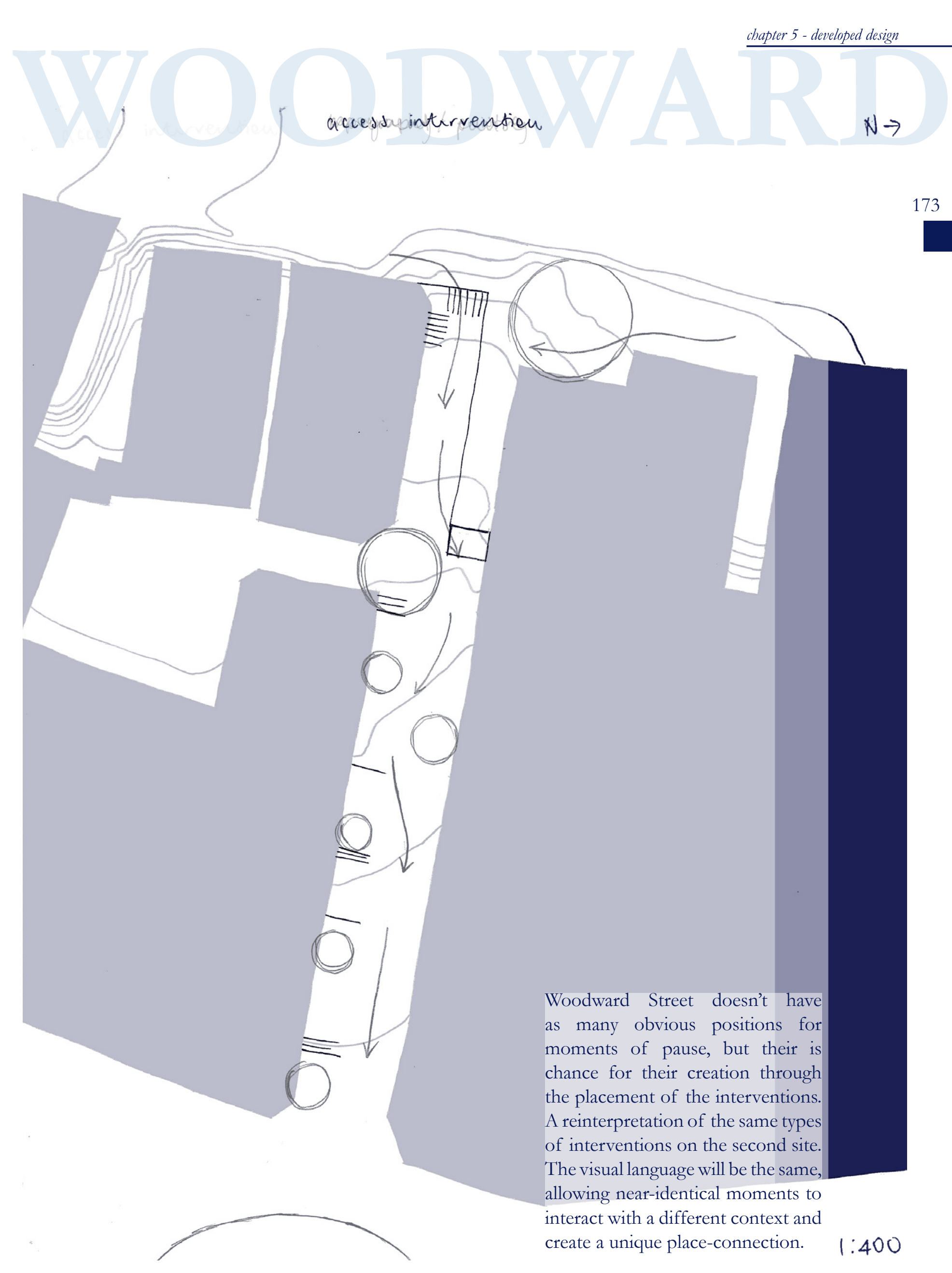



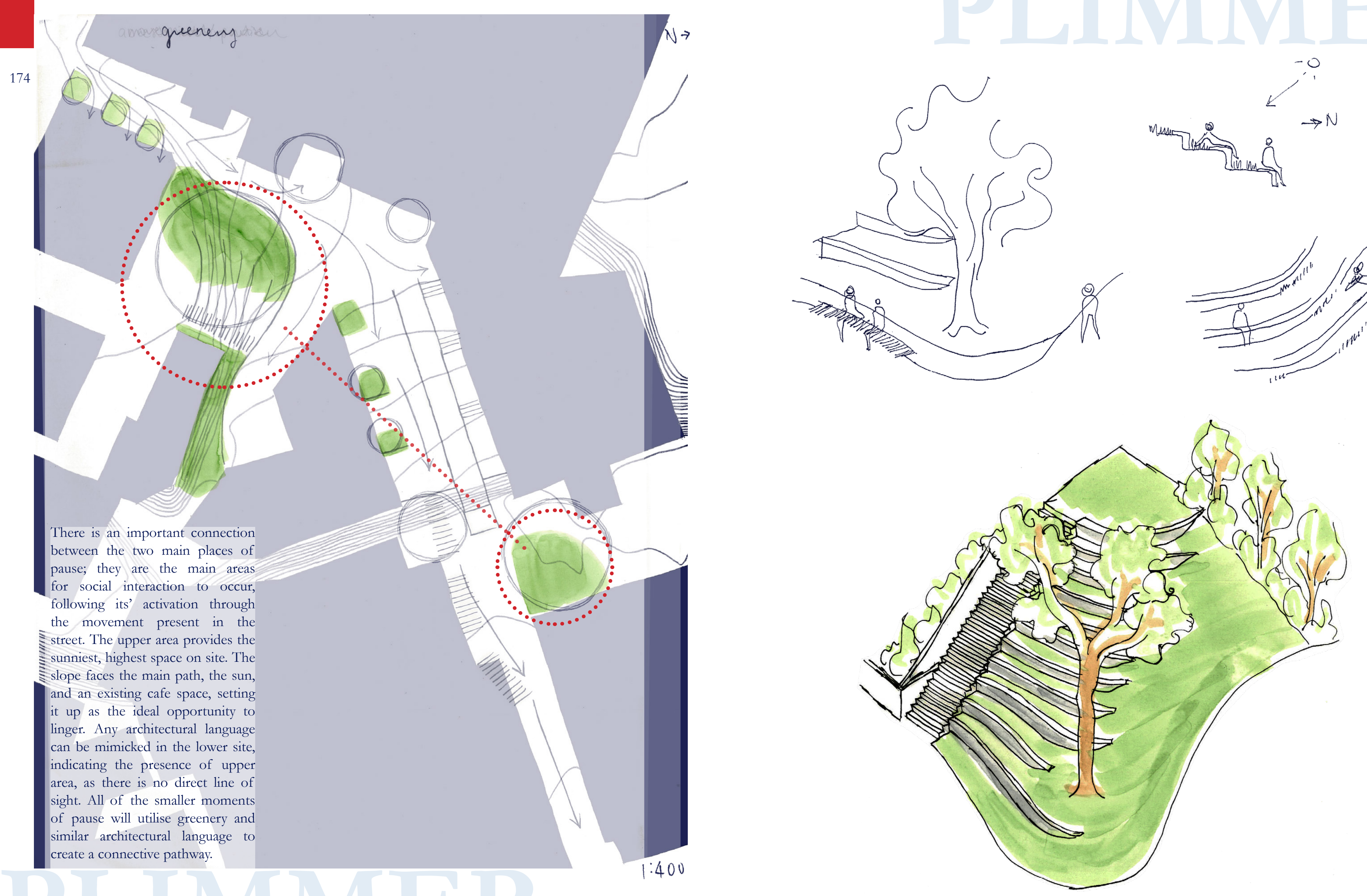
On the Woodward site, similar

connections are present, however

the opportunities for pause smaller.

There is an important connection

to Midland Park, an adjacent gre

Lambton Quay. The two areas with

the most potential for green spaces

are indicated.

.
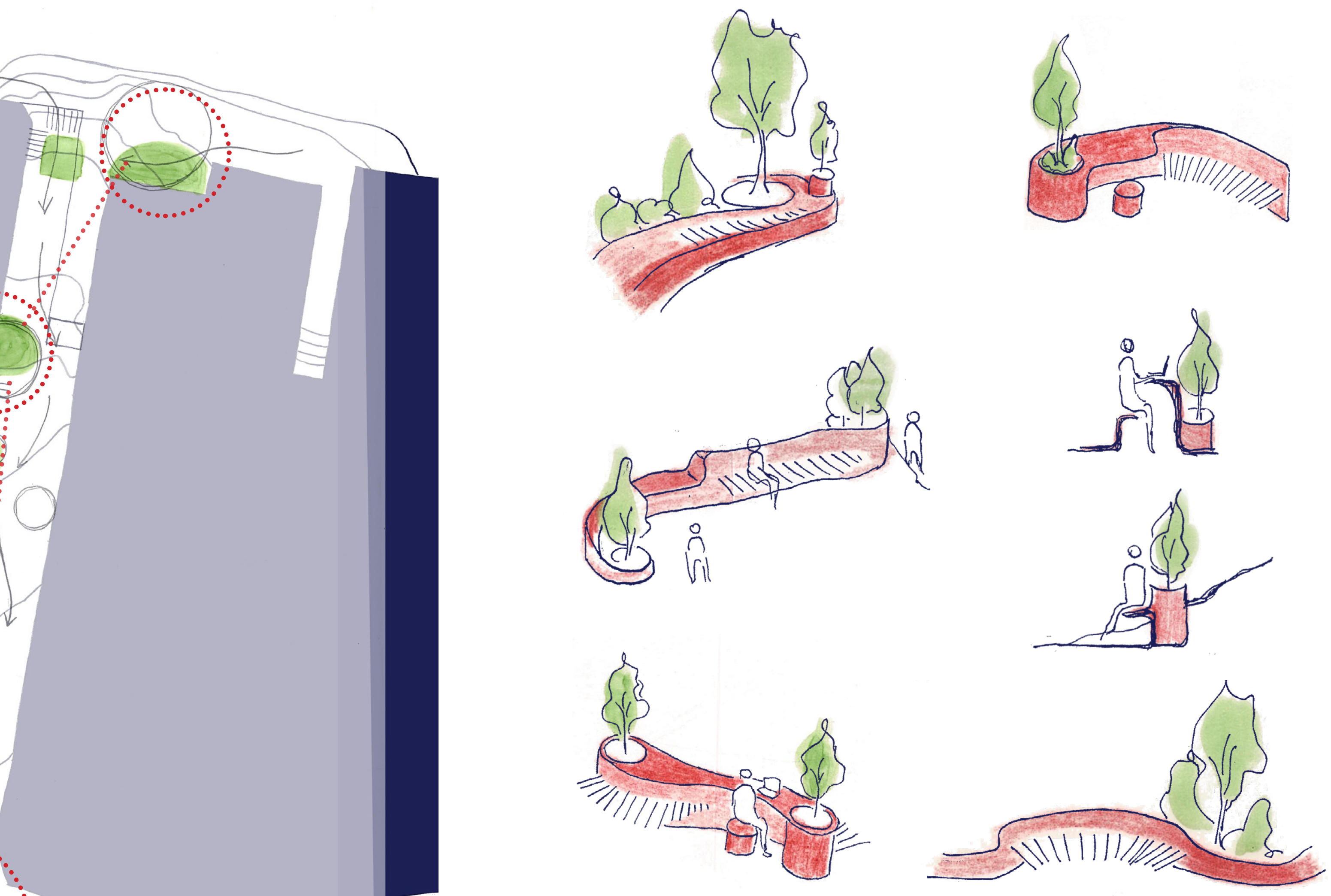

To provide spaces for working and thoroughfare, the suggested form social activities, the suggested places of the furniture is curved, inspired of pause can be filled with furniture by the circles in the diagrams. The interventions. To create enclosed form integrates seating, desk space, spaces, separate from the main and planters. 

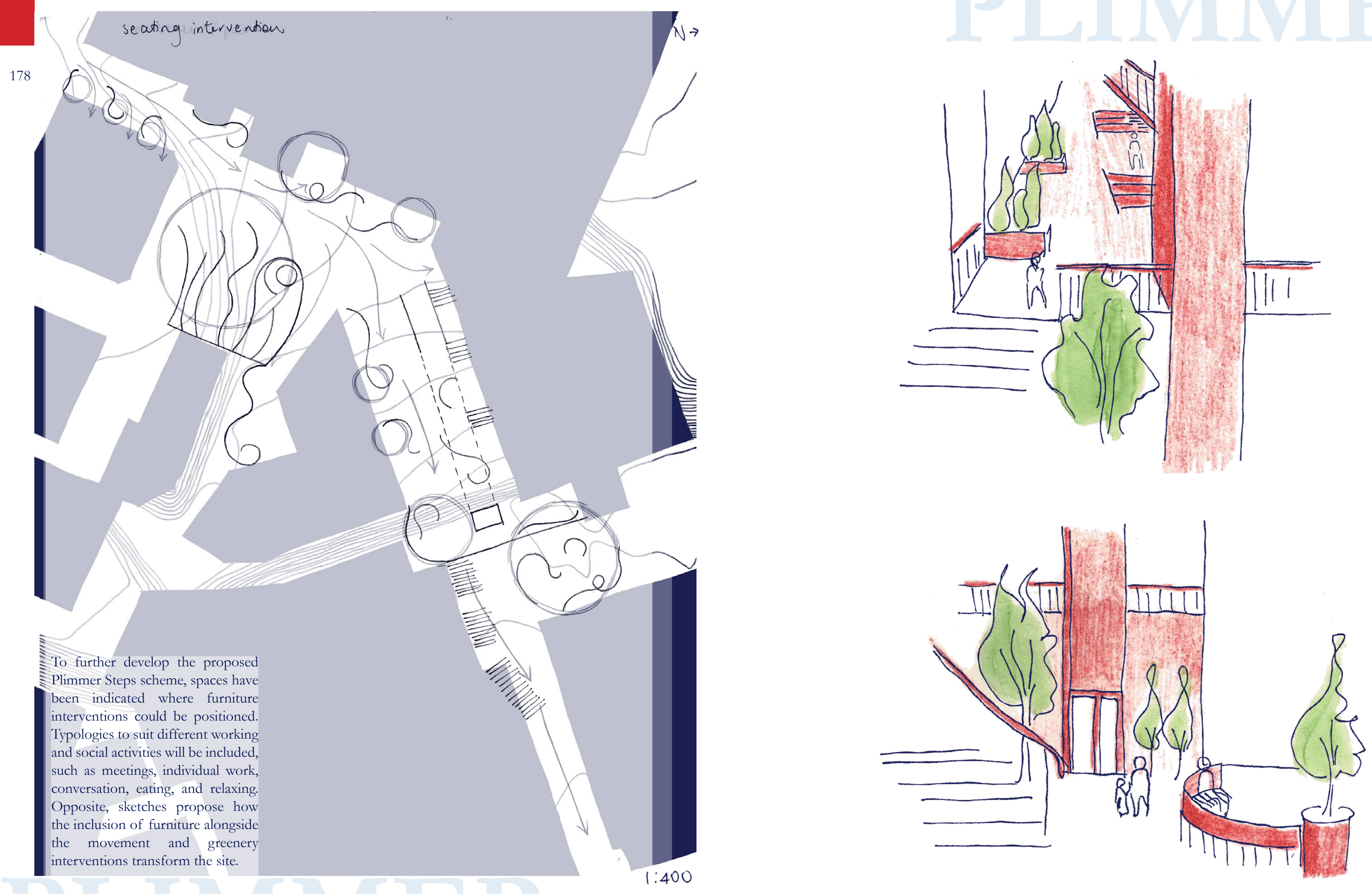
The final design proposal redesigns Plimmer Steps and Woodward Street, creating two pedestrian street that cater to working activities, while enhancing the existing access routes, and amplifying the opportunity for social interaction and community building. Through critical reflection throughout the design process, affective relationships were

\section{final design} proposal
This increases accessibility, provides opportunity for a range of social and working spaces at multiple levels, and makes use of the preexisting verticality of each site.

The design aims to enhance the sense of place in each site individually, but to also together create an affective relationship che that may start to alter the city block between them, as they play off one another within the CBD context. The final proposition redesigns the two individual sites, and also suggests an alternate workp ce typology; an accessible public third place for mobile and freelance work to occur alongside social, community-creating activity. feature the insertion of a lift and elevated walkway into each site.
183 

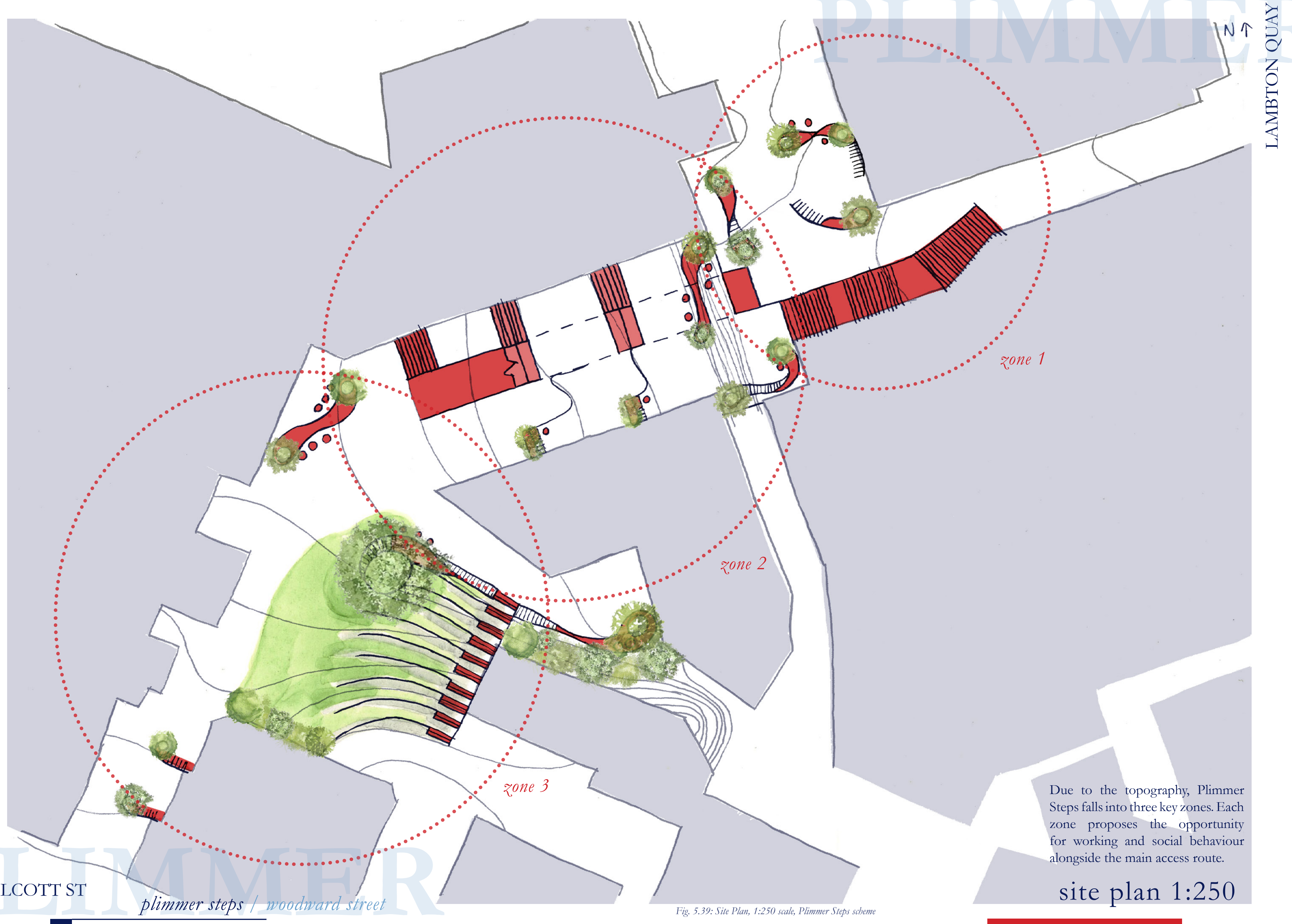

Due to the topography, Plimme Steps falls into three key zones. Each zone proposes the opportunity for working and social behaviour alongside the main access route. site plan 1:250 


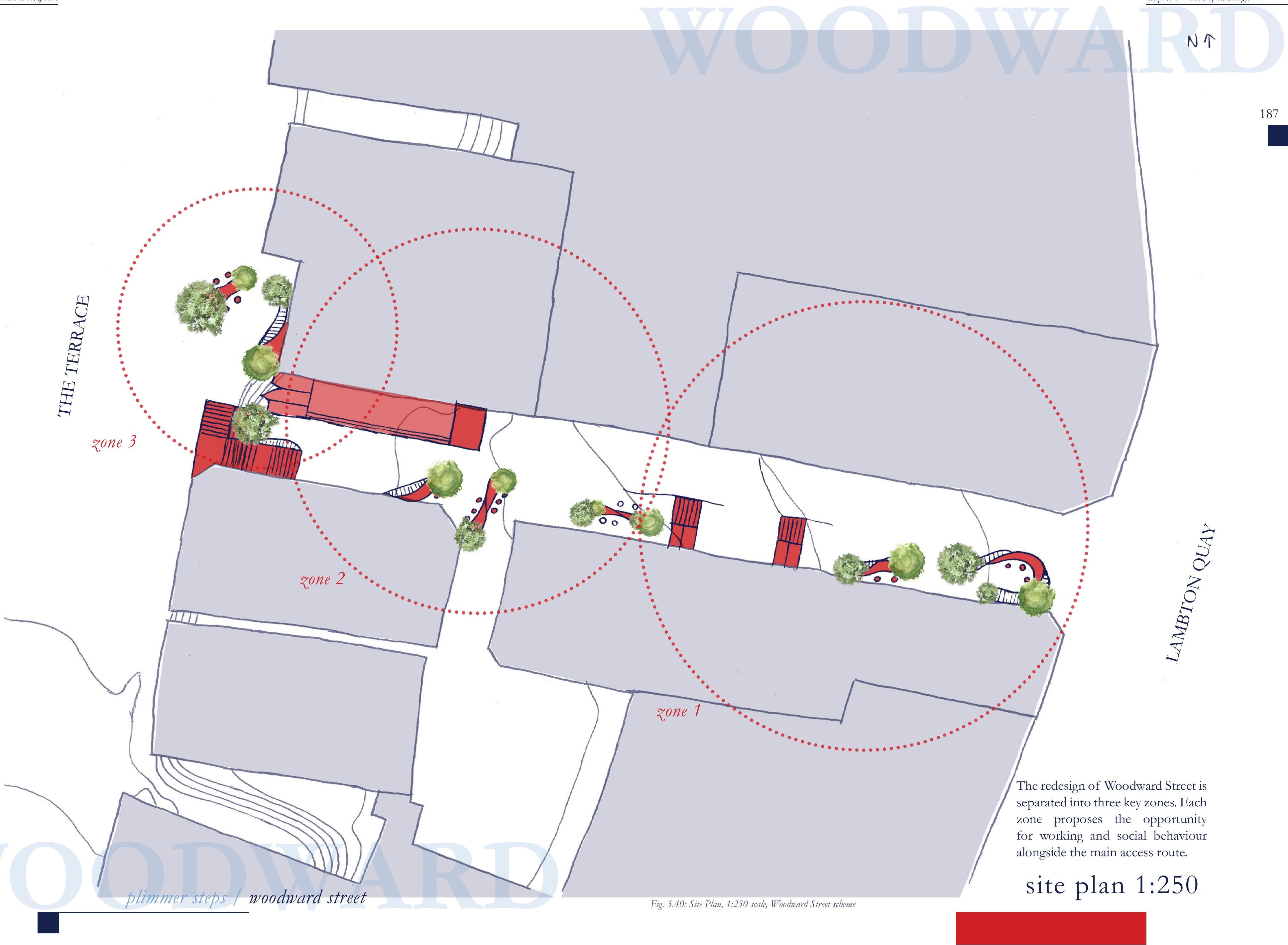



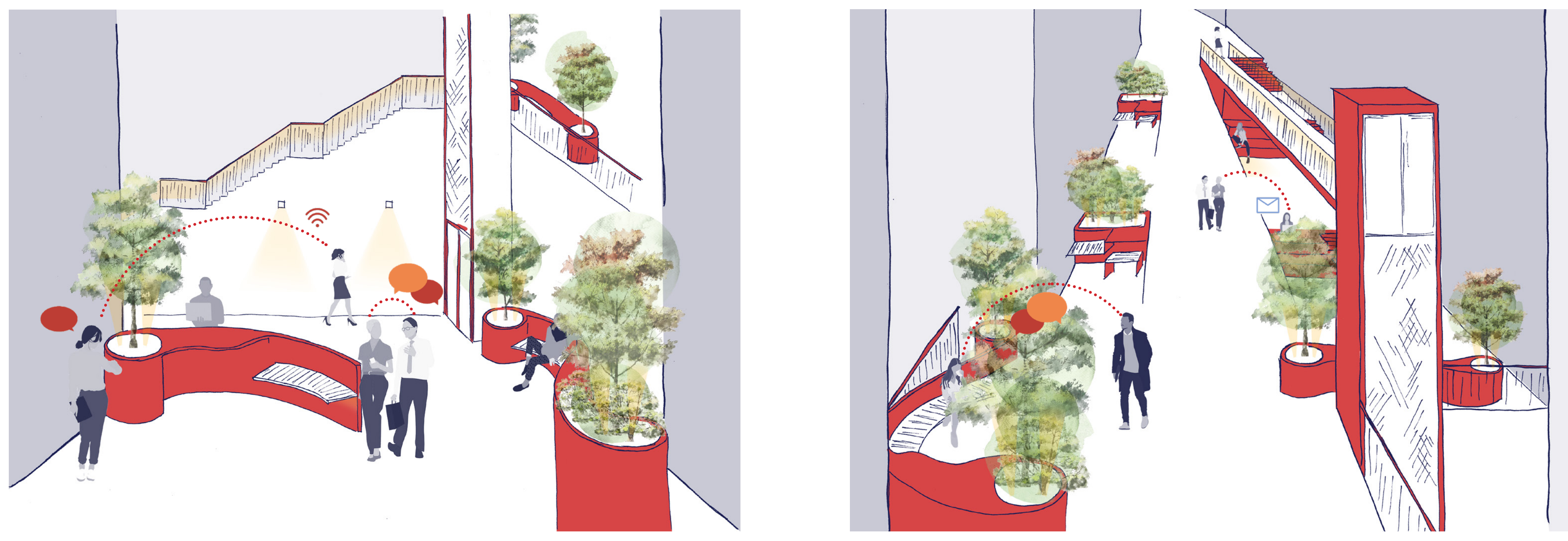

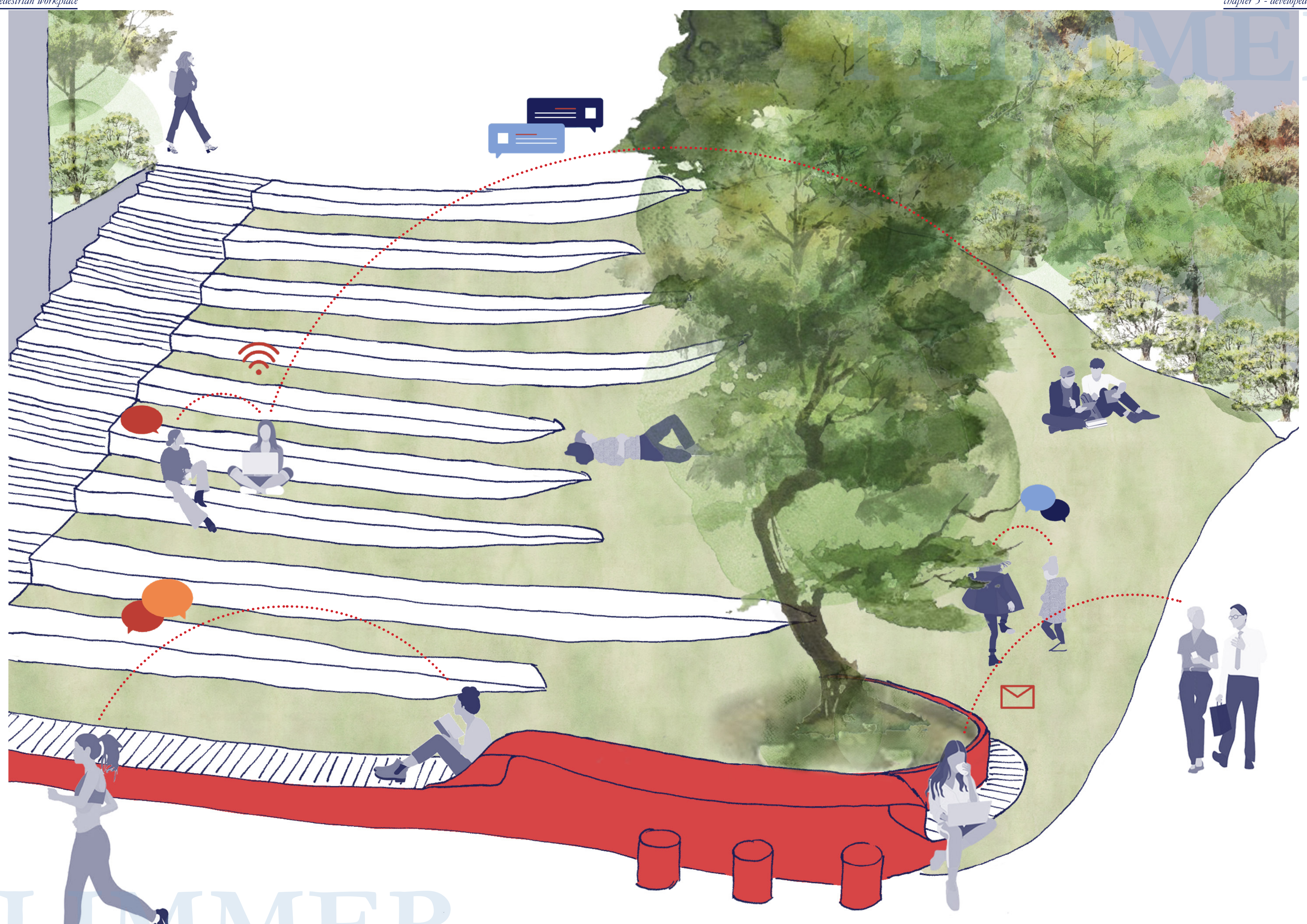

I 

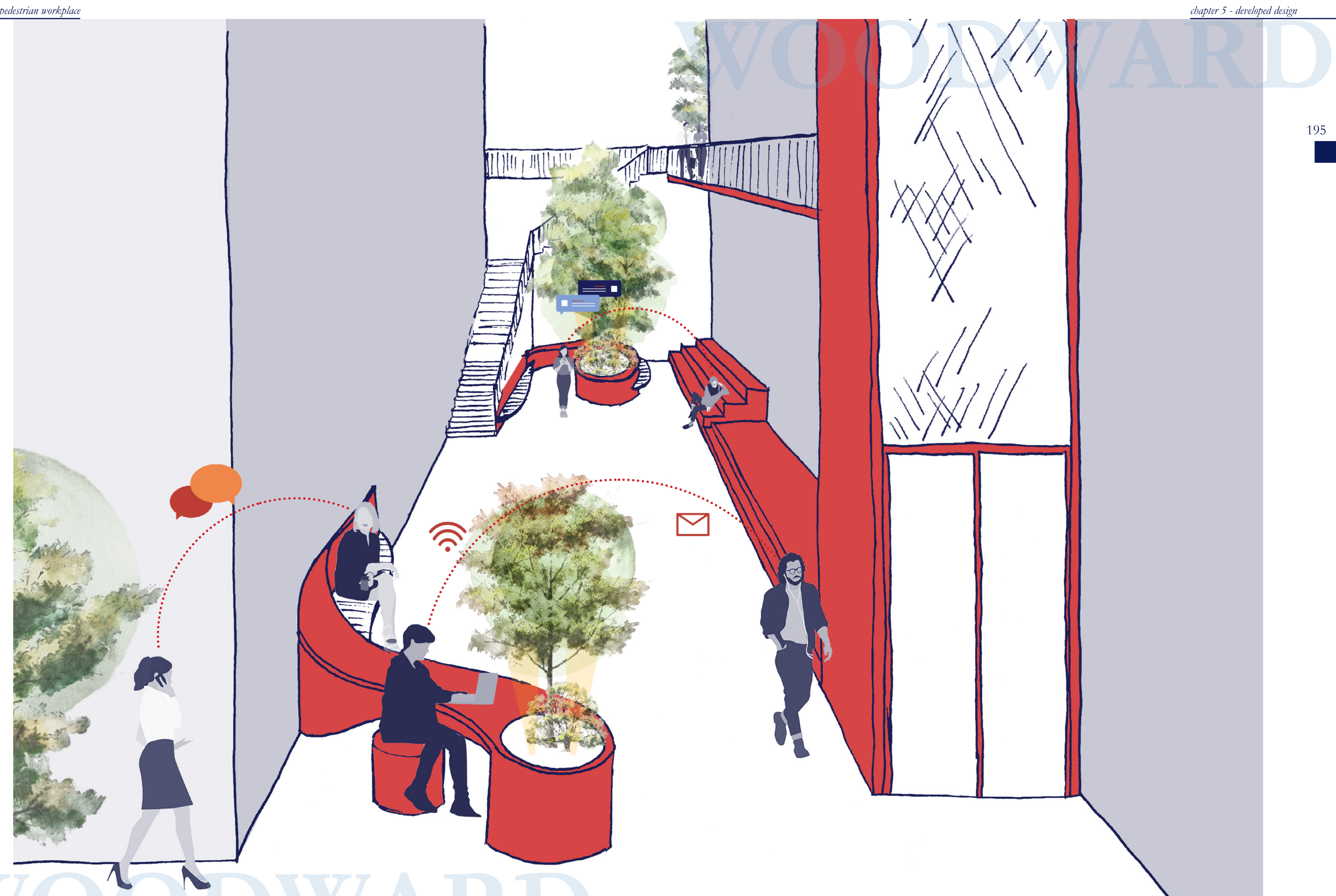

plimmer steps / woodward street
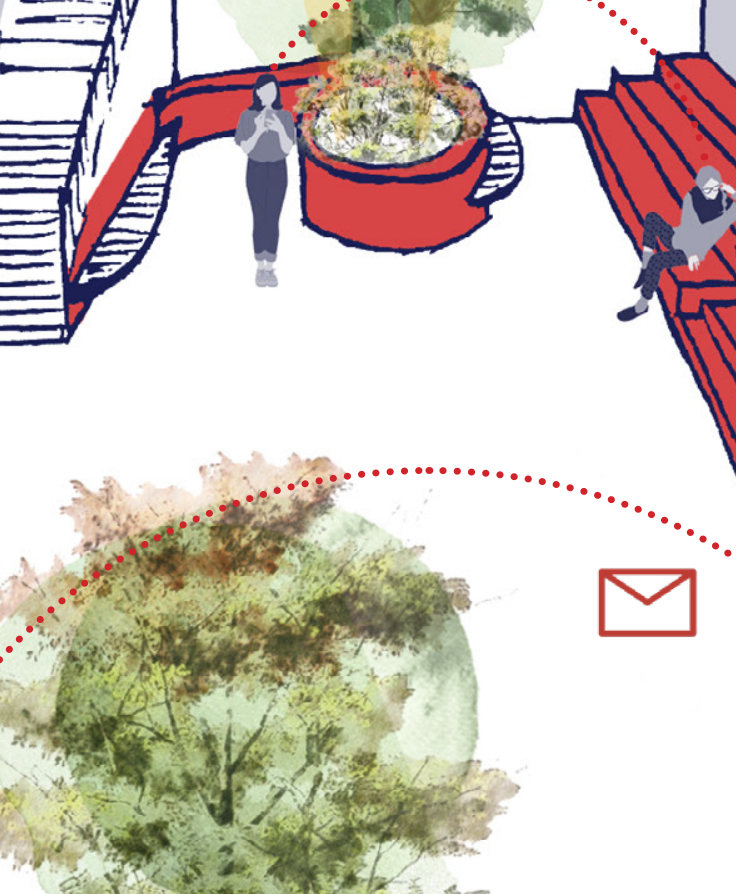

$2 m-x+45$
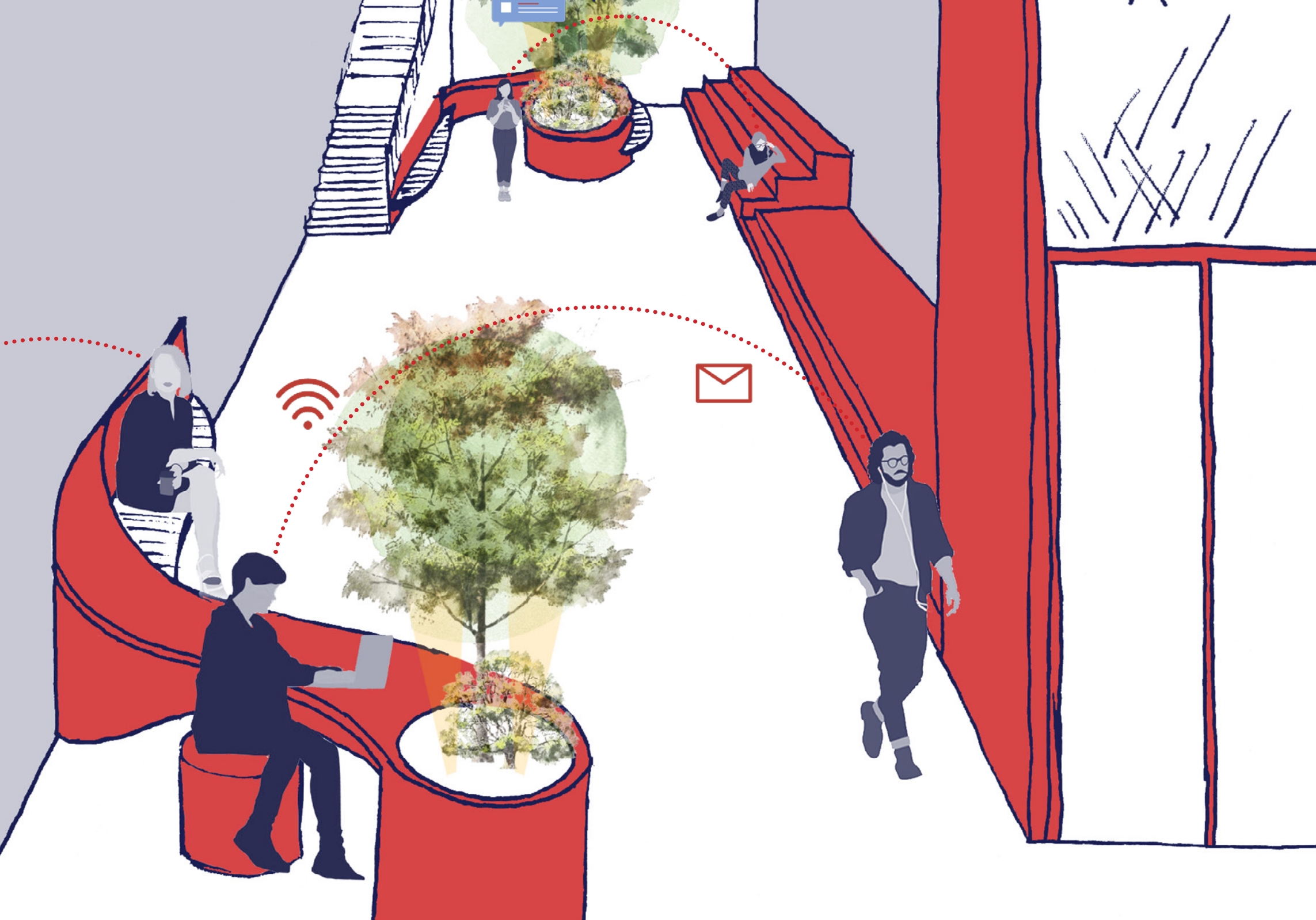
Timber slats extrude from the fibreglass form to provide bench-

style seating. Timber is warm, soft,

comfortable, and compliments the

existing site materiality.

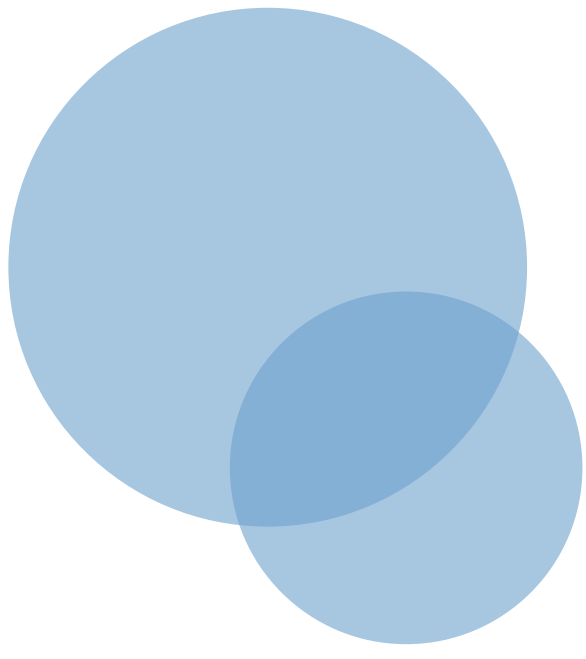

The furniture interventions are moulded fibreglass on a steel frame. Fibreglass was selected for its durability, lasting colour, its' smooth texture, and the ease with which organic forms can be created.

Red is vibrant, contrasts the greenery, and is conscious of the existing colour palette; warm-toned tiles, bricks, and existing red accents on Woodward Street.

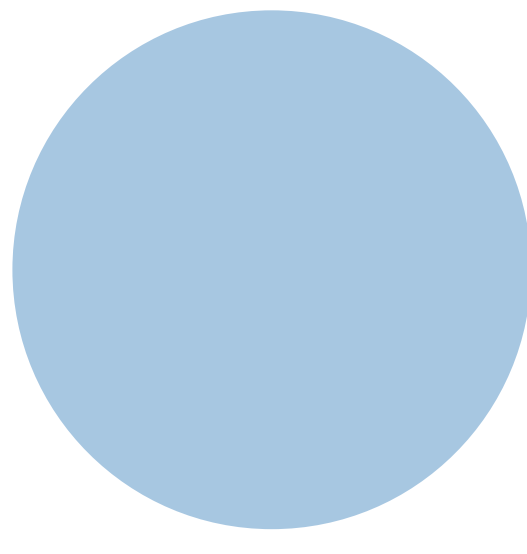

Planters to be inserted into holes

\section{materiality}

street furniture intervention. 
This thesis proposed that Wellington Central Business conceptions of the public street District. The initial design responses could be adjusted, through design proposed at the end of Phase 2 resulted from andysis of the 2. resuted analysis of the relationships, to create a pedestrian literature and site. These influences workplace.

were considered throughout the developed design phase, refining The developed design process a series of interventions proposed critiques the sites in their current into a cohesive redesign of the two condition, considering analysis of existing and imagined affective relationships (phase 1 and 2) and (phase pedestrians to perform social and fnal design working activities alongside the proposition. The final design pre-existing opportunity for access proposes urban pelestinn spaces social public spaces, where workin and social activities can occur. Plimmer Steps and Woodward mobile working behaviour can between Lambton Quay and The Terrace. An additional/result of the redesign is the suggestion of a public street space where Street were chosen as the street occur alongside typical pedestrian sites to be redesigned, creating movements. two pedestrian workplaces in the

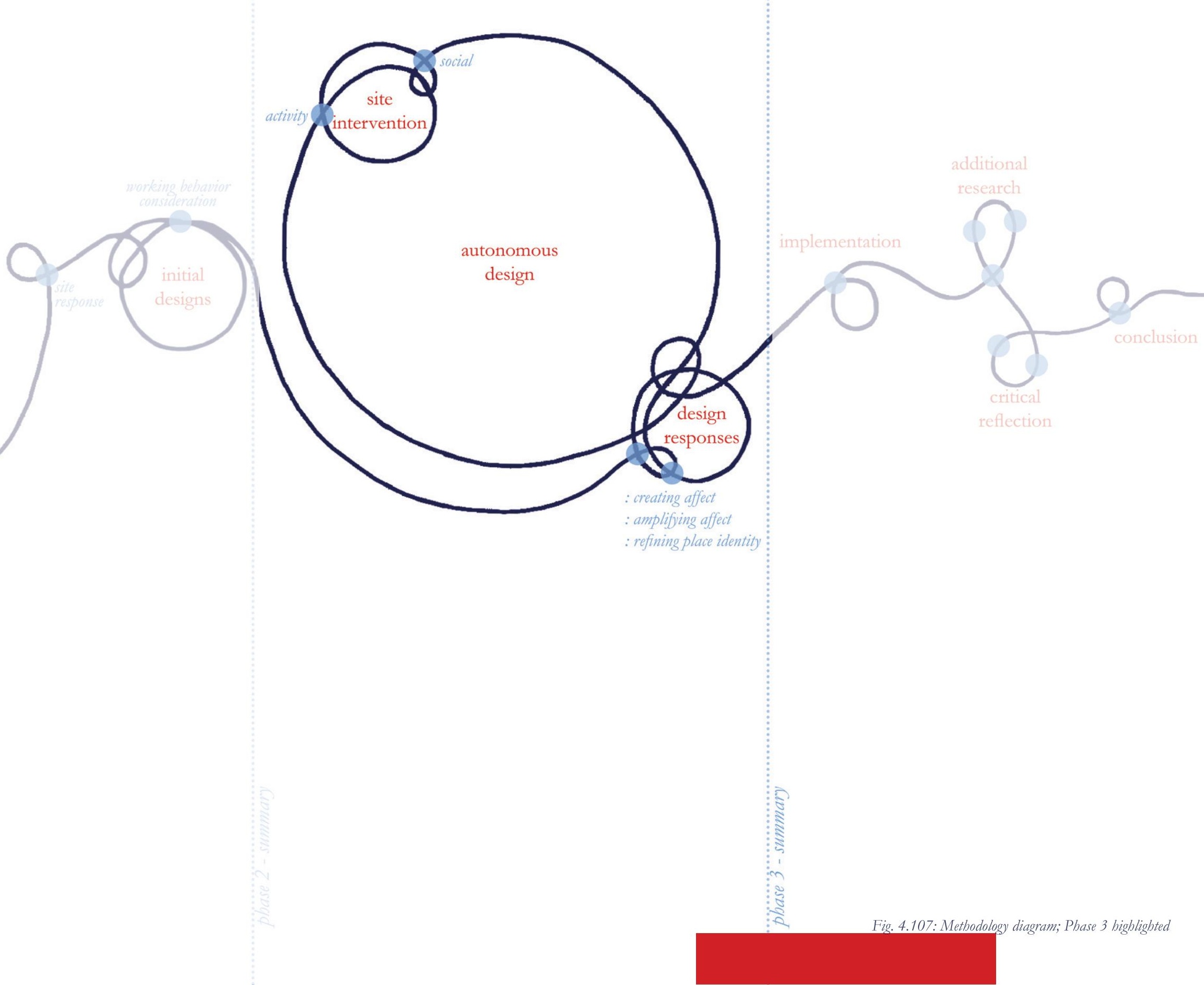




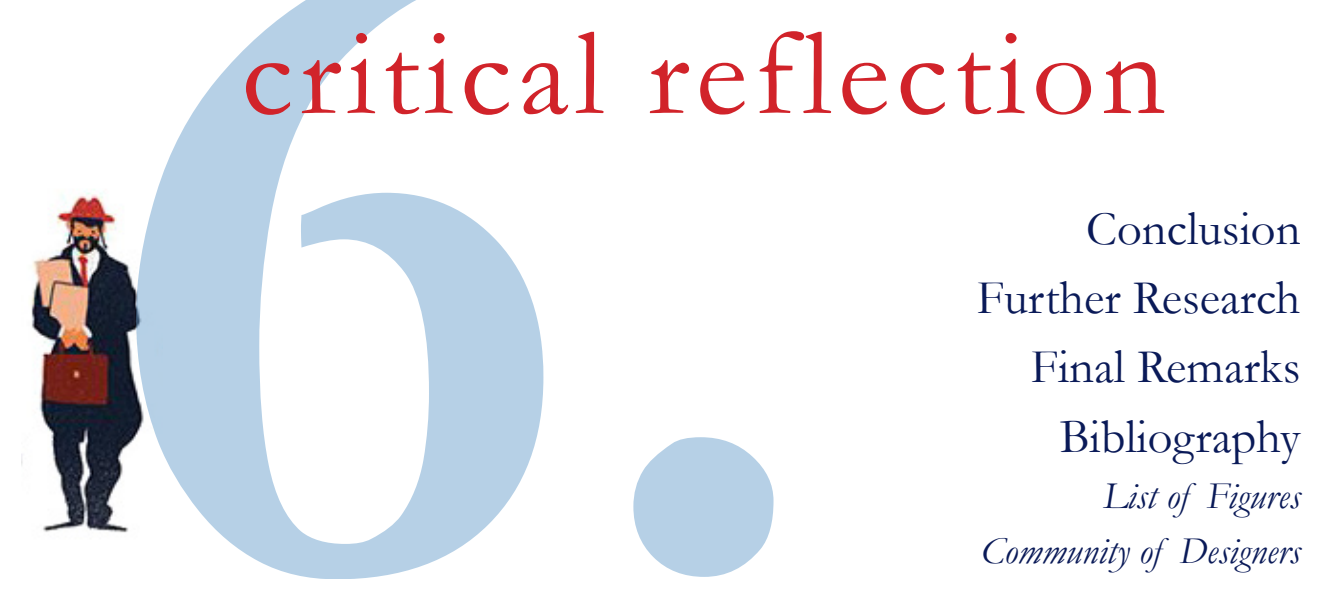

\section{$\square$}




\section{conclusion}

The public street has long been a location for social interaction. The Pedestrian Workplace: Affective Relationships on the Street has established the possibility for the street to be redefined as more than an access route, becoming a place that merges the notions of second and third place; the place of work, and the place of socialisation and community building. Through analysis of affective relationships between person and place, contextualised in the relationship between the pedestrian and the street, the street has been conceived as a workplace.

This thesis argues for a reconsideration of architectures' approach to both the public street and the contemporary workplace. Combining the opportunity for mobile working activity with

the pre-existing condition of pedestrian movement suggests a return to street spaces that are spatially diverse, fostering faceto-face social interaction in technology-dominated working world. The design response was to develop human-scale interventions that promote a range of activities; movement, social, working, and more, to be inserted into two sites, prompting complete redesign into a proposed pedestrian workplace.

Broadening the perception of the contemporary workplace and the public street, this thesis proposed that design intervention can establish an inclusive public workplace typology. This research investigated possibilities for creating defined sites that integrate typical pedestrian movement and activities alongside the opportunity for social and working activities. The proces of design-led research created public spaces that reconnect the mobile worker with a physical location, where working activities can occur alongside social interactions.

Promoting the engagement of mobile workers with their physical environment, this thesis acts as an initiative to redevelop city streets to create locations that support both working activity and place attachment through the dedicated creation of affective relationships. The designs proposed provide sinoular solutions for the selected sites, and indicate a design strategy for the redevelopment of future streets. The strategy proposed allows for designed spaces that are flexible, anticipatory, and dynamic; responding to future developments in contemporary workplace activity that are currently uncertain. The designs can initiate new projects in Wellington City, or other urban locations, furthering the aim to accommodate affective relationships in the age of the mobile workplace.

In recognising the limitations of this thesis, and considering direction of possible future research; the conception of the contemporary workplace, and notions of place and space, are evolving and interdisciplinary. In order to approach the design alteration of the street to be a pedestrian workplace, connection and consultation with the existing site and community is essential.

Critical reflection was engaged as an opportunity to consider the design process and the resulting successes and limitations. The Literature Review highlighted contemporary notions in the research areas of workplace, affect, and space and place, to position the possibility for new adaptation of these ideas into the conception of the street as a pedestrian workplace.

The selected methodology, moving through case study and site analysis, to then reflect through design and respond to the existing site, was important to establish a pedestrian workplace that connected with the context of Wellington City. 
bapte

\section{further research}

The design itself affords the mobile worker a public space that allows their activity to occur in conjunction with typical pedestrian behaviours. A pedestrian workplace brings the possibility to attract more people into public spaces through the support of multiple activity types in one location; in the case of this project, the pedestrian access route in Wellington.

The design proposals offered were derived from site analysis and architectural testing to influence the final design. The resulting design evolved from analysis of affective relationships specific to firstly streets in Wellington City (Phase 1), and then specific to the selected sites of Plimmer Steps and Woodward Street (Phase 2) This process would be applicable to other sites. To further this research, the creation of pedestrian workplaces could be conducted on streets with existing vehicular movement, in Wellington City, or other urban locations across New Zealand, and perhaps, even, the world. The affective relationships uncovered would be changed by this shift in site condition Pursuing this line of research would enable a broader understanding of the mobile working condition in the urban environment.

Contemporary heories dese and place supported the

esearch. Further engagement with the Centra Business District or Wellington City would bring in the surrounding urban environment to benefit from the manipulation of the urban landscape. Questioning spatial boundaries and creating overlap and hierarchy through circulation wa engaged significantly, and achieved through the synthesisation of interventionsintoacohesiveredesign of each site, connecting spaces through architectural intervention

The two sites were linked through the with different arrangement, providing both sites with similar spaces; for meetings, individual work, social connection, and pedestrian access. The possibility for different interventions is suggested, as the manipulation to the urban surface extends across the city.

Testing at multiple scales was undertaken, however, further consideration could be given to architectural versus urban scale. This could suggest the possibility for different design interventions to support various activities to a greater extent. Focus on differing realms of possible pedestrian activity, such as play, trade, or performance, would further influence the inclusion of different interventions 


\section{final remarks}

Research into the realms of workplace, affect, and place and space has provoked a thesi responds to the changing nature of our place attachment to different areas of our lives; the home, the workplace, and the social realm.

The Pedestrian Workplace has been an investigation into these places we

feel attachment to, considering the possibility that through increased mobility in a technology-driven working world, we may be becoming detached from the physical locations we live in.

The street was selected as the site for the testing to be undertaken, as it is a public space where spatial relationships collide. Pedestrian movement promotes social interaction, and the introduction of new typologies through $T$ be Pedestrian

Workplace fosters further connection.

The insertion of the workplace

typology suggests that mobile work can occur alongside access and social interaction.

The development of a pedestrian workplace typology has suggested that the conception of the street as more than an access route allows for desioned spaces that are dynamic, anticipatory and flexible. Affective links between person and place worker and street - are enhanced as working behaviours occur alongside, and concure social and tre new typology has been developed that allows mobile working activities that are increasingly performed by the contemporary worker to occu in public space, promoting place attachment and social connection, furthering the understanding of the connections people have with places, and how this manifests in daily life.

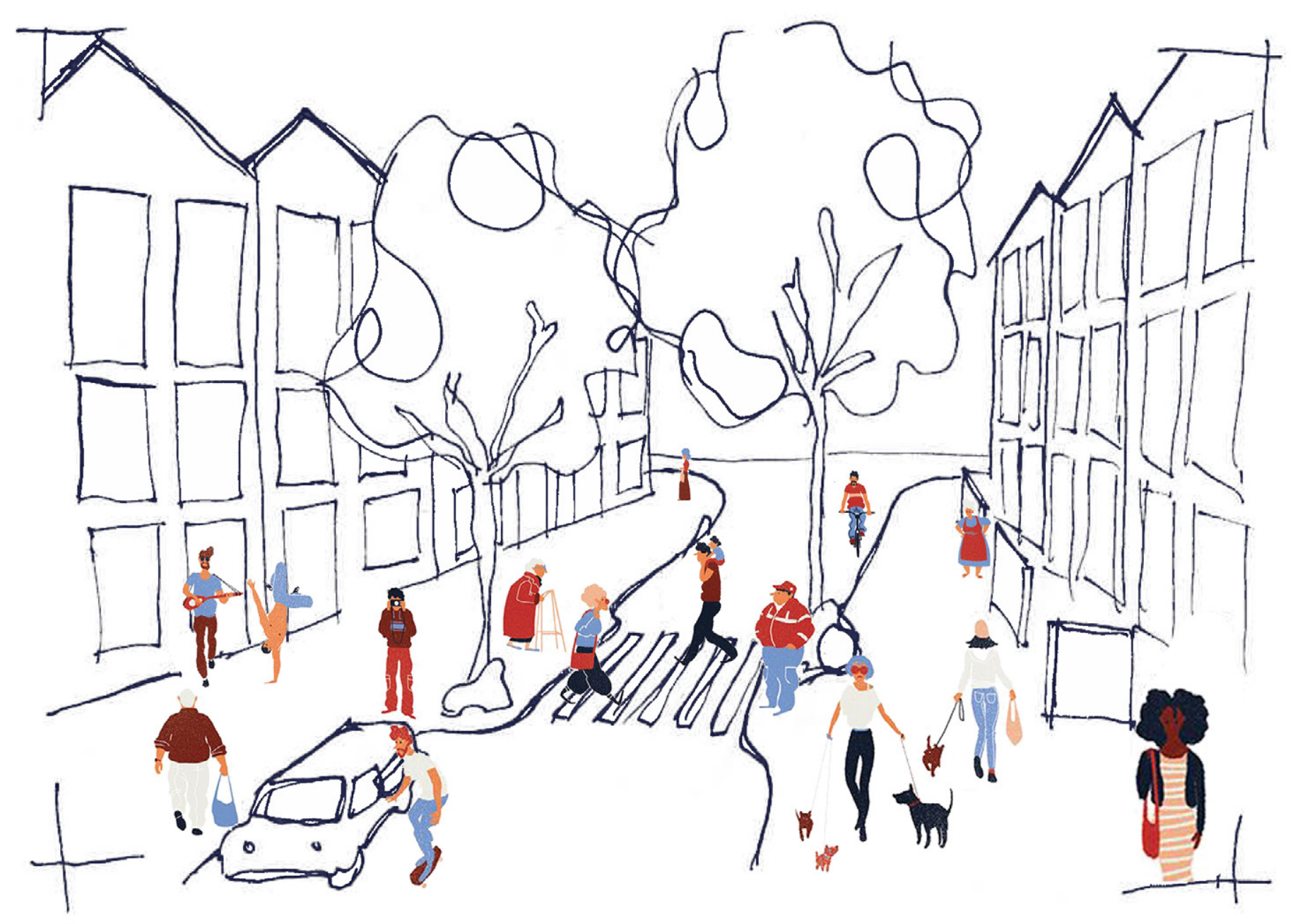


Augé, M. (1992). Non-Places: Introduction to an Anthropology of Supermodernity. Translated by J. Howe. Paris: Le Seuil

Casey, E. S. (2001). Body, Self, and Landscape: A Geographical Inquiry into the Place-world. In P. C. Adams, S. Hoelscher, \& K. E. Till, Textures of Place (pp. 403-425). Minneapolis: University of Minnesota Press

de Certeau, M. (1984). The Practice of Everyday Life (S. Rendell, Trans.). Berkeley and Los Angeles: University of California Press

Duncan, J. S. \& Duncan, N. G. (2001). Sense of Place as a Positional Good: Locating Bedford in Space and Time. In P. C. Adams, S. Hoelscher \& K. E. Till, Textures of Place (pp. 41-54). Minneapolis: University of Minnesota Press

Duyvendak, J. W. (2011). The Politics of Home: Belonging and Nostalgia in Europe and the United States. Basingstoke: Palgrave MacMillan

Easthope, H. (2004). A Place Called Home. Housing, Theory and Society, 21(3), $128-138$

Feuerstein, M. F. (2013). Theatrical Doubles: The Affecting Presence of Oskar Schlemmer's Wall Designs. Arcbitecture as a Performing Art, Ashgate Studies in Arcbitecture Series, 177-194

Frichot, H. (2008). Olafur Eliasson and the Circulation of Affects and Percepts: In Conversation. Architectural Design, 78(3), 30-35

Gattey, M. (2015, July 6). The 'Father of Wellington' honoured by Plimmer Steps. The Wellingtonian. Retrieved July 18, 2019, from https://www.stuff. co.nz/dominion-post/news/69977834/

Gruen, V. (1955). Cityscape and Landscape. Arts and Arcbitecture, 18-37.

Gustafson, P. (2001). Roots and Routes: Exploring the Relationship between Place Attachment and Mobility. Environment and Behavior, 33(5), 667-686

Holder, R. (2014, January 17). A street with a stream and a turntable The Wellingtonian. Retrieved July 18, 2019, from http://www.stuff.co.nz/ dominion-post/news/local-papers/the-wellingtonian/9615565/A-streetwith-a-stream-and-a-turntable 
Idenburg, F. (2013). Workspheres: Anticipatory environments that foster interaction. In J. Kuo, A-Typical plan: Projects and essays on identity, flexibility and atmosphere in the office building (pp. 116-123) Zurich: Park Books

Irvine-Smith, F. L. (1948). The streets of my city: Wellington, New Zealand. Wellington: Reed

Kiddle, R. (2019). Where Do We Dance? City Talks: City Gallery Wellington. Wellington, New Zealand

Kraftl, P., \& Adev, P. (2008). Architecture/Affect/Inhabitation: Geographies of Being-In Buildings. Annals of the Association of American Geographers, 98(1), 213-231 Abingdon-on-Thames: Taylor \& Francis

Locke, J. (1959). An Essay concerning Human Understanding. Ed. A. C. Fraser. New York: Dover

Love, M. (n. d.). Te Ara o nga Tupuna: The Path of our Ancestors. Wellington: Wellington City Libraries

Massumi, B. (2002). Parables for the Virtual: Movement, Affect, Sensation. Durham: Duke University Press

Massumi, B. (2003). Navigating movements: An interview with Brian Massum [nterview by M. Zournazi]. Retrieved March 10, 2019, from http://www. assembly-international.net/Interviews $/ \mathrm{html} / \mathrm{brian} \% 20$ massumi.html

McKee Fehl (2018). Press Hall. Recent Projects. Accessed May 6, 2019, from https://www.mckeefehl.co.nz/our-projects/press-hall/

McLintock, A. H. (1966). An Encyclopaedia of New Zealand. Wellington: Government of New Zealand

Mehta, V. and Bosson, J. K. (2010). Third Places and the Social Life of Streets. Environment and Behavior, 42(6), 779-805

Morrison, P. S. (2011). Local Expressions of Subjective Well-being: The New Zealand Experience. Regional Studies, 45(8), 1039-1058

Mozas, (2017). The Liquid Nature of Workplace. In Caruso St John Architects, Mozas, Fernández Per, The Office on the Grass: The Evolution of the Workplace. Alava: A+T Architecture Publishers
Oldenburg. R. (1991). The Great Good Place: Cafes, coffee shops, bookstores, bars hair salons, and other hangouts at the heart of a community. New York: Marlowe

Press Hall (2019). About Us. Accessed May 6, 2019, from https://www. presshall.co.nz/about-us/

Schlemmer, T (1990). The Letter and Diaries of Oskar Scblemmer. (K. Winston, Trans.) Evanston: Northwestern University Press.

Schrader, B. (2010, March 11). Street life. Te Ara - the Encyclopedia of Nen Zealand. Retrieved June 20, 2019, from http://www.TeAra.govt.nz/en/ street-life

Schrader, B. (2016, October 16). Saturday Morning: Ben Schrader: New Zealand's Urban History Interview by K. Hill]. Retrieved June 26, 2019, from https: // www.rnz.co.nz/national/programmes/saturday/audio/201820088/benschrader-new-zealand's-urban-history

Schrader, B. (2016, October 25). Why the future of our cities can be seen in the past. Dominion Post. Retrieved June 26, 2019, from https://www.stuff. co.nz/dominion-post/comment/85702634/ben-schrader-why-the-futureof-our-cities-can-be-seen-in-the-past

Schrader, B. (2016). The Big Smoke: New Zealand Cities, 1840-1920. Wellington, New Zealand: Bridget Williams Books

Thomson, R. (2013, August 28). Streetwise History: Lambton Quay. Dominion Post. Retrieved June 21, 2019, from http://www.stuff.co.nz/dominionpost/news/local-papers/the-wellingtonian/6975460/Streetwise-HistoryLambton-Quay

Thrift, N. (2008). Non-Representational Theory: Space, Politics, Affect. Oxon: Routledge

Tuan, Y.-F. (1974). Topophilia: A Study of Environmental Perceptions, Attitudes, and Values. Englewood Cliffs: Prentice-Hall Inc.

Wall, A. (1999). Programming the Urban Surface. In J. Corner (Ed.), Recovering Landscape: Essays in Contemporary Landscape Architecture (pp. 233249). New York: Princeton Architectural Press 
Wassilieff M. (2006, June 12). Estuaries - Where fresh water meets the sea. Te Ara - the Encyclopedia of New Zealand. Retrieved June 20, 2019, from http:// www.TeAra.govt.nz/en/photograph/4617/woodward-st-wellington

Wellington City Council (n.d.) Cuba Street has time on its side. About Wellington: History. Retrieved May 6, 2019, from https://wellington.govt.nz/ about-wellington/history/throwbackthursday/cuba-street

Winter, C. (2013, August 28). Street History: Cuba St. Dominion Post. Retrieved May 6, 2019, from http://www.stuff.co.nz/dominion-post/7575996/ Street-history-Cuba-St

Winter, C. (2018, February 26). Twelve Eateries open at Wellington Press Hall. Stuff Business. Retrieved May 6, 2019, from https://www.stuff.co.nz/ business/101705787/twelve-eateries-open-at-wellington-press-hall

\section{list of figures}

All figures not attributed are author's own

Fig. 1.05 - Daniel Carsten, Herman Miller (2017). Wallpaper based on the 'global spirit of a modern digital workspace' that recreates the landscape work of the Living Office Series [llustration]. Retrieved from Mozas: "The Liquid Nature of Workplace" in Caruso St John Architects, Mozas, Fernandez Per "The Office on the Grass"

Fig. 1.06 - Kraftl and Adey (2008). The Kindergarten Interior, Nant-y-Cwm Steiner School [Photograph]. Retrieved from Kraftl and Adey: "Architecture/ Affect/Inhabitation: Geographies of Being-In Buildings"

Fig. 1.07 - Kraftl and Adey (2008). The Garden and Liverpool John Lennon Airport [Photograph]. Retrieved from Kraftl and Adev: "Architecture/ Affect/Inhabitation: Geographies of Being-In Buildings"

Fig. 1.08 - Author's own, adapted from Peri Bader (2019). Dimensions of Attention Diagram [lllustration]. Retrieved from Peri Bader: "A model for the everyday experience of the built environment: the embodied perception of architecture

Fig. 1.09 - Olafur Eliasson (2011). Olafur Eliasson's "Your Rainbow Panorama", at the Aarbus Kunstmuseum, Denmark, 2006-2011 [Photograph]. Retrieved from https:/olafureliasson.net/archive/artwork/WEK100551/yourrainbow-panorama
Fig. 1.10 - Tate Photography: Andrew Dunkley and Marcus Leith (2003). Olafur Eliasson's "The Weather Project", at the Tate Modern, London, United Kingdom, 2003 [Photograph]. Retrieved from https://olafureliasson.net/ archive/artwork/WEK101003/the-weather-project

Fig. 1.11 - Marcia Feuerstein (2013). Oskar Schlemmer's one-eyed face painted within the corner of the stair in the Rabe House [Photograph]. Retrieved from Feuerstein: "Theatrical Doubles: The Affecting Presence of Oskar Schlemmer's Wall Design

Fig. 1.12 - Peter Cook (1970). Instant City: Sequence of Effect. The descent of the event-structure "instant city airships' on a typical English town intensifies, infiltrates, and stimulates new networks in the old, sleeping city [lllustration]. Retrieved from http://www.frac-centre.fr/_en/art-and-architecture-collection/cookpeter $/$ instant-city-317.html?authID $=44 \&$ ensembleID $=113$

Fig. 1.13 - Office for Metropolitan Architecture (1991). Site diagram for Ville Nowvelle Melun Senart [lllustration]. Retrieved from https://oma.eu/ projects/ville-nouvelle-melun-senart

Fig. 1.14 - Office for Metropolitan Architecture (1991). Diagrammatic sketch for Yokohama Masterplan [lllustration]. Retrieved from https://oma.eu/ projects/yokohama-masterplan

Fig. 2.03 - Duncan Winder (c. 1960s). Cuba Mall Entrance, Cuba Street [Photograph]. Retrieved from the National Library, DW-4160-F

Fig. 2.05 - Unknown Photographer (1929). Willis Street, Wellington City [Photograph]. Retrieved from the National Library, 1/1-006168-F

Fig. 2.07 - Unknown Photographer for the Evening Post. (1928). The Evening Post Building Wellington showing 1928 election returns [Photograph]. Retrieved from the National Library, EP-0373-1/2-G

Fig. 2.08 - Author's own, adapted from Peri Bader (2019). Dimensions of Attention Diagram [lllustration]. Retrieved from Peri Bader: "A model for the everyday experience of the built environment: the embodied perception of architecture

Fig. 2.28 - Tate Photography: Andrew Dunkley and Marcus Leith (2003). Olafur Eliasson's "The Weather Project", at the Tate Modern, London, United Kingdom, 2003 [Photograph]. Retrieved from https://olafureliasson.net/ archive/artwork/WEK101003/the-weather-project 
Fig. 2.29 - Olafur Eliasson (2011). Olafur Eliasson's "Your Rainbow Panorama", at the Aarbus Kunstmuseum, Denmark, 2006-2011 [Photograph]. Retrieved from https://olafureliasson.net/archive/artwork/WEK100551/yourrainbow-panorama

Fig. 2.30 - Anders Sune Berg (2015). Olafur Eliasson's Seu corpo do Obra (Your body of work), Moderna Museet, Stockholm 2015 [Photograph]. Retrieved from https://olafureliasson.net/archive/artwork/WEK107097/seu-corpo-daobra-your-body-of-work

Fig. 2.79 - Kraftl and Adey (2008). Exterior of the Kindergarten building, Nanty-Cwm Steiner School [Photograph]. Retrieved from Kraftl and Adey: "Architecture/Affect/Inhabitation: Geographies of Being-In Buildings"

Fig. 2.80 - Kraftl and Adey (2008). The Kindergarten in context, showing the conical grass roof, Nant-y-Cwm Steiner School [Photograph]. Retrieved from Kraftl and Adey: "Architecture/Affect/Inhabitation: Geographies of Being-In Buildings"

Fig. 2.81 - Kraftl and Adey (2008). The Garden and Liverpool John Lemnon Airport [Photograph]. Retrieved from Kraftl and Adev: "Architecture/ Affect/Inhabitation: Geographies of Being-In Buildings"

Fig. 3.02, 3.03, 3.04: Author's Own (2019). Collage, images from National Library's Alexander Turnbull and Papers Past collections, and Author's Own [Collage, Illustration]. Images retrieved from;

https://natlib.govt.nz/collections/a-z/turnbull-library-pictures

https://paperspast.natlib.govt.nz/

Fig. 4.63: Office for Metropolitan Architecture (1991). Site diagram for Ville Nouvelle Melun Senart [lllustration]. Retrieved from https://oma.eu/ projects/ville-nouvelle-melun-senart

Fig. 4.64: Office for Metropolitan Architecture (1991). Diagrammatic sketch for Yokohama Masterplan [Illustration]. Retrieved from https://oma.eu/ projects/yokohama-masterplan

Fig. 5.47: TF Urban (2019). Botanic Twist: Green Urban Bench [Photograph]. Retrieved from https://furniturefashion.com/botanic-twist-benchcollection-tf-urban/
Fig. 5.48: Turenscape (2009). Qinhuangdao Red Ribbon Park [Photograph] Retrieved from https://www.turenscape.com/en/project/detail/336.html

Fig. 5.49: GeoMet (2019). Serpentine Modern Modular Seating [Photograph]. Retrieved from https://www.suigeneris.co.uk/grp_seating/sgf109 serpentine modular seating.html

Fig. 5.50: Alfredo Tasca (2018). Victor Bench with Planter [Photograph]. Retrieved from https://www.metalco.it/prodotto/victor-bench-withplanter/?lang $=$ en

215 
